LUIZ EDUARDO WILBERT ALBERNAZ ANDRADE

IMPACTOS DA REFORMA TRIBUTÁRIA: AVALIANDO A INFLUÊNCIA DO NOVO IMPOSTO DE CIRCULAÇÃO DE MERCADORIAS E SERVIÇOS (ICMS) NA RECONFIGURAÇÃO DA MALHA LOGÍSTICA BRASILEIRA 
LUIZ EDUARDO WILBERT ALBERNAZ ANDRADE

\title{
IMPACTOS DA REFORMA TRIBUTÁRIA: AVALIANDO A INFLUÊNCIA DO NOVO IMPOSTO DE CIRCULAÇÃO DE MERCADORIAS E SERVIÇOS (ICMS) NA RECONFIGURAÇÃO DA MALHA LOGÍSTICA BRASILEIRA
}

\author{
Dissertação apresentada à Escola \\ Politécnica da Universidade de São \\ Paulo para obtenção do Título de \\ Mestre em Engenharia. \\ Área de Concentração: \\ Engenharia de Sistemas Logísticos \\ Orientador: Professor Livre-Docente \\ Hugo Tsugunobu Yoshida Yoshizaki
}

São Paulo

2013 


\section{FICHA CATALOGRÁFICA}

Andrade, Luiz Eduardo Wilbert Albernaz

Impactos da reforma tributária: avaliando a influência do ovo Imposto de Circulação de Mercadorias e Serviços (ICMS) na reconfiguração da malha logística brasileira / L.E.W.A. Andrade. -- São Paulo, 2012.

$162 \mathrm{p}$.

Dissertação (Mestrado) - Escola Politécnica da Universidade de São Paulo. Departamento de Engenharia de Transportes. Sistemas Logísticos.

1.Pesquisa operacional 2.Planejamento de redes 3.Logística 4.Imposto sobre Circulação de Mercadorias e Serviços I.Univer sidade de São Paulo. Escola Politécnica. Departamento de Enge nharia de Transportes II.t. 
"No que diz respeito ao desempenho, ao compromisso, ao esforço, à dedicação, não existe meio termo. Ou você faz uma coisa bem-feita ou não faz." 


\section{AGRADECIMENTOS}

Ao Professor Livre-Docente Hugo Yoshizaki pelas orientações e conversas acerca deste mestrado e outros assuntos profissionais.

A todos os professores com quem tive contato ao longo do mestrado, pelos ensinamentos passados, os quais hoje fazem parte do meu conhecimento, o maior bem que se pode ter em vida.

Aos meus amigos e colegas de trabalho das salas GOL e GEE, pelas valiosas conversas sobre logística, programação, ICMS etc.

Aos meus pais Carlos Eduardo Albernaz e Marcia Wilbert pelo apoio e, por me darem toda a estrutura que me permitiu chegar até aqui. Aos meus irmãos Felipe Wilbert e Fernando Wilbert e, minha namorada Carolina Israel, pelas conversas e apoio acerca de minhas decisões.

Aos meus amigos, que por muitas vezes entenderam a minha ausência e que ainda assim se mostraram próximos.

A todos os meus colegas do CISLOG que ajudaram de forma direta ou indireta na construção deste trabalho.

Aos meus avôs e avós que fizeram parte de minha formação e que torcem por $\operatorname{mim}$.

À Deus. 


\section{RESUMO}

A estrutura tributária brasileira proporciona uma dificuldade a mais no planejamento de redes logísticas, principalmente no caso do Imposto sobre Circulação de Mercadorias e Serviços (ICMS). A omissão do fator tributário na modelagem de redes logísticas no cenário brasileiro atual poderá resultar em cenários não ótimos, devido à marcante influência da mesma na localização das instalações e na definição dos fluxos de origem e destino.

Devido aos impactos da legislação brasileira na perda de competitividade das empresas brasileiras atualmente, a Reforma Tributária se faz necessária por estas e outras razões não logísticas, alterando a forma como este imposto é cobrado.

Alguns estudos foram realizados para avaliar o impacto da reforma tributária no planejamento de redes logísticas, porém o presente estudo atualizou a demanda e os custos logísticos para os valores atuais de mercado, buscando aprofundar a compreensão sobre as principais modificações da rede. Além disso, procurou-se avaliar o impacto da modificação da alíquota interna e externa na configuração de redes logísticas.

Para estudar o impacto do ICMS na rede logística de uma empresa, recorreu-se ao modelo de Programação Linear Inteira Mista (PLIM).

Os resultados do estudo evidenciam que a reforma tributária irá trazer melhorias significativas no aspecto de fluxo origem e destino e na localização das instalações. Porém, a estruturação da rede logística ainda irá sofrer interferência do ICMS, contribuindo assim para o aumento do Custo Brasil pela permanência do turismo fiscal.

Palavra chave: pesquisa operacional, planejamento de redes, logística e imposto de circulação de mercadorias e serviços (ICMS). 


\section{ABSTRACT}

The Brazilian tax structure provides a further difficulty in the planning of logistics networks, especially in the case of the Tax on Circulation of Goods and Services. The omission of the tax factor in modeling logistics networks in the current Brazilian scenario could result in non-optimal, due to the strong influence in the same location of facilities and on defining the flows of origin and destination.

Due to the impacts of the Brazilian legislation in the loss of competitiveness of Brazilian companies currently the Tax Reform is needed for these and other logistical reasons not changing the way this tax is levied.

Some studies were conducted to evaluate the impact of tax reform in the planning of logistics networks, but the present study updated the demand and logistics costs for the current market values, seeking to deepen the understanding of the main changes to the network. In addition, we sought to evaluate the impact of changes of the internal rate in the configuration of logistics networks.

To study the impact of the ICMS in the logistics network of a company, we used the model of Mixed Integer Linear Programming (MILP).

The study results show that tax reform will bring significant improvements in the appearance of flow origin and destination and the location of facilities. However, the structuring of the logistics network will still suffer interference from the ICMS, thus contributing to the increase in Brazil cost the tax residence of tourism.

Keyword: operational research, network planning, logistics and road tax for goods and services (ICMS). 


\section{FIGURAS}

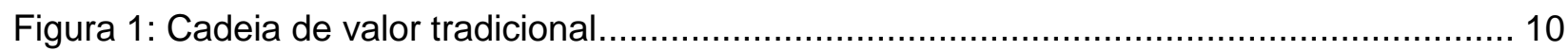

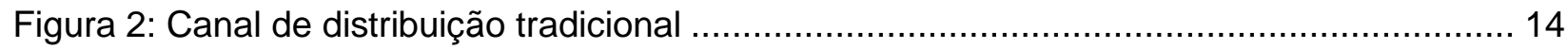

Figura 3: Modelo visual de tomada de decisão em cadeia de suprimentos............................. 17

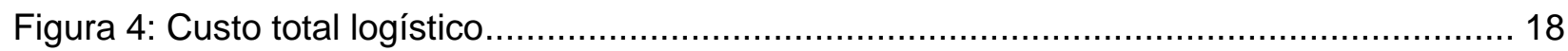

Figura 5: Comparação entre os custos logísticos............................................................ 19

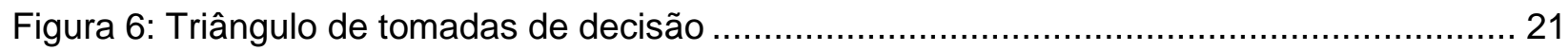

Figura 7: Modelo visual de tomada de decisão em projetos de redes.................................... 25

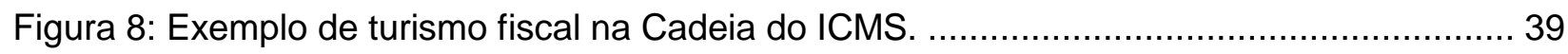

Figura 9: Localização das fábricas, depósitos e dos mercados............................................. 59

Figura 10: Mapa de localização das fábricas e dos centros de distribuição. ..............................6 60

Figura 11: Demanda da fábrica de São Paulo por mesorregião............................................ 62

Figura 12: Demanda da fábrica de Joinville por mesorregião............................................... 62

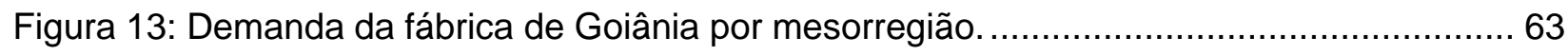

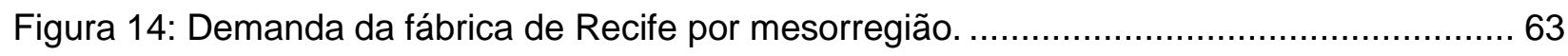

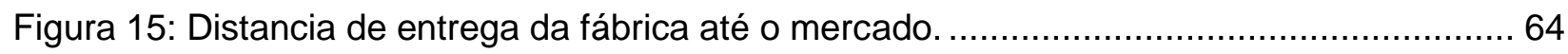

Figura 16: Nível de serviço de todos os centros de distribuição juntos. .................................. 64

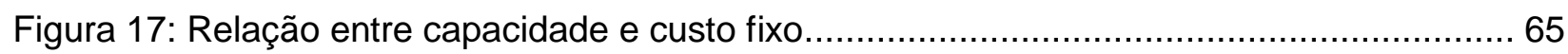

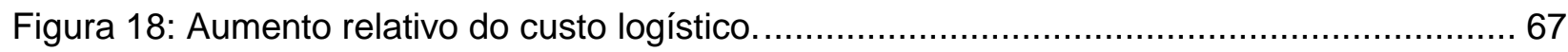

Figura 19: Comparação dos custos logísticos do ICMS Atual e da Reforma Tributária............... 68

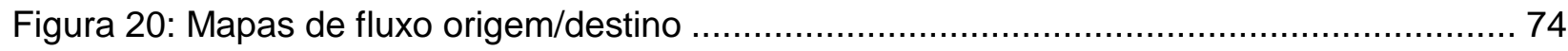

Figura 21: Quantidade movimentada em toneladas por faixa de distância (Fábrica - Mercado) 80

Figura 22: Quantidade movimentada em toneladas por faixa de distância (CD - Mercado) ..... 80

Figura 23: Quantidade movimentada em toneladas por faixa de distância (Fábrica - CD) ....... 81

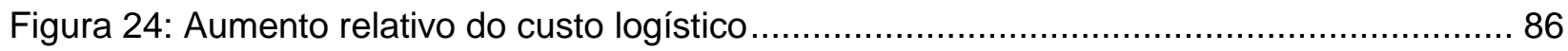

Figura 25: Relação entre a quantidade de mesorregiões e suas respectivas demandas .......... 89

Figura 26: Comparação do custo logístico com e sem restrição de nível de serviço .................. 91

Figura 27: Modificação do volume transportado em toneladas (ICMS Atual) ............................ 92

Figura 28: Modificação do volume transportado em toneladas (RT 2\%) ................................. 92

Figura 29: Custo logístico com e sem restrição de nível de serviço - ICMS Atual ....................... 93

Figura 30: Custo logístico com e sem restrição de nível de serviço - RT 2\% ........................... 94

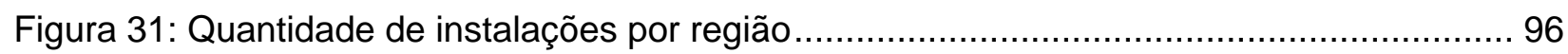

Figura 32: Localização e capacidade das instalações......................................................... 98

Figura 33: Análise do volume movimentado por fluxo e por produto. ................................... 100 
Figura 34: Mapas de fluxos por produto e cenário .... 101

Figura 35: Mapas de distribuição do volume por produto em cada centro de distribuição 111 Figura 36: Evolução do custo logístico e do número de instalações de acordo com o aumento do nível de serviço. 113

Figura 37: Mapa de localização, fluxo e nível de serviço. 114

Figura 38: Aumento relativo do custo logístico..... 116 


\section{TABELAS}

Tabela 1: Projetos logísticos divididos em níveis estratégicos. ........................................... 22

Tabela 2: Cálculo de operação via Centro de Distribuição (CD). ....................................... 40

Tabela 3: Resultados encontrados por Yoshizaki (2008). ............................................ 49

Tabela 4: Resumo das principais características dos modelos de planejamento de redes com

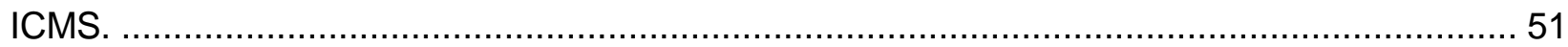

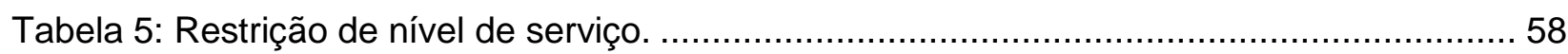

Tabela 6: Quantidade e localização das instalações................................................... 70

Tabela 7: Localização e capacidade das instalações.................................................... 73

Tabela 8: Representatividade dos fluxos origem/destino por região ..................................... 78

Tabela 9: Representatividade dos fluxos com origem no Estado ...................................... 79

Tabela 10: Localização e capacidade das instalações................................................... 87 


\section{SUMÁRIO}

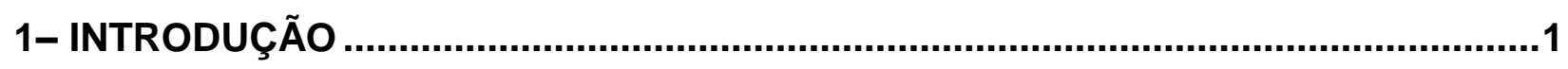

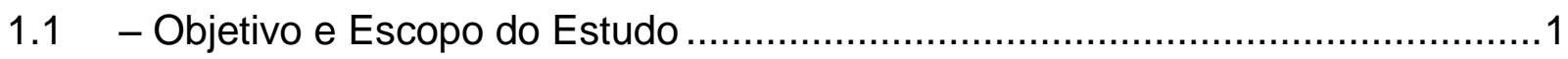

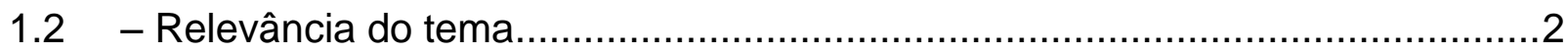

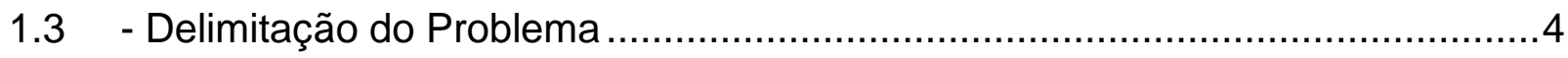

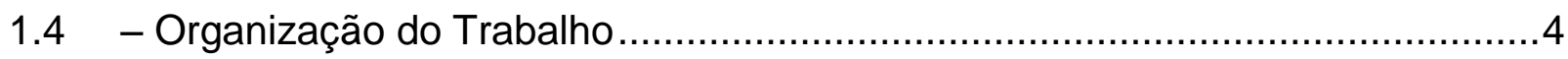

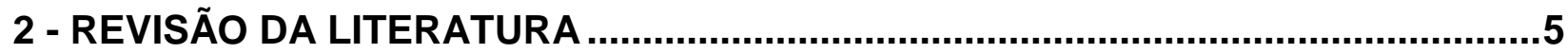

2.1 - Entendimento da Estratégia Competitiva ….................................................

2.2 - Logística e Distribuição Física ....................................................................

2.3 - Gerenciamento da Cadeia de Suprimentos ................................................15

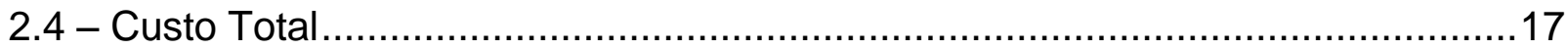

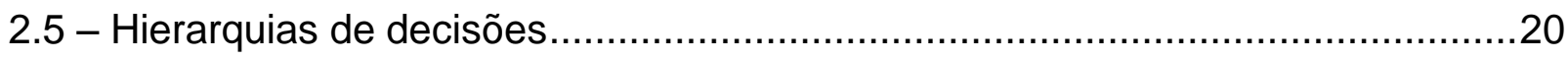

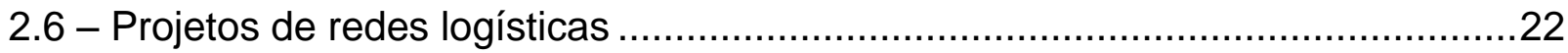

2.7 - Aspectos importantes do direito tributário brasileiro ........................................29

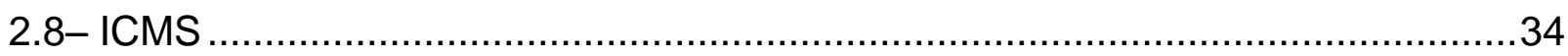

2.9 - Trabalhos prévios de logística e ICMS ....................................................... 42

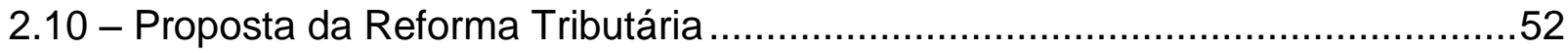

3 - METODOLOGIA E MODELAGEM DO PROBLEMA …......................................55

3.1 - Localização dos centros de distribuição e fábricas ..........................................58

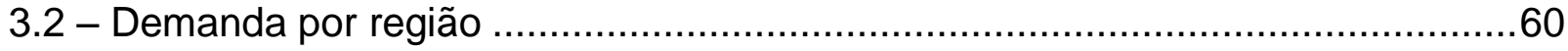

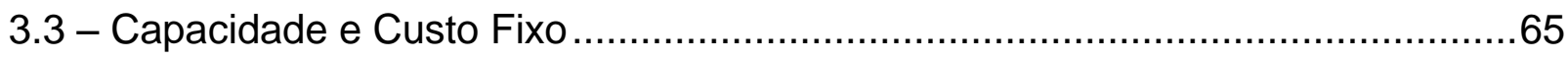

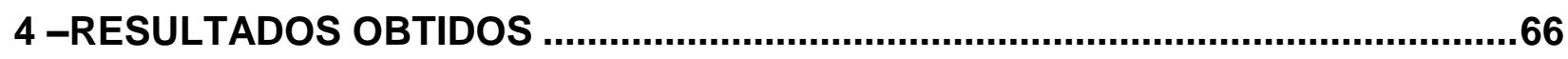

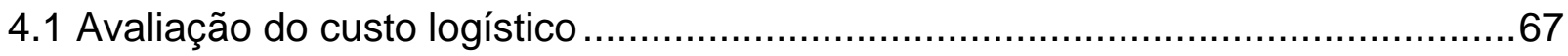

4.2 Avaliação da localização e da capacidade das instalações ................................69

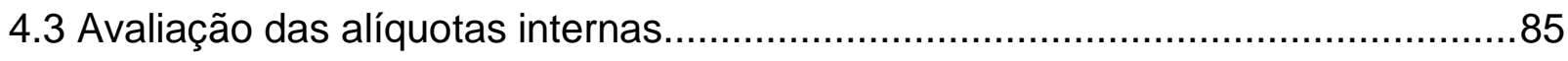

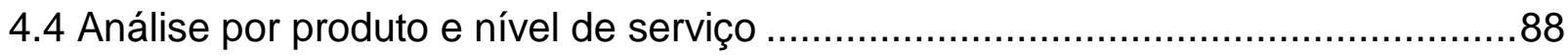

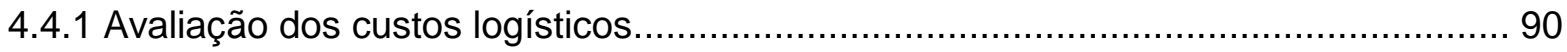

4.4.2 Avaliação da localização e da capacidade das instalações..................................... 95

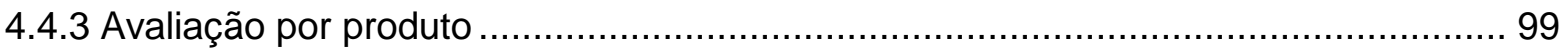


4.4.4 Modificação do nível de serviço ................................................................ 112

4.4.5 Modificação na alíquota interestadual da Reforma Tributária............................... 115

5 -CONCLUSÃO ................................................................................................118

BIBLIOGRAFIA ........................................................................................... 122

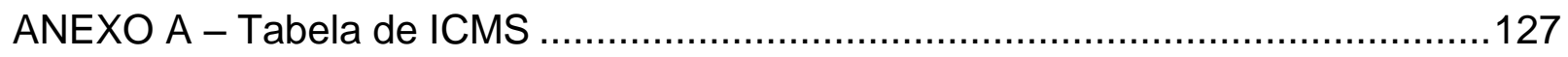

ANEXO B - Mapa com os fluxos de origem e destino e nível de serviço ................128

ANEXO C - Tabela de custos logísticos absolutos e relativos. ............................129

ANEXO D - Modelo Matemático - IBM ILOG CPLEX ..................................130 


\section{1- INTRODUÇÃO}

\section{1 - Objetivo e Escopo do Estudo}

Esta pesquisa objetiva analisar os impactos do Novo ICMS (reforma tributária) na rede logística brasileira. Em particular, a questão principal a ser analisada será se o novo imposto poderá resolver o problema do turismo fiscal (trânsito de produtos e mercadorias de forma artificial) devido à estrutura de alíquotas diferenciada. As principais diferenças entre a estrutura atual de ICMS e o Novo ICMS estão nas alíquotas interestaduais, que serão modificadas dos atuais $7 \%$ e $12 \%$ para $2 \%$, eliminando a diferença de alíquotas entre os Estados exportadores e importadores. As alíquotas Internas permanecem inalteradas e variam de 17\% a $19 \%$.

A rede logística em estudo é composta por quatro grandes fabricantes de produtos típicos de supermercado (que não necessitem de refrigeração) e devem abastecer o país com itens de grande consumo (massas e biscoitos, higiene e limpeza, alimentos enlatados e óleo de cozinha), com participações de mercado equivalentes a um líder de mercado. O modelo simula uma cadeia de suprimentos de três estágios (4 fábrica, 51 CD's, 137 cliente) com total simetria de custos logísticos, gerando uma rede logística que minimiza o custo logístico total considerando uma dada proporção (de zero a 100\%) de clientes informais. As fabricas estão localizadas nos Estados de São Paulo, Joinville, Goiânia e Recife. Para estudar o impacto do ICMS foi utilizado o modelo de Programação Linear Inteira Mista (PLIM) desenvolvido em Yoshizaki (2002).

O estudo foi realizado com dois cenários básicos: estrutura atual de ICMS e Novo ICMS. Ambos os cenários foram divididos em 5 variantes de acordo com o nível de sonegação ( $0 \%, 25 \%, 50 \%, 75 \%$ e $100 \%)$. Para compreender os impactos do Novo ICMS foram estudadas as modificações nos seguintes aspectos logísticos:

1. A modificação nos custos logísticos (custo fixo, transferência e distribuição); 
2. A modificação da rede logística e dos seus fluxos de origem e destino nos três estágios da cadeia (fábrica para o CD, CD para o mercado e fábrica para o mercado);

3. A modificação da localização e da capacidade das instalações;

4. A modificação do volume movimentado por produto nos fluxos de transferência e distribuição.

Após a compreensão da mudança na estrutura logística será realizada uma análise de sensibilidade para mostrar o comportamento da rede a partir de algumas modificações no nível de serviço e nas alíquotas internas e externas.

\section{2 - Relevância do tema}

No contexto atual, as diferentes formas de tributação interferem na configuração espacial das redes logísticas do país, sobrecarregando a infraestrutura brasileira. Um exemplo é a política de incentivos concernentes ao Imposto sobre Produtos Industrializados (IPI) e ao Imposto de Importação, que viabiliza a Zona Franca de Manaus, mas ocasiona elevado fluxo de mercadorias de e para a Região Amazônica. Algo semelhante ocorre com o tributo com a maior arrecadação no conjunto da carga tributária do país, o Imposto sobre Circulação de Mercadorias e Serviços (ICMS). O ICMS rendeu aos Estados uma receita recorde de $\mathrm{R} \$ 268,6$ bilhões em 2010, alta nominal de 17\% frente a 2009 (SENADO, 2010).

$\mathrm{Na}$ sua forma presente, este imposto proporciona o trânsito de produtos e mercadorias de forma artificial, o que é conhecido por turismo fiscal, apenas com o intuito de beneficiar-se de incentivos fiscais ou aproveitar-se das diferenças de alíquotas interestaduais (YOSHIZAKI, 2003). Uma solução hipotética foi modelada por Yoshizaki (2002), composta por uma cadeia de distribuição de produtos de grande consumo encontrados em supermercado (massas e biscoitos, higiene e limpeza, alimentos enlatados e óleo de cozinha), e clientes finais (atacadistas, varejistas), com 
diversos graus de informalidade (não recolhimento do ICMS). Ao se encontrar a configuração ótima da rede logística necessária, o autor verificou que o acréscimo no custo logístico total poderia variar entre $3,5 \%$ e $11,6 \%$, ocasionado pela diferença estrutural das alíquotas entre Estados. Assim, a estrutura atual do ICMS contribui para aumentar o chamado "Custo Brasil", que pode ser descrito como o impacto das ineficiências do país aplicadas aos negócios, segundo Castro (2004).

A Reforma Tributária em curso é uma necessidade por estas e outras razões não logísticas (SENADO, 2010) e deverá gerar uma alteração na forma como este imposto é cobrado, chamado de Novo ICMS pelo poder público. Segundo a proposta do Novo ICMS, elaborada pelo Ministério da Fazenda (FAZENDA, 2008), o Novo ICMS continuará seguindo o princípio da não-cumulatividade (ou seja, taxa apenas o valor agregado em cada estágio da cadeia produtiva e comercial), mas traz algumas novidades fundamentais:

1. A unificação da legislação dos 27 Estados;

2. A fixação de cinco alíquotas diferenciadas para um número limitado de bens e serviços;

3. A divisão do Novo ICMS entre Estados de origem e destino, cabendo ao Estado de origem pagar $2 \%$ do valor do imposto;

4. A suspensão dos repasses de fundos constitucionais, como o Fundo de Participação dos Estados (FPE) para os Estados que promoverem a guerra fiscal por intermédio de concessão de incentivos fiscais.

A implementação do Novo ICMS deverá reduzir a guerra fiscal entre os Estados para atrair novas fábricas e, portanto, o turismo fiscal ocasionado por incentivos também deverá ser reduzido (SENADO, 2010). Entretanto, nada se comenta do outro fato gerador de turismo fiscal, ou seja, a informalidade que se aproveita da atual estrutura do ICMS. 


\section{3 - Delimitação do Problema}

O escopo do estudo limita-se à parte de distribuição física de produtos acabados, não avaliando o impacto do ICMS nas etapas de movimentação de insumos industriais e seu processamento. Assim, não se pretende explorar todo o encadeamento do ICMS na cadeia de suprimentos, mas apenas na parte final da mesma, onde se concentra o maior potencial do turismo fiscal. A influência de incentivos fiscais do ICMS não foi incluída no presente trabalho.

\section{4 - Organização do Trabalho}

A dissertação é composta por cinco capítulos, descritos a seguir.

No Capítulo 1 é feita uma introdução do problema, em que é mostrado o objetivo do trabalho, a relevância do assunto a ser estudado e quais as suas delimitações.

No Capítulo 2 é feita uma revisão da literatura a respeito das principais referências da área de estratégia, logística, planejamento de rede, ICMS e trabalhos prévios sobre logística e ICMS.

No Capítulo 3 é descrita a metodologia bem como são apresentados os dados utilizados, as premissas, assim como o modelo matemático e o estudo de caso construído.

No Capítulo 4 são apresentados os resultados encontrados para os cenários estudados. É feita ainda uma comparação entre as redes logísticas com e sem influência do ICMS e da reforma tributária.

No Capítulo 5 é realizada a conclusão do trabalho, apresentando-se os principais pontos abordados, resultados obtidos, conclusões finais e propostas para estudos futuros. 


\section{2 - REVISÃO DA LITERATURA}

Neste capítulo é feita uma revisão da literatura empregada acerca dos temas relevantes para o desenvolvimento e conclusão deste trabalho.

Inicialmente é feita uma revisão sobre logística e supply chain management, custo total, projetos de redes logísticas, estrutura de ICMS atual e a reforma tributária. Posteriormente, apresentam-se os principais trabalhos desenvolvidos na área de planejamento de redes com tributos e incentivos fiscais, além de suas variações.

Como parte do objetivo deste trabalho é implantar um modelo de planejamento de redes logísticas, será considerada a implementação da reforma tributária.

\section{1 - Entendimento da Estratégia Competitiva}

Em um mercado competitivo, onde as mudanças e as inovações ocorrem em um ritmo acelerado, a existência de consumidores exigentes, com diferentes necessidades a serem atendidas, conduz as empresas a buscarem novas formas de gestão de seus negócios em direção à fidelização dos seus clientes. Juntamente com a busca da satisfação de seus clientes, as empresas devem remunerar o capital investido pelos acionistas, garantindo assim, a sobrevivência da empresa. Este mecanismo de melhoria e busca pelos objetivos acima citados contribui para aumentar as chances da empresa se manter no mercado ao qual ela está inserida, e também, para se ter melhores condições de enfrentar seus concorrentes (FLEURY, et al., 2000).

O crescente aumento da competitividade torna o desenvolvimento da estratégia um fator de extrema importância para a permanência da empresa no mercado. Para Porter (1999), o processo de desenvolvimento de estratégias exige a participação de todo corpo gerencial da empresa, além disso, é importante contar com o apoio de bons estrategistas que, de certa forma, fornecerão uma base sólida no desenvolvimento das atividades. 
A definição da estratégia adequada tem por objetivo criar vantagens competitivas sobre os concorrentes e também manter as vantagens já existentes (DAY, 1999). Porter (1999) ressalta que o gestor deve compreender os fatores ambientais predominantes no contexto para melhor posicionar a empresa no ambiente, ou buscar influenciá-lo a favor da empresa. Sendo assim, as estratégias devem ser flexíveis a ponto de acompanhar um mercado que sofre alterações constantemente, possibilitando assim alcançar o desempenho esperado.

Diversos autores contribuíram para construir a concepção do conceito de estratégia existente na literatura atual. Chandler (1962) descreve a estratégia como o ponto determinante das metas básicas de longo prazo de uma empresa, a adoção dos cursos de ação e a alocação de recursos necessários para se atingir estas metas. Ackoff (1983) destaca que a estratégia está preocupada com objetivos de longo prazo da empresa e os meios para alcançá-los que afetam o sistema como um todo. Ansoff (1977) evidencia que o comportamento estratégico diz respeito ao processo de interação da empresa com seu ambiente, que traz modificações à empresa pela transformação constante do ambiente. Porter (1980) complementa que a estratégia é o produto de um ato criador, inovador, lógico e aplicável, que gera um conjunto de ações coerentes de alocação de recursos e de decisões táticas, objetivando colocar a empresa em posição competitiva vantajosa.

Minzberg et al. (2000) agruparam estes conceitos de estratégia em 10 escolas de pensamento de acordo com o entendimento do processo de formação da estratégia empresarial. Cada uma das dez escolas reforça uma maneira diferente de formular e/ou formar estratégias, sendo divididas em dois grandes grupos: as escolas prescritivas e as escolas descritivas.

Segundo Minzberg et al. (2000), as 10 escolas de planejamento são:

1 - A escola de design compreende a construção da estratégia como o ajuste entre as forças e as fraquezas internas da empresa com as ameaças e oportunidades externas de seu ambiente. A gerência sênior é responsável pela formulação da estratégia em um processo de pensamento consciente, ou seja, o gerente sênior cria 
mentalmente as estratégias deliberadas. Este processo não é formalmente analítico e nem informalmente intuitivo, de forma com que todos possam implementar a estratégia.

2 - A escola de planejamento utiliza a maior parte das ideias da escola de design, modificando a ideia de que o processo estratégico não é apenas cerebral, mas também formal. Isto significa que o processo pode ser decomposto em passos bem definidos, estruturados por listas de verificação e sustentado por técnicas como orçamentação, programas e planos operacionais. As técnicas de planejamento estratégico estão inseridas nesta escola.

3 - A escola de posicionamento foi introduzida principalmente por Michael Porter, que introduz a visão de que a estratégia se reduz a posições genéricas selecionadas por meios de análises formalizadas das situações, feitas a partir do modelo das cinco forças de Porter. A formalização da estratégia deve ser precedida por uma análise profunda e minuciosa do ambiente interno e externo da empresa. Um modelo genérico de estratégia deve ser adotado pela empresa para avaliar as ameaças e oportunidades do ambiente e "as forças e fraquezas" da organização.

4 - A escola empreendedora contrariou as escolas anteriores ao basear o processo nos mistérios da intuição. Sendo assim, a estratégia e sua construção passam de projetos, planos e posições precisas para visões vagas ou perspectivas amplas. Nesta escola o líder detém o controle em relação à implementação de sua visão, sendo o detentor de todo o processo estratégico.

5 - A escola cognitiva estuda os processos mentais de criação da estratégia desenvolvida nas mentes das pessoas, cujo objetivo é categorizar os processos em estruturas, modelos, conceitos e esquemas. $O$ modo pelo qual o cérebro humano processa a informação é foco da pesquisa nesta escola, focalizando, portanto, a cognição na criação da estratégia. Outro direcionamento desta escola está no modo como a cognição é usada para formular estratégias por meio de interpretações e não simplesmente para mapear a realidade de uma forma mais ou menos objetiva e distorcida. 
6 - A escola de aprendizado busca entender a estratégia como um processo emergente cuja origem está em toda a organização por meio de seus membros individualmente ou coletivamente. Os padrões comportamentais praticados dentro da organização originam as estratégias. As estratégias seriam o aprendizado da organização que surge por intermédio do fluxo das ações organizacionais.

7 - A escola de poder visualiza a construção da estratégia como um processo de negociação, dividido em duas dimensões (micro poder e macro poder). O micro poder compreende o desenvolvimento da estratégia como um fenômeno político de modo que o processo de construção envolve barganha e confrontação entre os agentes que compartilham o poder. O macro poder enxerga a empresa como uma entidade que utiliza o poder sobre os outros e seus parceiros de alianças, construindo joint-ventures e outras redes de relacionamentos para negociar estratégias de seu interesse.

8 - A escola cultural compreende a estratégia como um processo social fundamentado na cultura da empresa. Enquanto o poder concentra-se no interesse próprio e na fragmentação, a cultura concentra-se nos interesses comuns e na integração dentro da organização. A ideia central da escola está ligada à cognição coletiva caracterizada pela "mente da organização", expressa em crenças comuns que se refletem nas tradições e nos hábitos. A cultura seria responsável pelas mudanças estratégicas e pela formulação na estratégia.

9 - A escola ambiental coloca a estratégia como um processo reativo, considerando a empresa como um ente passivo que utiliza seu tempo reagindo a um ambiente que estabelece a ordem a ser seguida. $O$ grau de estabilidade e instabilidade determina o ambiente, além de estabelecer as pressões institucionais de cunho político e ideológico, sofridas pela empresa.

10 - A escola de configuração entende o processo de formalização da estratégia como um processo de transformação. As configurações são determinadas por agrupamentos coerentes de comportamentos. A transformação de uma organização está na modificação de uma configuração para outra e, o entendimento da configuração organizacional é o ponto de partida para a construção da estratégia corporativa. 
Minzberg et al. (2000) ressaltam que as estratégias empresariais existentes são construídas por meio da combinação do conhecimento das várias escolas estratégicas, tornando a formação da estratégica uma entidade dinâmica que poderá ser dotada tanto de processos cognitivos conscientes, deliberados e analítico-formais, como inconscientes, não deliberados e intuitivo-informais.

O principal motivo para a definição de estratégias é a criação de riqueza para os acionistas por meio da fidelização dos clientes. Desta forma, a definição de diretrizes estratégicas tem como objetivo conduzir o processo de adaptação de acordo com as novas realidades do mercado e, também, para que atendam aos objetivos da empresa (WRIGHT, et al., 2000).

A situação econômica do Brasil sofre atualmente um processo de reestruturação em virtude da globalização e da abertura do mercado. A chegada de empresas internacionais, evidenciada pelo processo de globalização e abertura do mercado, inicia as atividades impulsionando à implementação de ferramentas modernas de planejamento, que agregam valor aos serviços oferecidos aos clientes, contribuindo, assim, para tornar o setor mais dinâmico (FLEURY, et al., 2000).

No cenário atual, as atividades de transporte e distribuição, cuja finalidade é mover e armazenar um produto, desde o estágio do fornecedor até o estágio do cliente na cadeia de suprimentos, ganham cada vez mais importância no âmbito empresarial. Chopra e Meindl (2003) descrevem a distribuição como um fator-chave da lucratividade geral da empresa, pois afeta diretamente tanto o custo de cadeia de suprimento quanto à experiência do cliente (facilidade com que os clientes podem fazer e receber pedidos).

Neste contexto, Ballou (2006) ressalta que a utilização de ferramentas de gestão definida como o planejamento logístico tem por objetivos formalizar as diretrizes cruciais ao desenvolvimento das atividades tais como: localização de centros de distribuição, planejamento de redes, seleção de modais e determinação do nível de serviço. Chopra e Meindl (2003) complementam esta ideia ao definir o conceito de estratégia competitiva. Este conceito define, em relação a seus concorrentes, um conjunto de 
necessidades do cliente que se procura satisfazer por meio de produtos e serviços, como, por exemplo, estratégia de menor custo, maior qualidade ou maior nível de serviço.

O relacionamento entre a estratégia competitiva e a cadeia de suprimentos pode ser exemplificado a partir da cadeia de valor da empresa (cf. PORTER, 1999). O conceito de cadeia de valor visualiza a empresa como um conjunto de atividades funcionais, avaliando a contribuição de cada atividade para a formação do custo e da competitividade. Para Porter (1999), a empresa adquire vantagem competitiva ao executar atividades estratégicas de forma mais barata e melhor do que a concorrência. A Figura 1 mostra a cadeia de valor e as relações entre as atividades.

\begin{tabular}{|c|c|c|c|c|}
\hline \multicolumn{5}{|c|}{ Infra-estrutura da Empresa } \\
\hline \multicolumn{5}{|c|}{ Gerência de Recursos Humanos } \\
\hline \multicolumn{5}{|c|}{ Desenvolvimento de Tecnologia } \\
\hline \multicolumn{5}{|c|}{ Aquisição } \\
\hline $\begin{array}{l}\text { Logística } \\
\text { Interna }\end{array}$ & Operações & $\begin{array}{l}\text { Logística } \\
\text { Externa }\end{array}$ & $\begin{array}{l}\text { Mkt \& } \\
\text { Vendas }\end{array}$ & \\
\hline
\end{tabular}

Figura 1: Cadeia de valor tradicional Fonte: Porter (1999).

A cadeia de valor dá ênfase ao estreito relacionamento entre as estratégias funcionais dentro de uma empresa. Cada função é fundamental se uma empresa quiser satisfazer as necessidades do cliente de modo lucrativo. Assim, as estratégias funcionais não podem ser formuladas isoladamente e devem ajudar a dar suporte umas às outras (CHOPRA e MEINDL, 2003).

Segundo estes autores, para que uma empresa tenha sucesso, as estratégias competitivas e as estratégias na cadeia de suprimentos devem estar alinhadas. Este alinhamento estratégico ocorre quando as duas estratégias possuem objetivos alinhados, ou seja, as prioridades em satisfazer as necessidades dos clientes e a 
capacidade da cadeia de suprimento estão consistentes e conduzem a empresa a atingir as metas globais.

\section{2 - Logística e Distribuição Física}

De acordo com Bowersox e Closs (2001), o conceito de logística envolve a integração de informação, transporte, manuseio de materiais e embalagens, cuja finalidade é auxiliar o processo de criação de valor para o cliente. Desta forma, as operações logísticas podem gerar vantagens competitivas para a empresa ao se transformarem em uma competência chave.

Nesse contexto, o conceito de logística empresarial, definido por Ballou (2006), engloba todas as atividades de movimentação e armazenagem que facilitam o fluxo de produtos e os fluxos de informação necessários para movimentar o produto desde a fabricação até o consumidor final a um custo razoável. Ou seja, o objetivo principal da logística é providenciar bens e serviços corretos, no lugar certo, no tempo exato e na condição desejada ao menor custo possível.

Contribuindo com este pensamento, Bertaglia (2005) descreve que o processo de integração da economia mundial conduz as empresas a criarem produtos para um mercado globalizado, com processos mais racionais. As empresas planejam suas atividades considerando a globalização de seus negócios e, por ser um tema estratégico, a logística deve receber uma atenção especial.

Desta forma, os fatores externos de mercado devem ser inseridos no desenvolvimento estratégico, sendo imprescindível o conhecimento do mercado consumidor para realizar um serviço com qualidade, menor prazo e preço justo.

Os conceitos gerenciais sofreram grandes transformações entre o período de 1980 e 2000, especialmente no que tange à função de operações. Para Fleury et al. (2000), o movimento de qualidade total e o conceito de lean manufacturing trouxeram um conjunto de técnicas e procedimentos como o JIT, CEP (Controle Estatístico de 
Processos), QFD (Quality function deployment), SMED (Single-Minute Exchange of Die), Kanban e engenharia simultânea.

Os mesmos autores descrevem que estas técnicas contribuíram para um grande avanço da qualidade e produtividade, colaborando para o surgimento do conceito de logística integrada. A revolução da tecnologia da informação, as exigências crescentes de desempenho em serviços de distribuição e o surgimento e desenvolvimento dos prestadores de serviço logístico impulsionaram a consolidação do conceito de logística integrada no começo da década de 80.

Em pesquisa realizada pelo centro de estudos em logística (CEL/COPPEAD, 2008), a porcentagem dos custos logísticos do Brasil no PIB (produto interno bruto) é de $11,7 \%$ (US $\$ 125$ bilhoes). Em contrapartida, esta porcentagem é de 9,3\% nos Estados Unidos. Os principais motivos que contribuem para esta diferença nos gastos com logística são: má conservação de estradas, burocracia, problemas de segurança, pouca utilização dos rios navegáveis e diminuição de investimentos em infraestrutura e os aspectos tributários. Estes problemas encontrados justificam a importância da logística na situação econômica brasileira, colaborando para a redução da competitividade das empresas brasileiras.

As interfaces da logística ultrapassam o conceito de transporte e armazenagem. Para Bowersox et al. (2002), as decisões logísticas permeiam atividades como estoque, processamento de pedidos, distribuição, transporte, armazenagem, lotes de compra e distribuição. O conceito de logística integrada pode contribuir para responder importantes perguntas como:

1. Quanto comprar?

2. De quem comprar?

3. Como avaliar os compradores?

4. Quanto manter em estoque?

5. Como controlar o sistema dia a dia?

6. Qual política de estoque? 
7. Qual tecnologia empregar no processamento de pedidos?

8. Qual a frequência de entrega para determinada região?

9. Qual será o lead time?

10. Qual será o tamanho da frota?

11. Quanto e onde localizar os armazéns?

12. Qual a porcentagem de pedidos deve ser atendida?

Para responder a estas perguntas, será necessário envolver mais de uma área funcional da empresa, contribuindo para o entendimento de que as consequências de uma decisão individual influenciam diversas áreas da empresa. A tomada de decisão conjunta se faz necessária na medida em que as metas e objetivos são globais, diferenciando-se da ideia de que ótimos locais conduzem ao ótimo global (BALLOU, 2006).

Sendo a logística responsável pelo transporte e distribuição, um conceito importante, ressaltado por Slack et al. (1996), é o conceito de canais de distribuição. Um canal de distribuição representa a sequência de organizações ou empresas cuja finalidade é transferir a posse de um produto desde o fabricante ate o consumidor final. Primeiramente a empresa define qual será o canal de distribuição para que, posteriormente, possa ser definida a distribuição física dos produtos. A Figura 2 mostra um canal de distribuição tradicional.

O mesmo autor ressalta que a utilização de empresas intermediárias oferece à empresa uma gama razoavelmente ampla de produtos e serviços. A produção desta grande variedade de produtos e serviços internamente implicaria em uma utilização excepcional de recursos financeiros, além de forçar a empresa a atuar fora de seu core competence. 


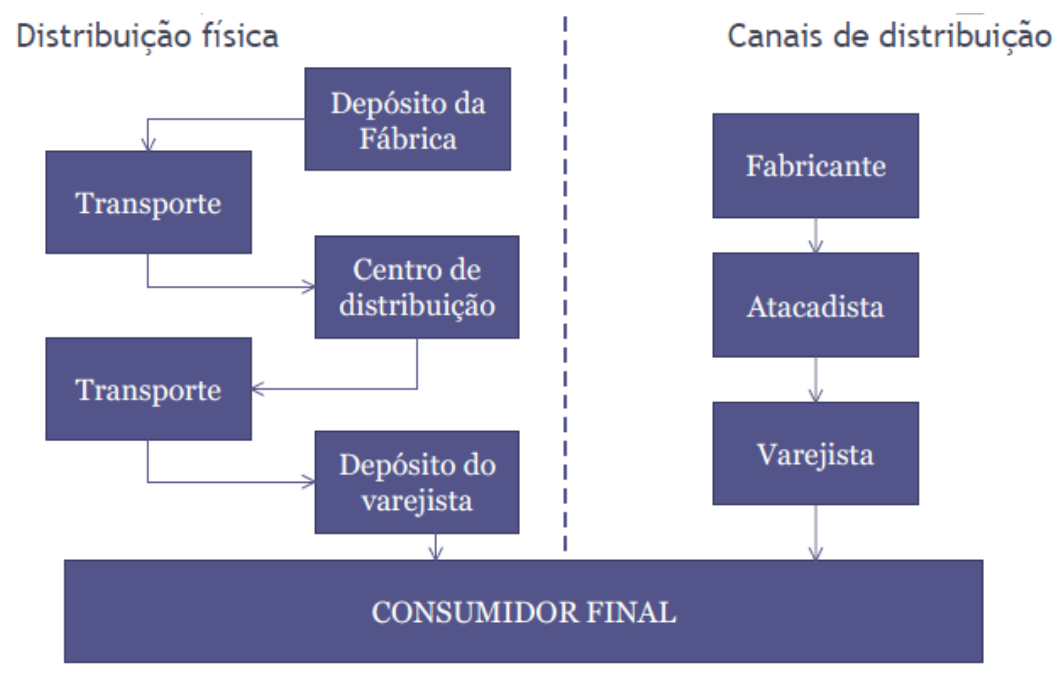

Figura 2: Canal de distribuição tradicional

Fonte: Slack (1996)

Para Bowersox e Closs (2001), se a manufatura for responsável por todas as funções dos canais de distribuição, verifica-se que pode não ser economicamente produtiva. Além disso, para a indústria é interessante que ela tenha ganhos de eficiência a partir da sua concentração no seu core competence. Assim, a utilização de intermediários na cadeia de suprimento se justifica por sua maior eficiência na colocação dos produtos no mercado, dividindo-se em 2 grupos: primários (fabricantes, atacadistas, distribuidores e varejistas), que participam diretamente assumindo o risco de posse do produto, e os secundários (empresas de transporte, armazenagem, processamento de dados e prestadores de serviço logístico), que não assumem o risco de posse do produto.

A principal funcionalidade das estruturas dos canais está relacionada com a ideia de segmentação de mercado e especialização do trabalho, facilitando a tendência de verticalização e maior controle bem como coordenação do canal, necessitando de uma maior sincronização e troca de informações. Para Ballou (2006), os distribuidores e atacadistas têm um papel econômico e logístico fundamental, pois conseguem ganhar escala de operações pela consolidação de cargas de diversos fornecedores e clientes. 
Com o crescimento dos canais de distribuição, o aumento da competitividade e a redução das margens de contribuição, o conceito de logística integrada foi ampliado para um conceito chamado de supply chain management (SCM).

Para Fleury et al. (2000), devido à necessidade de integração dos processos da cadeia de suprimento, o SCM representa o esforço de integração dos diversos participantes do canal por meio da administração compartilhada de processos-chave, interligando as diversas unidades organizacionais e participantes do canal, desde o consumidor até o fornecedor inicial de matéria-prima.

\section{3 - Gerenciamento da Cadeia de Suprimentos}

O gerenciamento da cadeia de suprimentos pode ser considerado uma abordagem sistêmica (cf. GUALDA, 1995) de razoável complexidade, que implica em alta interação entre os participantes, exigindo a consideração simultânea de diversos trade-offs. Fleury et al. (2000) descrevem que o SCM implica em uma visão além das fronteiras organizacionais, considerando tanto os trade-offs internos quanto os Inter organizacionais, relativamente a quem se deve responsabilizar pelos estoques e, em que estágio as diversas atividades deveriam ser realizadas.

Segundo Chopra e Meindl (2003), a cadeia de suprimentos consiste em todas as partes envolvidas, direta ou indiretamente, na realização de um pedido do cliente, incluindo não apenas o fabricante e os fornecedores, mas também transportadores e varejistas. Cada estágio em uma cadeia de suprimentos está conectado pelo fluxo de produtos, informações e fundos que normalmente ocorrem em duas direções e podem ser gerenciados por um estágio ou intermediário.

O objetivo da cadeia de suprimentos deve ser maximizar o valor gerado, ou seja, a diferença entre o que produto final vale para o cliente e os custos que incorrem a ela ao atender à solicitação do cliente. A estratégia competitiva formulada pela empresa contribui para a compreensão dos custos no canal, por exemplo: numa estrutura de canal onde o fabricante distribui diretamente para o consumidor final, a empresa possui 
um maior controle sobre as funções de marketing, porém o custo de distribuição tende a ser maior, exigindo do fabricante um número maior de vendas (BALLOU, 2006).

Chopra e Meindl (2003) explicam que diferentes formas de planejamento da rede de distribuição podem ser construídas de acordo com a estratégia competitiva. A organização precisa avaliar o impacto do serviço ao cliente e os custos envolvidos enquanto compara diferentes opções de rede de distribuição. Além disso, as necessidades dos clientes que devem ser atendidas influenciam as receitas da empresa, as quais, junto com o custo, decidem a lucratividade da rede de entrega.

O mesmo autor comenta que muitos componentes podem influenciar na decisão acerca da melhor rede de distribuição, sendo que os principais componentes podem ser descritos como:

1. Tempo de resposta

2. Variedade do produto

3. Disponibilidade de produto

4. Experiência do cliente

5. Tempo de lançamento ao mercado

6. Facilidade de devolução

Para Bowersox e Closs (2001), a compreensão dos fatores-chave logísticos (instalação, transporte, estoque, informação, sourcing e precificação) e interfuncionais da cadeia de suprimento auxiliam no equilíbrio entre responsividade e eficiência, contribuindo para suporte da estratégia competitiva da empresa. Com isto, a escolha da configuração adequada dos canais de distribuição possibilita a criação de vantagem competitiva, sendo muitas vezes um fator decisivo para a sobrevivência da empresa.

Chopra e Meindl (2003) ressaltam que os fatores-chave não atuam independentemente, mas interagem entre si para determinar o desempenho geral da cadeia de suprimentos. Um bom projeto faz escolhas apropriadas para oferecer o nível de responsividade desejado. 
Um modelo visual para estruturação de fatores-chave é descrito pelo autor na Figura 3. A tomada de decisão começa com uma estratégia competitiva e, a seguir é decidida a estratégia da cadeia de suprimentos, ou seja, como a cadeia de suprimentos deveria funcionar com relação à eficácia e à responsividade. Após a definição das estratégias, a cadeia de suprimentos precisa então utilizar os 3 fatores-chave logísticos e os 3 fatores-chave interfuncionais para atingir o nível de desempenho que a estratégia da cadeia de suprimentos determina.

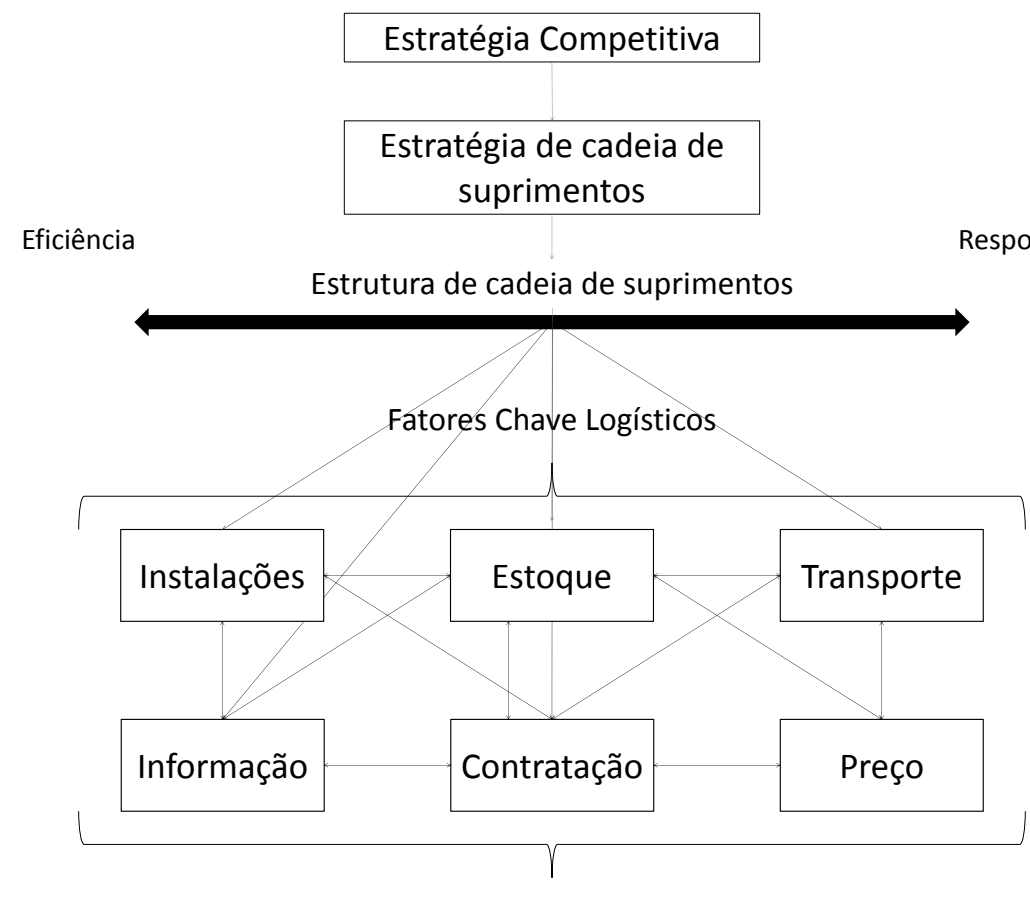

Fatores Chave Interfuncionais

Figura 3: Modelo visual de tomada de decisão em cadeia de suprimentos. Fonte: Chopra e Meindl (2003).

\section{4 - Custo Total}

Ao avaliar os fatores-chave para a definição das estratégias, é necessário avaliar os trade-offs. Para Ballou (2006), a expressão trade-offs define uma situação em que há conflito de escolha. Ele se caracteriza em uma ação econômica que visa à resolução de um problema, mas acarreta outro, obrigando uma escolha, por exemplo: se a estratégia de uma empresa é a centralização de estoque, reduzindo o custo de estoque, o custo de transporte irá aumentar. Se a empresa comercializa produtos com 
alto valor agregado, a centralização de estoque pode trazer muito ganhos, contudo se os produtos da empresa são de valor agregado baixo, a descentralização dos estoques pode reduzir o custo de transporte, pois o volume transportado tende ser maior.

Para Bowersox e Closs (2001), este conceito constitui uma peça fundamental para o escopo e os projetos logísticos, portanto, a questão básica é o gerenciamento coordenado dos conflitos de custos. A composição do custo total logístico se dá a partir da soma dos custos de estoque, transporte, armazenagem, compra (NOVAES, 2004). É possível representar este custo graficamente por meio da soma das curvas apresentadas na Figura 4.

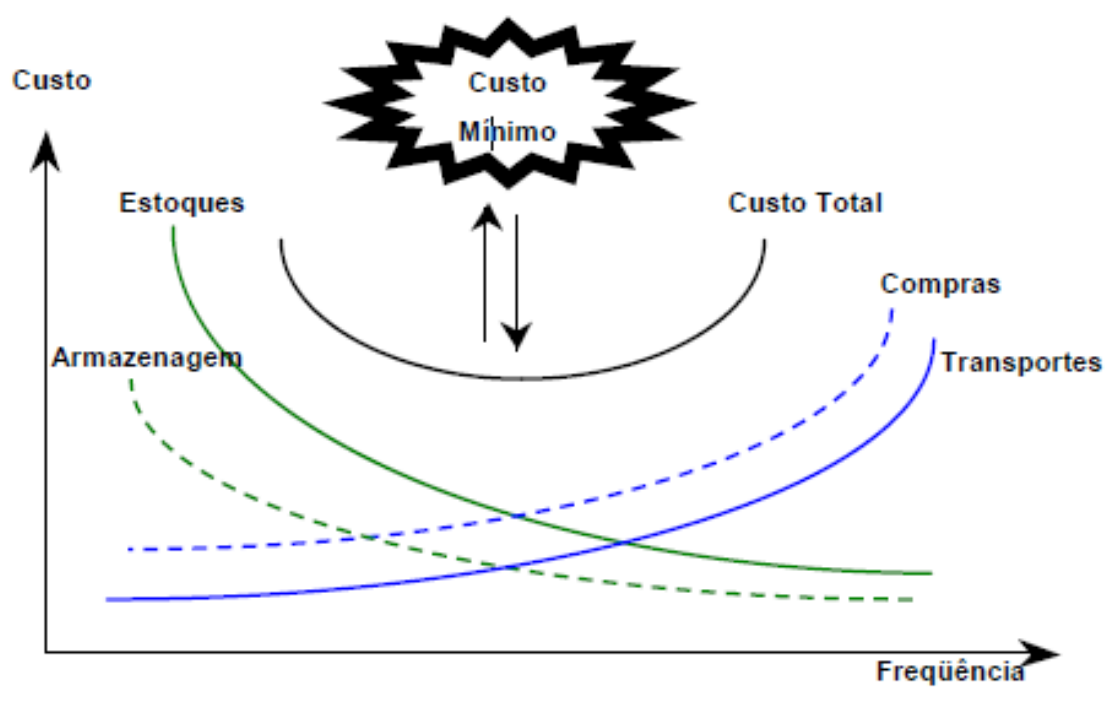

Figura 4: Custo total logístico Fonte: Novaes (2004).

De acordo com a pesquisa de custo logísticos, feita pelo centro de estudos em logística (CEL/COPPEAD, 2008), os custos de transporte, estoque, armazenagem e administrativo no Brasil são respectivamente $6.9 \%$, 3.7\%, 0.6\% e 0,5\% do PIB. Quando comparados aos custos do EUA, representados por $5.5 \%, 2.6 \%, 0.8 \%, 0.4 \%$ do PIB respectivamente, o somatório total dos custos é de $9.3 \%$ para os EUA, contra $11,7 \%$ do Brasil, ou seja, uma diferença de $4,6 \%$ entre os custos. A Figura 5 mostra o gráfico de comparação entre os custos. 


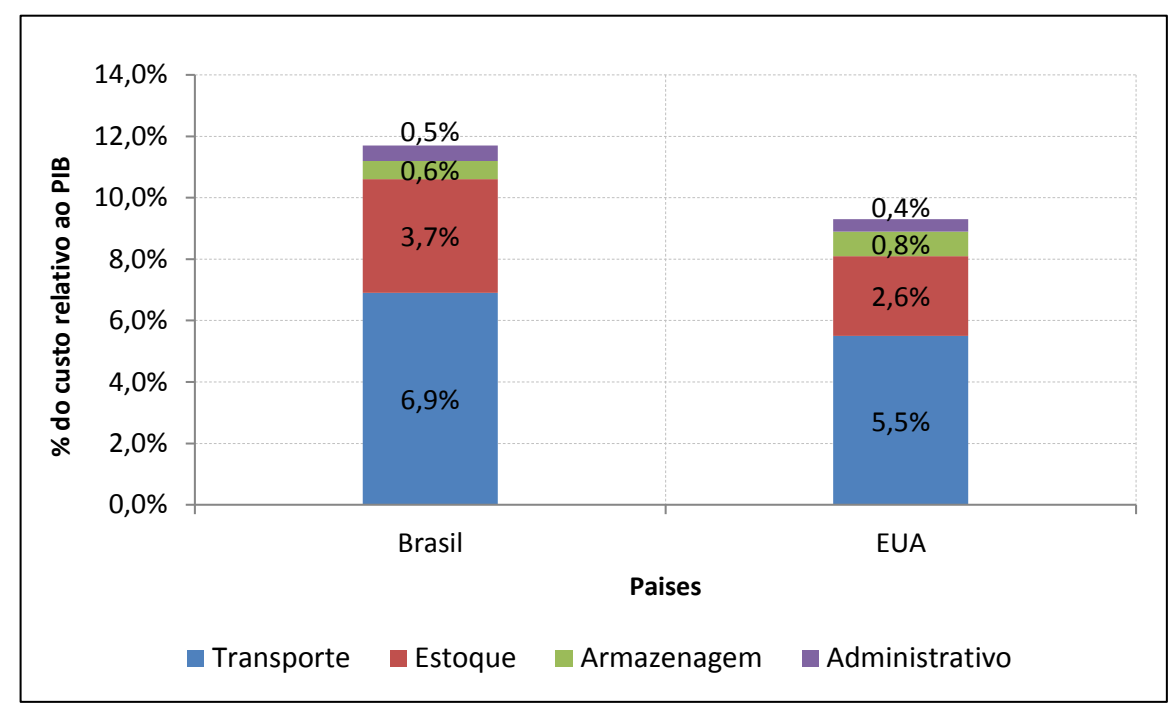

Figura 5: Comparação entre os custos logísticos Fonte: CEL/COPPEAD (2008).

O entendimento do custo logístico total representa um conceito fundamental para a logística, cuja finalidade é encontrar o equilíbrio operacional por intermédio da otimização conjunta dos componentes de custos. Em se tratando de uma particularidade brasileira, o cenário tributário se mostra um desafio no entendimento dos custos totais, por se tratar de uma variável com grande impacto no planejamento de redes logísticas, segundo Yoshizaki (2002).

O mesmo autor ressalta que, em problemas envolvendo planejamento de redes e avaliação de trade-offs, a utilização de modelos matemáticos simplificados é uma importante ferramenta analítica, porém o grande problema é que estes modelos não representam necessariamente a nossa realidade, tornando difícil a comparação direta destes modelos com decisões tomadas por diversas empresas.

Na prática, nem sempre é fácil obter uma visão sistêmica (cf. GUALDA, 1995) e se operar com custos totais otimizados, conduzindo a uma visão restrita da operação, devido a diversos motivos como: falta de conhecimento dos diversos trade-offs, impossibilidade de rever a forma de recompensas na empresa e indicadores de desempenho funcionais. 


\section{5 - Hierarquias de decisões}

Segundo Novaes (2004), o planejamento logístico pode se dividido em 4 áreas de problemas: níveis de serviço aos clientes, localização de instalações, decisões sobre estoque e decisões sobre transporte. Esta perspectiva pode ser representada em um triângulo onde o nível de serviço ao cliente é o resultado das estratégias formuladas nas outras 3 áreas. Os níveis de serviço ao cliente afetam diretamente o projeto logístico, portanto, a definição do nível adequado é o ponto de partida para as outras decisões logísticas, por exemplo: se uma empresa quer um mínimo de nível de serviço, menores serão os pontos de estocagem e transporte, porém, quanto melhor é o nível de serviço, maiores são os custos logísticos.

O mesmo autor comenta que a definição do nível de serviço possibilita a definição da localização das instalações, criando um esboço do plano logístico. Por

meio da definição do número, localização e tamanho destas instalações e, pela atribuição de uma fatia de demanda, é que se estabelecem os caminhos pelos quais os produtos são direcionados, definindo os custos de movimentação a partir da fabrica até o cliente. As decisões relacionadas ao estoque referem-se à definição do melhor método de controle, empurrar ou puxar (cf. WANKE, 2003), aos níveis de estoque e à localização dos estoques. As decisões de transportes estão relacionadas com a seleção de modais, o volume de embarque, as rotas e a programação, considerando fatores como distância entre os armazéns, clientes e fábricas.

O nível de serviço, a localização das instalações, o estoque e os transportes são algumas das mais importantes áreas de planejamento, visto que o impacto de cada uma delas pode modificar a lucratividade da empresa, tendo em vista o fluxo de caixa e o retorno dos investimentos, sendo que todas estas áreas estão inter-relacionadas e a avaliação dos trade-offs é necessária (FLEURY, et al., 2000). A Figura 6 mostra o triângulo de tomada de decisões logísticas. 


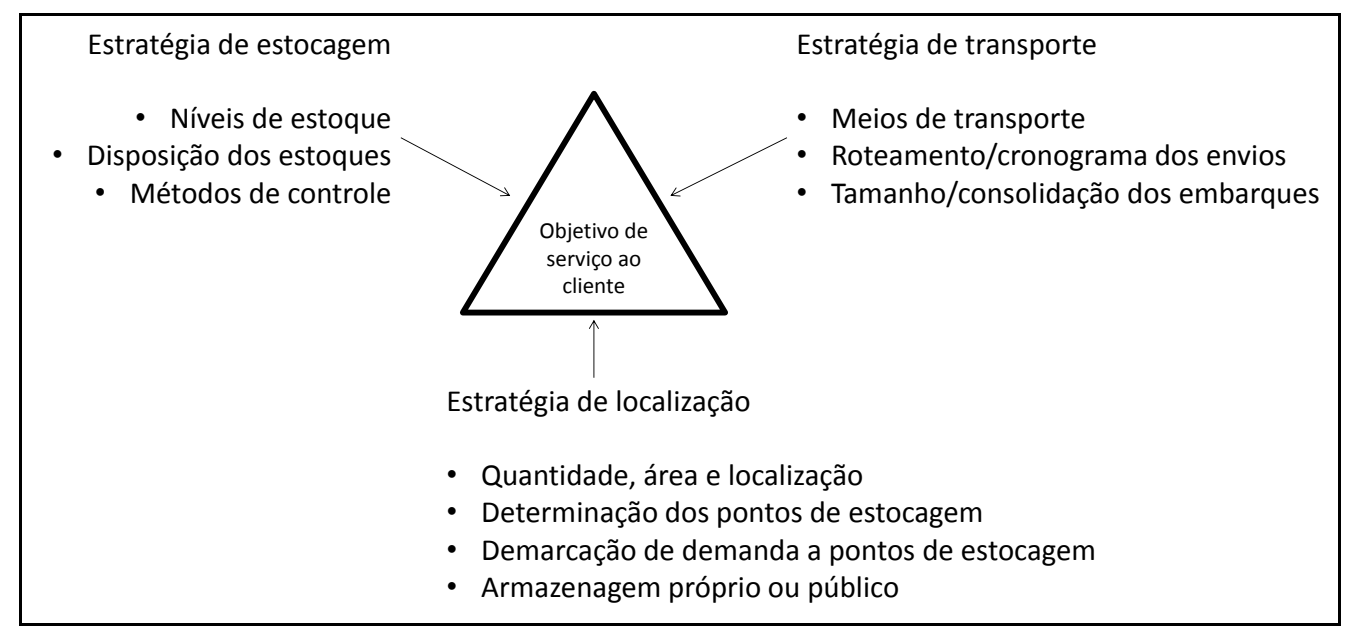

Figura 6: Triângulo de tomadas de decisão

Fonte: Ballou (2001).

As principais perguntas que o planejamento logístico tenta responder estão relacionadas com o quê, quando e como, e se desenvolvem em 3 níveis: estratégico, tático e operacional. Para Copacino e Donald (1985), a principal diferença entre eles está relacionada ao horizonte temporal de planejamento, sendo que cada um dos níveis requer uma perspectiva diferente.

Ballou (2006) explica que o planejamento estratégico requer um horizonte mais longo (maior que um ano) e, devido à dificuldade de se obter dados exatos e completos, pode-se obedecer à média e aos planos em geral, que são considerados adequados quando atingem um nível razoavelmente próximo ao ótimo. O planejamento tático traduz os planos estratégicos em ações rotineiras, focado na eficiência, melhor alocação dos recursos disponíveis e eficácia dos resultados. O horizonte de trabalho é intermediário (menor que um ano) e, a utilização de dados mais precisos e detalhados, sendo que, muitas vezes é necessário o conhecimento profundo do problema e, as soluções devem ser especificas e melhor elaboradas. O planejamento tático trabalha com dados precisos e, os métodos para o planejamento devem ter condições de operar com maior parte destes dados, e ainda, de elaborar planos razoáveis. O horizonte de planejamento pode ser tão pequeno quanto dias, semanas e, a frequência de decisão diária. A Tabela 1 mostra as principais decisões logísticas dividas em estratégico, tático e operacional. 
Tabela 1: Projetos logísticos divididos em níveis estratégicos.

\begin{tabular}{|c|c|c|c|c|c|c|}
\hline Níveis de decisão & Localização & Transportes & Estoques & $\begin{array}{c}\text { Processamento } \\
\text { do pedido }\end{array}$ & Armazenagem & Compras \\
\hline Estratégico & $\begin{array}{c}\text { Número, } \\
\text { tamanho e } \\
\text { intalaçães }\end{array}$ & $\begin{array}{c}\text { Seleção de } \\
\text { modal }\end{array}$ & $\begin{array}{c}\text { Políticas de } \\
\text { estoque, } \\
\text { rotatividade }\end{array}$ & $\begin{array}{c}\text { Projeto de } \\
\text { sistemas de } \\
\text { proc. De pedido }\end{array}$ & $\begin{array}{c}\text { Layout, seleção } \\
\text { de } \\
\text { equipamentos } \\
\text { de manuseio }\end{array}$ & $\begin{array}{c}\text { Politicas de } \\
\text { relacionamento }\end{array}$ \\
\hline Tático & $\begin{array}{c}\text { Posicionamento } \\
\text { de estoque }\end{array}$ & $\begin{array}{c}\text { Aluguel sazonal } \\
\text { de } \\
\text { equipamentos }\end{array}$ & $\begin{array}{c}\text { Estoque de } \\
\text { segurança, } \\
\text { regras de } \\
\text { controle }\end{array}$ & $\begin{array}{c}\text { Regras de } \\
\text { prioridades }\end{array}$ & $\begin{array}{c}\text { Utilização do } \\
\text { espaço, } \\
\text { escolhas } \\
\text { sazonais }\end{array}$ & $\begin{array}{c}\text { Contratação, } \\
\text { seleção de } \\
\text { fornecedores }\end{array}$ \\
\hline Operacional & $\begin{array}{c}\text { Determinação } \\
\text { de carga }\end{array}$ & $\begin{array}{c}\text { Roteirização } \\
\text { agendamento e } \\
\text { despacho }\end{array}$ & Reposição & Atendimento & $\begin{array}{c}\text { Coleta e } \\
\text { arrumação }\end{array}$ & $\begin{array}{c}\text { Liberação de } \\
\text { pedidos }\end{array}$ \\
\hline
\end{tabular}

Fonte: Ballou (2001).

De acordo com a problemática definida na dissertação, os projetos logísticos obedecem a uma abordagem conceitual, tendo em vista a localização de múltiplas instalações, sendo que Yoshizaki (2002) descreve a relação entre a logística e o ICMS, aplicando o conceito de escala de abstração (cf. YOSHIZAKI, 1997). No nível operacional, o problema de curto prazo está relacionado à disponibilidade de itens nas diversas instalações para se encontrar a rota de menor custo total, sem modificação na localização das instalações. No nível tático, as instalações não irão sofrer modificação, porém o problema está relacionado à localização dos estoques e a área de influência de cada instalação. No nível estratégico, a problemática está relacionada com a definição e localização das instalações, cujo objetivo é reduzir o custo logístico total (fixo, variável, transporte, estoque e ICMS).

\section{6 - Projetos de redes logísticas}

A configuração de uma rede de distribuição é considerada um dos problemas macro logísticos mais importantes, sendo que frequentemente grandes empresas necessitam realizar estudos físico-espaciais e temporais das origens e destinos de produtos acabados, bem como dos fluxos e dos demais aspectos relevantes (CUNHA e MUTARELLI, 2004). 
Segundo Chopra e Meindl (2003), as decisões de projetos de redes impactam significativamente no desempenho da cadeia de suprimentos, pois formalizam a configuração da cadeia de suprimentos, estabelecendo restrições cujo objetivo pode ser reduzir os custos ou aumentar a responsividade, determinando a quantidade de flexibilidade que a empresa atende à demanda.

As decisões de localização de instalações exercem um impacto de longo prazo no desempenho de uma cadeia de suprimentos, ou seja, a definição de uma boa localização pode ajudar a cadeia de suprimentos a ser mais responsiva enquanto mantém os custos mais baixos, sendo o contrário também verdadeiro (LACERDA, 2000).

Além da localização, Ballou (2006) descreve que a alocação da capacidade, volume máximo de produção, movimentação, transporte ou armazenagem (cf. SLACK, et al. 1996), também possuem, um impacto significativo sobre o desempenho da cadeia de suprimentos, apesar de a alteração da capacidade ser mais fácil do que a mudança na localização da instalação. Atribuir muita capacidade pode aumentar os custos ocasionados pela má utilização da instalação e, a alocação de pouca capacidade pode prejudicar no atendimento da demanda e ocasionar baixa responsividade.

O mesmo autor comenta que a alocação desordenada, ou seja, definição de fluxos origem/destino cuja distância média é maior quando comparado ao ótimo logístico (cf. SLACK, et al. 1996), de fontes de suprimentos e mercados para determinadas instalações pode resultar em um aumento de custo de transporte, estoque e produção. As condições do mercado mudam constantemente e a decisão dos fluxos deve ser feita regularmente, porém a instalação deve ser flexível o bastante para comportar esta variação, por isso, as decisões de fluxos são consideradas decisões táticas.

A necessidade de utilização maciça de dados, software e hardware sofisticados e uma quantidade de variáveis de decisão que se influenciam mutuamente tornam os problemas de configuração de redes de distribuição e localização de um problema atividades bastante complexas. Para Nazário (2000), este tipo de problema possui dois 
aspectos importantes, um de natureza espacial e outro de natureza temporal. O aspecto espacial refere-se à localização destas instalações e aos fluxos entre os pontos. Já o aspecto temporal refere-se à disponibilidade dos produtos solicitados pelos clientes, no prazo adequado, considerando o tempo de ciclo do pedido.

À medida que a empresa cresce ou quando duas empresas se unem, o planejamento de redes deve ser refeito. Em decorrência da diferença entre as redes logísticas de empresas em processo de fusão, um planejamento de rede pode reduzir o número de instalação, consolidar cargas e otimizar os fluxos que muitas vezes podem estar duplicados (WANKE, et al., 2009).

De acordo com Robeson e Copacino (1994), existem 3 razões fundamentais que exemplificam os principais desafios da gestão de uma rede de distribuição:

1. Complexidade: grande quantidade de instalações, canais, unidades industriais e produtos necessitam de sistemas grandes para gerenciar o processo de armazenagem, transporte e manuseio. Além disso, a agregação dos dados de uma rede grande e complexa dificulta a construção do modelo.

2. Necessidade de mercado: uma rede de distribuição construída através de um planejamento adequado pode trazer vantagens competitivas em um mercado cada vez mais exigente onde as entregas, os prazos estão cada vez mais rápidos em uma qualidade cada vez maior.

3. Custos: o planejamento adequado pode reduzir significativamente os custos de produção, transporte, armazenagem e estoque de uma rede de distribuição física.

Por se tratar de um problema que abrange uma quantidade de temas e dados diversos, Lacerda (2000) ressalta que o conceito de custo total deve ser aplicado nos projetos de redes devido ao fato de muitos destes custos apresentarem trade-offs. Além disso, uma ampla variedade de fatores influencia nas decisões de projetos de redes em cadeia de suprimentos. 
Chopra e Meindl (2003) descrevem estes fatores como: estratégicos (instalação exportadora, supridora, servidora, colaborativa, de ponta e diretora), tecnológicos, macroeconômicos (tarifas e incentivos fiscais, taxa de câmbio e risco de demanda), políticos, competitivos (externalidades positivas entre empresa, localização para dividir o mercado, tempo de resposta e custos logísticos) e infraestrutura. A Figura 7 mostra um modelo visual criado pelo autor para descrever o processo de tomada de decisão em projetos de redes.

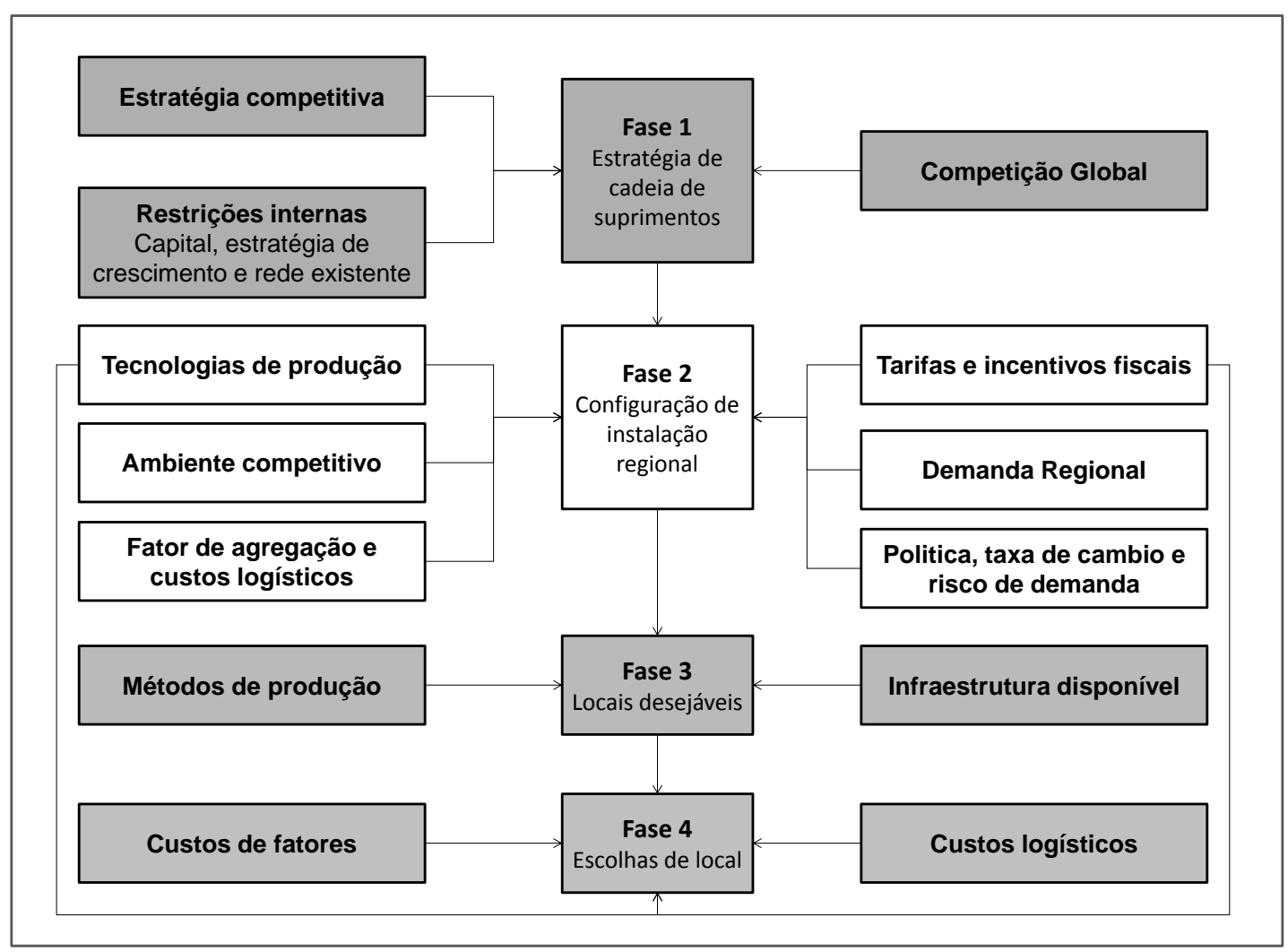

Figura 7: Modelo visual de tomada de decisão em projetos de redes. Fonte: Chopra e Meindl (2003).

Chopra e Meindl (2003) dividem o modelo proposto em 3 fases. O objetivo da fase 1 é definir o projeto em geral da cadeia de suprimentos, isto inclui determinar as funções de cada nível do canal e, se as atividades serão realizadas internamente ou terceirizadas. O planejamento começa por meio da identificação das necessidades dos clientes e dos requisitos básicos para se atingir estes objetivos, sendo que a estratégia especifica precisa dar suporte à estratégia competitiva. Uma análise da concorrência e 
da provável evolução da competição pode trazer importantes informações para a definição da rede, visto que o planejamento de redes é uma decisão de longo prazo.

A fase 2 do processo de planejamento tem por objetivo identificar regiões onde as instalações estarão localizadas, seus potenciais e suas capacidades. Para isso, é necessário realizar a previsão da demanda e a identificação, tendo em vista se as economias de escala poderem desempenhar um papel significativo na redução dos custos. O risco de demanda, a taxa de câmbio, os riscos políticos e a concorrência precisam ser analisados também, pois podem influenciar no planejamento de redes como, por exemplo: o ICMS e os incentivos fiscais.

O objetivo da fase 3 é selecionar um conjunto de localizações desejáveis que atendam aos requisitos pré-estabelecidos como infraestrutura, suporte a metodologias de produção, proximidade com empresas fornecedoras de matéria-prima, comunicação e serviços públicos. $\mathrm{Na}$ fase 4 , com as informações detalhadas sobre cada localização fornecidas pela fase 3 , a rede é projetada para maximizar os lucros totais, levando em consideração a margem e a demanda esperada em cada mercado, os diversos custos logísticos e de instalação, os impostos e tarifas.

Para Ballou (2006), os problemas de localização podem ser classificados de acordo com 5 critérios:

Força direcionadora: este fator pode ser considerado o mais importante no planejamento de redes devido ao impacto do mesmo na tomada de decisão, ou seja, qual será o objetivo principal que conduz a empresa a realizar esse estudo. Este objetivo pode ser aumentar o nível de serviço, reduzir custo de transporte, centralização de estoque, planejamento dos fluxos etc.

Número de instalações: a empresa pode escolher localizar uma ou mais instalações, porém a escolha de uma única instalação pode ser considerada um problema mais fácil por não haver necessidade de divisão da demanda, efeito de consolidação e custos de instalação. 
Descontinuidade de escolhas: as escolhas podem ser contínuas ou discretas. Se a empresa quer avaliar alguns possíveis locais já pré-determinados, será considerada uma avaliação discreta. Caso a empresa não tenha opções viáveis e a localização de instalações possa ser localizada em qualquer lugar de um plano contínuo, será considerada uma avaliação contínua.

Grau de agregação: este fator é considerado muito importante, porque tem relação com os níveis de planejamento, ou seja, para um planejamento de rede onde o objetivo é localizar as instalações, a demanda deve ser agregada em famílias e em macrorregiões, porém quanto mais operacional é o estudo, menor é o grau de agregação necessário para a análise.

Horizonte de tempo: a análise pode ser estática ou dinâmica. A análise estática refere-se a um tempo único, por exemplo: um ano ou um mês. A avaliação dinâmica pode cobrir muitos anos de uma só vez, especialmente quando as instalações representam um investimento fixo e o custo de modificação for elevado.

O mesmo autor descreve que para resolver os problemas de planejamento de redes, diversos métodos podem ser utilizados como, por exemplo: métodos exatos e otimizadores, heurística e simulação (cf. BALLOU, 2006). Wanke et al. (2009), em seu livro intitulado "Introdução ao planejamento de redes logísticas", realizou uma pesquisa extensa sobre os autores e as suas principais contribuições para o entendimento dos modelos de planejamento de rede.

Os principais modelos de localização foram descritos por Maciel e Dalvi (2006) apud Current et al. (2002) e, são divididos em 8 modelos:

Set Covering (Cobertura de Conjuntos): o objetivo central deste modelo é localizar o menor número possível de instalações, sendo que todos os pontos devem ser atendidos (cobertos) por pelo menos uma instalação.

Maximal Covering (Cobertura Máxima): este modelo foi formulado para solucionar um problema de cobertura máxima cuja função é localizar o máximo de 
instalações dado uma restrição, por exemplo: um modelo de localização de escolas públicas que maximize a cobertura dado uma restrição financeira.

P-Center (P-Central): este modelo é utilizado para minimizar distância para a cobertura dos pontos de demanda, a partir de um número $p$ de instalações.

P-dispersion (P-Dispersão): o objetivo deste modelo é minimizar a distância entre os pontos de demanda e as novas instalações que devem ser localizadas, por exemplo: localização de bases militares.

P-Median (P-Mediana): o objetivo deste modelo é localizar $p$ instalações, minimizando a demanda multiplicada pela distância entre os pontos de demanda e as instalações.

Fixed Charge (Custo Fixo): o objetivo deste modelo é minimizar o custo total (fixo e transporte) levando em consideração que os custos fixos para qualquer instalação são iguais, assumindo que as instalações não possuem capacidade de cobertura e, somente um número pré-determinado de instalações pode ser localizado.

Hub-Location (Localização de Hub): este método utiliza um ponto central que consolida as cargas de diversas localizações, designados para utilizar veículos com altas capacidades de carga, ou mais rápidos, nos longos trechos entre uma instalação e outra. Consequentemente, este modelo reduz o custo médio por viagem, tendo sido bastante utilizado no transporte aéreo nos EUA, após a desregulamentação em 1978.

Maximum Location Problem (Máxima Distância): os modelos de localização assumem que a instalação deve estar mais próxima dos pontos de demanda, porém instalações indesejáveis como presídios, usinas de processamento de lixo orgânico deveriam estar localizadas o mais distante possível. Este método tem por objetivo localizar $p$ instalações, em que a demanda multiplicada pela distância entre os pontos de demanda e as instalações seja maximizada.

Para Geoffrion e Powers (1995), com a disponibilidade de software, hardware e algoritmos, o uso de métodos otimizadores se tornaram métodos viáveis. Além disso, as 
empresas possuem sistemas de banco de dados automatizados, facilitando a obtenção de informações necessárias para este tipo de estudo, como por exemplo: localização da demanda, média de venda, demanda por família de produtos, custos de transporte e estoque etc.

Historicamente os problemas de planejamento de redes não eram resolvidos mesmo com a utilização de computadores mais poderosos porém, com o avanço dos computados e técnicas de programação, hoje em dia é possível realizar este tipo de estudo, por não se tratar de um problema NP Hard (cf. DASKIN, 1995). A técnica mais utilizada para resolver este tipo de problema é a programação linear inteira por causa da facilidade em manipular custos fixos e modelar economias de escala em instalações (BALLOU, 2006).

\section{7 - Aspectos importantes do direito tributário brasileiro}

As normas jurídicas apresentam-se hierarquizadas. Segundo Souza (2005), existe uma normal fundamental da qual se originam varias leis, de cada lei é possível que se originem vários decretos, contratos e sentenças, idealizando assim uma "pirâmide jurídica". Carrazza (2009) explica que a ordem jurídica é resultado da hierarquia, diferenciando-se de um sistema de regras dispostas horizontalmente, sendo que a constituição possui a supremacia hierárquica, ou seja, "o escalão de Direito Positivo mais elevado".

O mesmo autor desenvolve esta ideia, também explicando que a constituição de um Estado é o conjunto de normas que indicam quem detém os poderes estatais, quais são estes poderes, como devem ser exercidos e quais os direitos e garantias que as pessoas têm em relação a eles. A constituição se posiciona acima de qualquer escala hierárquica no ordenamento jurídico, sendo a mesma não subordinada a nenhuma outra norma e servindo como base a todas as outras normas (MOREIRA e CANOTILHO, 1991). 
Lopes (2009) define que o Estado é corresponde a uma comunidade humana localizada em uma base espacial (território) e que, dentro das fronteiras desse território, institui uma forma de organização do poder politico soberano (acima de qualquer controle), cuja finalidade é garantir o bem estar econômico e social, a justiça e a segurança.

O mesmo autor comenta que para alcançar esta finalidade, o Estado necessita de recursos financeiros, vigorando o principio da liberdade de iniciativa, incumbindo ao Estado não o papel de protagonista, mas sim o papel de agente normativo e regulador. Contudo, a exploração direta da atividade econômica pelo Estado Brasileiro é excepcional, permitida apenas em certas hipóteses pela norma do art. 173 da constituição federal (CF).

A tributação é, portanto, um instrumento de que se vale o Estado Brasileiro para obter recursos financeiros, e assim custear suas atividades em prol da coletividade, já que em regra não explora diretamente a atividade econômica (SOUZA, 2005). Sendo assim, a garantia de que o cidadão possa exercer suas liberdades no plano econômico, sem amarras estatais que prejudiquem tal exercício, contrapõe-se com a obrigação na prestação pecuniária compulsória (pagamento obrigatório em moeda) que permite o Estado realizar atividades públicas em prol do coletivo (LOPES, 2009).

O art. 3a do Código Tributário Nacional (lei n⿳a 5.172 / 1966) em consonância com o art. 146, III, a, da Constituição Federal estabelecem a definição de tributo como:

"Tributo é toda prestação pecuniária compulsória, em moeda, ou cujo valor se possa exprimir, que não constitua sanção de ato ilícito, instituída em lei e cobrada mediante atividade administrativa plenamente vinculada".

Lopes (2009) explica que o conceito de pecuniária está relacionado ao dinheiro, ou seja, todo o pagamento deve ser representado pela entrega de dinheiro ao Estado. Este conceito é importante, pois existem outras formas de extinção da obrigação 
tributária, sendo que as leis são fontes da obrigação tributária e o fato gerador são as fontes materiais.

O mesmo autor descreve os nove princípios fundamentais descritos nos artigos 150 a 152 da Constituição. Os noves princípios são:

1. Princípio da legalidade: toda tributação deve ser formalizada através de uma lei.

2. Princípio da igualdade: empresas ou contribuintes que estejam em condições de igualdade, devem receber tratamento igual.

3. Princípio da irretroatividade: nenhum imposto deve ser cobrado antes do início da vigência do mesmo.

4. Princípio da anterioridade: é vedada a cobrança de tributos no mesmo exercício financeiro em que haja a publicação da lei.

5. Princípio da vedação de confisco: é vedada a utilização de tributos cujo efeito é o confisco.

6. Princípio da vedação à limitação ao tráfego de pessoas e bens: veda o estabelecimento de qualquer limitação à circulação de pessoas e bens, por meio de tributos interestaduais ou intermunicipais, exceto pela cobrança de pedágio pela utilização de vias de circulação públicas.

7. Princípio da imunidade: visa resguardar a liberdade de expressão, do livre pensamento, da política, da religião, da expansão, da cultura, do desenvolvimento econômico, pois é a União, Estados e Municípios o estabelecimento de tributos renda ou serviços.

8. Princípio da uniformidade de tributos federais: é vedado o estabelecimento de tributos que não seja uniforme em todo o território nacional, possibilitando a diferenciação e a preferência de um Estado, Município ou ao Distrito Federal. É permitida a criação de incentivos 
fiscais para promover o equilíbrio no desenvolvimento de regiões menos favorecidas.

\section{Princípio da uniformidade de tributos Estaduais, do Distrito Federal e} dos Municípios: é vedado o estabelecimento de diferentes tributos para serviços e bens de acordo com sua procedência ou destino.

Souza (2005) explica que existe uma diferença entre multa e tributo. A primeira possui caráter repressivo cuja medida é disciplinar. O tributo não tem caráter punitivo, embora seja recolhido com sacrifício pelos cidadãos. A sua razão está na repartição das despesas públicas entre os membros da coletividade.

O fato que origina a obrigação de recolhê-lo aos cofres públicos é a qualificação de um tributo, independente do nome do tributo ou da destinação do mesmo. $O$ fato gerador pode indicar a natureza específica de um tributo, sendo que o mesmo pode se dividir em vinculados (a obrigação se origina em alguma atividade exercida pelo Estado) ou não vinculado (a obrigação se origina independente da atividade do Estado).

A simples distinção das situações que originam os fatos gerados de obrigação permite identificar pelo menos 3 espécies tributáveis, segundo Lopes (2009):

1. Imposto: tributos não vinculados cuja atividade independe do Estado.

2. Taxa: tributos vinculados cujo fato gerador envolve atividades públicas específicas.

3. Contribuições de melhoria: tributos vinculados, cujo fato gerador envolve atividade pública específica, qual seja a realização de obra pública que decorra de valorização imobiliária.

O artigo 144 da Constituição Tributária Nacional conceitua o fato gerador da obrigação principal como: "a situação definida em lei como necessária e suficiente à sua ocorrência". Esta definição pode ser esclarecida por Souza (2005), onde se entende que o surgimento da obrigação tributária é indispensável à sua realização. 
Assim o fato gerador engloba fatos (como a morte de uma pessoa que deixa seus bens), atos (como a compra e venda de uma casa) ou situações jurídicas (como a propriedade de um veículo motor). O fato gerador principal pode ser analisado de acordo com 5 aspectos e foram descritos por Souza (2005) como:

1. Aspecto Material: neste aspecto extrai-se o respectivo núcleo, que poderia ser a propriedade de um bem (IPTU, ITR e IPVA), a circulação de bens e mercadorias (ISS e ICMS), a realização de atividades de importação e exportação (II e IE), a valorização imobiliária em decorrência de uma obra pública (contribuição de melhoria) e a utilização efetiva ou potencial de serviços públicos (taxa de serviço).

2. Aspecto Temporal: neste aspecto define-se o momento de consumação do fato gerador, onde a partir deste momento o vínculo estará inaugurado. Por exemplo: quando se considera a importação do produto, o vinculo só se formalizará a partir do momento da apresentação do desembaraço aduaneiro, quando então está nascida a relação tributária.

3. Aspecto Espacial: neste aspecto determina-se o local de ocorrência do fato gerador. É possível que ocorram algumas exceções que estão inseridas no art. $3^{\text {a }}$.

4. Aspecto Quantitativo: neste aspecto é definido o valor da prestação tributária, quando fixa, ou dos elementos que permitem sua apuração, a saber, a base de cálculo e a alíquota.

5. Aspecto Pessoal: neste aspecto são identificados os sujeitos ativos e passivos envolvidos no vinculo obrigacional.

O Código Tributário Nacional, em seu artigo 119, descreve o sujeito ativo como a pessoa jurídica de direito público competente para exigir o respectivo cumprimento. $\mathrm{O}$ sujeito passivo estará na pessoa física ou jurídica obrigada por lei ao cumprimento de dever jurídico tributário, seja ele em dar, em fazer, um não fazer ou tolerar. A relação 
jurídica é o elo entre o sujeito ativo e passivo devido à ocorrência do fato gerador (LOPES, 2009).

A diferenciação entre os conceitos de evasão, elisão e sonegação podem ser encontrados em Souza (2005). O conceito de evasão fiscal enquadra qualquer conduta, comissiva ou omissiva, tendente a elidir, reduzir, retardar ou burlar a incidência tributária. A evasão omissiva divide-se em imprópria (quando o fato gerador deixa de existir) e inação (quando o fato gerador existe, mas não ocorre o pagamento do tributo).

Quando a evasão por inação é intencional, diz-se que há sonegação.

O segundo grupo é a evasão comissiva (por ação), que é sempre intencional, mas pode ser lícita ou ilícita. Quando o agente se vincula direta e pessoalmente à situação que constitui fato gerador de obrigação principal, mas no intuito de se furtar ao dever fiscal, falsifica documentos, simula a realização de negócios jurídicos, omite declaração para diminuir a ou excluir o tributo devido. A evasão comissiva pode ser lícita quando for realizada antes do fato gerador, denominando-se elisão fiscal.

\section{8- ICMS}

Com origem no antigo ICM, criado pela Ementa Constitucional $n^{\mathrm{a}}$ 18/1965, o ICMS foi genericamente previsto no artigo 155, II, da Constituição Federal, que estatui: "Compete aos Estados e ao Distrito Federal instituir imposto sobre: operações relativas à circulação de mercadorias e sobre prestação de serviços de transporte interestadual e intermunicipal e de comunicação, ainda que as operações e as prestações se iniciem no exterior" (LOPES, 2009).

O mesmo autor comenta que a sigla ICMS abrange pelo menos 5 impostos diferentes e diferem de acordo com a hipótese de incidência e bases de cálculo diferentes. $\mathrm{O}$ imposto incide:

1. Sobre operações mercantis (operações relativas à circulação de mercadorias). 
2. Sobre serviços de transporte interestadual e intermunicipal.

3. Sobre serviços de comunicação.

4. Sobre produção, importação, circulação, distribuição ou consumo de lubrificantes e combustíveis líquidos e gasosos e de energia elétrica.

5. Sobre a extração. Circulação, distribuição ou consumo de minerais.

A Constituição de 1988 descreveu os impostos supracitados em um mesmo rótulo (ICMS), causando na prática grandes confusões. Mas, embora estes impostos não se confundam, todos possuem o mesmo "núcleo central", que permite que sejam estudados conjuntamente, como por exemplo: todos devem obedecer ao regime da não-cumulatividade.

A expressão "operações relativas à circulação de mercadorias" abrange qualquer negócio que enseje circulação de mercadorias, desde a produção até o consumidor, tornando-se um imposto plurifásico, incidindo tantas vezes quantas sejam as operações dentro do ciclo econômico. O conceito de mercadoria engloba bens móveis e semoventes enquanto objeto de circulação econômica, ou seja, envolvidos em atividades mercantis (SOUZA, 2005).

O momento de ocorrência do fato gerador é considerado no instante em que a mercadoria sai do estabelecimento do empresário ou ocorre a modificação da propriedade ou título da mercadoria. Além disso, o local de ocorrência do fato gerador pode ser identificado no local do estabelecimento, onde a mercadoria se encontre, no momento da ocorrência do fato gerador, no local do estabelecimento onde ocorre a troca de propriedade ou título, no estabelecimento do destinatário quando se trata de importação.

A base de calculo do ICMS, no caso de saídas de mercadorias em geral é o valor da operação, ou, na falta deste, o valor corrente da mercadoria, ou de seu similar, no mercado atacadista do local da operação. Além disso, o ICMS é considerado não cumulativo, ou seja, deve-se compensar o que for devido em cada operação relativa à 
circulação de mercadorias ou prestação de serviços com o montante cobrado nas anteriores pelo mesmo ou outro Estado ou mesmo pelo Distrito Federal (LOPES, 2009).

A característica plurifásica do ICMS exige que o mesmo seja não cumulativo. A obediência à regra se faz de forma escritural, ou seja, as entradas de mercadorias e recebimento de serviços tributados pelo ICMS ensejam lançamentos de crédito na escrituração fiscal do contribuinte. As saídas de mercadorias e de prestação de serviços tributados ensejam débito. No fim do período de apuração, calcula-se o resultado: sendo negativo (débito), recolhe-se o montante tributário pertinente, sendo positivo (crédito), é transferido para o período seguinte.

A disposição constitucional do artigo 155, IV, atribuída pelo Senado, foi cumprida inicialmente com a edição da Resolução $n^{2}$ 22, de 1989, que estabeleceu: a) em 12\% a alíquota básica para as operações e prestações interestaduais; b) em 7\% a alíquota para as operações e prestações realizadas nas regiões Sul e Sudeste, destinadas às regiões Norte, Nordeste e Centro Oeste e ao Estado do Espírito Santo; c) as exportações estão isentas de alíquotas de ICMS (LOPES, 2009).

Outro ponto importante é o conceito de seletividade. Este conceito, descrito no artigo 155, III, diz que o ICMS poderá ser seletivo, em função da essencialidade das mercadorias e serviços, ou seja, podem existir diferentes alíquotas para diferentes produtos. O legislador pode adotar um sistema no qual as alíquotas variem na razão inversa do grau de essencialidade das mercadorias e dos serviços tributados. As mercadorias consideradas básicas terão uma menor incidência de ICMS (ex.: remédios), compensando-se a arrecadação mediante tributação gravosa suportada pelos adquirentes dos gêneros supérfluos (CARAZZA, 2009).

Segundo Yoshizaki (2002), por se tratar de um imposto criado na esfera estadual, sua uniformidade é garantida apenas dentro do Estado onde ocorre o fato gerador. Esta peculiaridade torna o ICMS um dos impostos com maior impacto nas operações logísticas, podendo afetar a competitividade das empresas. As alíquotas interestaduais têm alíquotas significativamente inferiores às alíquotas internas aos 
Estados, possibilitando a indústria utilizar em seu favor o "turismo fiscal", caso os clientes que atendem não se interessem pelo crédito do ICMS.

O mesmo autor explica que a sonegação é significativa e, portanto, tais clientes (clientes sonegadores) são indiferentes ao crédito do imposto. Outro ponto importante é que a sonegação acontece no estabelecimento do cliente e não da indústria. Atender um cliente de uma filial localizada em outro Estado é competência da indústria, que utiliza dessa artimanha para reduzir sua tributação.

Segundo Yoshizaki (2002):

"Uma maneira de coibir ou evitar a perda de receita devido à sonegação e, desta forma, tornar o turismo de mercadorias uma prática desnecessária e custosa, é a prática da substituição tributária pelos governos estaduais".

A substituição tributária é definida por Lopes (2009), como um mecanismo utilizado pelos governos federais e estaduais e, que consiste em deslocar a responsabilidade do pagamento do tributo para o contribuinte. A responsabilidade poderá ser atribuída em relação ao imposto incidente sobre uma ou mais operações ou prestações, sejam antecedentes, concomitantes ou subsequentes, inclusive ao valor decorrente da diferença entre alíquotas interna e interestadual, nas operações e prestações que destinem bens e serviços ao consumidor final localizado em outro Estado, que seja contribuinte do imposto.

Porém, Yoshizaki (2002) descreve que a substituição tributária é uma alternativa funcional quando se tem uma cadeia de valor onde ocorre o afunilamento ou concentração em poucas empresas, como por exemplo: Petrobrás. Outro fator que contribui para a dificuldade de implementação da substituição tributária é a diferença de preços ocasionada pelas diferentes estruturas da cadeia de suprimento. Além disso, é necessário realizar uma previsão do valor final do produto, para que assim então seja calculado o valor do imposto porém, o preço final do produto pode variar, ocasionando um valor que pode estar acima ou abaixo do valor real do tributo. 
O mesmo autor sugere que ao analisar a formação dos custos logísticos e do ICMS, imagina-se a priori que deve existir alguma forma de compensação (trade-off) para justificar os fluxos observados nas diferentes cadeias de suprimentos. Porém, isso não é verdade. Se os membros da cadeia de distribuição forem bons contribuintes (não há informalidade $\mathrm{e}$, portanto, não há sonegação fiscal), o princípio da nãocumulatividade garante que não haja nenhum conflito entre o ICMS e os custos logísticos.

Para ilustrar a afirmação anterior, é usado um exemplo para melhor entendimento dos mecanismos da tributação do ICMS nas transações interestaduais, de acordo com as observações de Yoshizaki (2002). Nele, um fabricante vende seu produto por $\mathrm{R} \$ 100,00$ e sempre utiliza um depósito (ponto intermediário de transbordo) para consolidar e entregar suas mercadorias.

A fábrica deste produtor está localizada no Estado de São Paulo e, os clientes (atacadistas ou varejistas) também se encontram no mesmo Estado. O preço pago pelo produto é considerado constante para o consumidor final. Utilizando uma margem hipotética de $15 \%$, o preço final então é de $R \$ 115,00$. O cálculo de créditos e débitos de ICMS para cada fato gerador (troca de posse ou transferência da mercadoria) está na parte superior da Figura 8.

O valor que a indústria almeja receber (custos mais lucro) é de $R \$ 82,00$ por unidade. Logo, caso a venda ocorra dentro do Estado de São Paulo, o preço recebido pelo varejista é de $R \$ 100,00$, pois se devem aplicar os $18 \%$ de imposto para transações neste Estado. O ICMS é calculado sobre o preço cheio, ou seja, o preço final pode ser calculado como o valor desejado, dividido por $(1$ - alíquota $)=R \$ 82,00 /$ $(1-0,18)=R \$ 100,00$. Pode-se perceber que, no preço final ao consumidor $(R \$$ 115,00 ), a alíquota de $18 \%$ resulta em um valor de $R \$ 20,70$.

Este fato é explicado pelo princípio da não-cumulatividade. Para facilitar a compreensão, pode-se assumir, sem perda de generalidade, que o valor de repasse da mercadoria da fábrica ao depósito seja o mesmo (no caso, $R \$ 100,00$ ). Como o trânsito 
de mercadoria é um fato gerador, ou seja, determinador do ICMS, torna-se importante calcular o quanto cada membro da cadeia de distribuição precisaria pagar.

No caso da indústria, esta deve recolher $R \$ 18,00$ da circulação do produto ao centro de distribuição (CD), que terá um crédito e um débito de mesmo valor (pois este vende o produto pelo mesmo preço que recebeu como pagamento por este). Como resultado, a empresa obtém um saldo (chamado de débito) a pagar de $R \$ 18,00$. $O$ cliente paulista obterá um crédito de $R \$ 18,00$ (proveniente da etapa anterior) e um débito de $R \$ 20,70$ (os $18 \%$ de imposto dentro do Estado de São Paulo aplicados ao seu preço final, de $R \$ 115,00$ ), tendo um saldo a pagar de $R \$ 2,70$ (parte superior da Figura 8).

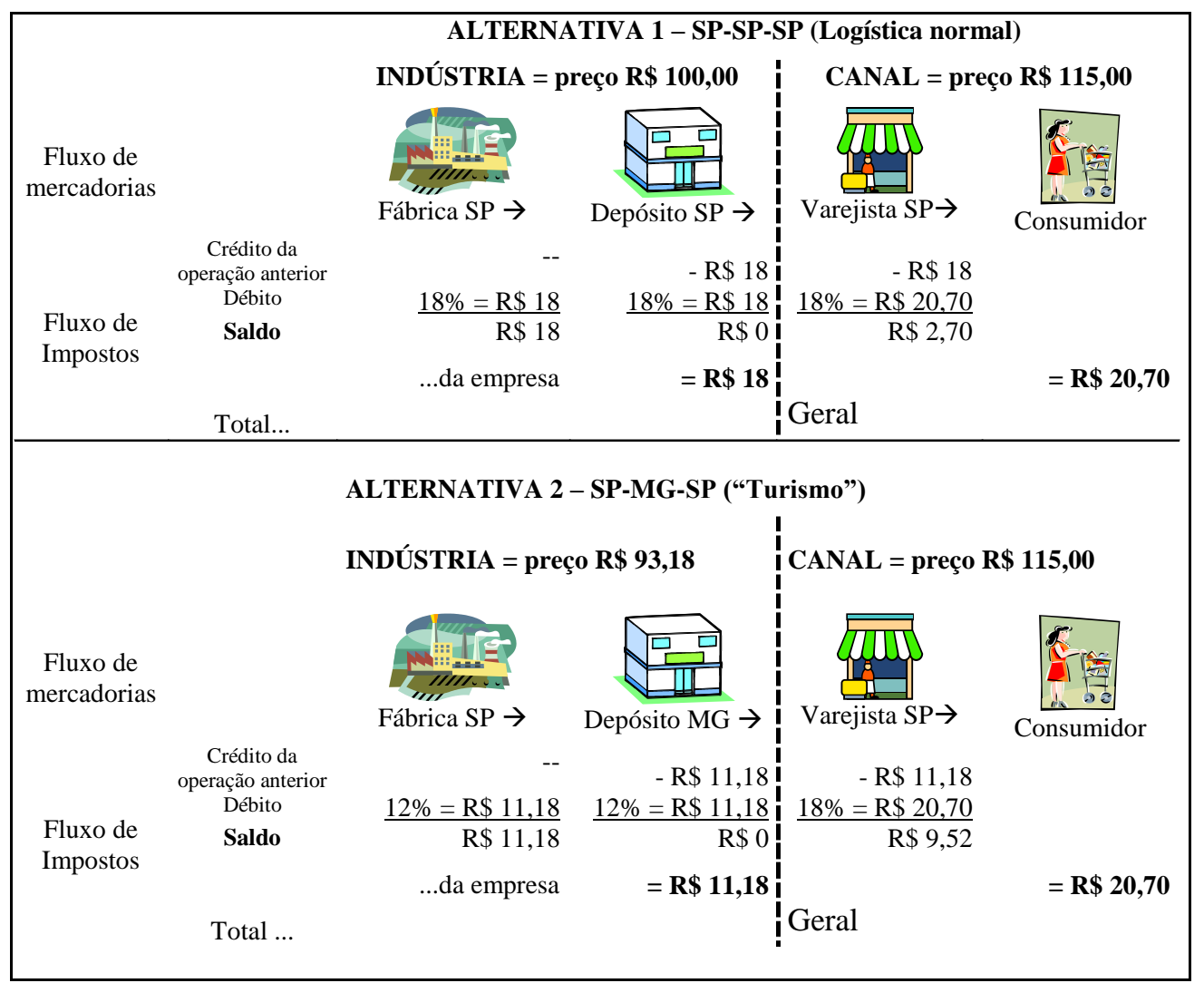

Figura 8: Exemplo de turismo fiscal na Cadeia do ICMS. Fonte: Yoshizaki (2002).

A cadeia toda recolhe $R \$ 20,70$ de impostos, mas isto é totalmente compensado pelo consumidor, para quem o imposto está embutido no preço final do produto. Logo, o 
consumidor é quem paga todo o imposto que incide sobre o produto, e cada elo recolhe apenas a parcela referente a seu valor adicionado, como se fizesse o adiantamento ao governo do imposto devido pelo consumidor. Logo, o ICMS é um tributo que incide sobre o consumo da mercadoria, ou seja, sobre a compra do consumidor final.

Caso o fabricante tivesse optado por localizar o seu depósito no Estado de Minas Gerais, ao invés do Estado de São Paulo (parte inferior da Figura 8), os impostos pagos seriam diferentes. A alíquota interestadual é de $12 \%$ e, o preço de transferência da fábrica ao CD será de $R \$ 82,00 /(1-0,12)=R \$ 93,18$, diminuindo o saldo final do fabricante para $R \$ 11,18$ por produto. O preço ao cliente paulista neste caso será de $R \$$ 93,18 . Porém, como o preço de venda do produto ao consumidor final não se alterou, o cliente terá de recolher $18 \%$ sobre o valor adicionado. Ou seja, como seu crédito é menor $(R \$ 11,18)$, o saldo do cliente será agora maior, equivalendo a $R \$ 9,52$. A Tabela 2 mostra que o lucro de ambos agentes econômicos não muda neste caso.

Tabela 2: Cálculo de operação via Centro de Distribuição (CD). Fonte: Yoshizaki (2002).

\begin{tabular}{l|cc}
\hline & $\mathrm{SP}-\mathrm{SP}-\mathrm{SP}$ & $\mathrm{SP}-\mathrm{MG}-\mathrm{SP}$ \\
\hline Custo Fábrica SP & $\mathrm{R} \$ 82,00$ & $\mathrm{R} \$ 82,00$ \\
Preço Fábrica CD & $\mathrm{R} \$ 100,00$ & $\mathrm{R} \$ 93,18$ \\
Débito ICMS Fábrica & $\mathrm{R} \$ 18,00$ & $\mathrm{R} \$ 11,18$ \\
\hline Preço CD - Varejista & $\mathrm{R} \$ 100,00$ & $\mathrm{R} \$ 93,19$ \\
Crédito CD & $\mathrm{R} \$ 18,00$ & $\mathrm{R} \$ 11,18$ \\
Débito CD & $\mathrm{R} \$ 18,00$ & $\mathrm{R} \$ 11,18$ \\
Saldo CD & $\mathrm{R} \$ 0,00$ & $\mathrm{R} \$ 0,00$ \\
Saldo Fabricante & $\mathrm{R} \$ 18,00$ & $\mathrm{R} \$ 11,18$ \\
Lucro Fabricante & $\mathrm{R} \$ 82,00$ & $\mathrm{R} \$ 82,00$ \\
\hline Preço Mercado & $\mathrm{R} \$ 115,00$ & $\mathrm{R} \$ 115,00$ \\
Crédito Varejista & $\mathrm{R} \$ 18,00$ & $\mathrm{R} \$ 11,18$ \\
Débito Varejista & $\mathrm{R} \$ 20,70$ & $\mathrm{R} \$ 20,70$ \\
Saldo Varejista & $\mathrm{R} \$ 2,70$ & $\mathrm{R} \$ 9,52$ \\
Lucro Varejista & $\mathrm{R} \$ 12,30$ & $\mathrm{R} \$ 12,30$ \\
\hline Total de impostos & $\mathrm{R} \$ 20,70$ & $\mathrm{R} \$ 20,70$ \\
\hline Lucro do Varejista se sonegar & $\mathrm{R} \$ 15,00$ & $\mathrm{R} \$ 21,82$ \\
\hline
\end{tabular}

Pode-se observar na Tabela 2 que tanto o lucro do fabricante quanto do cliente se mantém ( $R \$ 82,00$ e $R \$ 12,30$, respectivamente), dado o princípio da não- 
cumulatividade. Entretanto, existe ainda outra situação a ser considerada: caso o cliente paulista não tenha interesse em seu crédito de ICMS para reduzir o saldo, pois participa da economia informal, o que é caracterizado como sonegação de impostos, neste caso, ele maximizará seu lucro caso compre produto originado no Estado de Minas Gerais (penúltima linha da Tabela 2).

Esta situação gera uma demanda artificial de fluxo de mercadorias entre os dois Estados, o que é chamado de "turismo" de produtos. Assim, o cliente informal vai preferir ser abastecido a partir de um armazém situado em outro Estado, desde que o incremento no frete não exceda o "lucro" informal.

O "turismo" fiscal supracitado distorce o custo logístico total, incentivando vendas para Estados vizinhos e não para o próprio Estado no qual o CD se localiza. Isto é resultado direto da diferenciação de alíquotas internas e interestaduais (18\% e $12 \%$ ou $7 \%$, respectivamente), parte da estrutura do ICMS atual. Logo, não há trade-off entre Logística e ICMS, e sim uma compensação entre custos logísticos e a sonegação de ICMS.

Segundo Yoshizaki (2002), os profissionais do ramo avaliam que o nível de sonegação de ICMS na cadeia de distribuição é muito alto, pois a fiscalização direta de todos os estabelecimentos comerciais é impraticável na realidade brasileira. Isto levou os Estados a criar formas alternativas de coibir esta prática, como a substituição tributária.

Como ocorre um aumento nos custos logísticos devido aos efeitos supracitados, o agente econômico em questão precisa verificar se este "turismo de produtos" compensa, considerando um custo total que englobe tanto os custos logísticos totais quanto a diferença do ICMS, possibilitada pela indiferença ao crédito do ICMS à jusante na cadeia de suprimentos.

O turismo fiscal é agravado pela diferença ainda maior na alíquota interestadual entre Estados denominados exportadores (Estados das Regiões Sul e Sudeste, exceto 
Espírito Santo) e importadores (os outros Estados), que é de somente 7\%, ao invés de $12 \%$.

Conforme Yoshizaki (2002), para uma tonelada de produto típico de supermercado (que valia cerca de $\mathrm{R} \$ 2.500,00$ ), a diferença de alíquotas é suficiente para pagar um frete adicional de mais de $1.000 \mathrm{~km}$. Não surpreende assim que alguns comerciantes das regiões Norte e Nordeste prefiram comprar diretamente de CDs localizados em São Paulo ou Minas Gerais, ao invés de se abastecer em depósitos na sua própria região. Um dos autores observou um êxodo de comerciantes do Estado do Rio de Janeiro para Minas Gerais, quando o primeiro aumentou sua alíquota interna para 19\%. O atual ICMS tem gerado assim grandes distorções na rede logística nacional, onerando o chamado "Custo Brasil".

\section{9 - Trabalhos prévios de logística e ICMS}

Um dos primeiros autores a trabalhar especificamente com o tema de planejamento de redes e ICMS foi Yoshizaki (2002). Antes deste trabalho, as questões fiscais relativas ao ICMS eram consideradas em segundo plano, porém alguns autores, como Ribeiro (1999), desenvolveram um estudo aplicado à indústria de bens de consumo, onde foi realizado um modelo de caminho mínimo cuja função era encontrar o melhor caminho dado a uma rede logística fixa, ou seja, não era possível modificar a localização das instalações. Neste estudo, de natureza tático-operacional, foi utilizado um algoritmo de Djiskstra (cf. WINSTON, 1995), penalizando os arcos do grafo com custo de transporte e manuseio, assim como os tributos, considerados como custos.

Para estudar o impacto do ICMS na rede logística de uma empresa, Yoshizaki (2002) utilizou um modelo de Programação Linear Inteira Mista (PLIM), no qual as decisões de instalação dos centros de distribuição na rede de distribuição consideram questões logísticas e fiscais.

O modelo empregado, no estudo feito por Yoshizaki (2002) pode ser definido como um problema de transbordo multiproduto, com custos fixos de instalação dos 
CD's, tratados com variáveis binárias. Além disso, dado que existe economia de escala na operação de depósitos, modelou-se tal fato usando-se variáveis binárias adicionais (WINSTON, 1995).

Para determinar o grau de turismo fiscal, Yoshizaki (2002) modelou uma situação hipotética, onde quatro grandes fabricantes de produtos típicos de supermercado (que não necessitem de refrigeração) devem abastecer o país com itens de grande consumo (massas e biscoitos, higiene e limpeza, alimentos enlatados e óleo de cozinha), com participações de mercado equivalentes a um líder de mercado.

Todos os custos logísticos provinham de valores efetivamente contratados no mercado à época do estudo, podendo ser considerados realistas. O modelo simula uma cadeia de suprimentos de três estágios (fábrica, $C D$, cliente), com total simetria de custos logísticos, gerando uma rede logística que minimiza o custo logístico total, considerando uma dada proporção (de zero a 100\%) de clientes informais.

A modelagem matemática desenvolvida por Yoshizaki (2002) é mostrada a seguir:

Índices (entre colchetes: número de elementos na dimensão)

i ... Fábricas [4]

j... Depósitos [51]

$k$... Mercados (agregados em mesorregiões) [137]

p ... Produtos (agregados por classes e setores, um por fábrica) [4]

$n$... Nível de depósito (indicador para custo fixo e capacidade de depósito) [10]

$s$... Nível de tributação ( $s=1$ para tributo incorporado na função objetivo - cliente indiferente ao crédito de ICMS, pois pode sonegar; e $s=2$ para tributo fora da função objetivo - cliente quer 0 crédito, pois não sonega) [2]

\section{Parâmetros}

$D e m M_{k p s} \ldots$ Demanda do produto $p$ no mercado $k$ com tributação ao nível $s$ (em $\left.\mathrm{t}\right)$.

$C a p D_{j n} \ldots$ Capacidade do depósito $j$ no nível de capacidade $n(\mathrm{t})$.

$C a p F_{i p} \ldots$ Capacidade da fábrica $i$ para a classe de produto $p(t)$. 
Cus $T_{i j} \ldots$ Custo unitário de transferência da fábrica i para o depósito $j(\mathrm{R} \$ / \mathrm{t})$.

Cus $_{j k} \ldots$ Custo unitário de distribuição do depósito $j$ para o mercado $k(\mathrm{R} \$ / \mathrm{t})$.

CusF $_{i k} \ldots$... Custo unitário de distribuição da fábrica i para o mercado $k(\mathrm{R} \$ / \mathrm{t})$.

$\operatorname{CusB}_{j p} \ldots$ Custo unitário de transbordo da classe de produto $p$ no depósito $j(\mathrm{R} \$ / \mathrm{t})$.

$F i x D_{j n} \ldots$ Custo fixo do depósito $j$ com capacidade $n$, (R\$/ano).

Cus $_{j k}$... Taxa do ICMS na mercadoria na distribuição a partir do depósito $j$ para o mercado $k$. CusIF $i k$... Taxa do ICMS na mercadoria na distribuição a partir da fábrica $i$ para o mercado $k$. CusM $_{p}$... Custo (preço) médio da classe de produto $p$ (no qual incide o ICMS), em R $\$ /$ t.

FICMS ... Fator linear de indicação do nível de tributação $(0 \leq F I C M S \leq 1)$. Seja $D e m M_{k p}$ a demanda do produto $p$ no mercado $k(\mathrm{t})$, então:

$$
\begin{aligned}
\operatorname{DemM}_{k p, s=1} & =\operatorname{DemM}_{k p}{ }^{*} \text { FICMS } \\
\operatorname{DemM}_{k p, s=2} & =\operatorname{DemM}_{k p}{ }^{*}(1-\text { FICMS })
\end{aligned}
$$

Quando $F I C M S=1$, admite-se que todo o sistema paga $100 \%$ do ICMS; quando $F I C M S=0$, admite-se que todo o sistema ignora o ICMS (sonega).

\section{Variáveis}

$\operatorname{Trns}_{i j p s}$... Quantidade transferida da classe de produto $p$ da fábrica i para o depósito j com nível de tributação $s$. (t)

$D s t r D_{j k p s} \ldots$ Quantidade distribuída da classe de produto $p$ do depósito $j$ para o mercado $k$ com nível de tributação $s$. (t)

$D s t r F_{i k p s}$... Quantidade distribuída da classe de produto $p$ da fábrica $i$ para o mercado $k$ com nível de tributação $s$. (t)

$Z_{j n} \ldots$ Assume valor 1 caso o depósito j estiver operando no nível de depósito $n, 0$ em caso contrário.

$C T$... Custo total de operação (R\$/ano).

\section{Restrições/Equações}

Função de mérito, que é minimizar o custo total CT. 


$$
\begin{aligned}
& \min C T=\sum_{i} \sum_{k} \sum_{p}\left\{\left[\left(\operatorname{CusF}_{i k}+C u s I F_{i k} \times C u s M_{p}\right) \times \sum_{s \mid s=1} D_{s t r F}\right]+\left[C u s F_{i k} \times \sum_{s \mid s=2} D s t r F_{i k p s}\right]\right\} \\
& +\sum_{i} \sum_{j} \sum_{p} \sum_{s}\left(C u s T_{i j} \times \operatorname{Trns}_{i j p}\right) \\
& +\sum_{j} \sum_{k} \sum_{p}\left\{\left[\left(\operatorname{CusD}_{j k}+\operatorname{CusB}_{j}+\operatorname{CusI}_{j k} \times \operatorname{CusM}_{p}\right) \times \sum_{s \mid s=1} \operatorname{DstrD}_{j k p s}\right]+\left[\left(\operatorname{CusD}_{j k}+C u s B_{j}\right) \times \sum_{s \mid s=2} D_{s t r D} D_{j k p s}\right]\right\} \\
& +\sum_{j} \sum_{n} \text { FixD }_{j n} \times Z_{j n}
\end{aligned}
$$

Restrição de atendimento da demanda da classe de produto $p$ no mercado $k$.

$$
\operatorname{Dem}_{k p s} \leq \sum_{i} D s t r F_{i k p s}+\sum_{j} D_{s t r} D_{j k p s} \quad \forall k, \forall p, \forall s .
$$

Restrição de capacidade de produção da classe de produtos $p$ na fábrica $i$.

$$
\sum_{i} \sum_{s} \operatorname{DstrF}_{i k p s}+\sum_{j} \sum_{s} \operatorname{Trns}_{i j p s} \leq \mathrm{CapF}_{i p} \quad \forall i, \forall p . \text { (3) }
$$

Restrição de capacidade e operação do depósito $j$.

$$
\sum_{i} \sum_{p} \sum_{s} \operatorname{Trns}_{i j p s} \leq \sum_{n} Z_{j n} \times \operatorname{CapD}_{j n} \quad \forall j .
$$

Relação entre capacidades de depósitos.

$$
\sum_{n} Z_{j n}=1 \quad \forall j .
$$

Balanço de massa da classe de produto $p$ no depósito j com nível de tributação $s$.

$$
\sum_{i} \text { Trns }_{i j p s}=\sum_{k} D s t r D_{j k p s} \quad \forall j, \forall p, \forall s .
$$

Não negatividade.

$$
\begin{array}{ll}
\operatorname{Trns}_{i j p s} \geq 0 & \forall i, \forall j, \forall p, \forall s . \\
\operatorname{DstrD}_{j k p s} \geq 0 & \forall j, \forall k, \forall p, \forall s . \text { (7) } \\
\operatorname{DstrF}_{i k p s} \geq 0 & \forall i, \forall k, \forall p, \forall s .
\end{array}
$$

Variáveis binárias. 
$Z_{j n}=\left\{\begin{array}{l}1, \text { se deposito } j \text { com capacidade } n \text { ficar aberto } \\ 0, \text { em caso contrário }\end{array} \forall j, \forall n\right.$.

A função objetivo é composta por quatro parcelas, identificadas pelas quatro somatórias. A primeira representa o custo de distribuição direta a partir da fábrica $i$ para o mercado $k$, que é o produto de um custo variável pelo fluxo $i k$. Se o cliente deste mercado $k$ quiser o crédito de ICMS, apenas o custo de transporte (Cus $\left.F_{i k}\right)$ deve ser considerado no custo variável (segunda parte da somatória, ou seja $s=2$ ), isto é, apenas a questão logística vai entrar no cômputo. Porém, se o cliente do mercado $k$ for indiferente a este crédito ( $s=1$, isto é, pode sonegar), o modelo pode direcionar o fluxo para o local que for mais vantajoso do ponto de vista fiscal + logística, ou seja, há tradeoff entre logística vs. ICMS. Assim, na determinação do custo variável, tem-se a parcela do custo de transporte e do débito de ICMS: o modelo escolherá o caminho que der o menor custo variável total (transporte e ICMS).

O débito do ICMS é calculado em função da alíquota do produto para aquela origem destino $\left(\right.$ CuslF $\left._{i k}\right)$ e do valor do produto $\left(\right.$ CusM $\left._{p}\right)$. A segunda parcela (somatória) da função objetivo representa o custo do transporte de transferência fábrica-CD ij. A terceira parcela é o custo de distribuição a partir do CD j para o mercado $k$, com a mesma lógica de construção feita para a distribuição fábrica-mercado na primeira parcela; sua diferença é que agora se deve acrescentar o custo variável $\operatorname{Cus}_{j}$ de manuseio (transbordo) no centro de distribuição. Finalmente, a quarta parcela representa o custo fixo do CD que for aberto no local $j$, em função de sua capacidade $n$.

O conjunto de restrições (2) representa o atendimento integral da demanda: para cada produto $p$ em cada mercado $k$, a demanda deve ser plenamente atendida. Esta demanda $k p$ está dividida entre demandas dos clientes $s=1$ e $s=2$ nas razões FICMS e (1- FICMS), respectivamente, ou seja, dividiu-se cada mercado conforme o fator de nível de tributação FICMS. Este fator representa o nível de sonegação potencial no sistema. Isto significa que, em que cada mercado $k$, o agregado de sonegadores potenciais (indiferentes ao crédito do ICMS) e não-sonegadores (querem o crédito), 
dada a demanda total naquele mercado. FICMS é considerado constante para todos os mercados.

O conjunto de restrições (3) limita o escoamento de produtos $p$ à capacidade da planta industrial $i$ de fabricá-los. No problema estudado, a capacidade das fábricas é irrestrita (ou seja, elas podem suportar toda a demanda).

As restrições (4) limitam o fluxo nos depósitos $j$ à sua capacidade de movimentação, que está associada ao nível $n$. Cada local candidato pode abrir um entre $n$ tamanhos de CD.

O grupo de restrições (5) faz com que haja pelo menos um depósito aberto no sítio candidato $j$. Para permitir ao modelo não abrir nenhuma instalação no local $j$, o nível $n=1$ tem capacidade de movimentação nula e custo zero.

O conjunto (6) representa o balanço de massa nos depósitos, ou seja, o fluxo de entrada é igual ao fluxo de saída. Os fluxos de mercadorias para clientes indiferentes ao ICMS $(s=1)$ são segregados dos fluxos de clientes que querem crédito $(s=2)$. Finalmente, os grupos de restrições (7) e (8) são as usuais exigências de nãonegatividade ou valores binários para as variáveis de decisão.

Não há equação para o nível de serviço, pois o mesmo foi modelado a partir das distâncias máximas permitidas: os arcos $i k$ ou $j k$ que correspondessem a uma distância acima da permitida eram simplesmente eliminados do modelo, ao invés de penalizá-los artificialmente com um valor muito grande na função-objetivo.

Com base no estudo de Yoshizaki (2002), é possível compreender o trade-off entre a logística e o ICMS. Segundo o autor, adotando-se uma hipótese conservadora de $20 \%$ de sonegação, ocorre um acréscimo de $3,49 \%$ no custo logístico ao introduzir a questão tributária, chegando a $11,63 \%$ nos cenários com sonegação de $80 \%$. Por meio da análise gráfica realizada pelo autor, é possível verificar o "turismo" de mercadorias ocasionando inúmeros malefícios como: aumento de tráfego de caminhões, congestionamento, acidentes, perda de competitividade etc. Além disso, é possível 
constatar que pequenas alterações na sonegação modificam os custos, a configuração da rede logística e a capacidade das instalações.

Maciel e Dalvi (2006) realizaram um estudo sobre o impacto dos tributos e estoques no planejamento de redes logísticas. O objetivo do estudo foi apresentar uma aplicação da modelagem de redes baseada em um estudo de localização de instalações, realizado para uma empresa do ramo de lubrificantes. O sistema logístico da empresa estudada continha cerca de 24 instalações e, o principal problema foi a redução dos níveis de serviço. Foi acrescentado na formulação matemática os conceitos de estoque descritos por Croxton e Zinn (2005). Os resultados do estudo mostraram que a não consideração dos tributos proporcionou uma rede de distribuição com menores custos logísticos, porém um custo tributário maior. Além disso, o custo de estoque pode modificar a configuração da rede logística e dependendo das características do produto, o mesmo deve ser acrescentado na modelagem.

O estudo realizado por Junqueira e Morabito (2006) envolveu o planejamento de redes no nível tático, ou seja, a decisão estava no planejamento dos fluxos entre as origens e os destinos e, não envolveu as decisões sobre localização de instalações. $O$ objetivo do estudo foi minimizar o custo total de produção e logística, incluindo os custos de transporte entre regiões agrícolas, unidades industriais e de entrega, os custos de processamento e os custos fiscais. $O$ alto grau de complexidade do estudo é devido ao fato da existência de algumas particularidades nas redes de distribuição física como: dispersão geográfica da produção agrícola, industrial e a demanda, sazonalidade dos produtos, múltiplos produtos e variabilidade da produção geográfica. Uma das conclusões do estudo foi a identificação do turismo fiscal como um fator de redução do custo total, indo ao encontro das conclusões encontradas em Yoshizaki (2002).

Diferenciando-se dos autores supracitados, Silva (2007) estudou a influência de determinados incentivos fiscais (presentes no Estado de Goiás e Minas Gerias), relacionados ao ICMS na estruturação de projetos de rede de distribuição física de uma empresa de bens de consumo não duráveis. A rede logística consiste em 3 fábricas 
localizadas em São Paulo, Minas Gerais e Goiás, 7 possíveis localizações para a instalação de centros de distribuição e 137 mesorregiões. O estudo constatou que para cada $R \$ 1,00$ que se ganha de incentivos fiscais presentes em Goiás, gasta-se $R \$ 0,09$ com custos logísticos e, para cada $R \$ 1,00$ que se ganha de incentivo fiscal no Estado de Minas Gerais, gasta-se $R \$ 0,16$ com custos logísticos.

Posteriormente, Yoshizaki et al. (2008) realizaram um estudo abordando o tema da reforma tributária, utilizando o mesmo modelo descrito por Yoshizaki (2002). A reforma tributária modificará as alíquotas interestaduais e será implementada ao longo de 6 anos com reduções graduais na alíquota. $O$ modelo desenvolvido e as análises realizadas permitiram concluir que o novo ICMS não trará mudanças significativas para o atual quadro de turismo fiscal e ineficiência logística, causados pela informalidade e sonegação no canal. Uma das mudanças encontradas no estudo foi a modificação na localização e nas capacidades das instalações, porém a economia brasileira continuará arcando com custos operacionais desnecessários à distribuição dos produtos, graças a certos agentes econômicos no canal de vendas, que têm vantagens por pagar menos impostos. A Tabela 3 mostra os resultados encontrados por Yoshizaki (2008).

Tabela 3: Resultados encontrados por Yoshizaki (2008). Fonte: Yoshizaki (2008).

\begin{tabular}{|l|c|c|c|c|c|c|}
\hline Índice de sonegação & $\mathbf{0 \%}$ & $\mathbf{2 0 \%}$ & $\mathbf{4 0 \%}$ & $\mathbf{6 0 \%}$ & $\mathbf{8 0 \%}$ & $\mathbf{1 0 0 \%}$ \\
\hline Incremento - Caso Atual & $0 \%$ & $3,49 \%$ & $6,33 \%$ & $9,24 \%$ & $11,63 \%$ & $14,00 \%$ \\
\hline Incremento - Novo ICMS & $0 \%$ & $2,92 \%$ & $5,40 \%$ & $7,94 \%$ & $9,86 \%$ & $12,06 \%$ \\
\hline
\end{tabular}

Junqueira e Morabito (2008) realizaram um estudo apresentando um modelo de programação linear para auxiliar nas decisões do planejamento tático da produção, estocagem e transporte de sementes de milho, de forma a otimizar os custos de produção, logísticos e fiscais. Este estudo foi uma continuação do estudo realizado por Junqueira e Morabito (2006), porém o estudo vigente implementou o modelo para gerar um planejamento agregado, otimizado de uma safra completa, diferenciando do estudo anterior no qual foi implementado em condições simplificadas. Os resultados do modelo mostram uma diferença de $23 \%$ no custo total entre o planejamento atual da empresa e o planejamento proposto pelo modelo. 
Posteriormente, Carraro (2009) realizou um estudo cujo objetivo era analisar os trade-offs existentes entre os custos logísticos, os incentivos fiscais baseados no ICMS e o custo de neutralização das emissões de carbono, geradas nos problemas de localização. Um modelo de programação linear inteira mista foi desenvolvido baseandose no modelo desenvolvido por Silva (2007). A aplicação do estudo foi realizada em uma empresa de bens de consumo não duráveis e, foram avaliados diversos cenários mostrando como a guerra fiscal no país pode influenciar decisões estratégicas de negócios. Os resultados obtidos justificaram a utilização de critérios fiscais na modelagem de redes de distribuição física, porém quanto aos custos ambientais relacionados à neutralização das emissões de carbono, estes não alteraram o resultado do modelo, evidenciando a forte influência dos aspectos fiscais na modelagem de redes.

Queiroz (2011) realizou um estudo cujo objetivo foi entender o efeito do ICMS na modelagem de redes logísticas. O modelo utilizado diferencia-se dos demais pela utilização de um modelo de programação não linear em uma rede composta por uma fábrica, 5 armazéns e 5 mercados. Além disso, o estudo buscou compreender como as características variam de um sistema logístico que influencia na decisão de alocação de estoque com o uso de técnicas de risk-pooling. O resultado do estudo mostrou apenas duas ocorrências de políticas de alocação de estoque: centralização total e política mista. A política de centralização total é caracterizada por valores mais altos de lead time de ressuprimentos dos armazéns e custo de colocação de pedidos na fábrica, acompanhados de valores mais baixos de custo de manutenção de estoques, preço unitários de produto e margem de lucro. A política de alocação mista comporta-se contrária a tais variáveis.

Abaixo se encontra a Tabela 4 com o resumo das características dos modelos utilizados pelos autores supracitados. 
Tabela 4: Resumo das principais características dos modelos de planejamento de redes com ICMS.

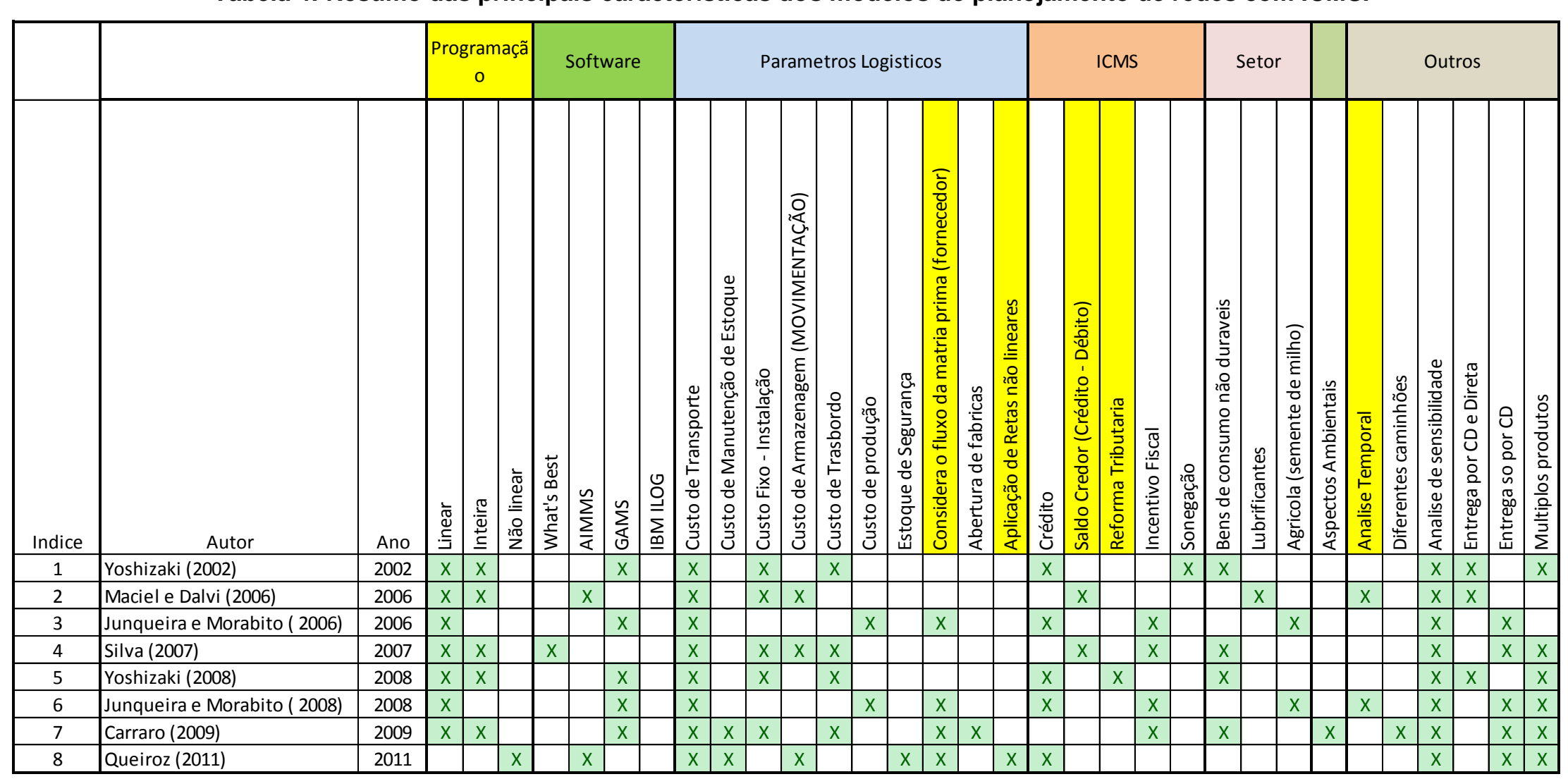




\subsection{0 - Proposta da Reforma Tributária}

A proposta da reforma tributária (FAZENDA, 2008) é decorrente de um processo de crescimento sustentável, caracterizado por um novo ciclo de crescimento. A estabilidade macroeconômica, caracterizado por uma politica fiscal adequada, cria condições para consolidar os avanços e acelerar o crescimento e a redução das desigualdades.

O principal objetivo da reforma tributária é reduzir os obstáculos para uma produção mais eficiente e menos custosa, reduzindo a carga tributária que incide sobre os produtos e consumidores e estimulando a formalização das empresas.

Os principais objetivos são:

1. Simplificar o sistema tanto no âmbito dos tributos federais quanto do ICMS, eliminando tributos, reduzindo e desburocratizando a legislação tributária;

2. Acabar com a guerra fiscal entre os Estados;

3. Implementar medidas de desoneração tributária, principalmente nas incidências mais prejudiciais ao desenvolvimento.

4. Corrigir as distorções dos tributos sobre bens e serviços que prejudicam o investimento, a competitividade das empresas nacionais e o crescimento;

5. Aperfeiçoar a politica de desenvolvimento regional;

6. Melhorar a qualidade das relações federativas.

A complexa estrutura tributária atual é formada por 6 tributos indiretos (ICMS, IPI, Confins, PIS, CIDE e ISS), diferenciando-se da maioria dos países que possuem até 2 tributos. Esse modelo implica em altos custos burocráticos para as empresas pagarem e apurarem seus impostos, além disso, constantemente ocorre alguma modificação nos mesmos, prejudicando o planejamento de longo prazo devido a essa instabilidade na regulamentação. 
Dentre todos os tributos, o ICMS é o imposto que gera maior número de problemas. Esses problemas estão relacionados com a forma de cobrança das alíquotas interestaduais, que são divididas entre o Estado de origem e destino. Essa divisão acarreta outro problema que está na resistência dos Estados em ressarcir as empresas dos créditos acumulados relativo ao ICMS sob o argumento de que teriam que ressarcir um imposto que foi pago em outra unidade da federação.

No inicio, a concessão de incentivos fiscais tinha o objetivo de estimular o desenvolvimento dos Estados chamados "pobres", atraindo investimentos. Todavia, muitos Estados começaram a adotar alguns incentivos, resultando na guerra fiscal e no prejuízo aos investidores.

A proposta da Reforma Tributária propõe a unificação das 27 legislações estaduais do ICMS em uma única legislação. A mudança será feita com a extinção do atual ICMS e a criação de um "Novo ICMS", que tem a mesma abrangência em termos de mercadorias e serviços do atual.

No novo imposto, que continuará sendo cobrado pelos Estados, as alíquotas serão nacionalmente uniformes e fixadas na seguinte sequência:

1. O Senado define quais serão as alíquotas aplicáveis (provavelmente 4 ou 5 alíquotas);

2. O Confaz propõe o enquadramento dos bens e serviços entre as diversas alíquotas;

3. O Senado aprova ou rejeita a proposta do Confaz.

Um dos principais objetivos da proposta de Reforma Tributária é acabar com a guerra fiscal entre os Estados, que hoje tem um impacto negativo sobre o crescimento. A forma mais segura de eliminar a guerra fiscal é modificando a cobrança do ICMS nas transações interestaduais, fazendo com que o imposto seja devido ao Estado de destino.

Uma mudança imediata no sistema de transações interestaduais não é, no entanto, viável, por pelo menos duas razões: 
1- A adoção da cobrança no destino tem forte impacto na distribuição de receitas entre os Estados, e uma transição brusca dificulta muito a montagem de um sistema confiável de compensação;

2- A desativação imediata dos benefícios já concedidos no âmbito da guerra fiscal é quase impossível de ser implementada, em função da dificuldade de extinguir abruptamente os compromissos assumidos por diversos Estados com as empresas.

A proposta apresenta uma transição gradual para a tributação do ICMS no destino, reduzindo-se a alíquota na origem progressivamente e completando-se o processo no oitavo ano após a aprovação da Reforma, com a criação do Novo ICMS. Caso as alíquotas fossem unificadas de imediato, a proposta teria que apresentar uma solução para os benefícios, criando um enorme obstáculo para a aprovação da Reforma.

Devido à preocupação com a manutenção de alguma cobrança no Estado de origem como forma de fiscalização, a proposta é que no Novo ICMS seja mantida uma alíquota de $2 \%$ no Estado de origem nas transações interestaduais. Porém, essa medida não será suficiente para induzir a guerra fiscal, sendo compatível com o objetivo de acabar com a competição entre os Estados. 


\section{3 - METODOLOGIA E MODELAGEM DO PROBLEMA}

Para estudar o impacto do ICMS na rede logística de uma empresa, recorreu-se ao modelo de Programação Linear Inteira Mista (PLIM), desenvolvido por Yoshizaki (2002), no qual as decisões de instalação dos centros de distribuição na rede de distribuição consideram questões logísticas e fiscais.

A utilização da PLIM em problemas de determinação da localização de depósitos é tradicionalmente abordada na literatura (GEOFFRION E GRAVES, 1974; AIKENS, 1985; LOVE et al. 1988; BRANDEAU E CHIU, 1989; KLOSE E DREXL, 2005; MELO et al. 2009). O modelo empregado pode ser definido como um problema de transbordo multiproduto com custos fixos de instalação dos CD's, tratados com variáveis binárias. Além disso, dado que existe economia de escala na operação de depósitos, modelouse tal fato usando-se variáveis binárias adicionais (WINSTON, 1995).

Para determinar o grau de turismo fiscal, foi então modelada uma situação hipotética, onde quatro grandes fabricantes de produtos típicos de supermercado (que não necessitem de refrigeração) devem abastecer o país com itens de grande consumo (massas e biscoitos, higiene e limpeza, alimentos enlatados e óleo de cozinha), com participações de mercado equivalentes a um líder de mercado. Todos os fabricantes podem abastecer-se diretamente de suas fábricas ou por intermédio de um ou mais CD's operados por terceiros. Isto permite o compartilhamento de custos fixos de CD's, reduzindo custos para os envolvidos e simulando o uso de operadores logísticos para ganhar escala. O modelo de otimização utilizado representa uma cadeia de suprimentos de três estágios (fábrica, $C D$, cliente), gerando uma rede logística que minimiza o custo logístico total, considerando uma dada proporção (de zero a 100\%) de clientes informais.

A principal justificativa do sistema idealizado (4 fábricas e operador logístico) é garantir volume e escopo geográfico de operação que permitam observar os ganhos de escala associados à distribuição física. O maior volume permite maior ganho potencial de consolidação de cargas nos CD's e também vantagens nos custos fixos dos 
depósitos (que tem economia de escala). A abertura do CD só é justificada se a economia de custos de frete de transferência e de entrega final for maior que o custo fixo de se manter esta estrutura.

Há outras hipóteses importantes no modelo. Primeiro, não se impôs conjunto adicional de restrições exigindo-se que um nó de demanda deva ser atendido por um único CD, utilizando variáveis binárias, como as de Geoffrion e Graves (1974). Tal relaxação dá maior grau de liberdade para que o modelo considere os custos adicionais do ICMS, permitindo que uma localidade receba produtos de dois CD's que estão em Estados diferentes.

Outro pressuposto é considerar um valor único para o produto ao longo da cadeia de distribuição. Assim, o cálculo do ICMS fica mais simples, pois não há agregação de valor na mercadoria devido a processos de transformação ou venda. Uma terceira hipótese é não haver restrição de capacidade de produção nas fábricas. Assume-se também que o custo variável de um CD (transbordo da mercadoria) é constante, não importando o tamanho do CD; os ganhos de escala estão associados aos custos fixos de instalação e operação (YOSHIZAKI, 2002).

Para tratar adequadamente o problema, definiu-se a demanda em nível de mesorregião do IBGE (excluindo-se certas porções da Amazônia, que não tem acesso rodoviário), num total de 137 mesorregiões do Brasil. O operador logístico é responsável por atender quatro fabricantes (um em cada região, NE, SE, CO e S), de forma que há o mesmo número de famílias de produtos e fábricas de origem, ou seja, como se cada fábrica fosse especializada em uma única categoria de produto. Para conseguir cobertura nacional, foram pré-selecionados 51 locais candidatos a CD's; naturalmente, o modelo decidirá quais devem ser abertos. Para aproximar a curva de economia de escala de um CD, foram definidos 10 níveis de capacidade. O modelo gerado tem cerca de 510 variáveis binárias, 1.100 restrições e 35.000 variáveis reais.

Os dados de demanda e custos de fretes e operações dos depósitos foram conseguidos de um instituto de pesquisa de mercado e de operadores logísticos de produtos iguais aos usados no modelo. De forma semelhante, os níveis de serviço 
foram definidos a partir de casos práticos obtidos diretamente com os principais fabricantes destas mercadorias.

Como pode haver grandes distâncias entre as cidades brasileiras (chegando a alguns milhares de quilômetros), isto leva indústrias a utilizarem CD's não apenas quando há economia em custos de transporte (fazendo transferências com menor custo unitário do que entregas aos clientes), mas também para se garantir um nível de serviço satisfatório (aqui avaliado em função da distância ao cliente).

O problema hipotético de localização de CD's e a definição de suas capacidades de transbordo, além dos fluxos de transferência e distribuição de produtos por meio de CD's ou diretamente a partir das fábricas, tem assim, as seguintes características segundo Yoshizaki (2002):

1. Quatro produtos, cada um com origem em fábricas com capacidade ilimitada em São Paulo (Sudeste), Joinville (Sul), Recife (Nordeste) e Goiânia (Centro-Oeste), todos comercializados com o valor de $\mathrm{R} \$ 2.500 /$;

2. Possibilidade de abertura de CD's em 51 municípios selecionados por serem próximos a uma área de grande demanda ou de divisas entre Estados (facilitando o turismo fiscal), com capacidades compatíveis aos existentes no Brasil (20.000 t/ano; 40.000 t/ano; 70.000 t/ano; 100.000 t/ano; 150.000 t/ano; 200.000 t/ano; 300.000 t/ano; 400.000 t/ano e 600.000 t/ano);

3. Custo operacional dos CD's, sem ganho de escala (igual a $R \$ 1,00 / t$ );

4. Custo de transferência $C T$ (em $R \$ / t$ ) entre fábricas e CD's conforme a regressão de fretes rodoviários dada por $(11,15+0,0516$ D), para distância de D km;

5. Custo de distribuição $C D$, dado em $R \$ / t$, (a partir dos CD's ou das fábricas), segundo a regressão de fretes rodoviários dada por $(19,45+$ 0,077 D), para distância de D km; 
6. Restrição de nível de serviço em função do tempo de viagem para atender as mesorregiões com maior população, conforme Tabela 5;

7. Distâncias entre centros geográficos das mesorregiões e os municípios medidos como menor distância na superfície terrestre (distância esférica);

8. ICMS incidindo sobre o valor da mercadoria, de acordo o Anexo A (situação atual) ou o novo ICMS (a diagonal da tabela - ICMS dentro dos Estados - se mantém e todo o resto é $2 \%$ );

9. Índice de sonegação variando de 0 a 1, ou seja, desde o limite inferior, em que nenhum varejista teria interesse em sonegar até o outro limite, em que todos os varejistas sonegariam o imposto.

10. O Anexo $D$ mostra a implementação do modelo matemático no software IBM ILOG CPLEX.

Tabela 5: Restrição de nível de serviço.

\begin{tabular}{|c|c|}
\hline População da mesorregião & $\begin{array}{c}\text { Distância máxima para } \\
\text { atendimento }\end{array}$ \\
\hline Menor que 1.000.000 & sem limites \\
\hline entre 1.000.000 e 3.000 .000 & $750 \mathrm{~km}$ \\
\hline maior que 3.000 .000 & $500 \mathrm{~km}$ \\
\hline
\end{tabular}

\section{1 - Localização dos centros de distribuição e fábricas}

O estudo utilizou 137 mesorregiões, 51 possíveis localizações para o centro de distribuição e 4 fábricas (YOSHIAZKI, 2002). As mesorregiões Vale do Acre/AC, Sul do Amapá/AP, Norte o Amapá/AP, Centro Amazonense/AM, Norte Amazonense/AM, Sul Amazonense/AM, Baixo Amazonas/PA, Marajó/PA, Sudeste Paraense/PA, Nordeste Paraense/PA, Sudoeste Paraense/PA, Norte de Roraima/RR e Sul de Roraima/RR foram desconsideradas no modelo, tendo suas demanda anuladas. A Figura 9 mostra a localização das fábricas, depósitos e mercados. A Figura 10 mostra um mapa com a localização geográfica das fábricas e centros de distribuição. 


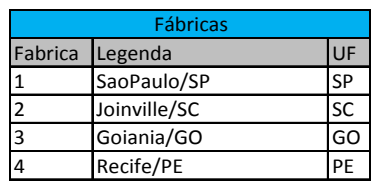

\begin{tabular}{|c|c|c|}
\hline \multicolumn{3}{|c|}{ Depósitos } \\
\hline Deposito & Legenda & UF \\
\hline 1 & PortoAlegre/RS & RS \\
\hline 2 & PassoFundo/RS & RS \\
\hline 3 & Imbituba/SC & SC \\
\hline 4 & Joinville/SC & SC \\
\hline 5 & Concórdia/SC & SC \\
\hline 6 & PortoUniao/SC & SC \\
\hline 7 & Curitiba/PR & PR \\
\hline 8 & Londrina/PR & PR \\
\hline 9 & UniaodaVitória/PR & PR \\
\hline 10 & SaoPaulo/SP & SP \\
\hline 11 & Ourinhos/SP & SP \\
\hline 12 & PresidentePrudente/SP & SP \\
\hline 13 & Franca/SP & SP \\
\hline 14 & SaojosédoRioPreto/SP & SP \\
\hline 15 & RiodeJaneiro/RJ & RJ \\
\hline 16 & Vitória/ES & ES \\
\hline 17 & BeloHorizonte/MG & MG \\
\hline 18 & JuizdeFora/MG & $\mathrm{MG}$ \\
\hline 19 & PousoAlegre/MG & $M G$ \\
\hline 20 & Uberaba/MG & $M G$ \\
\hline 21 & Uberlandia/MG & MG \\
\hline 22 & Unaí/MG & MG \\
\hline 23 & TeófiloOtoni/MG & $M G$ \\
\hline 24 & TrêsLagoas/MS & MS \\
\hline 25 & Cuiabá/MT & MT \\
\hline 26 & BarradoGarças/MT & MT \\
\hline 27 & Brasília/DF & DF \\
\hline 28 & Goiania/GO & $\mathrm{GO}$ \\
\hline 29 & Catalao/GO & GO \\
\hline 30 & Vitóriadaconquista/BA & BA \\
\hline 31 & Salvador/BA & $\mathrm{BA}$ \\
\hline 32 & Juazeiro/BA & BA \\
\hline 33 & PauloAfonso/BA & BA \\
\hline 34 & Aracaju/SE & SE \\
\hline 35 & Maceió/AL & $A L$ \\
\hline 36 & Recife/PE & $\mathrm{PE}$ \\
\hline 37 & Ouricuri/PE & PE \\
\hline 38 & JoaoPessoa/PB & PB \\
\hline 39 & Sousa/PB & PB \\
\hline 40 & Natal/RN & $\mathrm{RN}$ \\
\hline 41 & Mossoró/RN & $\mathrm{RN}$ \\
\hline 42 & Fortaleza/CE & CE \\
\hline 43 & JuazeirodoNorte/CE & CE \\
\hline 44 & Sobral/CE & CE \\
\hline 45 & Teresina/PI & $\mathrm{PI}$ \\
\hline 46 & Picos/PI & PI \\
\hline 47 & SaoLuís/MA & MA \\
\hline 48 & Timon/MA & MA \\
\hline 49 & Belém/PA & PA \\
\hline 50 & PortoVelho/RO & $\mathrm{RO}$ \\
\hline 51 & Palmas/TO & TO \\
\hline
\end{tabular}

\begin{tabular}{|c|l|c}
\multicolumn{3}{|c|}{ Mercado } \\
Mercado & \multicolumn{1}{|c|}{ Legenda } \\
\hline 1 & AgresteAlagoano/AL & $A L$ \\
\hline 2 & LesteAlagoano/AL & $A L$ \\
3 & SertaoAlagoano/AL & $A L$ \\
\hline 4 & ValedoAcre/AC & $A C$ \\
\hline
\end{tabular}

\begin{tabular}{l|l}
5 & ValedoJurua/AC \\
\hline
\end{tabular}

6 CentroAmazonense/AM

\begin{tabular}{l|l}
7 & NorteAmazonense/AM \\
\hline
\end{tabular}

8 SudoesteAmazonense/AM

9 SulAmazonense/AM

10 NortedoAmapa/AP

11 SuldoAmapa/AP

12 CentroNorteBaiano/BA

13 CentroSulBaiano/BA

14 ExtremoOesteBaiano/BA

15 MetropolitanadeSalvador/BA

NordesteBaiano/BA

17 SulBaiano/BA

18 ValeSao-FranciscanodaBahia/BA

Centro-SulCearense/CE

Jaguaribe/CE

MetropolitanadeFortaleza/CE

NoroesteCearense/CE

NorteCearense/CE

SertõesCearenses/CE

SulCearense/CE

DistritoFederal/DF

CentralEspírito-santense/ES

\begin{tabular}{|l|}
\hline UF \\
\hline AL \\
\hline AL \\
\hline AL \\
\hline AC \\
\hline AC
\end{tabular}

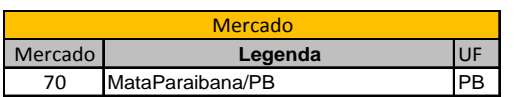

\begin{tabular}{|c|l|l|}
\hline 70 & MataParaibana/PB & PB \\
\hline 71 & SertaoParaibano/PB & PB \\
\hline 72 & CenntrocidentParanaense/PR & PR \\
\hline
\end{tabular}

\begin{tabular}{|l|l|l|}
\hline 72 & CentroOcidentalParanaense/PR & PR \\
\hline 73 & CentoOrientalParanaensePR & PR \\
\hline
\end{tabular}

\begin{tabular}{|c|l|l|}
\hline 73 & CentroOrientalParanaense/PR & PR \\
\hline 74 & Centro-SulParanaense/PR & PR \\
\hline 75 & Metropolanade & PR \\
\hline
\end{tabular}

\begin{tabular}{l|l}
74 & Centro-SulParanaense/PR \\
\hline 75 & MeropoltanadeCuitba/PR \\
\hline
\end{tabular}

75 MetropolitanadeCuritiba/PR

76 NoroesteParanaense/PR

\begin{tabular}{l|l}
77 & NorteCentralParanaense/PR \\
\hline 78
\end{tabular}

78 NortePioneiroParanaense/PR

79 OesteParanaense/PR

80 SudesteParanaense/PR

81 SudoesteParanaense/PR

82 AgrestePernambucano/PE

83 MataPernambucana/PE

84 MetropolitanadeRecife/PE

85 SaoFranciscoPernambucano/PE

86 SertaoPernambucano/PE

87 Centro-NortePiauiense/PI

88 NortePiauiense/PI

89 SudestePiauiense/PI

90 SudoestePiauiense/PI

91 Baixadas/RJ

92 CentroFluminense/R

93 MetropolitanadoRiodeJaneiro/RJ

94 NoroesteFluminense/RJ

95 NorteFluminense/R

96 SulFluminense/RJ

97 AgrestePotiguar/RN

98 CentralPotiguar/RN

LestePotiguar/RN

\begin{tabular}{l|l} 
NoroesteEspírito-santense/ES & ES \\
\hline
\end{tabular}

SulEspírito-santense/ES

CentroGoiano/GO

LesteGoiano/GO

NoroesteGoiano/GO

\begin{tabular}{c|c}
99 & LestePotiguar/RN \\
\hline 100 & OestePotiguar/RN
\end{tabular}

101 NortedeRoraima/RR

102 SuldeRoraima/RR

\begin{tabular}{lll}
103 & CentroOcidentalRio-grandense/RS & RR \\
\hline 104 & CentoOr \\
\hline
\end{tabular}

\begin{tabular}{lll}
104 & CentroOrientalRio-grandense/RS & RS \\
\hline 105 & Men
\end{tabular}

\begin{tabular}{lll}
105 & MetropolitanadePortoAlegre/RS & RS \\
\hline 106
\end{tabular}

106 NordesteRio-grandense/RS

107 NoroesteRio-grandense/RS

108 SudesteRio-grandense/RS

109 SudoesteRio-grandense/RS

110 LesteRondoniense/RO

111 Madeira-Guaporé/RO

112 GrandeFlorianópolis/SC

\begin{tabular}{l|l}
113 & NorteCatarinense/SC \\
\hline
\end{tabular}

114 OesteCatarinense/SC

115 Serrana/SC

116 SulCatarinense/SC

117 Valedoltajaí/SC

118 Araçatuba/SP

119 Araraquara/SP

\begin{tabular}{l|l}
120 & Assis/SP \\
\hline 121 & Baur/SP \\
\hline
\end{tabular}

\begin{tabular}{l|l}
121 & Bauru/SP \\
\hline 122 & Campinas/SP \\
\hline
\end{tabular}

122 Campinas/SP

\begin{tabular}{l|l}
123 & Itapetininga/SP \\
\hline 124 & Ling \\
\hline
\end{tabular}

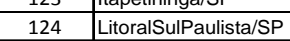

125 MacroMetropolitanaPaulista/SP

126 Marília/SP

127 MetropolitanadeSaoPaulo/SP

\begin{tabular}{l|l}
\hline 128 & Piracicaba/SP \\
\hline 129 & PresidentePruden \\
\hline
\end{tabular}

129 PresidentePrudente/SP

\begin{tabular}{l|l}
130 & RibeiraoPreto/SP \\
\hline
\end{tabular}

131 SaoJosédoRioPreto/SP

132 ValedoParaíbaPaulista/SP

\begin{tabular}{ll}
133 & AgresteSergipano/SE \\
\hline
\end{tabular}

\begin{tabular}{l|l}
134 & LesteSergipano/SE \\
\hline 135 & SertaoSergipano/SE \\
\hline
\end{tabular}

135 SertaoSergipano/SE

136 OcidentaldoTocantins/TO

137 OrientaldoTocantins/TO

Borborema/PB 


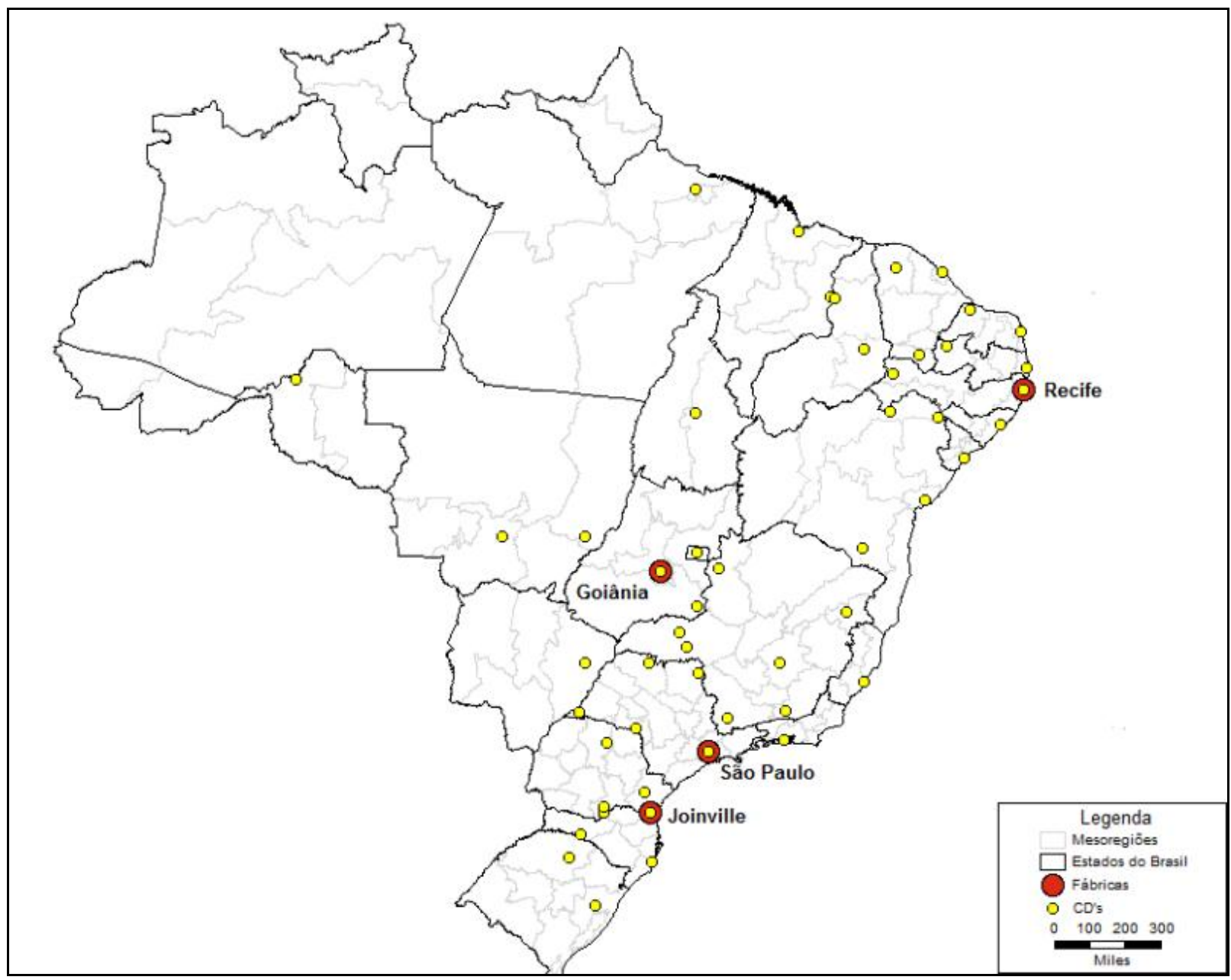

Figura 10: Mapa de localização das fábricas e dos centros de distribuição.

\section{2 - Demanda por região}

A demanda foi estabelecida de acordo com a demanda per capita fornecida pela ACNielsem, multiplicada pela população por mesorregião, segundo IBGE (2010). Por se tratar de uma representação da cadeia de suprimentos, cada fábrica ficou responsável por um tipo de produto especifico. A designação do produto à determinada fábrica seguiu os critérios: existência de uma indústria tradicional na região, produto não é sujeito à substituição tributária e, volume da fábrica é decrescente na seguinte ordem: São Paulo (430.783 t), Joinville (215.029 t), Goiânia (127.707 t) e Recife (58.775 t), totalizando $832.294 \mathrm{t}$. 
Os produtos destinados às fábricas foram:

1. São Paulo: sabão em pó, detergente, amaciante, bolachas e biscoitos, massas alimentícias.

2. Joinville: óleo de cozinha.

3. Goiânia: extrato de tomate, molho de tomate, purê de tomate, conserva em lata e maionese.

4. Recife: shampoo e sabonete.

Os motivos para a escolha destes produtos foram: disponibilidade de dados confiáveis, giro elevado, sazonalidade, o fato de serem facilmente encontrados em estabelecimentos varejistas, a existência de marcas líderes e diversos fabricantes por todo o país.

As Figuras 11, 12, 13 e 14 mostram os mapas com a distribuição da demanda por mesorregião e por fábrica.

Para melhor entendimento da distância entre as fábricas e os mercados, foi construído um mapa com uma escala colorida, representando a distância. É possível entender o nível de serviço que cada fábrica pode realizar dividindo a distância pela velocidade média de um veiculo de transporte de caga rodoviário. Os itens das Figura 15 e Figura 16 mostram a distância de entrega direta (fábrica para o mercado) e o nível de serviço para a entrega a partir do centro de distribuição respectivamente.

A visualização do nível de serviço a partir dos centros de distribuição permite compreender o potencial máximo que a empresa poderá oferecer. A partir disso, cada cenário permitirá compreender o impacto no nível de serviço em cada rede logística analisada. 


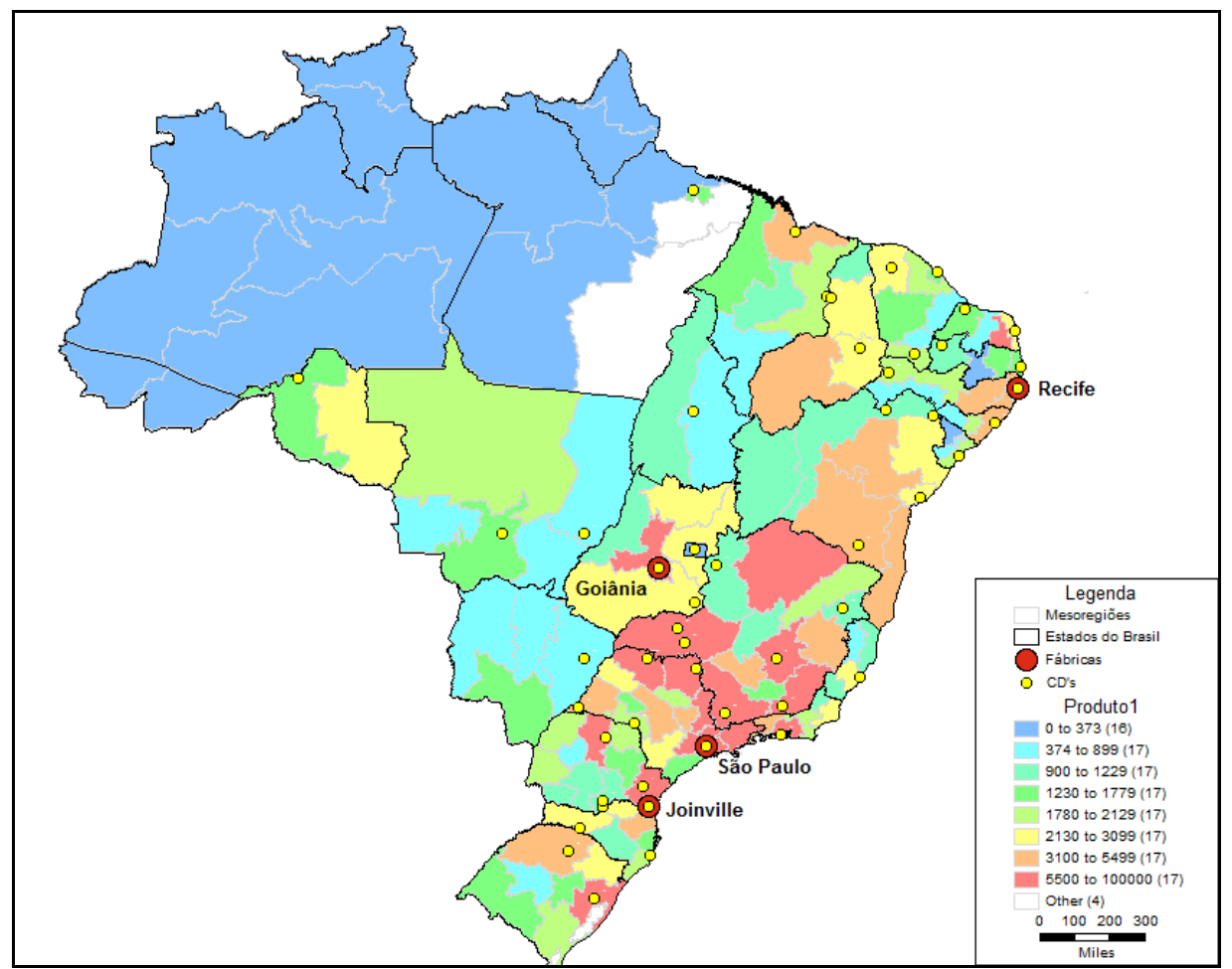

Figura 11: Demanda da fábrica de São Paulo por mesorregião.

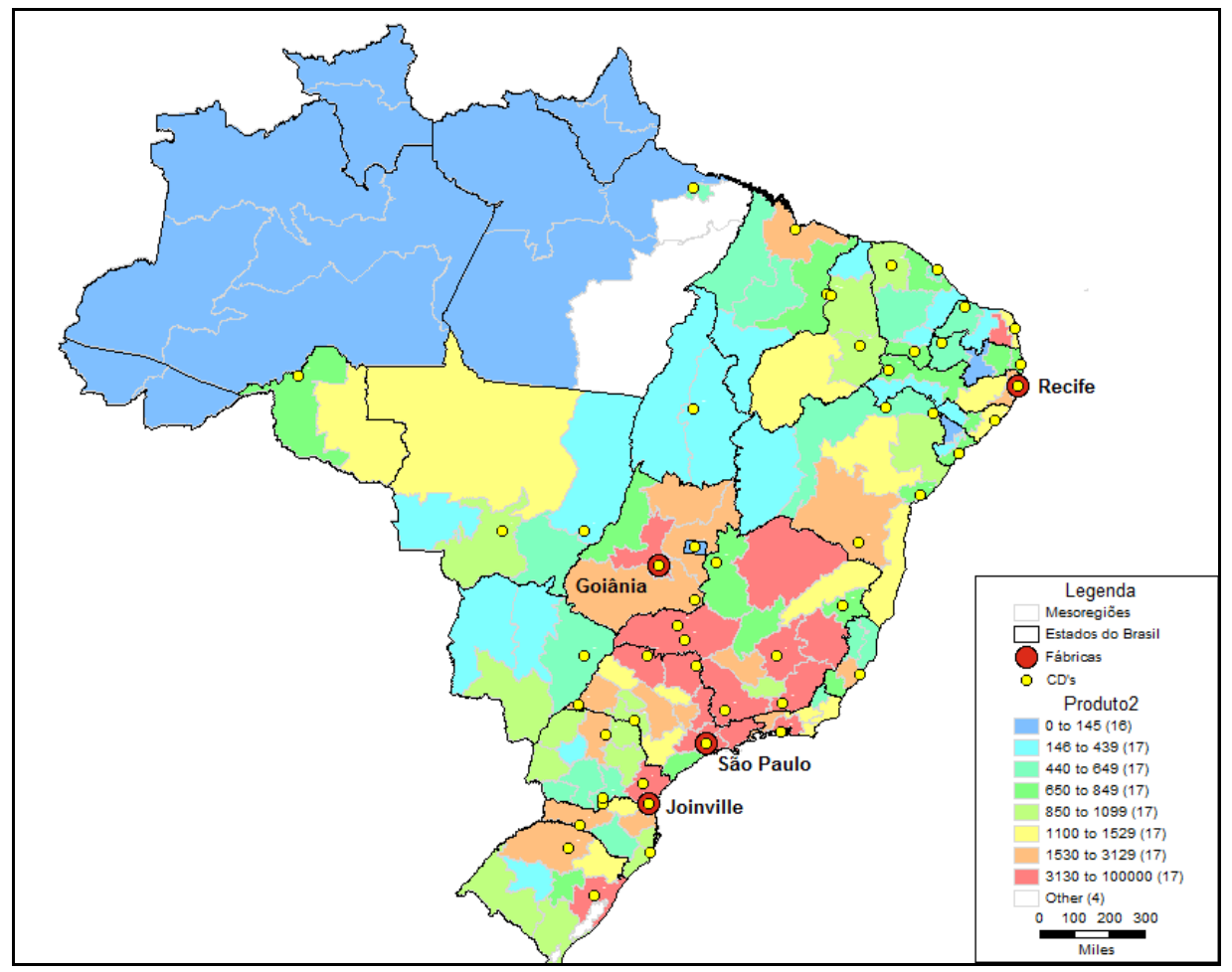

Figura 12: Demanda da fábrica de Joinville por mesorregião. 


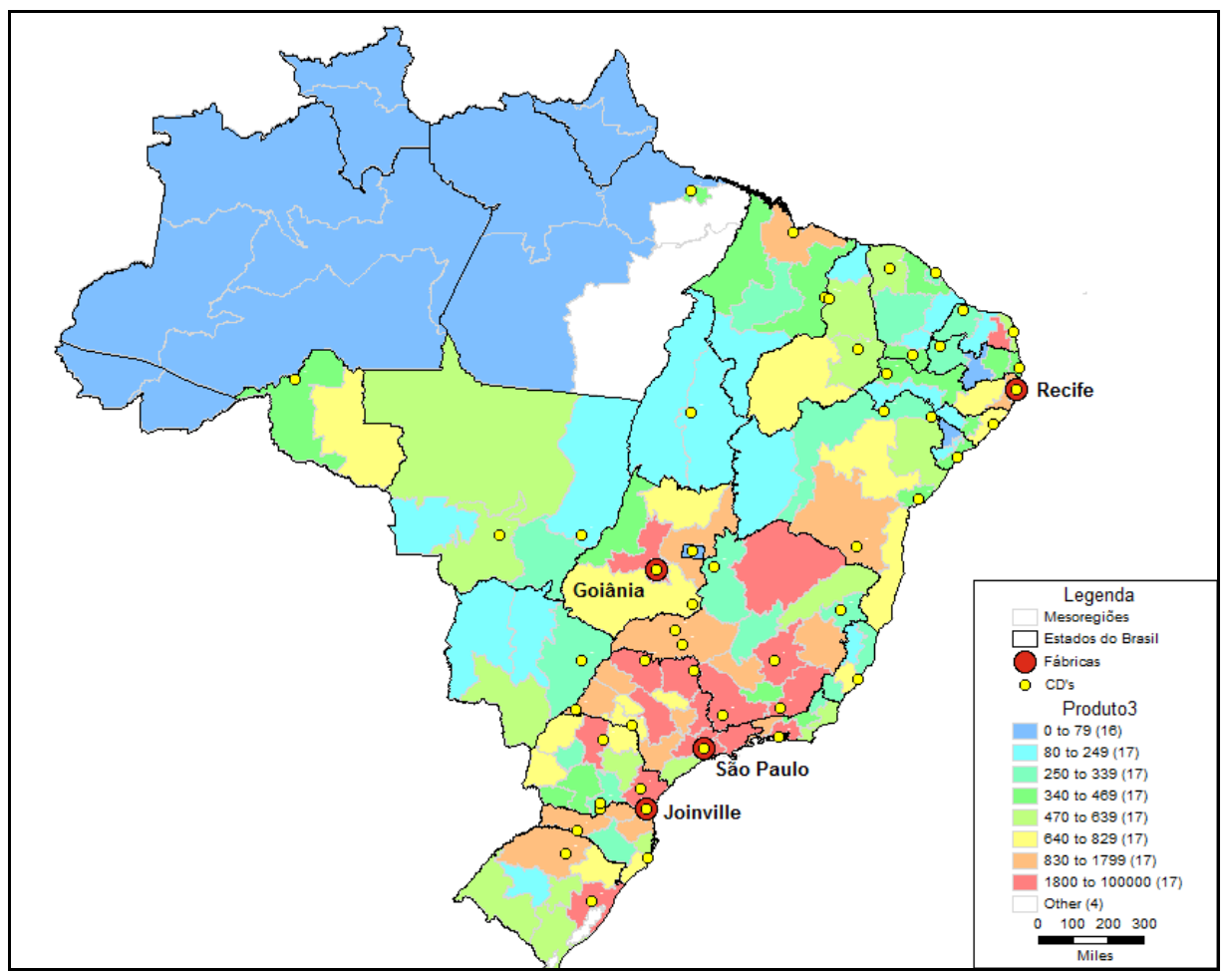

Figura 13: Demanda da fábrica de Goiânia por mesorregião.

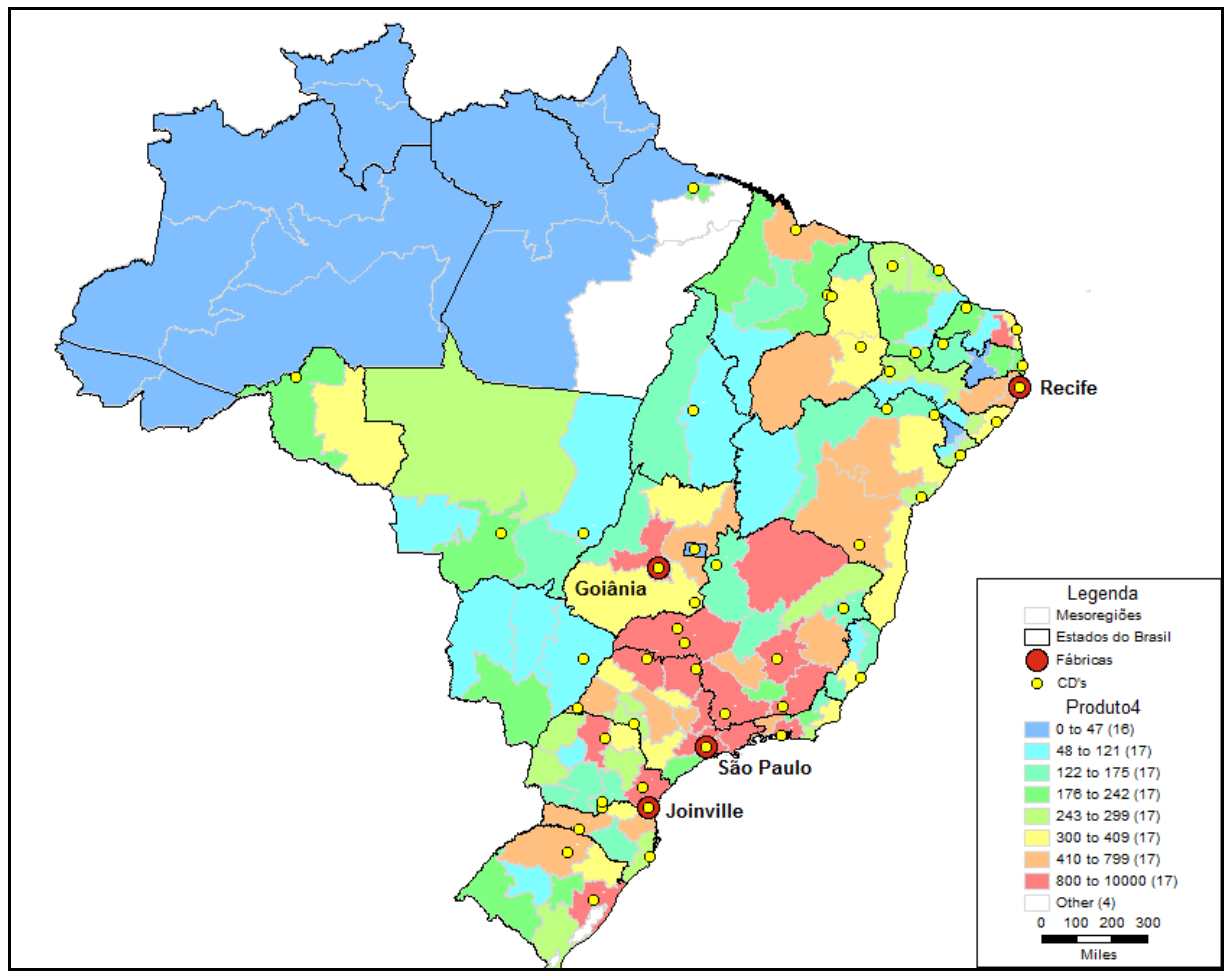

Figura 14: Demanda da fábrica de Recife por mesorregião. 


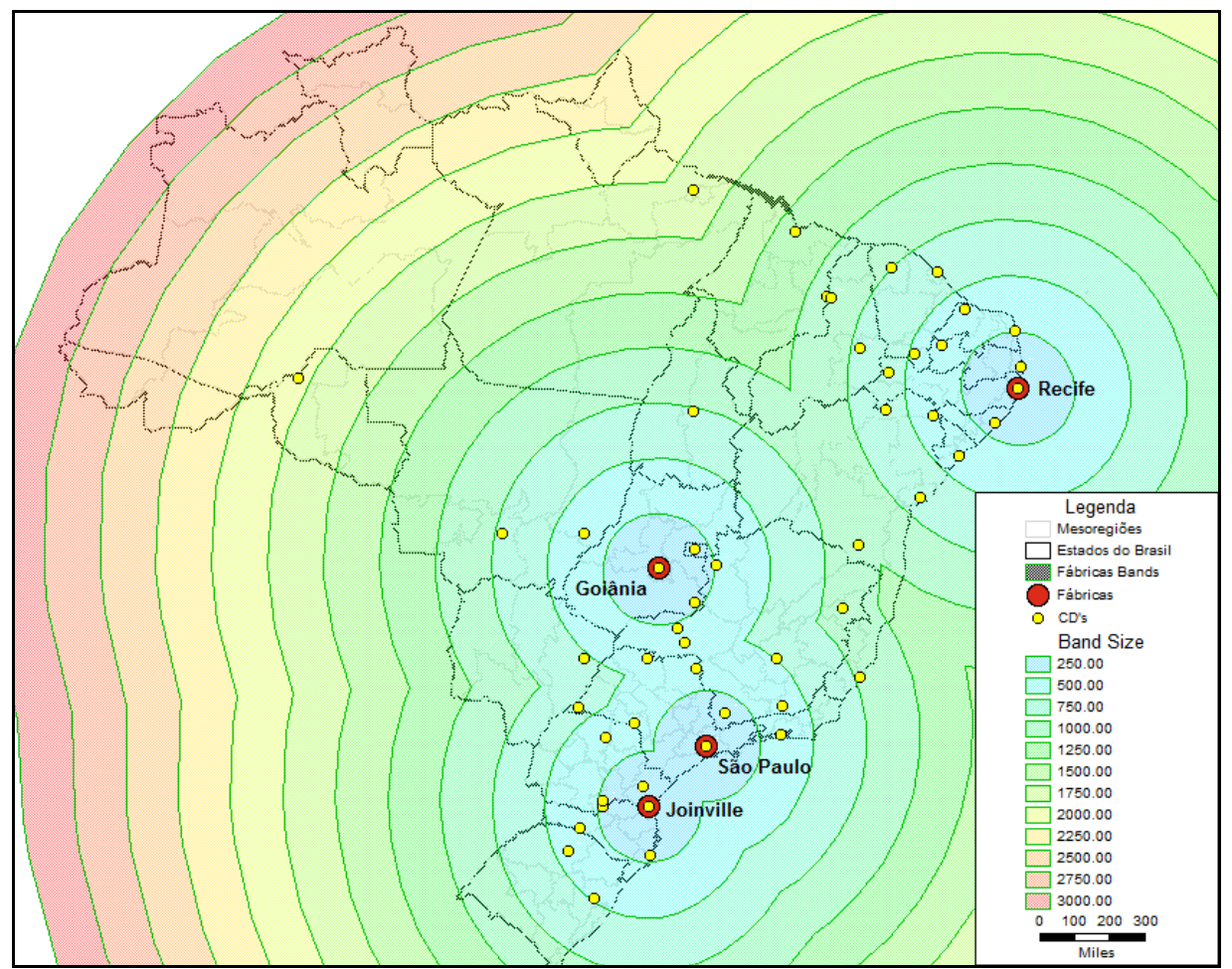

Figura 15: Distancia de entrega da fábrica até o mercado.

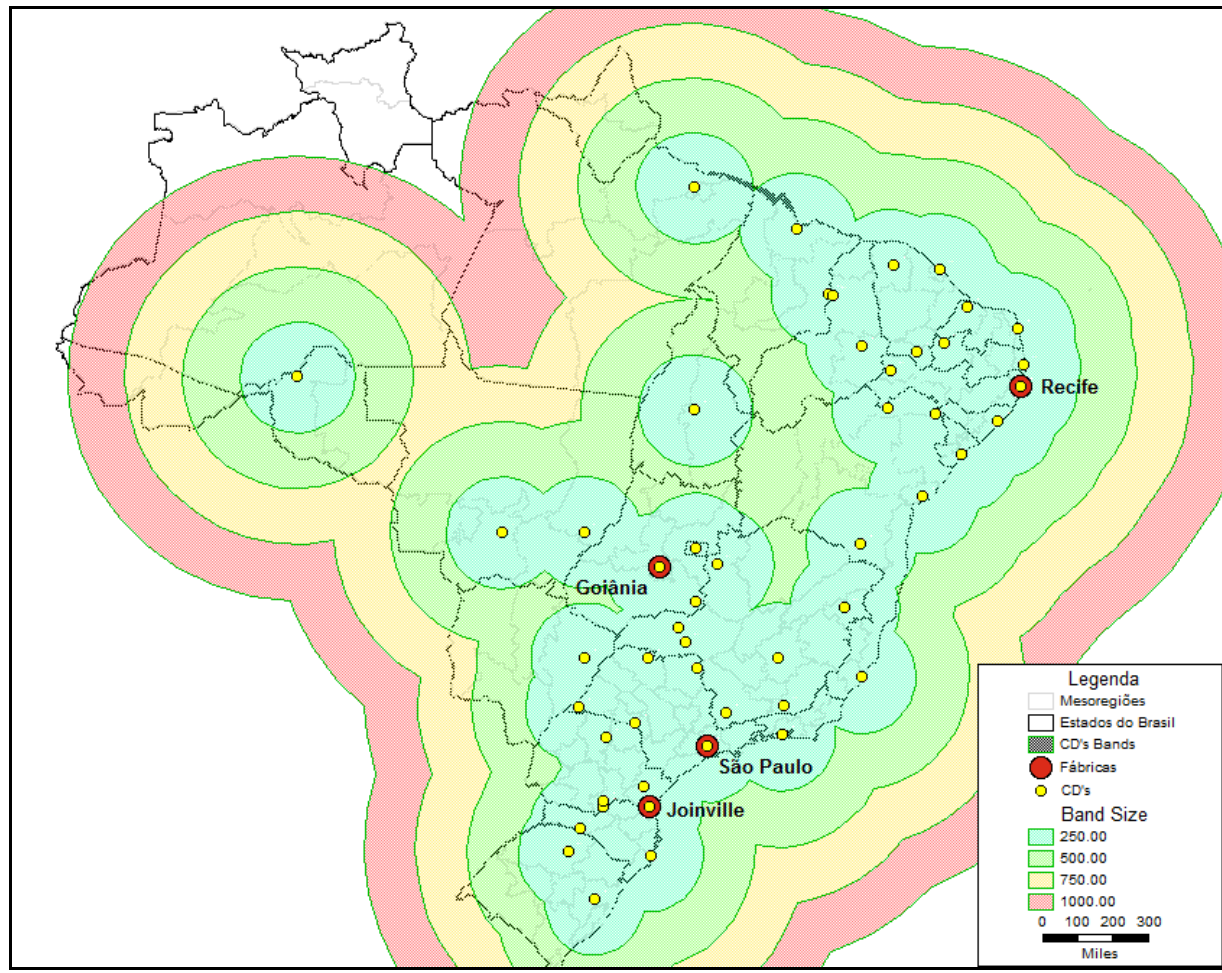

Figura 16: Nível de serviço de todos os centros de distribuição juntos. 


\section{3 - Capacidade e Custo Fixo}

O custo fixo foi determinado, segundo Yoshizaki (2002), a partir de pesquisa feita em 6 centros de distribuição (diferentes, mas com operações iguais), que trabalhavam com mercadorias secas acondicionadas em caixas de papelão ondulado. A Figura 17 mostra a relação entre a capacidade e o custo fixo.

Assume-se que o custo de transbordo é constante e igual ( $R \$ 1.00$ por tonelada), não importando o tamanho e a movimentação no $C D$. Os ganhos de escala estão associados aos custos fixos.

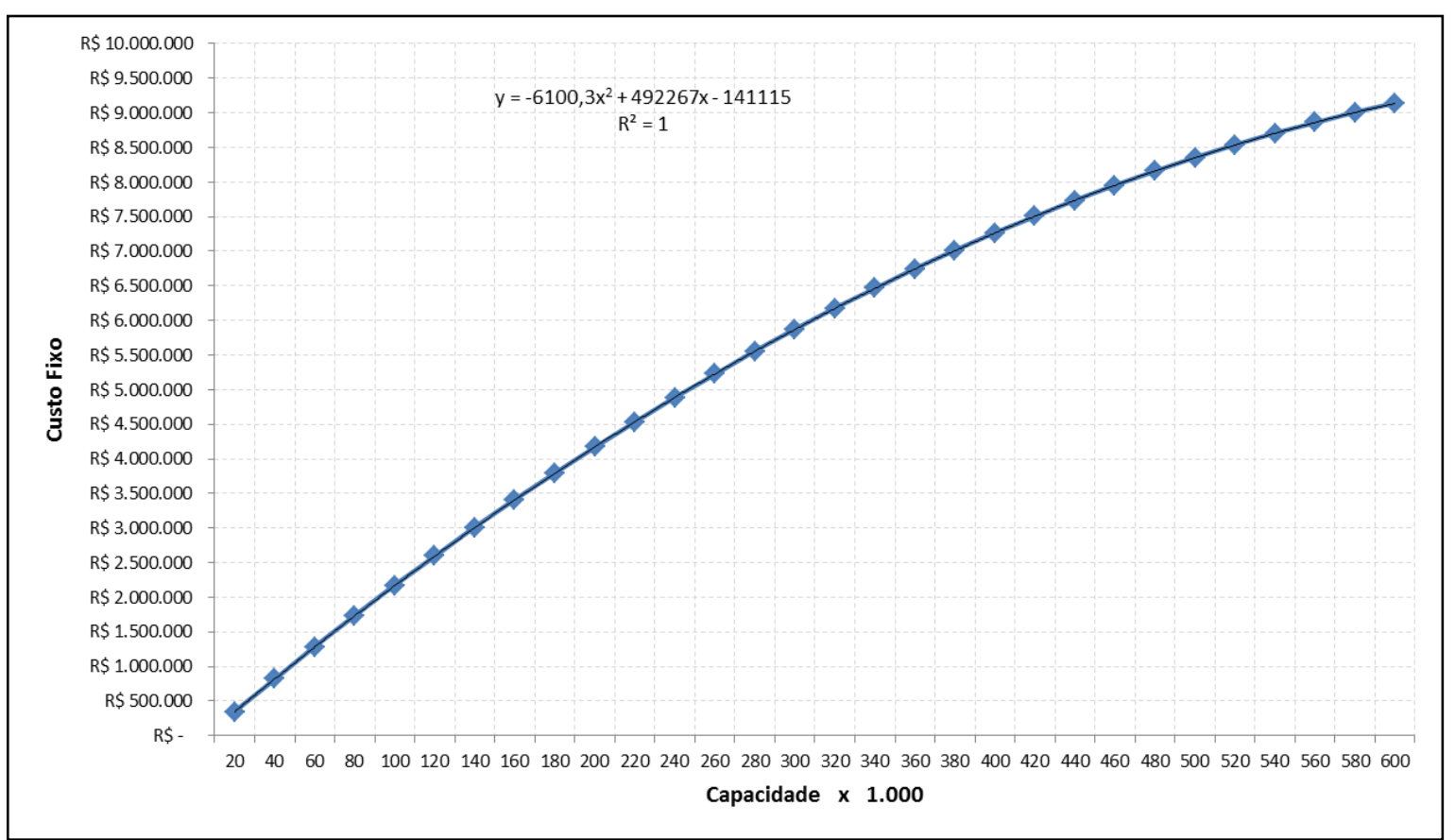

Figura 17: Relação entre capacidade e custo fixo 


\section{4 -RESULTADOS OBTIDOS}

O presente trabalho se concentra no efeito agregado do incremento do custo logístico pelo turismo fiscal e, em alguns aspectos, da geografia de distribuição, necessários para a demonstração das diferenças entre o cenário atual, o cenário futuro com o Novo ICMS e as simulações de ocorrência de sonegação.

É importante destacar a forma pela qual o ICMS influencia na localização das instalações. A comparação do custo logístico com o ICMS não deve ser realizada de forma direta, pois a forma de pagamento varia conforme o custo, sendo que o custo logístico representa um desembolso de caixa de forma mais direta, enquanto que o ICMS é contabilizado mensalmente por meio da diferença entre o crédito e o débito do agente.

Ao incorporar o ICMS no modelo de programação linear, o principal objetivo não é mensurar o custo tributário propriamente dito, mas sim o de utilizar o ICMS como um ponto de atração dos CD's. Estados que possuem taxas de ICMS menores funcionam como pontos de atração de CD's. A comparação pode ser feita como um jogo de "cabo de guerra", onde dois lados opostos puxam a corda até que um lado vença. Esta analogia funciona ao tentar explicar o tradeoff entre o custo logístico e a sonegação do ICMS.

O estudo foi realizado com dois cenários básicos: atual e Novo ICMS. Os dados utilizados nos dois cenários são exatamente iguais, diferenciando-se somente na tabela de alíquotas internas e interestaduais, possibilitando a comparação direta entre os mesmos:

- O primeiro cenário corresponde à estrutura atual do ICMS e está dividido em 5 variantes. Cada uma corresponde aos níveis de sonegação (0\%, 25\%, 50\%, $75 \%$ e $100 \%)$.

- O segundo cenário corresponde à reforma tributária e está dividido em 5 variantes. Cada variante corresponde aos níveis de sonegação (0\%, 25\%, 50\%, 75\% e 100\%). 
A diferença da estrutura das redes logísticas nos cenários analisados é demonstrada de acordo com comparações de: custos, localização de instalações, capacidade das instalações e modificação dos fluxos de origem/destino.

\subsection{Avaliação do custo logístico}

O primeiro aspecto analisado foi o incremento do custo logístico a partir do aumento da sonegação, ou seja, o aumento da proporção de clientes informais. Considerou-se como cenário base, aquele no qual há $0 \%$ de sonegação, ou seja, uma variante onde somente o custo logístico influencia o desenho da rede, de acordo com Yoshizaki (2002). A Figura 18 mostra o incremento do custo logístico à medida que se incrementa a informalidade.

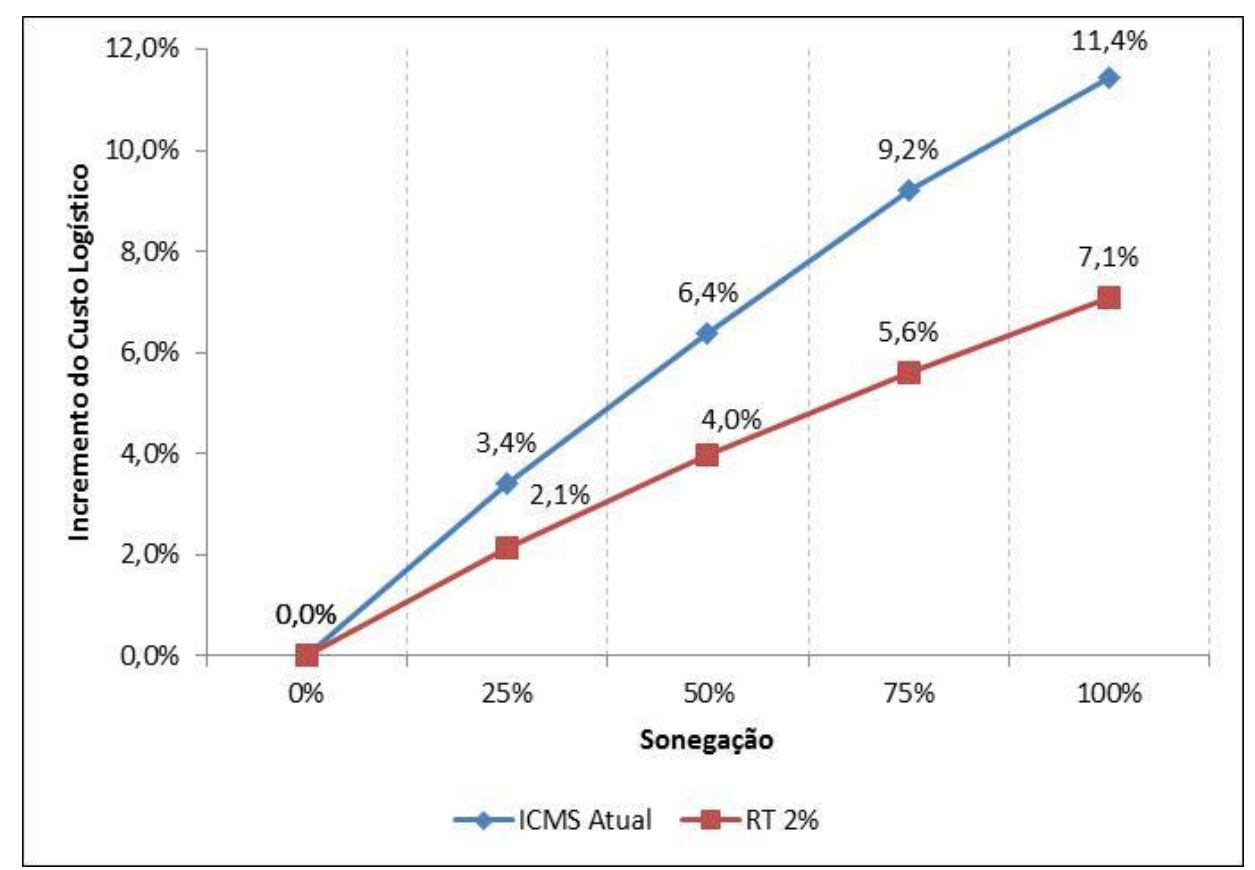

Figura 18: Aumento relativo do custo logístico.

Analisando-se a Figura 18, é possível se perceber o incremento relativo do custo logístico em função da sonegação que se comporta de forma semelhante em ambos os cenários e que, portanto, a reforma fiscal não consegue eliminar este tipo de turismo fiscal. Dada a ordem de grandeza das diferenças entre os cenários sem e com reforma 
tributária, parece que a reforma pouco vai alterar a geografia de rede logística resultante. Porém, para entender melhor a modificação da rede logística, é necessário analisar outros aspectos como custo de transferência, custo de distribuição e custo fixo. A Figura 19 mostra os custos de distribuição, custo de transferência e custo fixo para os cenários propostos.

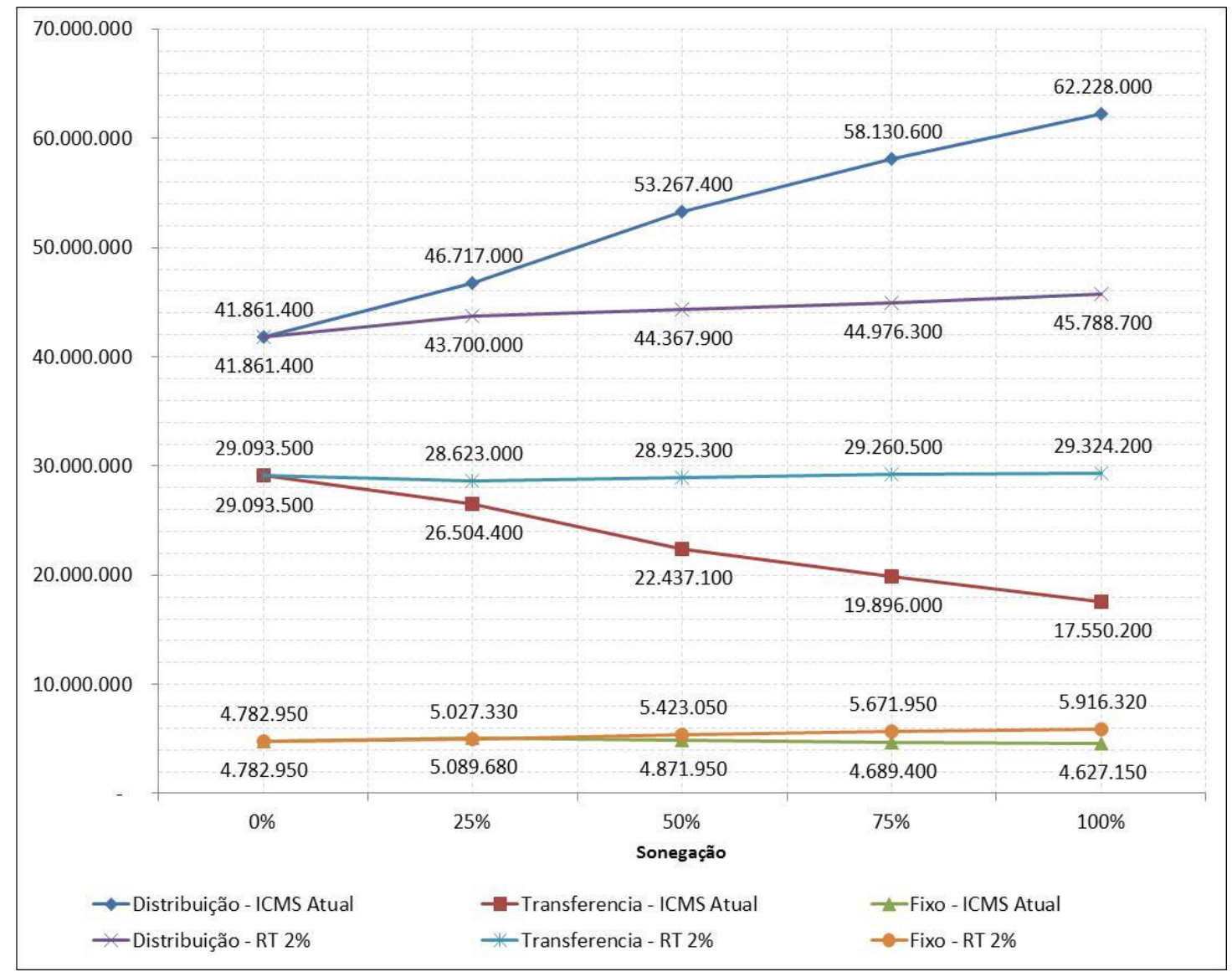

Figura 19: Comparação dos custos logísticos do ICMS Atual e da Reforma Tributária

A princípio, o custo de transferência no cenário com a estrutura atual de ICMS é modificado de $R \$ 41$ milhões (cenário sem sonegação) para $R \$ 61$ milhões (cenário com 100\% de sonegação), sendo que o custo de distribuição foi reduzido de $R \$ 29$ milhões (cenário sem sonegação) para $R \$ 17$ milhões (cenário com $100 \%$ de sonegação), uma diferença de $47 \%$ e $41 \%$ respectivamente.

No cenário com reforma tributária, o custo de distribuição aumentou de $R \$ 41$ milhões para $R \$ 45$ milhões no cenário com 100\% de sonegação, sendo que o custo de 
transferência aumentou de $R \$ 29$ milhões para $R \$ 29,3$ milhões no cenário com $100 \%$ de sonegação, uma diferença de $9 \%$ e $0,8 \%$ respectivamente.

Analisando os custos do cenário com o ICMS atual, existe uma relação direta entre o aumento da sonegação e o aumento do custo de distribuição, porém esta relação é modificada quando se analisa o custo de transferência, que possui uma relação inversamente proporcional ao aumento da sonegação. A relação encontrada na rede com a reforma tributária possui um aspecto diferente, pois não sofre muita alteração à medida que a sonegação aumenta.

O custo fixo está relacionado com a quantidade de instalações na rede logística. A Figura 19 mostra que a quantidade de instalações no cenário com reforma tributária não é modificado significativamente; em contrapartida, o cenário com a estrutura atual de ICMS sofre uma pequena redução de acordo com o aumento da sonegação, ocasionado pela modificação na quantidade de instalações. A diferença entre os custos pode ser melhor explicada na Tabela 6 , onde se mostra a localização e a quantidade de instalações por Estado.

\subsection{Avaliação da localização e da capacidade das instalações}

No cenário com o ICMS atual, à medida que ocorre o aumento da sonegação, o número de instalações é reduzido principalmente na Região Nordeste, justificada pela alteração nos fluxos origem e destino. A demanda da Região Nordeste começa a ser atendida pela Região Sudeste, justificando o aumento do custo de distribuição evidenciada no Figura 19. A verificação dos fluxos origem-destino deixa esta relação mais evidente.

Ao se comparar o cenário com $0 \%$ de sonegação (sem influência do ICMS) e o cenário de $25 \%$ de sonegação para a estrutura atual de ICMS, a Região de Minas Gerais passa de uma a cinco instalações (vide Tabela 6). Este aumento evidencia o forte posicionamento do Estado como ponto de triangulação para grandes atacadistas e distribuidores que atendem a um vasto número de varejistas por todo o país. 
As instalações localizadas na Região Sul não sofreram modificações nos cenários desenvolvidos, porém a Região Centro Oeste, o Estado de Mato Grosso e o Distrito Federal receberam instalações no cenário, com a reforma tributária. No cenário com a estrutura atual de ICMS, existe um tendência de redução do número de instalações à medida que a sonegação aumenta; em contrapartida, esta tendência não foi encontrada nos cenários com a reforma tributária, permanecendo a mesma localização à medida que a sonegação aumenta.

Tabela 6: Quantidade e localização das instalações

\begin{tabular}{|c|c|c|c|c|c|c|c|c|c|c|c|c|c|c|c|c|c|c|c|c|c|c|c|c|c|}
\hline & & & \multicolumn{4}{|c|}{ Região - Destino } & \multirow[b]{2}{*}{ Total } & \multicolumn{18}{|c|}{ UF - Destino } \\
\hline & & & SUL & SE & $\mathrm{NE}$ & $\mathrm{CO}$ & & DF & $\mathrm{GO}$ & $\mathrm{AL}$ & $\mathrm{BA}$ & $\mathrm{CE}$ & MA & $\mathrm{PB}$ & $\mathrm{PE}$ & $\mathrm{PI}$ & $\mathrm{RN}$ & SE & MG & $\mathrm{RJ}$ & $\mathrm{SP}$ & $\mathrm{PR}$ & $\mathrm{RS}$ & SC & Total \\
\hline \multirow{5}{*}{ ICMS Atual } & \multirow{5}{*}{$\begin{array}{l}0 \\
2 \pi \\
\widetilde{d} \\
\mathbb{0} \\
0 \\
0 \\
0 \\
0\end{array}$} & $0 \%$ & 2 & 4 & 7 & 1 & 14 & & 1 & & 1 & 1 & 1 & & 1 & 1 & 1 & 1 & 1 & 1 & 2 & & 1 & 1 & 14 \\
\hline & & $25 \%$ & 2 & 7 & 6 & & 15 & & & & 1 & 1 & 1 & & 1 & & 1 & 1 & 4 & 1 & 2 & 1 & 1 & & 15 \\
\hline & & $50 \%$ & 2 & 7 & 5 & & 14 & & & & 1 & & & 2 & & 1 & & 1 & 5 & 1 & 1 & 1 & & 1 & 14 \\
\hline & & $75 \%$ & 2 & 6 & 2 & & 10 & & & & & & & 1 & & & & 1 & 5 & & 1 & 1 & & 1 & 10 \\
\hline & & $100 \%$ & 2 & 6 & 1 & & 9 & & & 1 & & & & & & & & & 5 & & 1 & 1 & & 1 & 9 \\
\hline \multirow{5}{*}{ RT $2 \%$} & \multirow{5}{*}{ 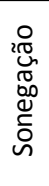 } & $0 \%$ & 2 & 4 & 7 & 1 & 14 & & 1 & & 1 & 1 & 1 & & 1 & 1 & 1 & 1 & 1 & 1 & 2 & & 1 & 1 & 14 \\
\hline & & $25 \%$ & 2 & 5 & 7 & & 14 & & & 1 & 2 & & & 2 & & 1 & & 1 & 3 & 1 & 1 & 1 & 1 & & 14 \\
\hline & & $50 \%$ & 2 & 4 & 7 & 2 & 15 & 1 & 1 & 1 & 1 & & & 2 & 1 & 1 & & 1 & 2 & 1 & 1 & 1 & & 1 & 15 \\
\hline & & $75 \%$ & 2 & 5 & 6 & 1 & 14 & 1 & & 1 & 1 & & & 2 & & 1 & & 1 & 4 & & 1 & 1 & & 1 & 14 \\
\hline & & $100 \%$ & 2 & 5 & 6 & 1 & 14 & 1 & & 1 & 1 & & & 2 & & 1 & & 1 & 4 & & 1 & 1 & & 1 & 14 \\
\hline
\end{tabular}

Nos dois cenários, o Estado de Minas Gerais concentrou um número de instalações muito maior que os outros Estados, porém o motivo para a localização das instalações foi diferente. No cenário com ICMS atual, o Estado de Minas Gerais funciona como um ponto de triangulação devido à diferença das alíquotas de ICMS e à medida que a sonegação aumenta, esta relação tende a aumentar.

No cenário da reforma tributária, as instalações são localizadas no Estado vizinho ao Estado no qual a instalação irá atender, aspecto evidenciado por Yoshizaki et al (2008). Como o Estado de Minas Gerais é localizado próximo aos Estados de maior demanda (Rio de Janeiro e São Paulo), o mesmo concentra uma grande quantidade de instalações.

Além da localização das instalações, outro ponto a ser destacado é a capacidade das instalações, evidenciado pela Tabela 7. A tabela mostra a cidade, a região de localização das instalações e suas respectivas capacidades de movimentação de produtos, representada pelo número no interior da célula. Foi identificada uma relação diretamente proporcional entre o aumento da capacidade e o aumento da sonegação, 
encontrado nos dois cenários. A Tabela 6 e a Tabela 7 evidenciam que não só a localização das instalações é modificada, mas também a capacidade das instalações. Porém, a rede logística com a reforma tributária possui uma descentralização geográfica maior do que o analisado no cenário com o ICMS Atual.

A modificação gradual dos custos no cenário com a reforma tributária, destacada pela Figura 19, é devido ao fato de a localização das instalações não sofrer grandes modificações com o aumento da sonegação. A reforma tributária favorece a localização de instalações na Região Nordeste e Centro-Oeste, diferentemente da Região Sul que não sofre modificações significativas.

A mostra os mapas de fluxos de mercadoria para os cenários de $0 \%$ de sonegação, $100 \%$ de sonegação (ICMS atual) e 100\% de sonegação (reforma tributária). Os mapas foram divididos em 3 fluxos: fluxos da fábrica até os centros de distribuição, fluxo do centro de distribuição até o mercado e, o fluxo da fábrica até o mercado consumidor (entrega direta).

A modificação da localização e da capacidade influencia na modificação dos fluxos origem e destino. $\mathrm{Na}$, é possível compreender a modificação da rede logística em função do ICMS. A diferença entre o custo de transferência e o custo de distribuição, nos cenários com o ICMS atual, é exemplificada ao se analisar a quantidade de fluxos de transferência (fábrica para o centro de distribuição) e a quantidade de fluxos de distribuição (centro de distribuição para o mercado). O cenário com o ICMS atual gera uma quantidade menor de fluxos de transferência quando comparado ao cenário base e ao cenário de reforma tributária. Os centros de distribuição estão concentrados no Estado de Minas Gerais, aspecto gerado pela diferença entre alíquotas da estrutura atual do ICMS. Porém, ao analisar os mapas de fluxo do centro de distribuição para o mercado, é possível verificar que conforme a distância, o volume e a quantidade de fluxos são maiores do que nos outros cenários.

A diferença sutil entre o custo de transferência e o custo de distribuição do cenário com a reforma tributária, demonstrados pela Figura 19, é perceptível ao observar a distância percorrida pelos fluxos do centro de distribuição até o mercado. A 
rede logística da reforma tributária não difere do cenário base tanto quanto a rede logística do cenário com ICMS atual difere, ou seja, a rede logística do cenário da reforma tributária está mais próxima do ótimo logístico, exemplificado pelo cenário base com $0 \%$ de sonegação.

A concentração dos fluxos na Região de Minas Gerais é um ponto a ser destacado. Os centros de distribuição localizados no Estado funcionam como um hub logístico, ou seja, ponto de triangulação de fluxos cujo objetivo é reduzir a carga tributária, prejudicando a rede com fluxos desnecessários e longos. Além disso, a capacidade das instalações no cenário com ICMS atual é maior do que a capacidade das instalações no cenário com reforma tributária. Esta diferença é devido ao fato do Estado de Minas Gerais ser um ponto concentrador da maioria dos fluxos de saída de mercadoria para os mercados, ocasionado pelo turismo fiscal. Este ponto é amenizado ao analisar a rede logística do cenário com a reforma tributária.

A diferença do custo de transferência e do custo de distribuição no cenário com a estrutura atual de ICMS é exemplificada nos mapas de fluxos da. No cenário com $100 \%$ de sonegação, as fábricas enviam as mercadorias diretamente para os centros de distribuição localizados em Minas Gerais, sendo que, a partir deste ponto, são atendidos os centros de demanda. No cenário com reforma tributária, o fluxo da fábrica para o centro de distribuição sofre uma variação significativa, porém os fluxos são parecidos com os fluxos do cenário base, justificando um custo semelhante. 


\section{Tabela 7: Localização e capacidade das instalações}

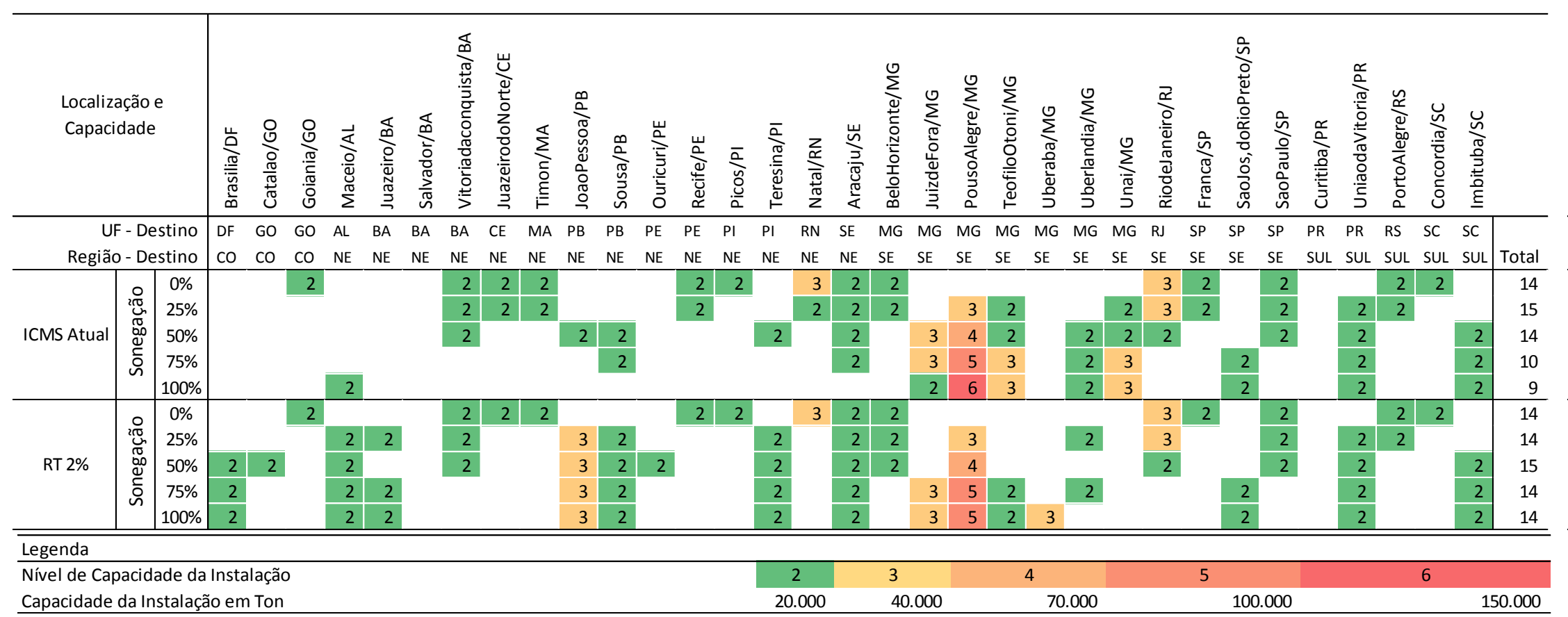


Figura 20: Mapas de fluxo origem/destino

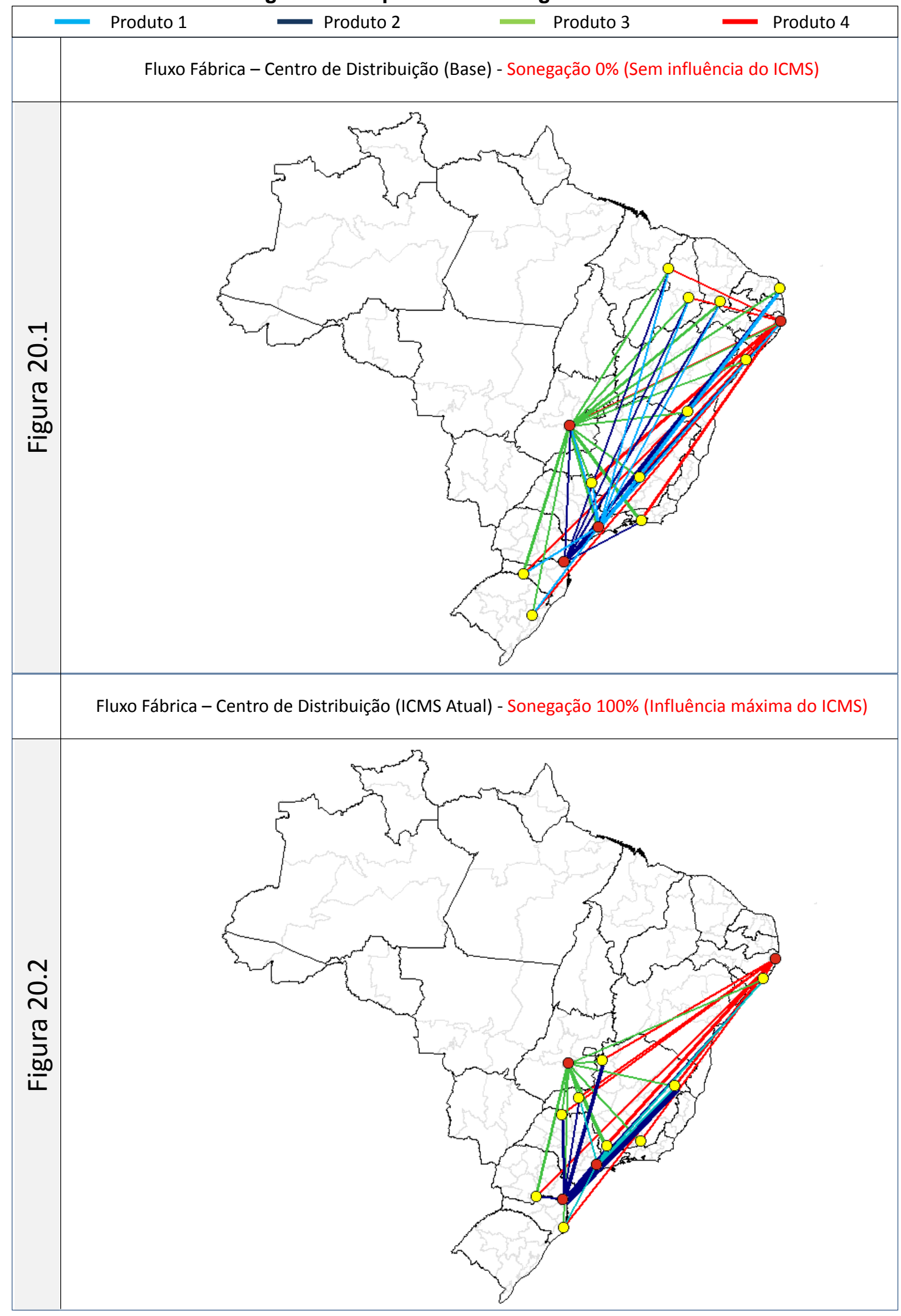


Figura 20: Mapas de fluxo origem/destino

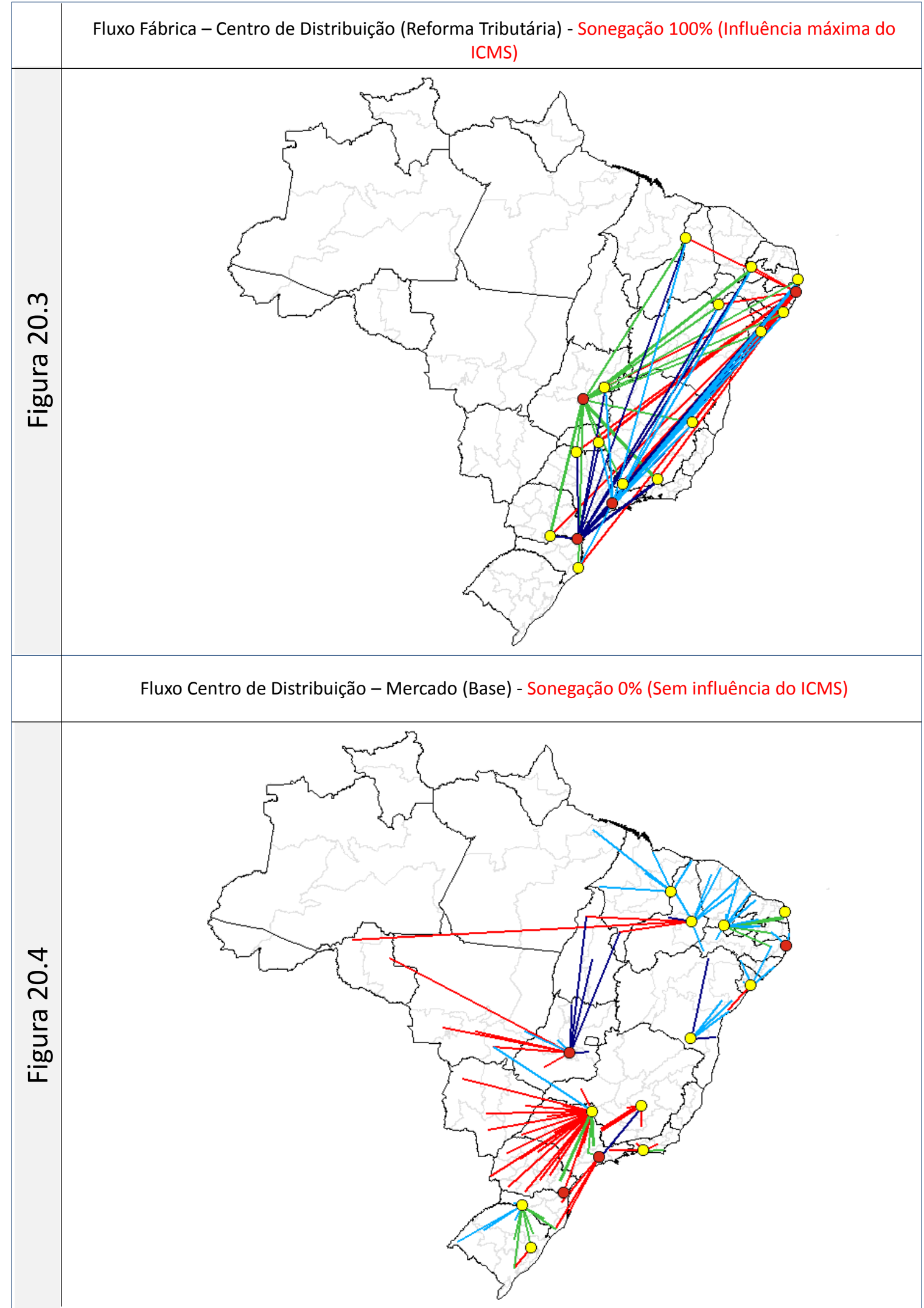


Figura 20: Continuação Mapas de fluxo origem/destino

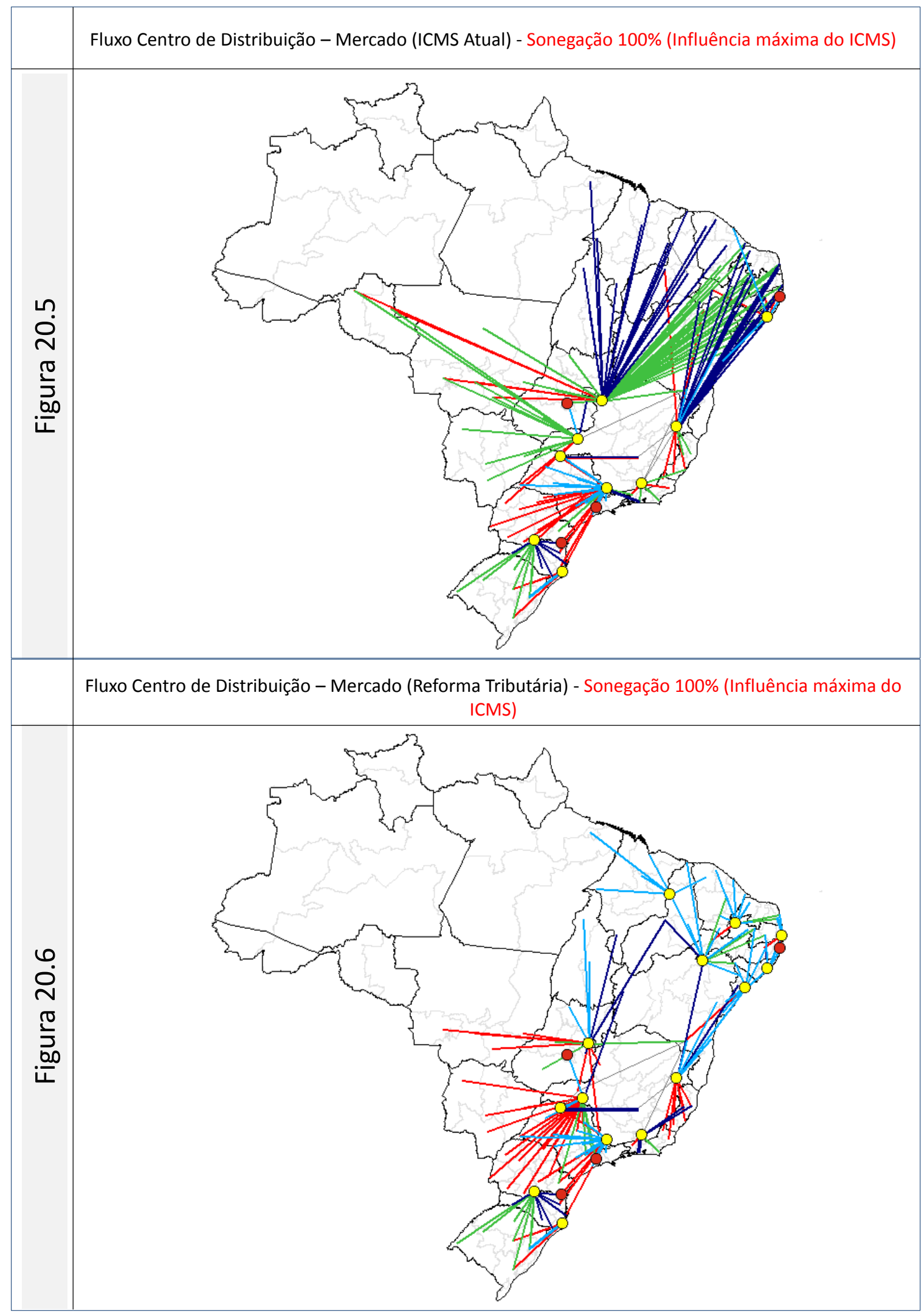


Figura 20: Continuação Mapas de fluxo origem/destino

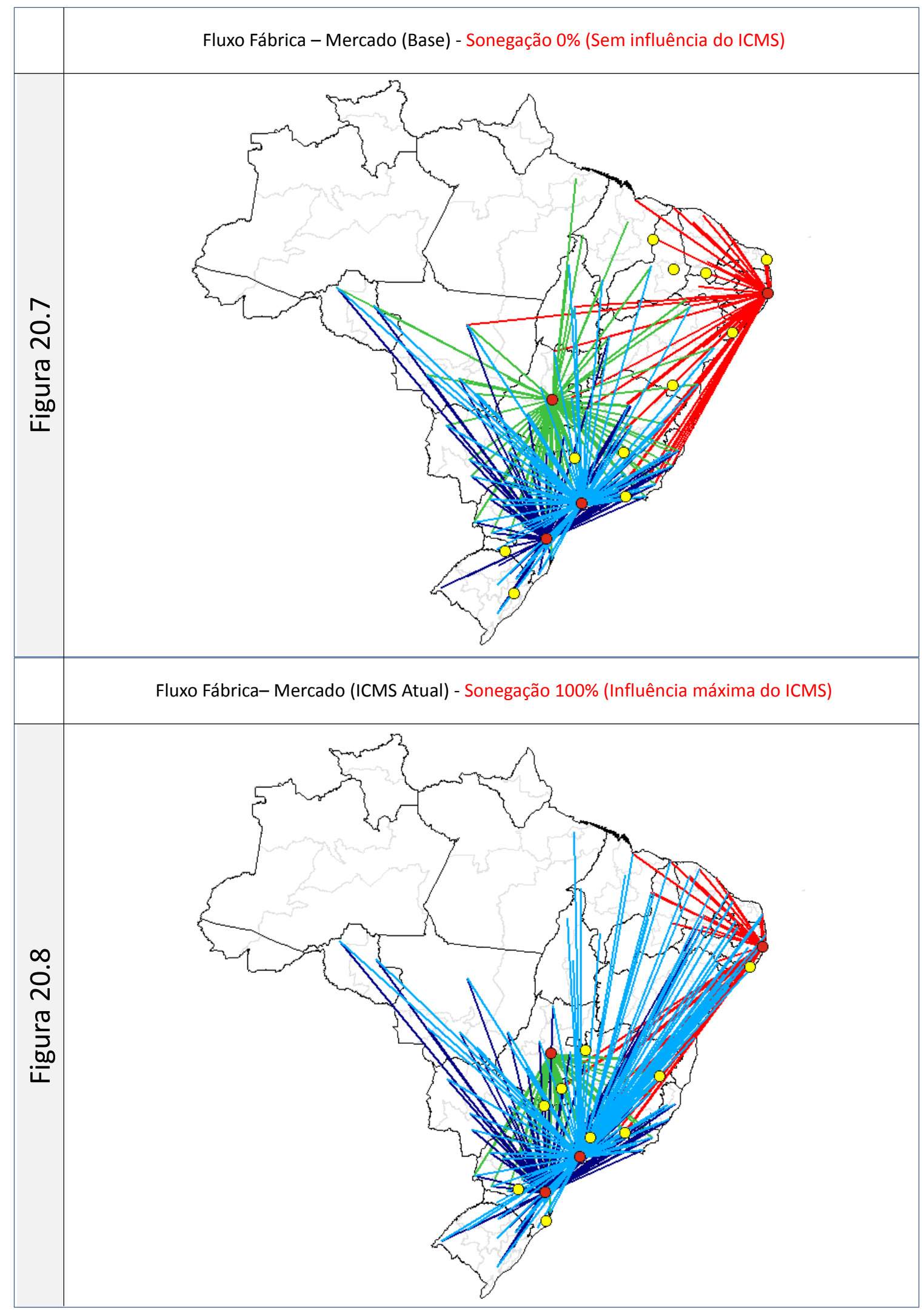


Figura 20: Continuação Mapas de fluxo origem/destino

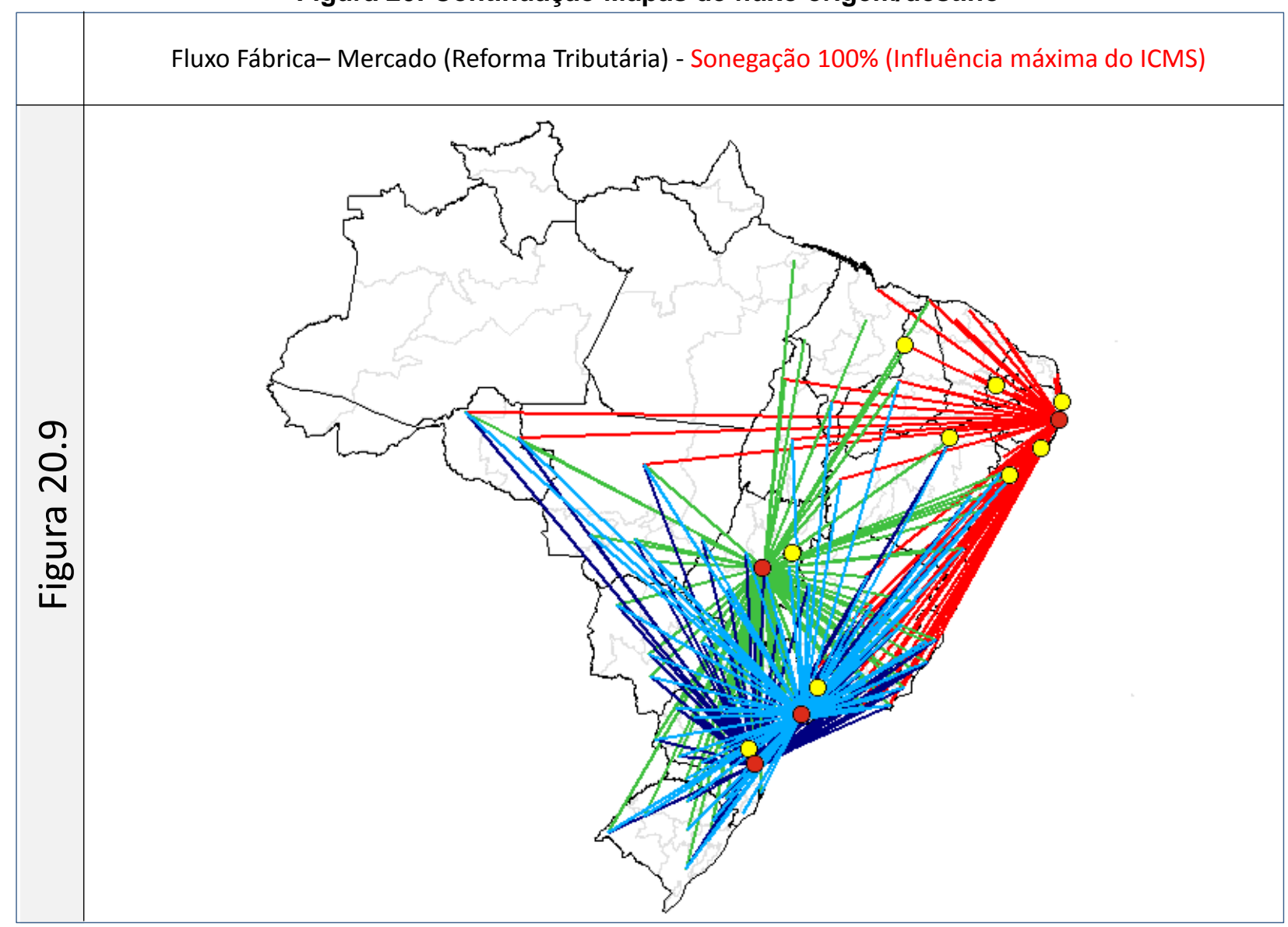

É possível verificar o efeito da descentralização nos mapas de fluxo do centro de distribuição para o mercado, onde ocorre uma redução da distância percorrida no cenário com reforma tributária. $O$ atendimento da demanda é feito pelo Estado vizinho, diferenciando-se do cenário com o ICMS atual. Estados do Nordeste passam a ser atendidos por centros de distribuição localizados no Nordeste. Na Tabela 8, é possível verificar a representatividade origem/destino dos fluxos por região para o cenário com $100 \%$ de sonegação.

Tabela 8: Representatividade dos fluxos origem/destino por região ( $100 \%$ de sonegação).

\begin{tabular}{|c|c|c|c|c|c|c|c|c|c|c|c|c|c|c|c|c|c|c|c|}
\hline \multirow{6}{*}{$\begin{array}{l}\text { QT de fluxo de } \\
\text { distribuição por } \\
\text { origem e destino }\end{array}$} & \multirow{3}{*}{\begin{tabular}{|l|} 
Origem \\
Destino \\
\end{tabular}} & \multicolumn{4}{|c|}{ Fluxo Interno } & \multicolumn{9}{|c|}{ Fluxo Externo } & \multirow[b]{3}{*}{ Total } & \multirow{2}{*}{\multicolumn{4}{|c|}{$\begin{array}{c}\text { Total de Saída por } \\
\text { região }\end{array}$}} \\
\hline & & $\mathrm{CO}$ & $\mathrm{NE}$ & SU & SUL & $\mathrm{CO}$ & $\mathrm{CO}$ & $\mathrm{CO}$ & $\mathrm{NE}$ & SU & SU & SU & SU & SUL & & & & & \\
\hline & & $\mathrm{CO}$ & $\mathrm{NE}$ & SU & SUL & $\mathrm{N}$ & $\mathrm{NE}$ & SU & $\mathrm{N}$ & $\mathrm{CO}$ & $\mathrm{N}$ & $\mathrm{NE}$ & SUL & SU & & $\mathrm{CO}$ & $\mathrm{NE}$ & SU & SUL \\
\hline & Base & $6 \%$ & $49 \%$ & $29 \%$ & $13 \%$ & $0 \%$ & $0 \%$ & & $1 \%$ & $0 \%$ & & & $2 \%$ & & $100 \%$ & $6 \%$ & $50 \%$ & $31 \%$ & $13 \%$ \\
\hline & ICMS Atual & $0 \%$ & $5 \%$ & $53 \%$ & $11 \%$ & & & & & $7 \%$ & $1 \%$ & $20 \%$ & $2 \%$ & $0 \%$ & $100 \%$ & $0 \%$ & $5 \%$ & $84 \%$ & $11 \%$ \\
\hline & Ref. Tributaria & $4 \%$ & $34 \%$ & $44 \%$ & $10 \%$ & $0 \%$ & $0 \%$ & $0 \%$ & $1 \%$ & $1 \%$ & & $5 \%$ & $2 \%$ & & $100 \%$ & $5 \%$ & $34 \%$ & $51 \%$ & $10 \%$ \\
\hline
\end{tabular}


O efeito centralizador da estrutura do ICMS atual pode ser verificado na Tabela 8. A Região Sudeste concentraria $84 \%$ do volume de mercadorias movimentadas no fluxo do $C D$, para o mercado no cenário com a estrutura atual de ICMS, além disso, $31 \%$ dos fluxos de mercadoria possuem origem no Sudeste e são destinadas para outra região. Ao comparar o cenário com a estrutura atual de ICMS com o cenário base, a diferença no total de fluxos com saída na Região Sudeste é de 53\% (84\% - 31\%).

Os fluxos com saída na Região Nordeste representam 5\% do volume no cenário com a estrutura atual de ICMS, contra $50 \%$ no cenário base. No cenário com a reforma tributária, o fluxo interno da Região Nordeste representa 34\% contra 5\% do cenário, com a estrutura atual de ICMS. Os fluxos da Região Sudeste foram modificados de $20 \%$ no cenário com a estrutura atual de ICMS, para 5\% com a reforma tributária, justificando a descentralização dos fluxos responsáveis pelo turismo fiscal na atual estrutura de ICMS. Esta diferença mostra o quanto a rede logística é modificada por causa da estrutura atual de ICMS. Na Tabela 9, é possível verificar a representatividade dos fluxos com origem no Estado.

Tabela 9: Representatividade dos fluxos com origem no Estado - $100 \%$ de sonegação

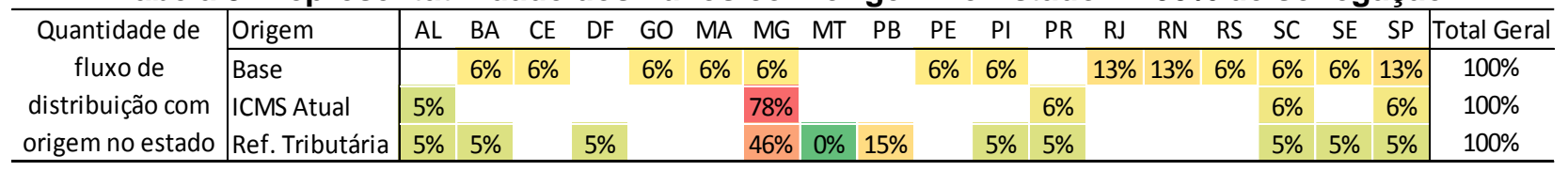

De acordo com a Tabela $9,78 \%$ do fluxo de mercadorias do centro de distribuição para o mercado possui origem no Estado de Minas Gerais no cenário com a estrutura atual de ICMS, contra $6 \%$ do cenário base e, $46 \%$ do cenário com reforma tributária. A reforma tributária modificou os fluxos de origem e destino, porém ao se comparar com o cenário base, a rede logística ainda sofre com os efeitos do ICMS. A estrutura do Novo ICMS possibilitou uma melhora do fluxo interno na Região Nordeste, reduzindo a distância de atendimento aos centros de demanda, porém ainda representa uma grande diferença em comparação com o cenário base.

Com a modificação dos fluxos, o nível de serviço foi alterado de acordo com o aumento da sonegação. Para melhor entender o impacto no nível de serviço, é 
necessário analisar o volume movimentado por faixa de distância. As Figuras 21, 22 e 23 representam o volume movimentado por faixa de distância e por sonegação.

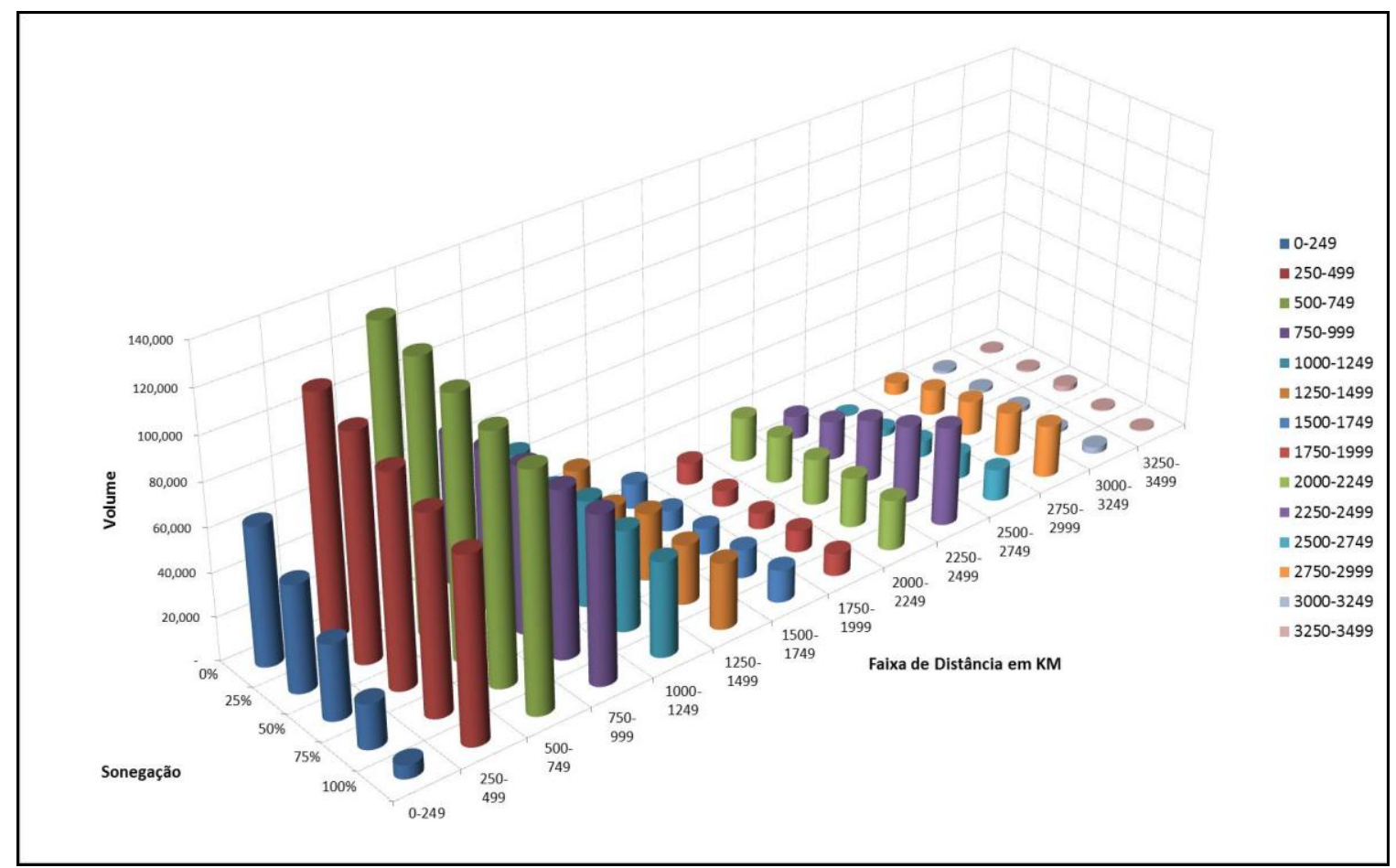

Figura 21: Quantidade movimentada em toneladas por faixa de distância (Fábrica - Mercado)

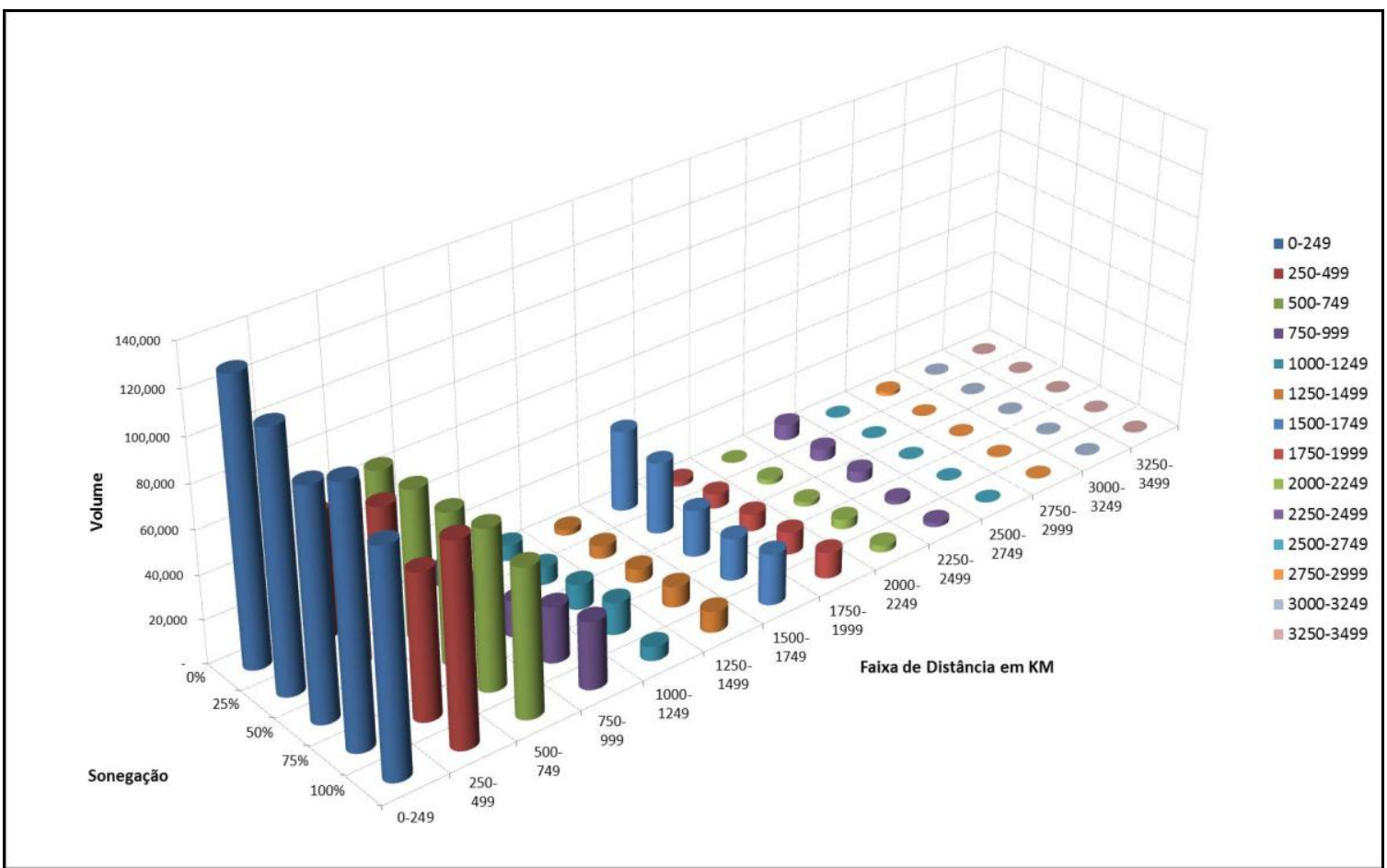

Figura 22: Quantidade movimentada em toneladas por faixa de distância (CD - Mercado) 


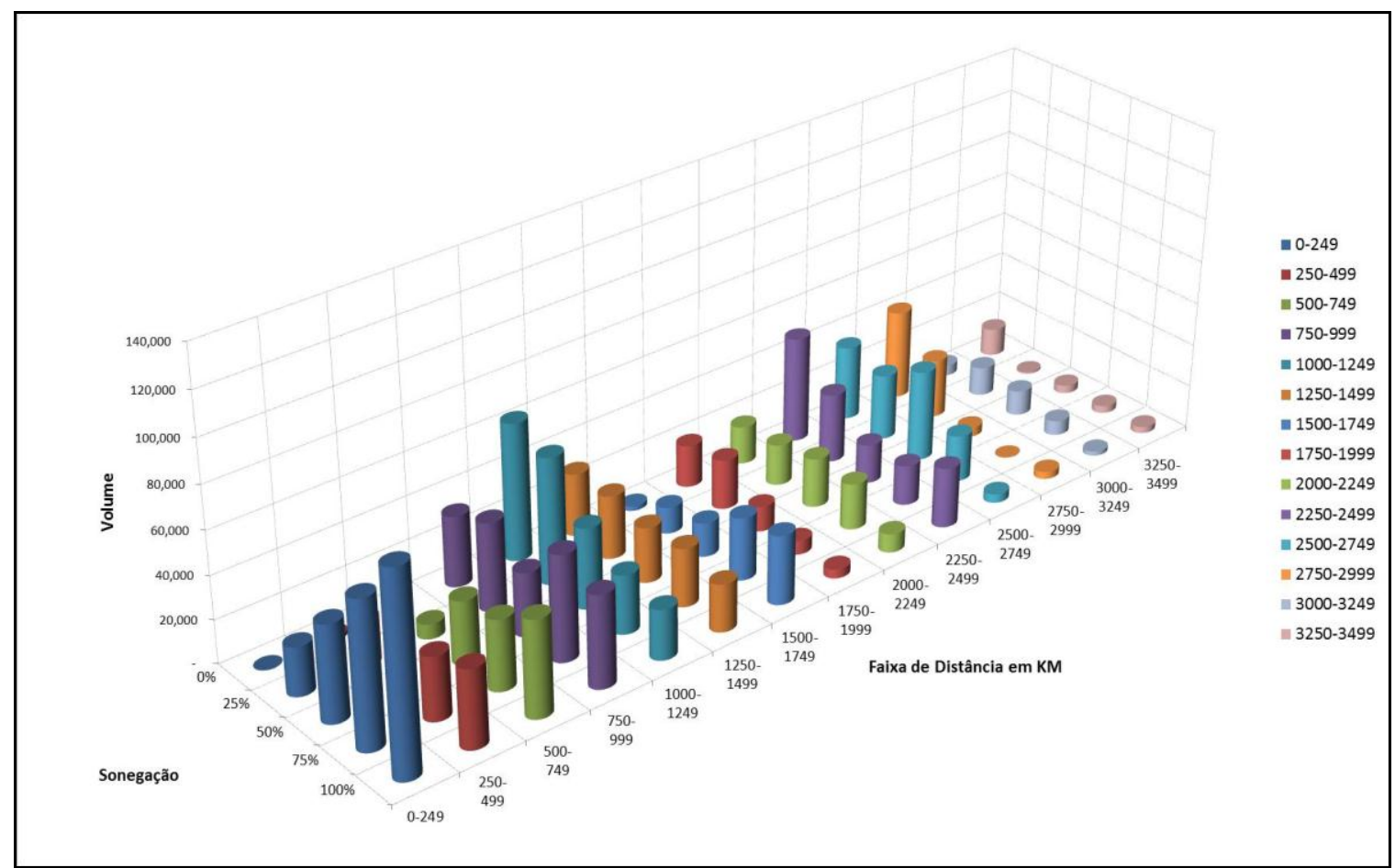

Figura 23: Quantidade movimentada em toneladas por faixa de distância (Fábrica - CD)

Uma das principais diferenças encontradas ao se comparar o cenário base e o cenário com a estrutura atual de ICMS está nos fluxos origem e destino. Esta diferença está relacionada à distância percorrida pelo caminhão, que é modificada de acordo com a localização das instalações. Sendo o tempo uma variável dependente da distância e da velocidade média, a compreensão dos principais motivos conduz a um entendimento maior das relações de causa e efeito.

Para isso, a análise será dividida em três partes. Primeiramente, serão analisadas as principais modificações por faixa de distância que impactaram no aumento ou na redução dos fluxos da fábrica para o mercado (vide Figura 21). Na segunda parte, serão analisados os fluxos do centro de distribuição até o mercado (vide Figura 22) e, em seguida, os fluxos da fábrica até o centro de distribuição (vide Figura 23).

As principais modificações nos fluxos da fábrica para o mercado por faixa de distância são: 
1. Redução do volume movimentado na faixa de 0 a 249 quilômetros. Essa modificação foi ocasionada pela redução na movimentação dos fluxos da fábrica de São Paulo para o interior do Estado de São Paulo. Como a alíquota interna é maior quando comparada à alíquota interestadual, muitos dos fluxos são direcionados para Minas Gerias, principalmente Pouso Alegre. Ocorre também a redução do fluxo da fábrica de Joinville para a mesorregião do Vale do Itajaí.

2. Redução do volume movimentado nas faixas de 250 a 499 e 500 a 749 quilômetros. Essa modificação foi ocasionada pela alteração nos fluxos da fábrica de São Paulo para o interior de São Paulo. O volume movimentado de São Paulo para o Rio de Janeiro se manteve o mesmo.

3. Aumento do volume na faixa de 2250 a 2499. Essa modificação foi ocasionada pelo aumento no fluxo da fábrica de São Paulo para a mesorregião do Agreste Potiguar/RN.

4. O aumento da sonegação contribuiu para o aumento dos fluxos da fábrica de São Paulo para a Região Nordeste (Ceara, Maranhão, Pernambuco e Rio Grande do Norte) nas faixas de 2500 a 2749 e 2750 a 2999 quilômetros.

As principais modificações nos fluxos do centro de distribuição para o mercado por faixa de distância são:

1. Redução no volume movimentado na faixa de 0 a 250 quilômetros. Essa modificação foi ocasionada principalmente pela eliminação dos fluxos de atendimento do CD do Rio de Janeiro para o mercado do Rio de Janeiro, que agora começa a ser atendido pelo CD de Juiz de Fora. Um ponto de destaque está relacionado ao atendimento da demanda de São Paulo pelo $C D$ de Pouso Alegre, que não sofre alteração significativa de acordo com o aumento da sonegação. 
2. Aumento do volume movimentado na faixa de 250 a 499. Essa modificação foi ocasionada pelo aumento do volume do CD de Pouso Alegre para as regiões de São Paulo e do Rio de Janeiro. Ocorre o aumento do volume movimentado pelo $C D$ de Uberlândia para a região de Goiás.

3. Aumento do fluxo da Região de São Paulo para Goiás na faixa de 500 a 749 (as alíquotas interestaduais de São Paulo, Minas Geais e Rio de Janeiro são iguais e, o atendimento por Minas Gerias só aumentaria o custo logístico). A Região do Rio Grande do Sul perde movimentação interna, sendo atendido por centros de distribuição em Santa Catarina.

4. Aumento do fluxo dos centros de distribuição em Minas Gerais para a Região da Bahia na faixa de 750 a 999.

5. Redução do volume encontrada na faixa de 1500 a 1749. Essa modificação foi ocasionada pela modificação dos fluxos de atendimento da Região Nordeste. Esta região começa a ser atendida a partir da Região de Minas Gerias (principalmente pelo CD localizado em Teófilo Otoni, cuja capacidade foi aumentada), impactando no aumento do volume em faixas com maiores distâncias.

6. Aumento do volume movimentado na faixa de 1750 a 1999. Essa modificação é ocasionada pelo aumento no volume do fluxo do CD de Unaí para o Nordeste (Maranhão, Ceará, Piauí e Pernambuco). Ocorre também uma redução do número de CD's no Nordeste e consequentemente o volume movimentado aumenta nos fluxos com origem em Minas Gerias (vide, ).

As principais modificações nos fluxos da fábrica para o centro de distribuição por faixa de distância são: 
1. Aumento no volume movimentado na faixa de 0 a 249 quilômetros. Essa modificação é ocasionada pela utilização do CD de Pouso Alegre como ponto de transbordo. Isso pode ser verificado também na Tabela 7, onde a capacidade do CD de Pouso Alegre chega a 6. Por se tratar de uma localidade perto de São Paulo e localizado em outro Estado, Pouso Alegre se consolidou como um ponto de concentração de demanda.

2. Aumento do volume movimentado na faixa de 250 a 499 quilômetros. Essa modificação é ocasionada pelo grande volume enviado da fábrica de Goiânia para o CD de Unaí (vide, ).

3. Na faixa de 500 a 750 quilômetros, a fábrica de Joinville utiliza o CD de Pouso Alegre para fazer transbordo de mercadoria.

4. Na faixa de 750 a 999 quilômetros ocorre o deslocamento de alguns fluxos da fábrica de Joinville para Minas Gerias.

5. Na faixa de 1000 a 1249 quilômetros ocorre à transferência de alguns fluxos da fábrica de Goiânia que eram transferidos diretamente para o Rio de Janeiro e, com o aumento da sonegação, os fluxos são transferidos para o CD de Juiz de Fora. Os fluxos de São Paulo para o CD de Teófilo Otoni são intensificados com o aumento a sonegação.

6. Na faixa de 1500 a 1750 quilômetros ocorre uma transferência de um volume significativo da fábrica de Joinville para o CD de Teófilo Otoni, que passa a ser um ponto de transbordo para atender aos mercados no Nordeste.

7. A redução do volume na faixa de 1750 a 1999 quilômetros está relacionada à redução do volume de transferência de São Paulo para a Bahia, que passa a ser atendido por Minas Gerais. 
8. A redução dos volumes acima de 2000 quilômetros está relacionada à localização dos CD's. Quando não ocorre a influência do ICMS ( $0 \%$ de sonegação), a localização dos CD's fica mais próxima do mercado. $\mathrm{O}$ aumento do volume nas faixas com poucos quilômetros está relacionado à transferência de mercadorias para CD's mais perto (Minas Gerias) e, a redução do volume em faixas com grande distância está relacionada à redução de fluxos diretamente para o Nordeste. No anexo B se encontra um mapa de fluxos de origem e destino com nível de serviço. Cada cor representa uma distância de 250 quilômetros.

\subsection{Avaliação das alíquotas internas}

Outro ponto importante são as alíquotas internas de ICMS que no sistema tributário atual variam de $17 \%$ a $19 \%$. A reforma tributária modificará as alíquotas interestaduais para $2 \%$, porém ainda não se sabe se as alíquotas internas irão ser modificadas.

A diferença entre as alíquotas internas e interestaduais na reforma tributária poderá prejudicar empresas que possuem fluxos prioritariamente internos, ou seja, será necessário atender ao Estado a partir do Estado vizinho, criando outro tipo de movimento das instalações. O presente trabalho realizou uma simulação com diferentes alíquotas internas, cujo objetivo é avaliar o impacto desta diferença na rede logística. Os cenários simulados levaram em consideração os mesmos parâmetros e dados do cenário com reforma tributária, modificando somente as alíquotas internas.

Partindo-se da atual estrutura com alíquotas entre 17\% e 19\%, a simulação foi realizada para as alíquotas internas de $12 \%, 10 \%, 8 \%, 5 \%, 3 \%$ e 2\%. Para os cenários com alíquotas de $12 \%, 10 \%, 8 \%$ e $5 \%$, a rede logística não sofreu alteração e permaneceu idêntica ao cenário com alíquotas de 17\% e 19\% (atual proposta da reforma tributária, sendo que os autores consideram pouco provável a diminuição das atuais alíquotas internas). A rede logística sofreu alteração somente a partir da alíquota interna de $3 \%$. Com isso, os dados apresentados abaixo referenciam somente os cenários com alíquota de $3 \%$ e $2 \%$. 
A Figura 24 mostra o incremento do custo logístico para os cenários analisados. O cenário da reforma tributária com alíquota interna de $2 \%$ representa a rede logística sem influência do ICMS, pois a alíquota interestadual de $2 \%$ se iguala à alíquota interna de $2 \%$, anulando o efeito da mesma. O cenário com alíquota de $3 \%$ mostra uma estrutura próxima ao cenário ótimo.

A modificação da rede logística ocorrida no cenário com alíquota de 3\% pode ser melhor entendida ao se analisar a localização e a capacidade das instalações na Tabela 7. Neste cenário, Pouso Alegre que antes no cenário com a estrutura atual de ICMS e com reforma tributária era um ponto com capacidade elevada, sofreu descentralização dos fluxos e por consequência reduziu a capacidade instalada. Esta diferença é visível na Figura 24, ao se comparar o incremento de custo entre os cenários. A concentração dos fluxos, identificada na estrutura atual de ICMS e na reforma tributária, é justificada pelo aumento de $5 \%$ e $9 \%$ no custo logístico ao se comparar com o cenário com alíquota interna de $3 \%$.

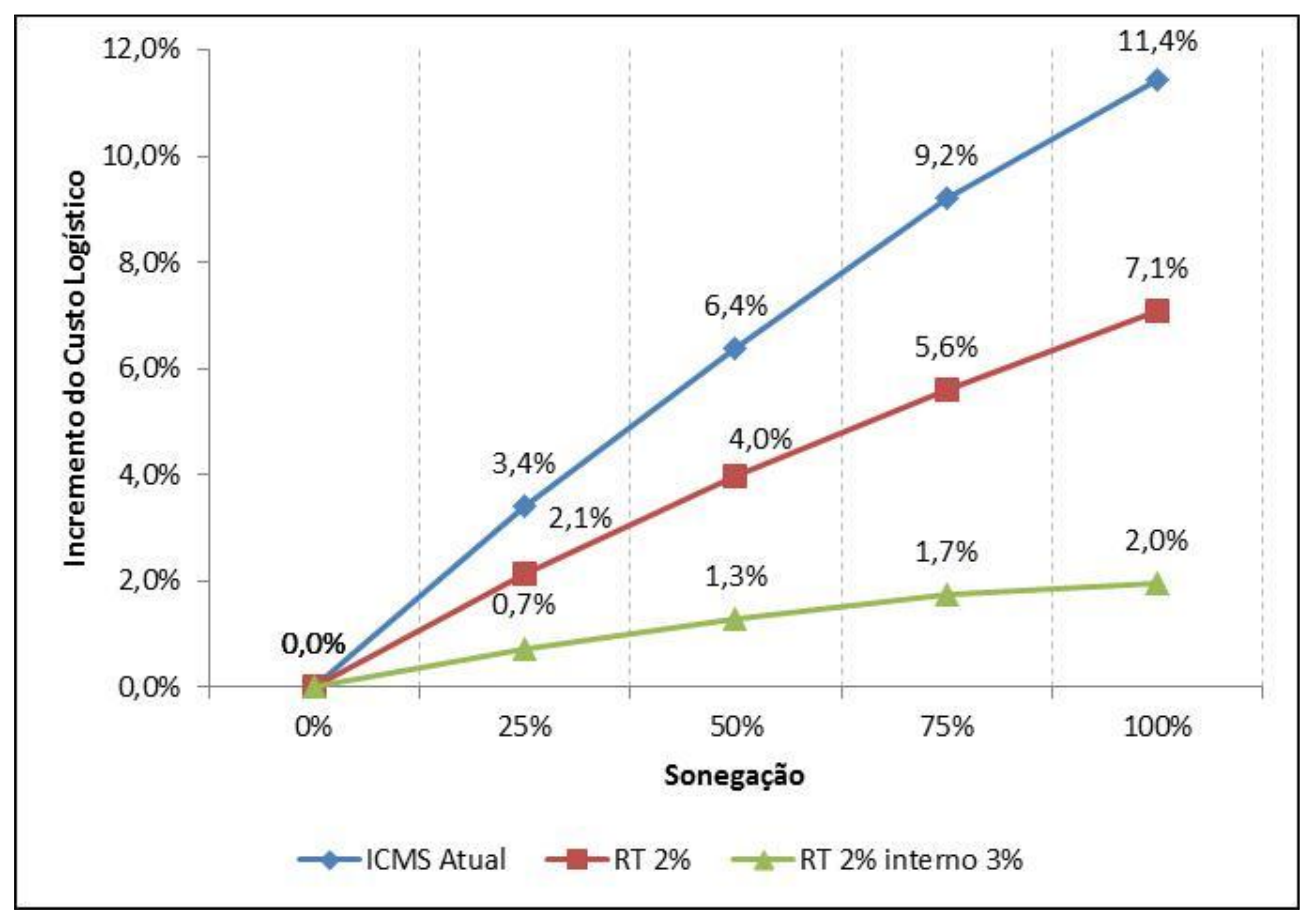

Figura 24: Aumento relativo do custo logístico 
Tabela 10: Localização e capacidade das instalações

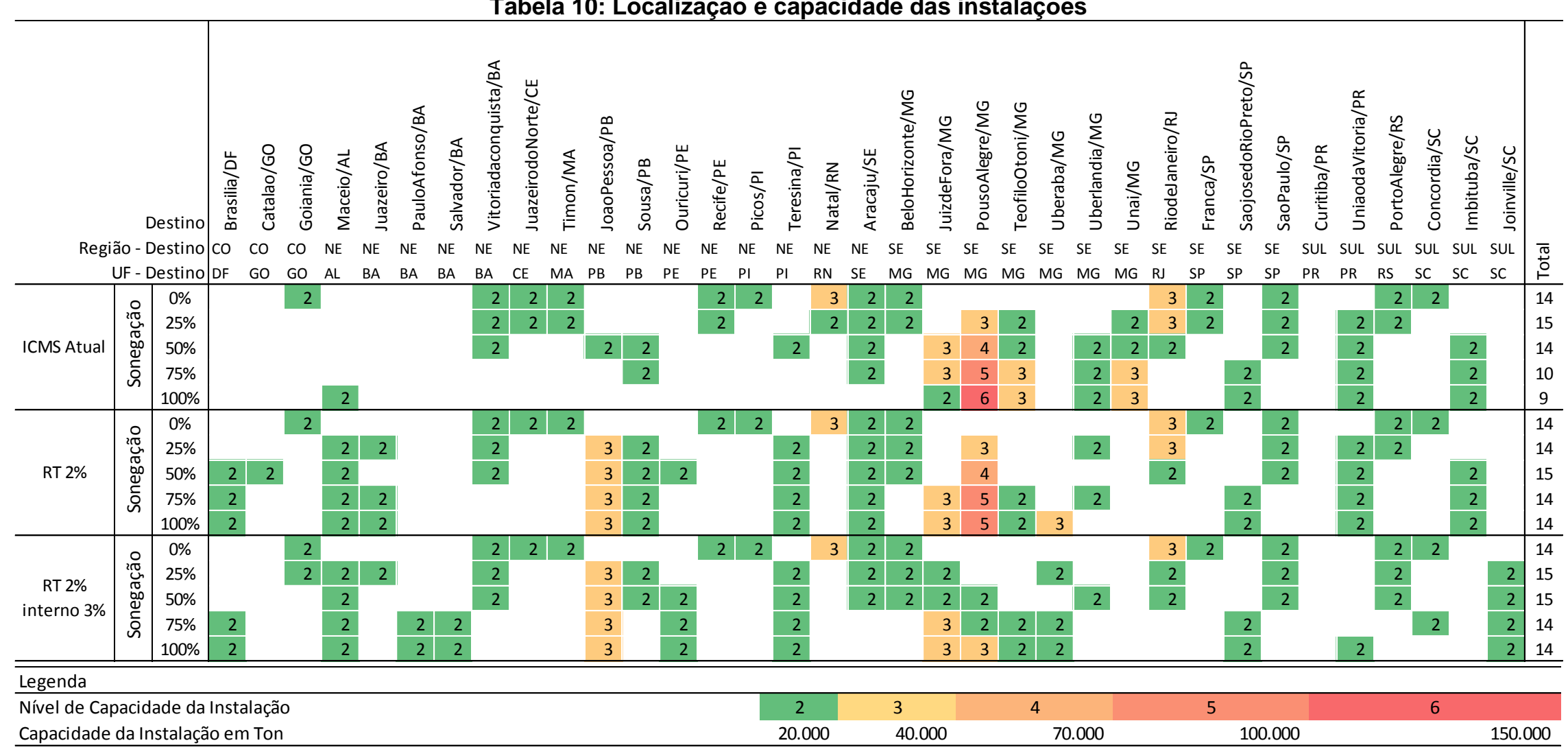


Outro ponto interessante é identificado ao se comparar os cenários com alíquota de $3 \%$ e $2 \%$. A rede logística sofreu significativa modificação somente com um acréscimo de $1 \%$ na alíquota interna, pois foi suficiente para alterar a solução ótima (fato bem conhecido em problemas de programação linear), mostrando a importância do ICMS na estruturação das redes logísticas. A Tabela 10 mostra a localização e as capacidades dos cenários analisados.

\subsection{Análise por produto e nível de serviço}

O nível de serviço é fator chave do conjunto de valores logísticos que as empresas oferecem a seus clientes para assegurar sua fidelidade, por isso é uma importante aliada da empresa na busca de novos mercados (BALLOU, 2006).

Bowersox e Closs (2001) definem o nível de serviço como a média e a variabilidade do tempo de preenchimento e entrega do pedido, a exatidão com que os pedidos são preenchidos, as condições com que os produtos chegam, a porcentagem de pedidos atrasados de cada fornecedor e o número de indisponibilidades resultantes de atrasos na produção.

Porém, a forma de estudar o nível de serviço é diferente de acordo com o produto e o cliente da empresa. Para Wanke, et al. (2009), clientes diferentes demandam níveis de serviço diferentes, portanto, a definição do nível de serviço adequado impacta diretamente na definição da localização das intalações, na capacidade, na definição dos fluxos de origem e destino e no custo logístico total.

A Tabela 5 mostra o nível de serviço utilizado de acordo com o tamanho da população para o estudo da malha logística brasileira. Para compreender o impacto dessa decisão de nível de serviço na modelagem realizada nesse estudo, a Figura 25 mostra a porcentagem de mesorregiões e suas respectivas demandas.

De acordo com a Figura $25,40 \%$ da demanda são destinadas a $7 \%$ das mesorregiões com população maior do que 3.000 .000 de habitantes. Para esse cenário, a restrição de nível de serviço foi de $500 \mathrm{~km}$. As mesorregiões com população de 
1.000.000 até 3.000.000 de habitantes (33\% do total de mesorregião) são responsáveis pelos outros $40 \%$ da demanda. Os $60 \%$ restantes do total de mesorregiões possuem até 1.000 .000 habitantes e correspondem a $20 \%$ da demanda total.

Figura 25: Relação entre a quantidade de mesorregiões e suas respectivas demandas

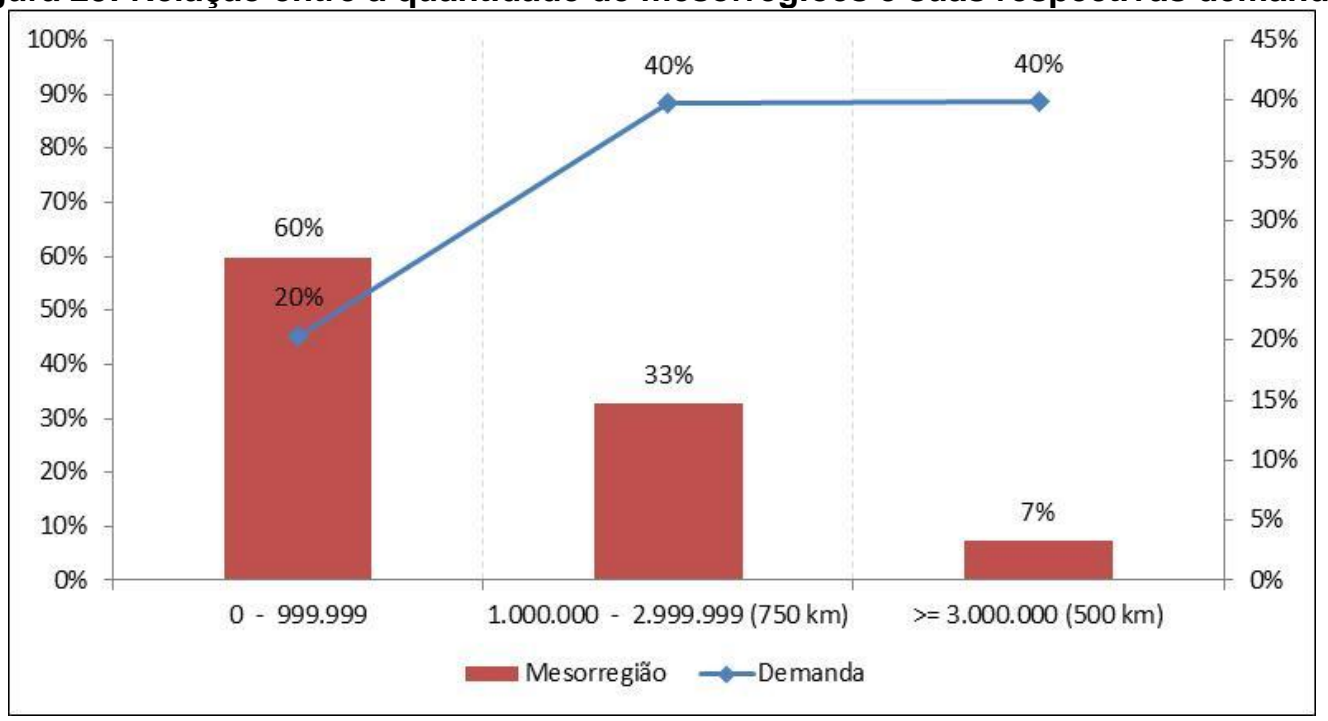

O entendimento dessa relação mostra que $80 \%$ da demanda é destinada a mesorregiões com algum tipo de restrição. Essa restrição impacta diretamente o custo logístico total.

Outro ponto observado no estudo de malha com ICMS é a concentração de fluxos no Estado de Minas Gerais. Por se tratar de um Estado com a posição geográfica favorável ao nível de serviço estabelecido $(500 \mathrm{~km}$ e $750 \mathrm{~km})$, os resultados encontrados sofreram influência do nível de serviço estabelecido, dificultando identificar o principal responsável pela concentração dos fluxos no Estado de Minas Gerias.

Para estudar o impacto do ICMS no planejamento de redes logística foi desenvolvida uma rede logística com quatro grandes fabricantes de produtos típicos de supermercado, situados em regiões diferentes (São Paulo, Joinville, Goiânia e Recife). Cada empresa, responsável por um tipo de produto, utiliza os centros de distribuição que são comuns a todas as empresas. Essa representação da malha logística construída proporciona uma compreensão dos impactos do ICMS por produto/região, visto que cada empresa está localizada em regiões distintas. 
Diante dessas dúvidas, foi necessário adicionar outros dois cenários, eliminando o nível de serviço da modelagem para os cenários com a estrutura atual de ICMS e reforma tributária.

Somente a partir dessa comparação será possível chegar a um entendimento dos principais fatores responsáveis pela modificação da localização e dos fluxos de origem e destino. O estudo do impacto da ICMS por região de distribuição proporciona a possibilidade de compreender qual região sofre maior impacto na modelagem de redes logísticas com ICMS. Além disso, a compreensão da influência do nível de serviço no planejamento de redes logísticas se mostra como um importante instrumento para evidenciar os principais conceitos da literatura até aqui estudados.

Para melhor compreender o impacto do nível do serviço e o impacto por produto/região no planejamento de redes, as análises realizadas seguiram os mesmo tópicos abordados na análise anterior, começando com a avaliação dos custos logísticos, seguido pela análise da localização e da capacidade das instalações.

Os cenários analisados foram:

1. Reforma tributária com alíquota interestadual de $2 \%$ (RT 2\%) com o nível de serviço estabelecido na metodologia do trabalho (Tabela 5).

2. Reforma tributária com alíquota interestadual de $2 \%$ (Sem NS - RT $2 \%$ ) sem nenhuma restrição de nível de serviço.

3. Estrutura atual de ICMS (ICMS Atual) com o nível de serviço estabelecido na metodologia do trabalho (Tabela 5).

4. Estrutura atual de ICMS (Sem NS - ICMS Atual) sem nenhuma restrição de nível de serviço.

\subsubsection{Avaliação dos custos logísticos}

O primeiro indicador analisado foi o incremento do custo logístico em relação ao nível de sonegação. A redução do nível de serviço proporcionou uma redução dos 
custos logísticos independente do cenário estudado (ICMS atual e reforma tributária). A Figura 26 mostra o incremento do custo logístico.

No cenário com $100 \%$ de sonegação, o incremento do custo logístico para a estrutura atual de ICMS modificou de 11,4\% para 10,7\%, uma diferença de 0,7\% em comparação ao cenário com restrição de nível de serviço. No cenário com a reforma tributária o incremento do custo logístico modificou de 7,1\% para 5,7\%, uma diferença de 1,4\% em comparação ao cenário com restrição de nível de serviço.

Figura 26: Comparação do custo logístico com e sem restrição de nível de serviço

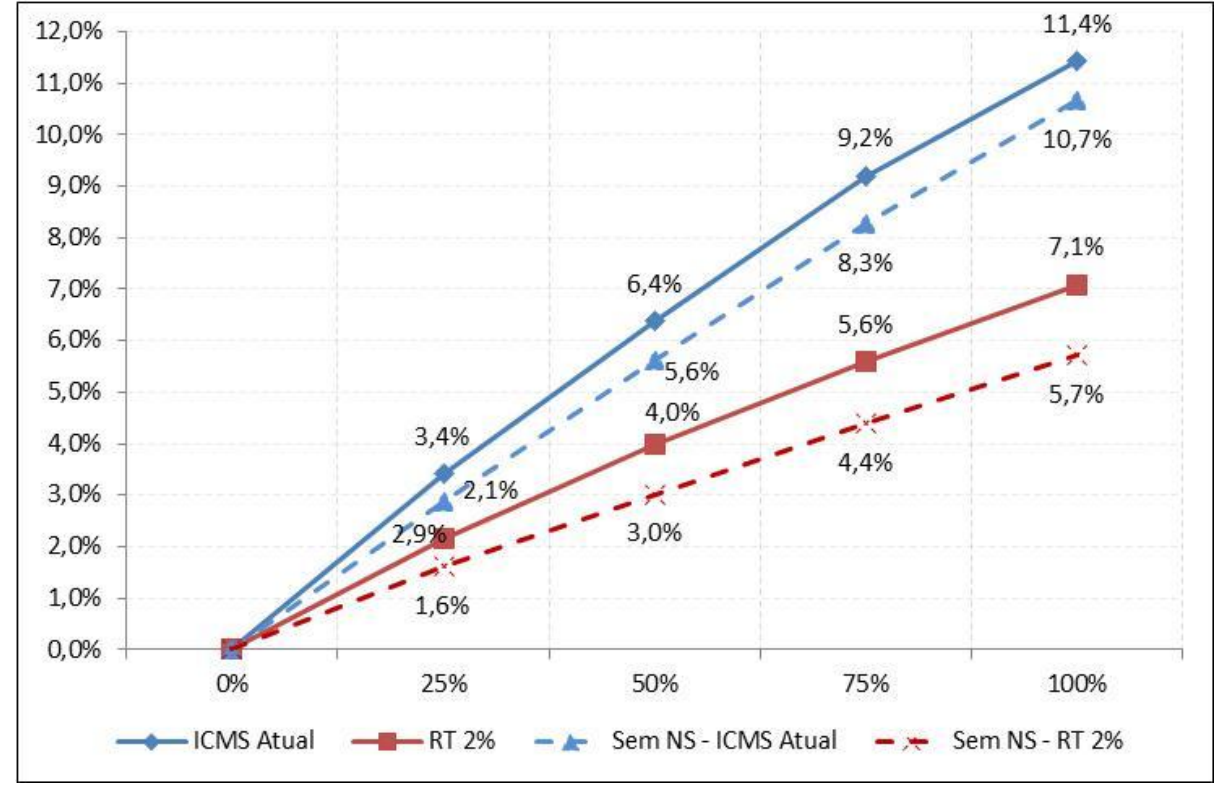

Para entender os motivos que conduzem a essa diferença, deve-se analisar o volume transportado em toneladas dos fluxos do CD para o mercado e o fluxo da fábrica para o mercado. A Figura 27 mostra a comparação do volume transportado no cenário com a estrutura atual de ICMS com nível de serviço (em vermelho) e sem nenhuma restrição de nível de serviço (em azul).

A modificação do nível de serviço alterou a proporção entre os fluxos da fábrica para o mercado e o fluxo do CD para o mercado. No cenário com nível de serviço a proporção era de $58 \%$ e $42 \%$ respectivamente ( $100 \%$ de sonegação) e no cenário sem restrição de nível de serviço essa proporção mudou para 76\% e $24 \%$ respectivamente. A proporção entre esses fluxos não sofreu alteração conforme a modificação da 
sonegação, porém a alteração do nível de serviço incentivou o fluxo direto (fábrica para o mercado), reduzindo assim o número total de CD's utilizados na malha.

Figura 27: Modificação do volume transportado em toneladas (ICMS Atual)

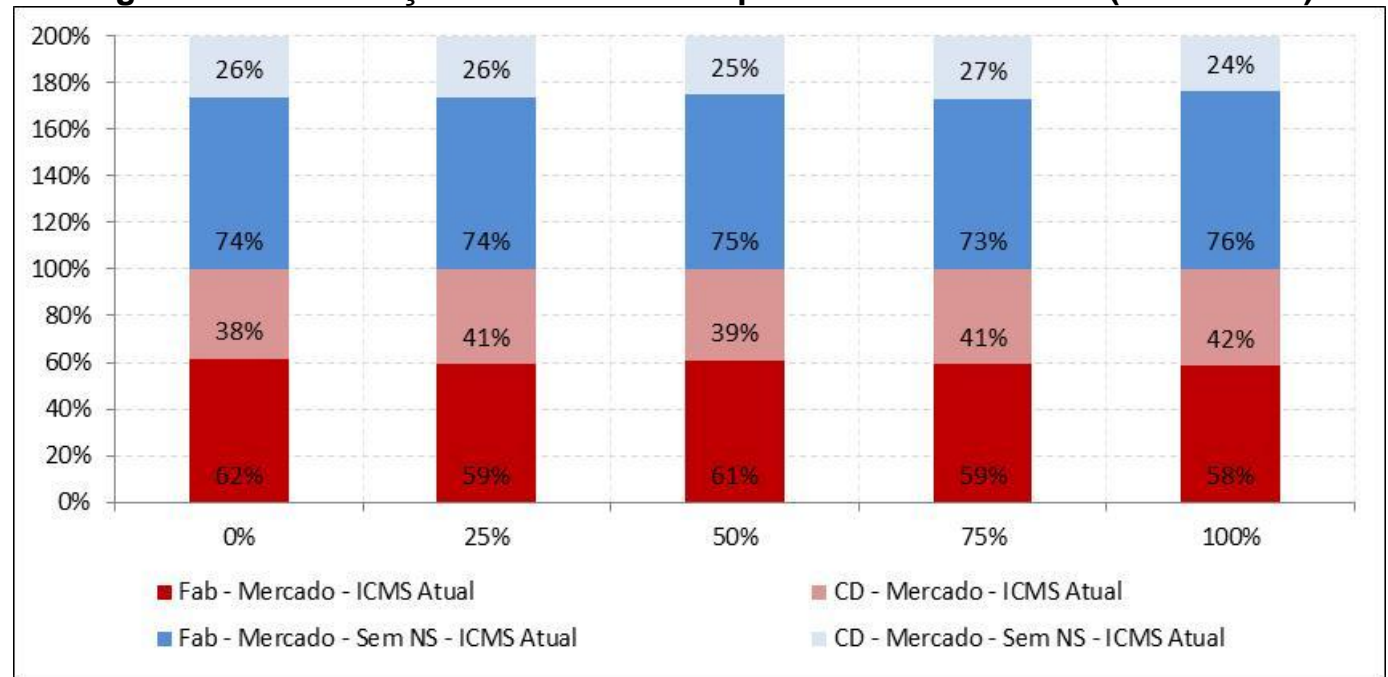

Esse efeito também é encontrado ao analisar os cenários com a reforma tributária (vide Figura 28), porém esse efeito é de menor intensidade. No cenário com $100 \%$ de sonegação, a proporção do fluxo direto e do fluxo do centro de distribuição para o mercado é de $50 \%$ e $50 \%$ respectivamente. Ao reduzir o nível de serviço, essa proporção modifica-se para $66 \%$ e $34 \%$ respectivamente. A alteração da sonegação não modificou significativamente a proporção entre esses fluxos.

Figura 28: Modificação do volume transportado em toneladas (RT 2\%)

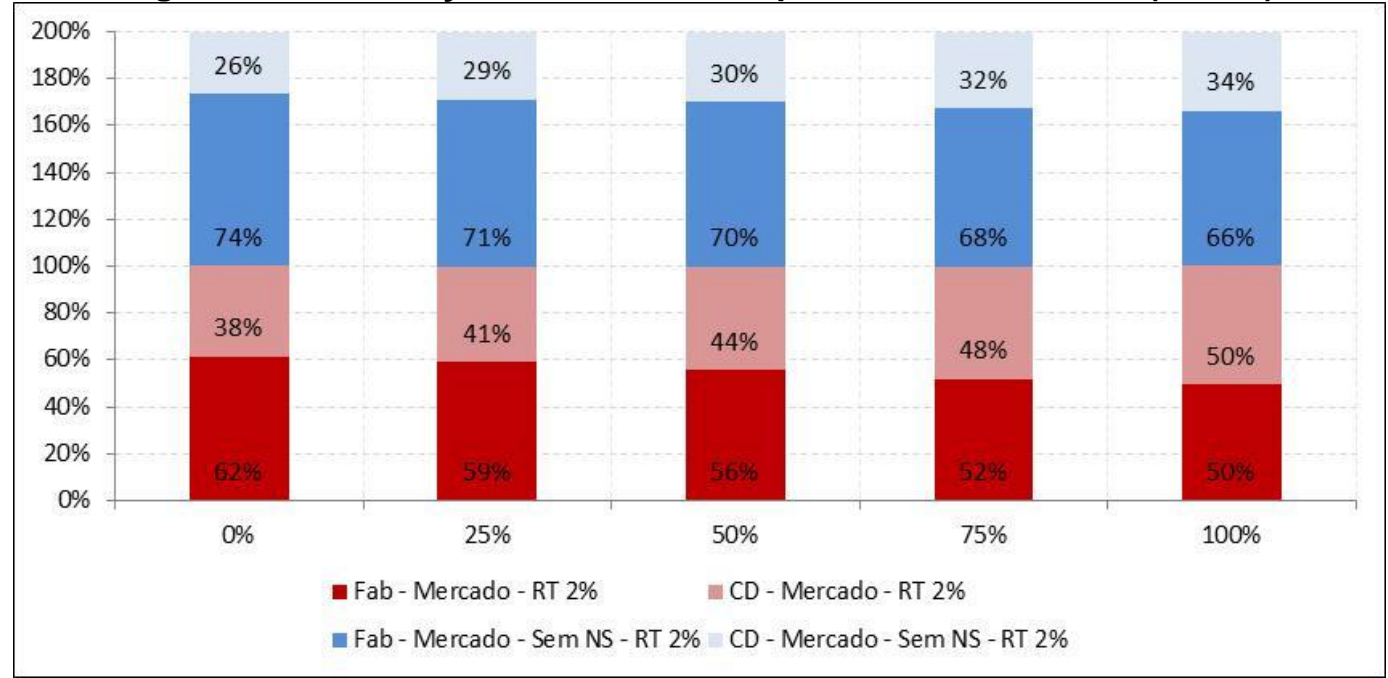


Essa alteração da proporção entre o fluxo direto e o fluxo do CD para o mercado impacta diretamente o custo de distribuição, transferência e fixo. A Figura 29 mostra o custo de distribuição, transferência e custo fixo para o cenário com a estrutura atual do ICMS. Percebe-se que a reta do custo de distribuição é "deslocada para cima", evidenciando um aumento do custo de distribuição em aproximadamente 15\% em comparação ao cenário com nível de serviço. Esse efeito é ocasionado pelo aumento do volume movimentado no fluxo da fábrica para o mercado.

Figura 29: Custo logístico com e sem restrição de nível de serviço - ICMS Atual

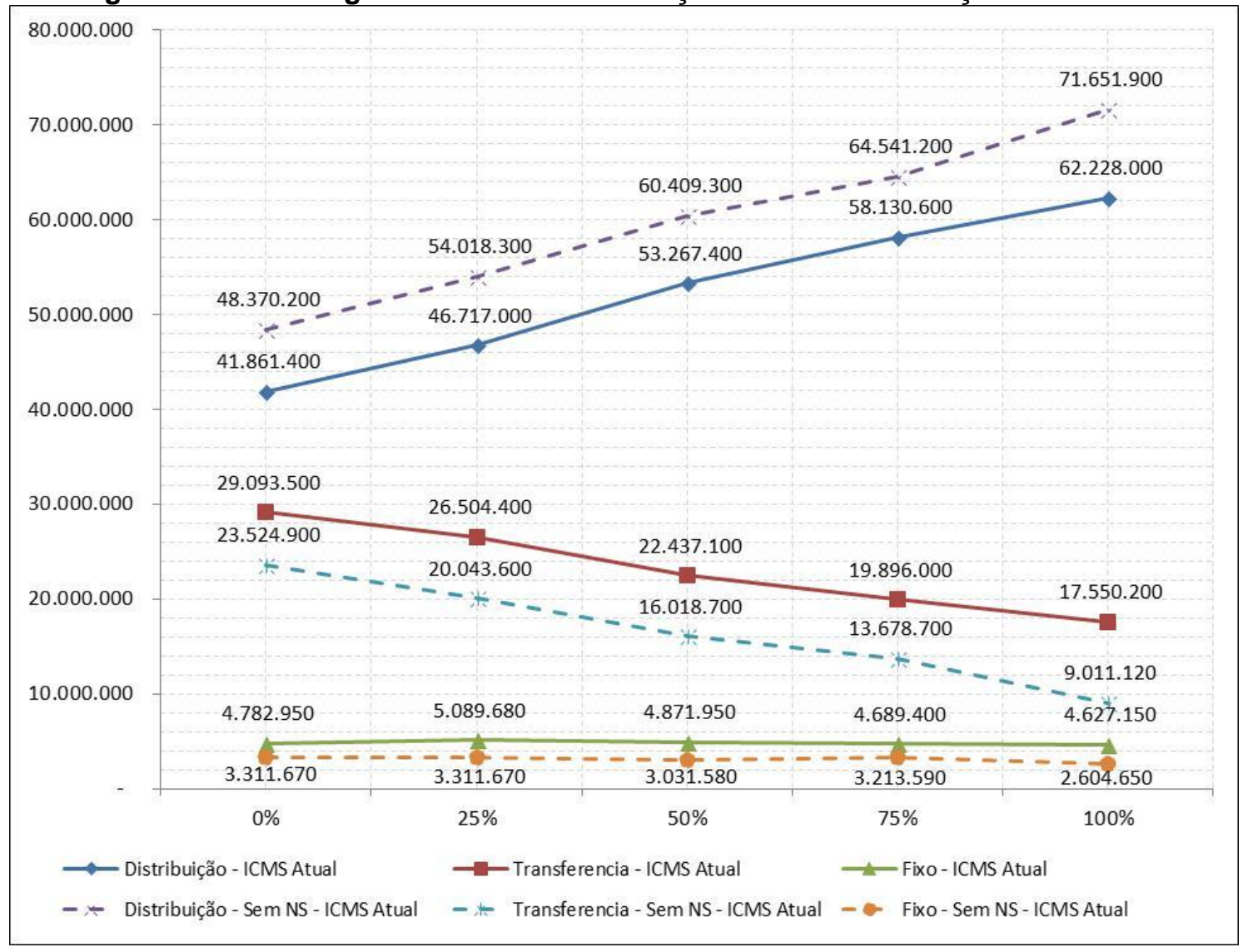

Em contrapartida, a reta do custo de transferência é "deslocada para baixo", evidenciando uma redução no custo de transferência. No cenário com 100\% de sonegação, o custo de transferência foi reduzido de $R \$ 17.550 .200$ para $R \$ 9.011 .120$, uma redução de aproximadamente $49 \%$. Essa diferença é ocasionada pela redução do volume transportado de $42 \%$ (cenário com nível de serviço) para $24 \%$ (cenário sem restrição de nível de serviço). A alteração no custo fixo está relacionada com a redução na quantidade de centros de distribuição utilizados. 
No cenário com a reforma tributária, percebe-se essa mesma relação de aumento do custo de distribuição e redução do custo de transferência. $O$ custo de distribuição aumentou de $\mathrm{R} \$ 45.788 .700$ no cenário com nível de serviço (100\% de sonegação) para $\mathrm{R} \$ 53.763 .300$ no cenário sem restrição de nível de serviço (100\% de sonegação). O custo de transferência reduziu de $R \$ 29.324 .200$ no cenário com nível de serviço para $R \$ 21.806 .600$ no cenário sem restrição de nível de serviço, uma redução de aproximadamente 25\%. A Figura 30 mostra os custos logísticos para 0 cenário RT 2\% (reforma tributária).

Figura 30: Custo logístico com e sem restrição de nível de serviço - RT 2\%

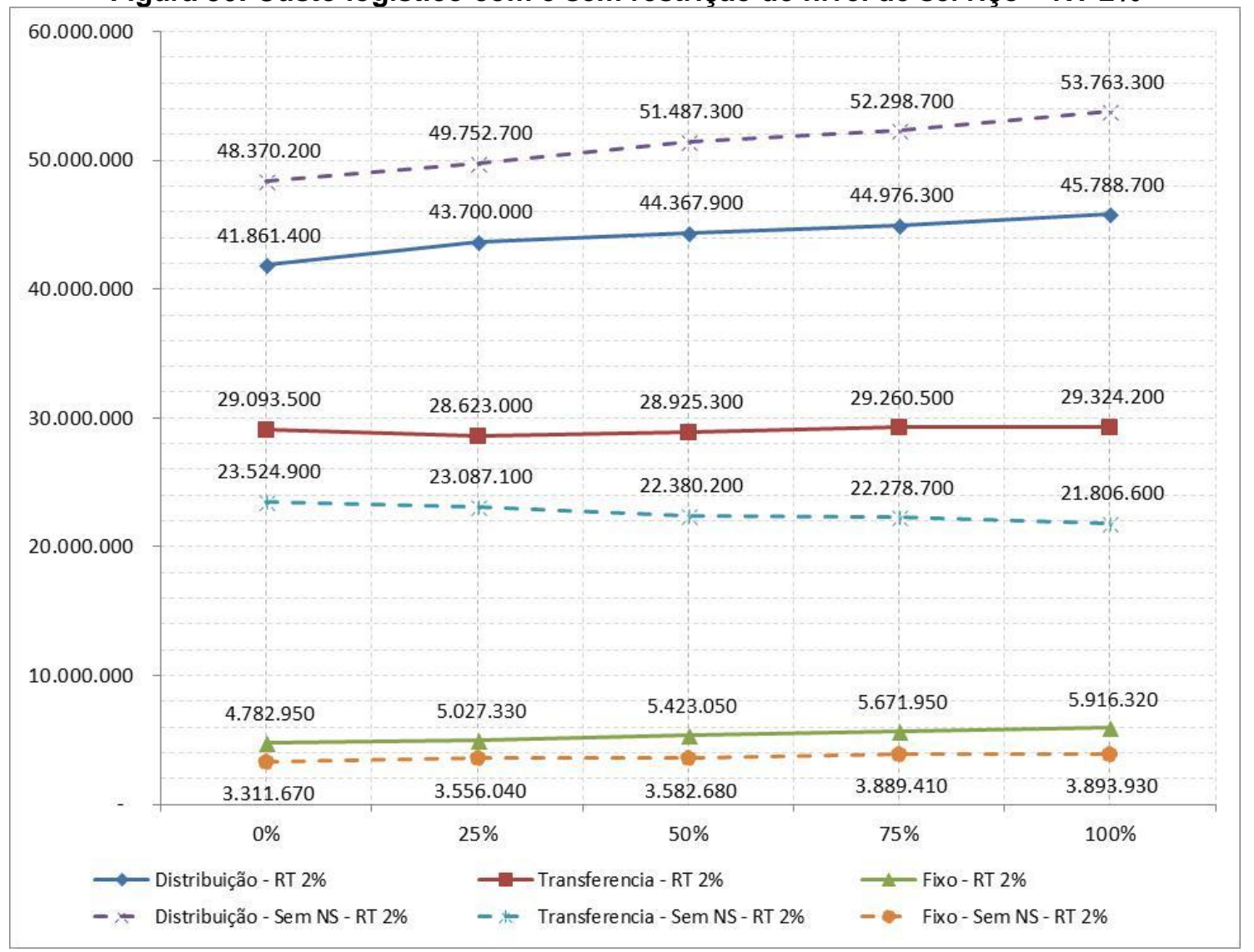

O impacto do nível de serviço no cenário com a reforma tributária foi menor que o impacto no cenário com a estrutura atual de ICMS, visto que o volume e o custo não foram modificados tanto quanto o volume e o custo logístico no cenário com a estrutura atual de ICMS. No cenário com a reforma tributária, a utilização de centros de distribuição foi maior do que no cenário com a estrutura atual de ICMS, sendo este um dos motivos para a diferença entre o custo e o volume transportado por fluxo em cada 
um dos cenários. O Anexo C mostra a tabela com os custos logísticos absolutos e relativos.

\subsubsection{Avaliação da localização e da capacidade das instalações}

A localização das instalações proporciona uma compreensão do impacto do nível de serviço no planejamento de redes. A comparação da diferença entre a localização nos cenários com e sem a influência do nível de serviço, esclarece quais localizações são necessariamente utilizadas independente do nível de serviço. A Figura 31 mostra a quantidade e a localização de instalações por região.

No cenário com a estrutura atual do ICMS, o primeiro ponto a observar é o cenário com $0 \%$ de sonegação (ótimo logístico). A quantidade de instalações é modificada de 14 instalações (com nível de serviço) para 10 instalações (sem restrição de nível de serviço), alterando o cenário de comparação. Essa diferença mostra que instalações localizadas no Rio de Janeiro, Santa Catarina e Goiás somente são utilizadas por causa do nível de serviço, porém o Estado de Minas Gerais ainda permanece como um Estado concentrador de centros de distribuição. No cenário com $100 \%$ de sonegação (sem restrição de nível de serviço), o Estado de Minas Gerias concentra 3 instalações de um total de 4 instalações.

O cenário com a reforma tributária e $0 \%$ de sonegação é exatamente igual ao cenário com a estrutura atual de ICMS, visto que não ocorre influência do ICMS. Ao retirar a restrição de nível de serviço no cenário com a reforma tributária, não ocorre uma redução da quantidade de instalações no mesmo grau que ocorre no cenário com a estrutura atual de ICMS. A descentralização proporcionada pela reforma tributária, conclusão sustentada no capitulo anterior, ocorre na mesma proporção quando comparado ao cenário com nível de serviço. 
Figura 31: Quantidade de instalações por região

\begin{tabular}{|c|c|c|c|c|c|c|c|c|c|c|c|c|c|c|c|c|c|c|c|c|c|c|c|c|c|}
\hline & & & \multicolumn{4}{|c|}{ Região - Destino } & & \multicolumn{18}{|c|}{ UF - Destino } \\
\hline & & & SUL & SE & $\mathrm{NE}$ & $\mathrm{CO}$ & Total & DF & $\mathrm{GO}$ & $\mathrm{AL}$ & BA & $C E$ & MA & PB & $P E$ & $\mathrm{PI}$ & $\mathrm{RN}$ & SE & MG & $\mathrm{RJ}$ & SP & $\mathrm{PR}$ & RS & $\mathrm{SC}$ & Total \\
\hline \multirow{5}{*}{ ICMS Atual } & \multirow{5}{*}{$\begin{array}{l}0 \\
2 \pi \\
\mathbb{W} \\
\mathbb{0} \\
\infty \\
0 \\
0 \\
0\end{array}$} & $0 \%$ & 2 & 4 & 7 & 1 & 14 & & 1 & & 1 & 1 & 1 & & 1 & 1 & 1 & 1 & 1 & 1 & 2 & & 1 & 1 & 14 \\
\hline & & $25 \%$ & 2 & 7 & 6 & & 15 & & & & 1 & 1 & 1 & & 1 & & 1 & 1 & 4 & 1 & 2 & 1 & 1 & & 15 \\
\hline & & $50 \%$ & 2 & 7 & 5 & & 14 & & & & 1 & & & 2 & & 1 & & 1 & 5 & 1 & 1 & 1 & & 1 & 14 \\
\hline & & $75 \%$ & 2 & 6 & 2 & & 10 & & & & & & & 1 & & & & 1 & 5 & & 1 & 1 & & 1 & 10 \\
\hline & & $100 \%$ & 2 & 6 & 1 & & 9 & & & 1 & & & & & & & & & 5 & & 1 & 1 & & 1 & 9 \\
\hline \multirow{5}{*}{$\begin{array}{c}\text { Sem NS - } \\
\text { ICMS Atual }\end{array}$} & \multirow{5}{*}{ 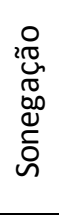 } & $0 \%$ & 1 & 2 & 7 & & 10 & & & & 1 & 1 & 1 & & 1 & 1 & 1 & 1 & 1 & & 1 & & 1 & & 10 \\
\hline & & $25 \%$ & 1 & 3 & 6 & & 10 & & & & 1 & 1 & 1 & & 1 & & 1 & 1 & 3 & & & 1 & & & 10 \\
\hline & & $50 \%$ & 1 & 3 & 4 & & 8 & & & 1 & 1 & & & & & 1 & 1 & & 3 & & & 1 & & & 8 \\
\hline & & $75 \%$ & 1 & 4 & 2 & & 7 & & & 1 & & & & & & 1 & & & 4 & & & 1 & & & 7 \\
\hline & & $100 \%$ & 1 & 3 & & & 4 & & & & & & & & & & & & 3 & & & 1 & & & 4 \\
\hline \multirow{5}{*}{ RT 2\% } & \multirow{5}{*}{ 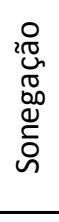 } & $0 \%$ & 2 & 4 & 7 & 1 & 14 & & 1 & & 1 & 1 & 1 & & 1 & 1 & 1 & 1 & 1 & 1 & 2 & & 1 & 1 & 14 \\
\hline & & $25 \%$ & 2 & 5 & 7 & & 14 & & & 1 & 2 & & & 2 & & 1 & & 1 & 3 & 1 & 1 & 1 & 1 & & 14 \\
\hline & & $50 \%$ & 2 & 4 & 7 & 2 & 15 & 1 & 1 & 1 & 1 & & & 2 & 1 & 1 & & 1 & 2 & 1 & 1 & 1 & & 1 & 15 \\
\hline & & $75 \%$ & 2 & 5 & 6 & 1 & 14 & 1 & & 1 & 1 & & & 2 & & 1 & & 1 & 4 & & 1 & 1 & & 1 & 14 \\
\hline & & $100 \%$ & 2 & 5 & 6 & 1 & 14 & 1 & & 1 & 1 & & & 2 & & 1 & & 1 & 4 & & 1 & 1 & & 1 & 14 \\
\hline \multirow{5}{*}{$\begin{array}{c}\text { Sem NS - } \\
\text { RT 2\% }\end{array}$} & \multirow{5}{*}{ 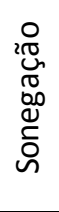 } & $0 \%$ & 1 & 2 & 7 & & 10 & & & & 1 & 1 & 1 & & 1 & 1 & 1 & 1 & 1 & & 1 & & 1 & & 10 \\
\hline & & $25 \%$ & 1 & 2 & 6 & 1 & 10 & 1 & & 1 & 1 & & & 2 & 1 & 1 & & & 2 & & & 1 & & & 10 \\
\hline & & $50 \%$ & 1 & 1 & 6 & 1 & 9 & 1 & & 1 & 2 & & & 2 & & 1 & & & 1 & & & 1 & & & 9 \\
\hline & & $75 \%$ & 1 & 2 & 6 & 1 & 10 & 1 & & 1 & 2 & & & 2 & & 1 & & & 2 & & & 1 & & & 10 \\
\hline & & $100 \%$ & 1 & 1 & 6 & 1 & 9 & 1 & & 1 & 1 & & & 2 & & 1 & & 1 & 1 & & & 1 & & & 9 \\
\hline
\end{tabular}


É possível concluir que a reforma tributária irá descentralizar a localização das instalações, contudo, o efeito de centralização das instalações no Estado de Minas Gerais, encontrado no cenário com nível de serviço, era proporcionado pelo nível de serviço e não por causa do ICMS.

A diferença entre os custos fixos é justificada pela diferença na quantidade de centros de distribuição. A expressiva diferença entre o custo de transferência no cenário com a estrutura atual de ICMS é justificada pela redução significativa do volume movimentado pelo fluxo do centro de distribuição para o mercado. Contudo, a utilização de 9 instalações (100\% de sonegação) no cenário com a reforma tributária justifica a pequena diferença entre o custo de transferência nos cenários com e sem restrição de nível de serviço.

De forma mais detalhada, a Figura 32 mostra a localização e a capacidade das instalações. O detalhamento desta análise mostra que regiões como Pouso Alegre, Teófilo Otoni e Unaí são regiões que independente do nível de serviço são utilizadas como ponto de triangulação no cenário com a estrutura atual de ICMS. No cenário com a reforma tributária, somente Pouso Alegre é utilizado quando o nível de serviço é reduzido. A quantidade de instalações na Região Sudeste também é reduzida, evidenciando que algumas localizações são utilizadas devido à restrição de nível de serviço. 


\section{Figura 32: Localização e capacidade das instalações}

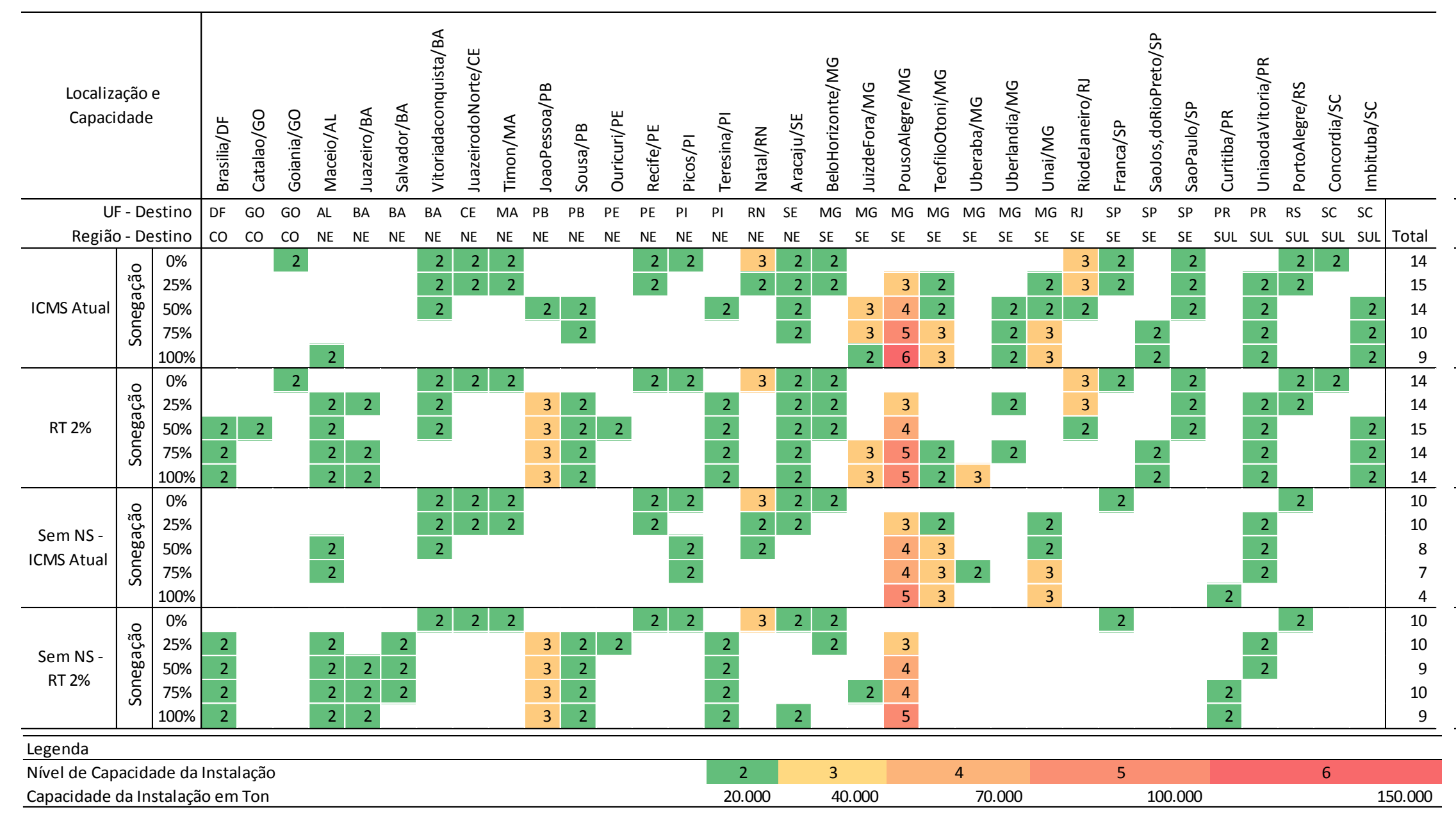




\subsubsection{Avaliação por produto}

A forma pelo qual o estudo foi construído, utilizando 4 diferentes empresas em 4 localizações diferentes, proporciona uma oportunidade de analisar cada uma das empresas e compreender o impacto do nível de serviço e do ICMS em cada rede individualmente. O total da demanda (832.294 toneladas) foi assim dividido:

1. São Paulo: sabão em pó, detergente, amaciante, bolachas e biscoitos, massas alimentícias (430.783 $\mathrm{t}-52 \%)$;

2. Joinville: óleo de cozinha (215.029 t $-26 \%)$;

3. Goiânia: extrato de tomate, molho de tomate, purê de tomate, conserva em lata e maionese. (127.707 $t-15 \%)$;

4. Recife: shampoo e sabonete. (58.775 $t-7 \%)$;

A análise do volume movimentado por fluxo e por produto em cada cenário (Figura 33) ajuda a entender o comportamento de cada rede de acordo com a alteração do nível de serviço e do ICMS. Essa figura está dividida 2 duas partes: a primeira parte mostra a rede estudada para o cenário com a estrutura atual de ICMS (com e sem restrição de nível de serviço) e a segunda parte mostra a mesma rede para a reforma tributária (com e sem restrição de nível de serviço).

Essa figura proporciona uma rápida visualização das modificações entre os cenários. A análise horizontal permite comparar os cenários com a estrutura atual de ICMS e a reforma tributária e a análise vertical permite comparar os cenários com e sem restrição de nível de serviço.

A porcentagem está relacionada ao volume total movimentado do produto por tipo de fluxo (CD para o mercado e fábrica para o mercado). Além disso, foi utilizada uma escala de "temperatura", facilitando a identificação dos valores extremos. A Figura 34 mostra os mapas de fluxo por produto e cenários (ICMS Atual e reforma tributária). 
Figura 33: Análise do volume movimentado por fluxo e por produto.

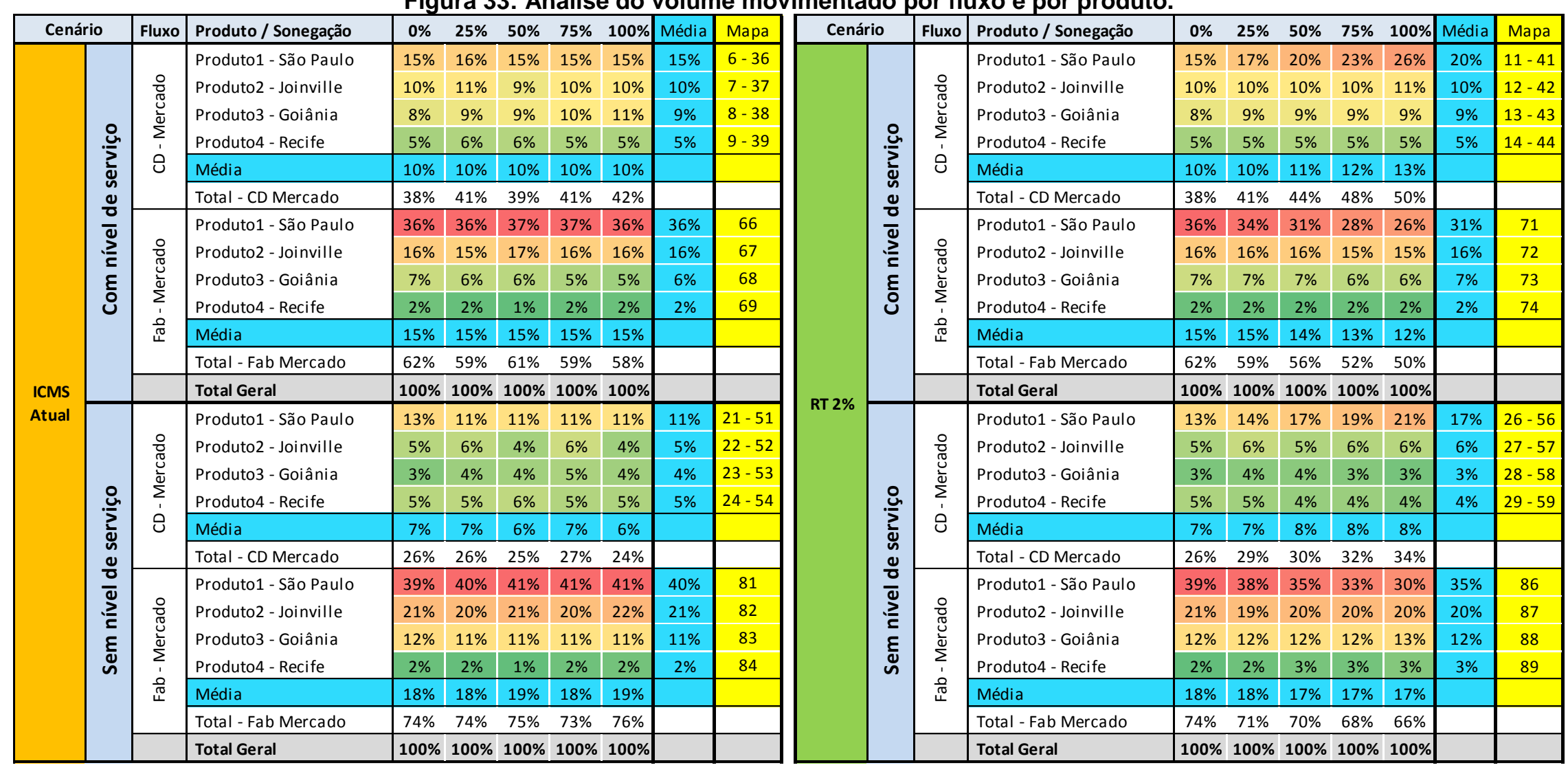


Figura 34: Mapas de fluxos por produto e cenário

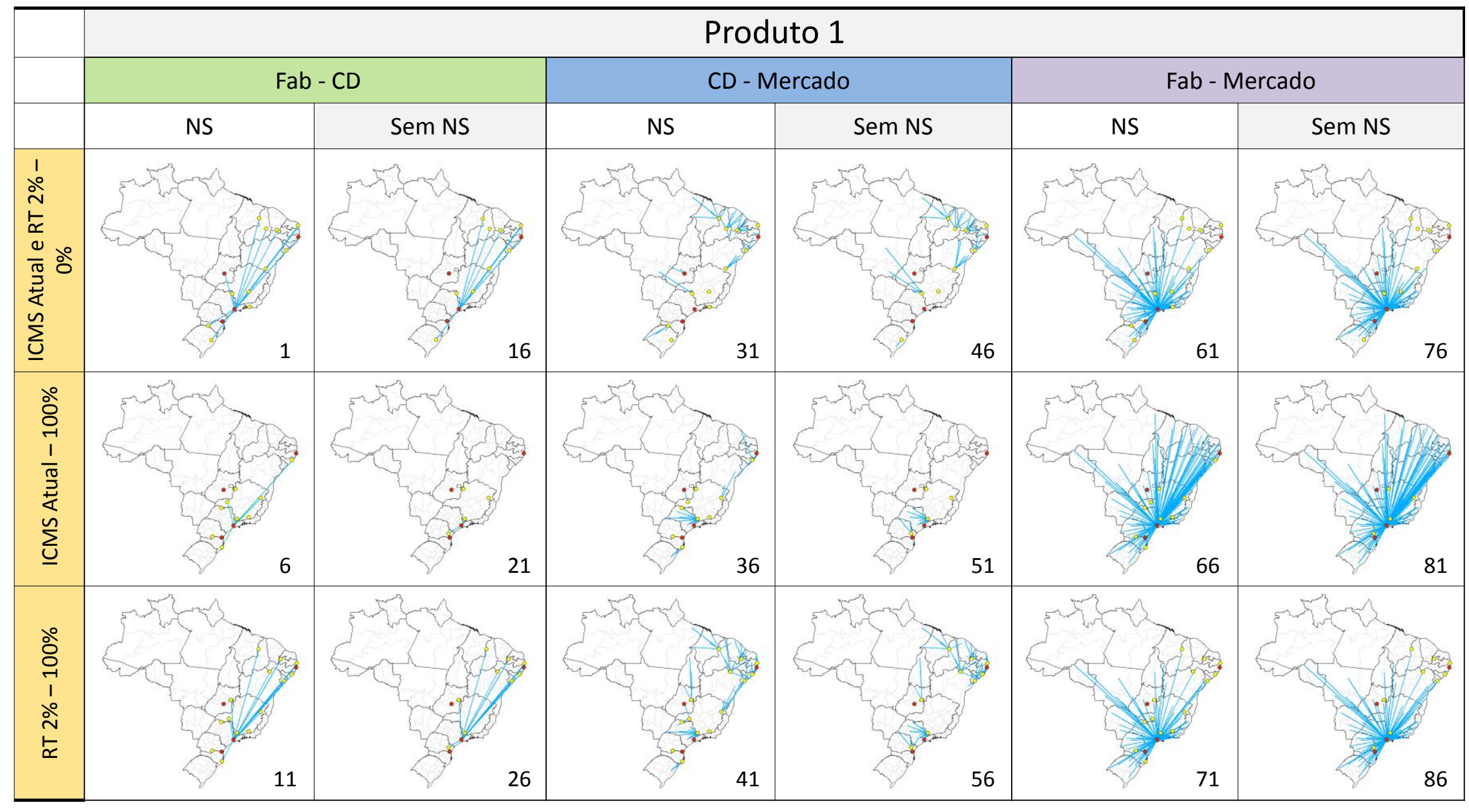


Figura 34: Mapas de fluxos por produto e cenário

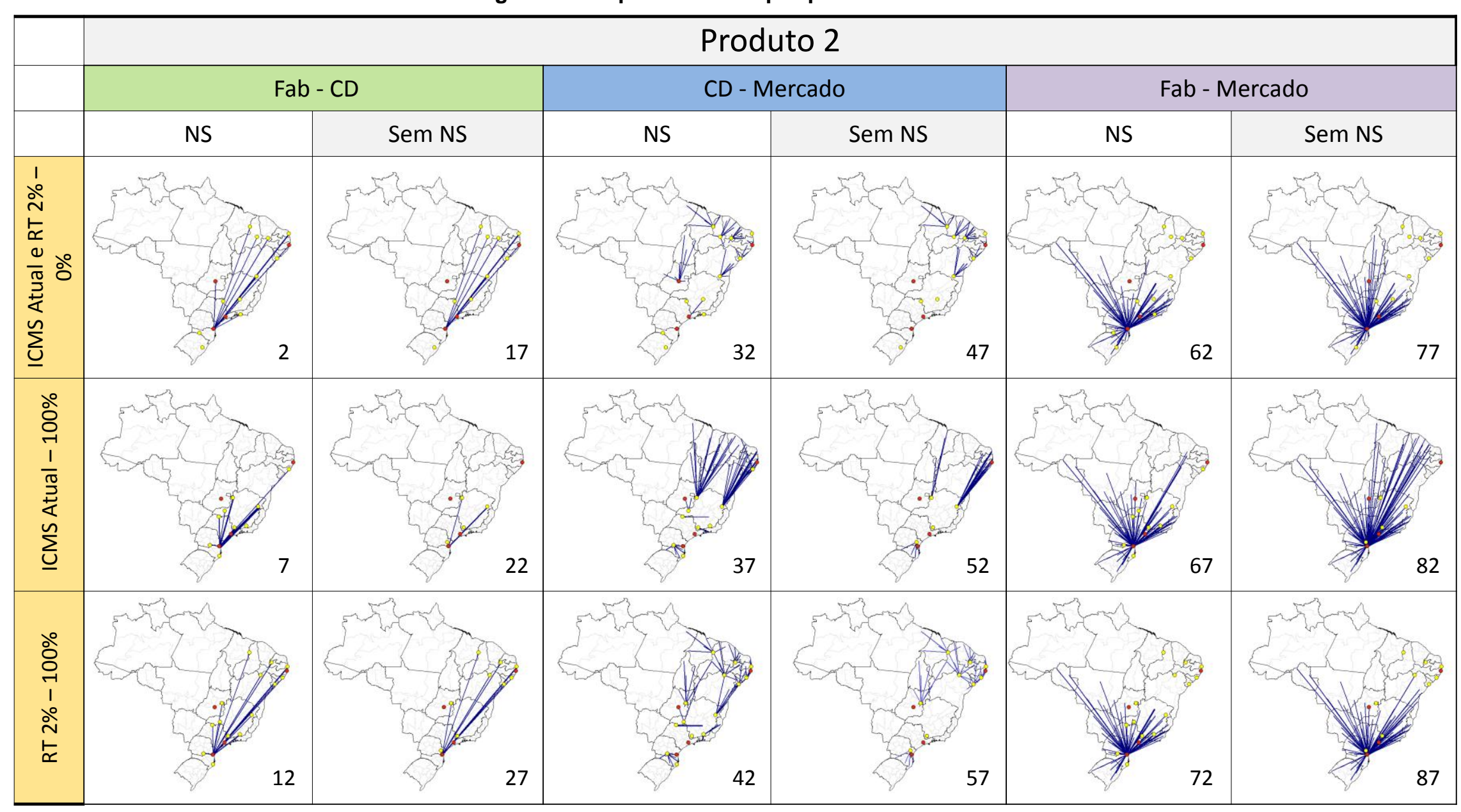


Figura 34: Mapas de fluxos por produto e cenário

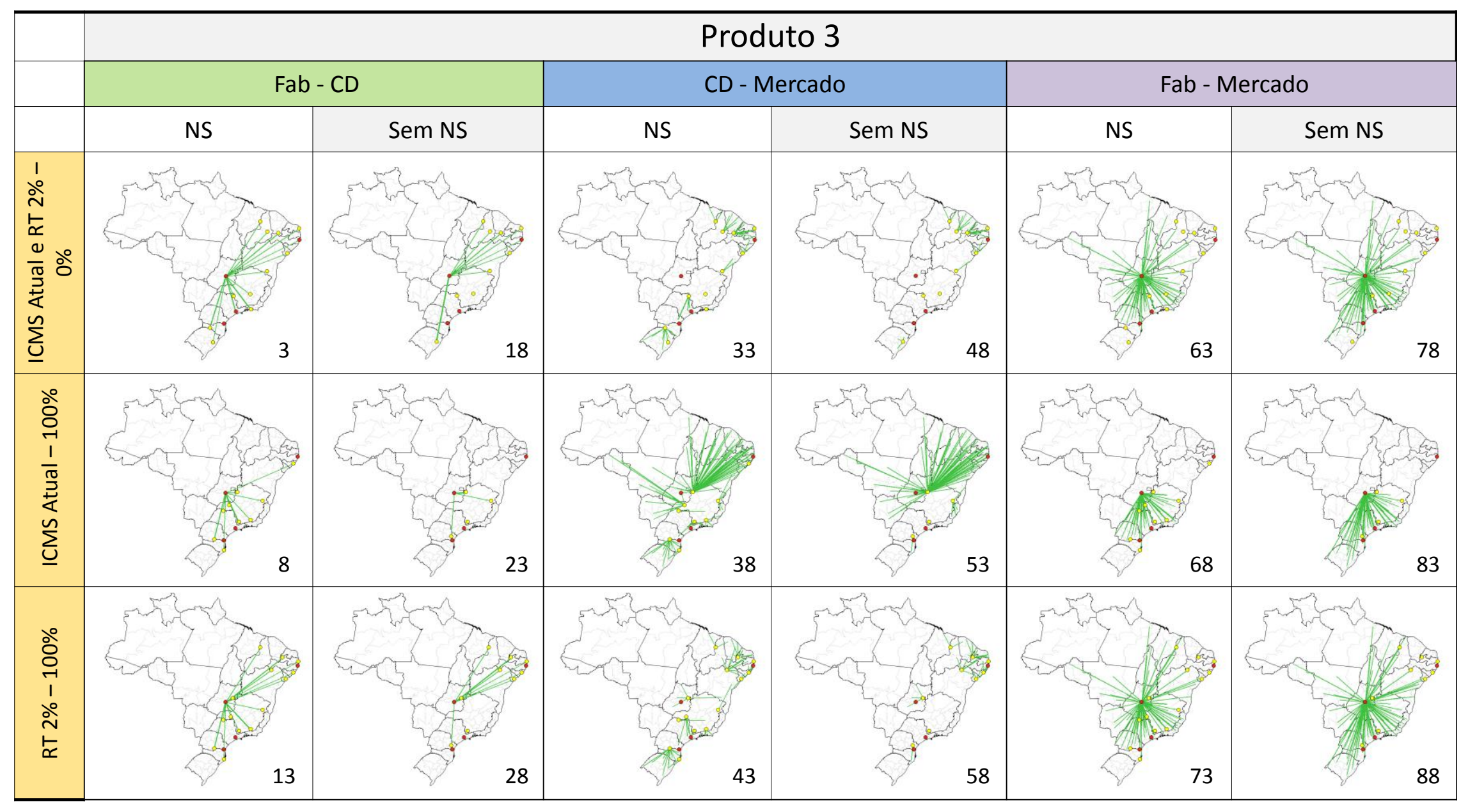


Figura 34: Mapas de fluxos por produto e cenário

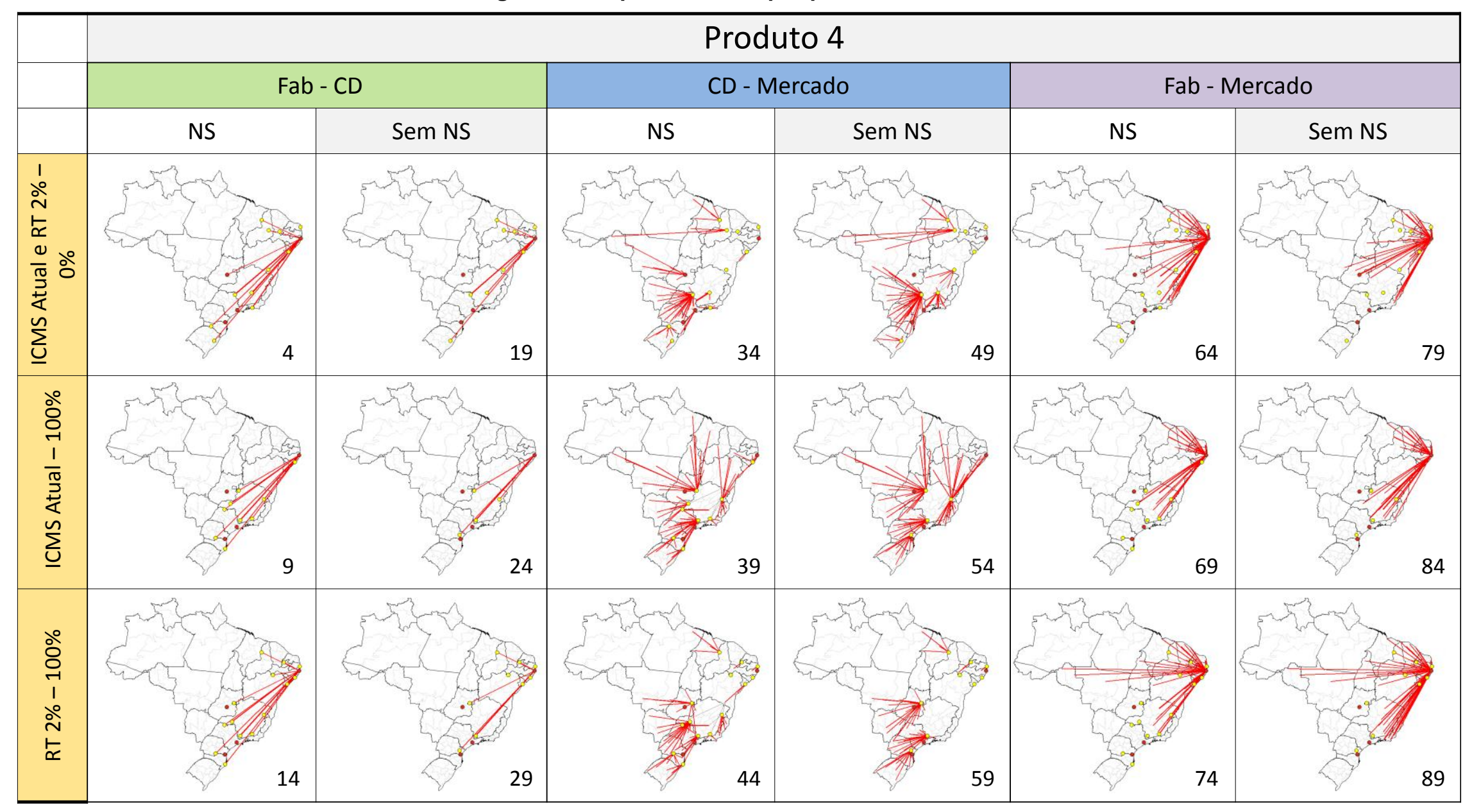


Figura 34: Mapas de fluxos por produto e cenário

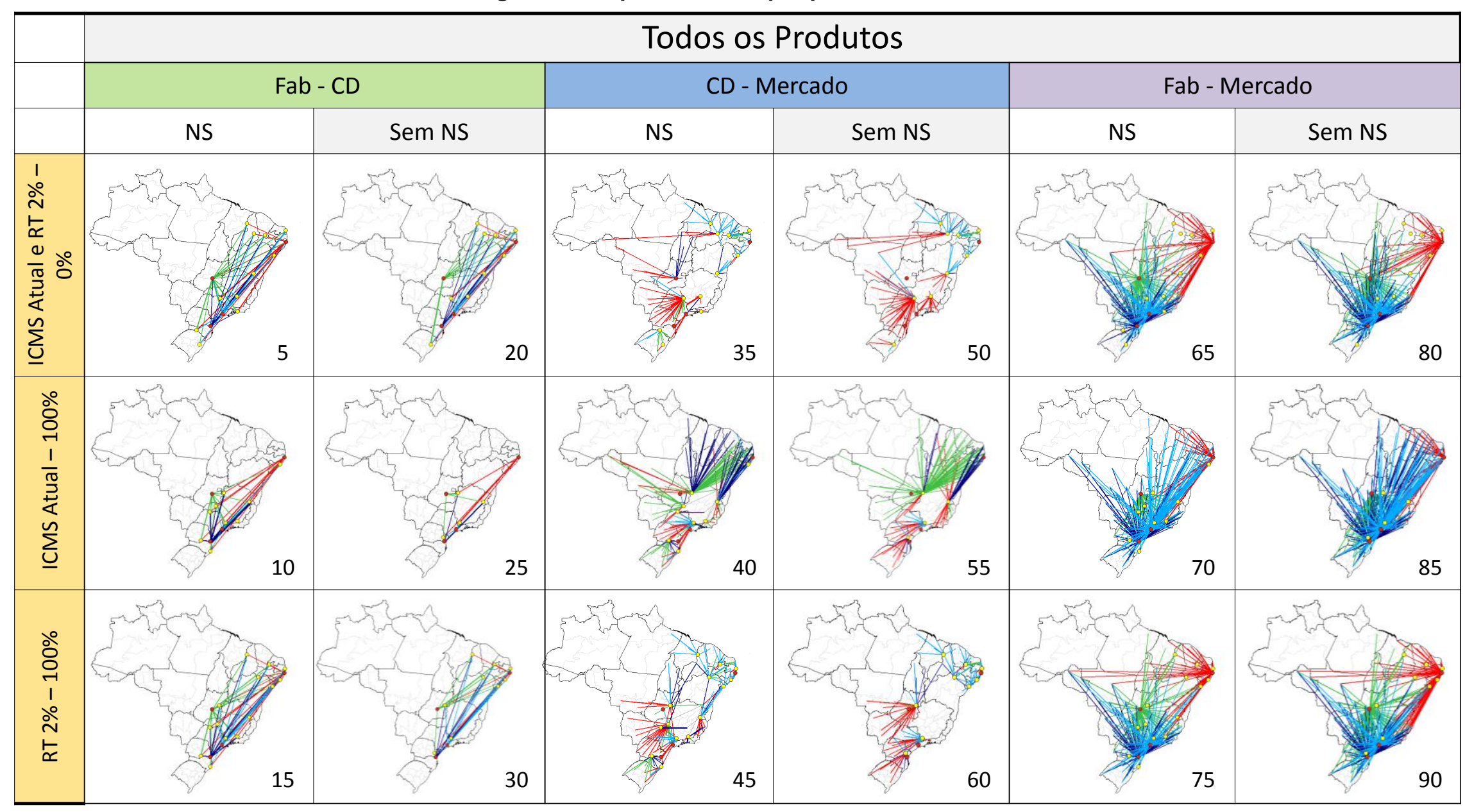


A Figura 33 e a Figura 34 devem ser analisadas juntas, permitindo assim uma melhor compreensão dos motivos que ocasionam as mudanças nos volumes dos fluxos por cenário. Todos os mapas da Figura 34 estão numerados para facilitar a localização dos mapas e respectivos fluxos. A Figura 33 contém uma coluna chamada mapa (em amarelo) contendo as numerações dos mapas de acordo com cada fluxo.

A Figura 33 permite analisar o fluxo do produto $1 \mathrm{em}$ diferentes perspectivas. Ao comparar o volume transportado por fluxo nos cenários com o ICMS Atual e a reforma tributária (análise horizontal) é possível compreender que o fluxo do CD para o mercado é incentivado, chegando a uma diferença de $11 \%$ no volume transportado no cenário com $100 \%$ de sonegação.

A justificativa para a alteração de $11 \%$ no volume transportado está na descentralização ocasionada pela reforma tributária, ou seja, a Região Nordeste começa a receber mais centros de distribuição e consequentemente a demanda das mesorregiões do Nordeste começam a ser atendidos por centros de distribuição localizados no Nordeste, incentivando a utilização do fluxo CD para o Mercado.

A Figura 34 (mapa 36 e 41) permite visualizar a alteração da rede do produto 1 para os cenários com a estrutura atual do ICMS e para a reforma tributária. Ao analisar os mapas fica evidente o melhor aproveitamento do fluxo CD para o Mercado. A Figura 34 (mapa 6 e 11) mostra o fluxo da fábrica para os centros de distribuição, evidenciando o aumento do fluxo de transferência para os centros de distribuição localizados no Nordeste. A alteração do nível de serviço não modifica significativamente o volume nos fluxos de transferência e entrega direta, essa relação é evidenciada na Figura 34 (mapa 36 e 51) e na Figura 34 (mapa 41 e 56).

O fluxo da fábrica para o mercado da rede logística do produto 1 é desestimulada ao modificar o cenário da estrutura atual de ICMS para a reforma tributária, porém o fluxo é incentivado ao modificar o nível de serviço. A Figura 34 (mapa 66, 71, 81 e 86) mostra a alteração da rede logística para o fluxo da fábrica para o mercado nos diferentes cenários analisados. 
O comportamento da rede logística do produto 2 (Joinville) é diferente da rede logística do produto 1. A modificação do cenário com a estrutura atual de ICMS para a reforma tributária não altera significativamente a proporção do volume movimentado no fluxo de transferência, Figura 34 (mapa 37 e 42) e no fluxo de entrega direta, Figura 34 (mapa 67 e 72). Porém, mesmo com uma pequena diferença no volume movimentado entre o cenário com a estrutura atual de ICMS e a reforma tributária, a rede logística do produto 2 é bastante modificada pela diferença na localização dos centros de distribuição.

A maior modificação na proporção do volume movimentado está na alteração do nível de serviço. Essa modificação proporciona um aumento do fluxo de entrega direta, modificando os fluxos de origem e destino conforme a comparação entre os mapas $67 \mathrm{e}$ 82 e os mapas 72 e 87 segundo a Figura 34 .

A rede logística do produto 3 possui um comportamento muito parecido com a rede logística do produto 2. A alteração do cenário com a estrutura atual de ICMS para o cenário com reforma tributária não modifica significativamente a proporção do volume movimentado, porém a alteração do nível de serviço proporciona uma alteração mais representativa, incentivando o fluxo direto. As comparações dos mapas 68 e 83 e os mapas 73 e 88 mostram a diferença entre os fluxos de entrega direta na rede logística. A comparação dos mapas 38 e 53 e os mapas 43 e 58 mostram a modificação do nível de serviço para os fluxos de transferência na rede logística do produto 3 .

Um ponto a se destacar é a utilização do centro de distribuição de Unaí como ponto de triangulação dos fluxos do produto 3 com destino ao Nordeste. Mesmo com a modificação do nível de serviço, o centro de distribuição em Unaí ainda é utilizado. Porém esse centro de distribuição não será utilizado a partir do momento que a reforma tributária entrar em vigor, incentivando o fluxo de entrega direta conforme os mapas 43 e 73 na Figura 34.

A rede logística do produto 4 (Recife) não sofreu alterações significativas com a mudança dos cenários. A baixa representatividade do volume do produto 4 não permite concluir se o motivo pelo qual a rede não sofreu nenhuma alteração é devido ao fato 
que a Região Nordeste não sofre influência dos cenários estudados, ou se a baixa representatividade da demanda influenciou essa decisão.

Ao alterar o nível de serviço, a representatividade do fluxo do CD para o Mercado é reduzido em ambos os cenários (ICMS Atual e reforma tributária) e o fluxo direto é incentivado para todos os produtos. Porém, a rede logística do produto 1 é mais sensível à alteração do cenário do ICMS Atual para a reforma tributária do que a alteração do nível de serviço. Contudo, ao analisar as redes dos produtos 2 e 3 essa relação se mostrou inversa, ou seja, a alteração do nível de serviço proporciona uma modificação da relação entre o volume movimentado por transferência e entrega direta maior do que a modificação da estrutura atual do ICMS para a reforma tributária.

Para complementar o entendimento dos efeitos dos cenários até aqui estudados, a Figura 35 mostra a representatividade do volume do produto no total movimentado em cada centro de distribuição. Essa análise permite compreender os principais motivos para a utilização do centro de distribuição em uma determinada região.

O primeiro produto a ser analisado será o volume movimentado do produto 1 . A Figura 35 (mapa 1) mostra que o volume movimentado do produto 1 (em azul claro) para o cenário com $0 \%$ de sonegação (ótimo logístico) está concentrado em centro de distribuição no Nordeste, representando em média $58 \%$ do volume movimentado. Essa informação pode ser confirmada ao analisar a Figura 34 (mapa 1 e 31), que mostra os fluxos da fábrica de São Paulo para os centros de distribuição.

No cenário com $100 \%$ de sonegação, os fluxos são direcionados para o centro de distribuição de Pouso Alegre, representando aproximadamente $60 \%$ do volume movimentado. A mudança dos fluxos está representada na Figura 34 (mapa 6 e 36). A proporção entre os fluxos de transferência e entrega direta não foram modificados conforme a Figura 33.

No cenário com a reforma tributária (100\% de sonegação), a utilização dos centros de distribuição está parecida com o ótimo logístico e o volume movimentado do produto 1 é em média $51 \%$ do total movimentado nos centros de distribuição localizados no Nordeste. A principal diferença está na utilização do centro de 
distribuição em Pouso Alegre, cuja representatividade do produto 1 é $81 \%$ do volume movimentado. Ao comprar os mapas 1 e 11 e os mapas 31 e 41 da Figura 34 é possível verificar que a rede logística não sofre mudanças significativas ao implementar a reforma tributária, aspecto analisado no capitulo anterior.

Porém, conforme a Figura 33, a proporção entre os fluxos de transferência e entrega direta é modificada significativamente, alterando de $15 \%$ para $26 \%$ (fluxo CD Mercado) respectivamente. Essa mudança é justificada pela modificação da dinâmica de localização, ou seja, na reforma tributária os centros de distribuição estão localizados no Estado vizinho, com isso, o volume movimentado no CD de Pouso Alegre é incentivado, por se tratar de um CD localizado ao lado do Estado com maior demanda.

A alteração do nível de serviço não modificou significativamente os resultados encontrados nos cenários com nível de serviço para o produto 1. Com isso, os mapas da Figura 34 e da Figura 35 não sofreram modificações significativas. A Figura 33 mostra a redução do volume movimentado de 15\% para 11\% (fluxo CD - Mercado e $100 \%$ de sonegação) e de $36 \%$ para $41 \%$ (fluxo Fab - Mercado) no cenário com a estrutura atual de ICMS.

As principais mudanças ao comparar o cenário com e sem restrição de nível de serviço estão relacionadas ao incentivo do fluxo direto e a redução do número de centros de distribuição de 9 (ICMS Atual, 100\% de sonegação e com nível de serviço) para 4 (ICMS Atual, $100 \%$ de sonegação e sem restrição de nível de serviço). Os mapas 2 e 5 da Figura 35 mostram a alteração dos centros de distribuição, sendo a concentração dos fluxos do CD de Pouso Alegre uma característica comum aos dois cenários.

Ao analisar a rede logística do produto 2 é possível verificar que a estrutura atual de ICMS proporciona uma concentração dos fluxos no Estado de Minas Gerias. Interessante notar que $O C D$ de Teófilo Otoni é o responsável pelo atendimento das mesorregiões do Nordeste, como ilustrado pelos mapas 37 e 52 da Figura 34. A alteração do nível de serviço reduziu a quantidade de mesorregiões que são atendidos 
pelos centros de distribuição, consequentemente aumentando o fluxo de entrega direta conforme os mapas 67 e 82 da Figura 34. Ao comparar o volume movimentado dos cenários com $0 \%$ de sonegação e 100\% sonegação para a reforma tributária (Figura 33), percebe-se que o volume é modificado de $10 \%$ para $11 \%$ (fluxo CD - Mercado).

Essa pequena modificação da rede é principalmente ocasionada pela modificação dos fluxos na Região Sudeste e independente do cenário, a Região Nordeste não é modificada significativamente. Essa relação é ilustrada ao comparar os mapas 1 e 3 da Figura 35, concluindo assim a relativa proximidade entre as redes logísticas.

A alteração do nível de serviço modifica a rede logística do produto 3 de uma forma muito parecida com a modificação do produto 2. O fluxo de entrega direta é incentivado ao reduzir o nível de serviço, aspecto evidenciado pela comparação entre os mapas 1 e 4 na Figura 35. O principal motivo da utilização do centro de distribuição localizado em Unaí é a proximidade do CD a região de origem do produto 3 (Goiânia). Esse aspecto é ilustrado pelo mapa 5 da Figura 35 e pelos mapas 38 e 53 da Figura 34. 
Figura 35: Mapas de distribuição do volume por produto em cada centro de distribuição

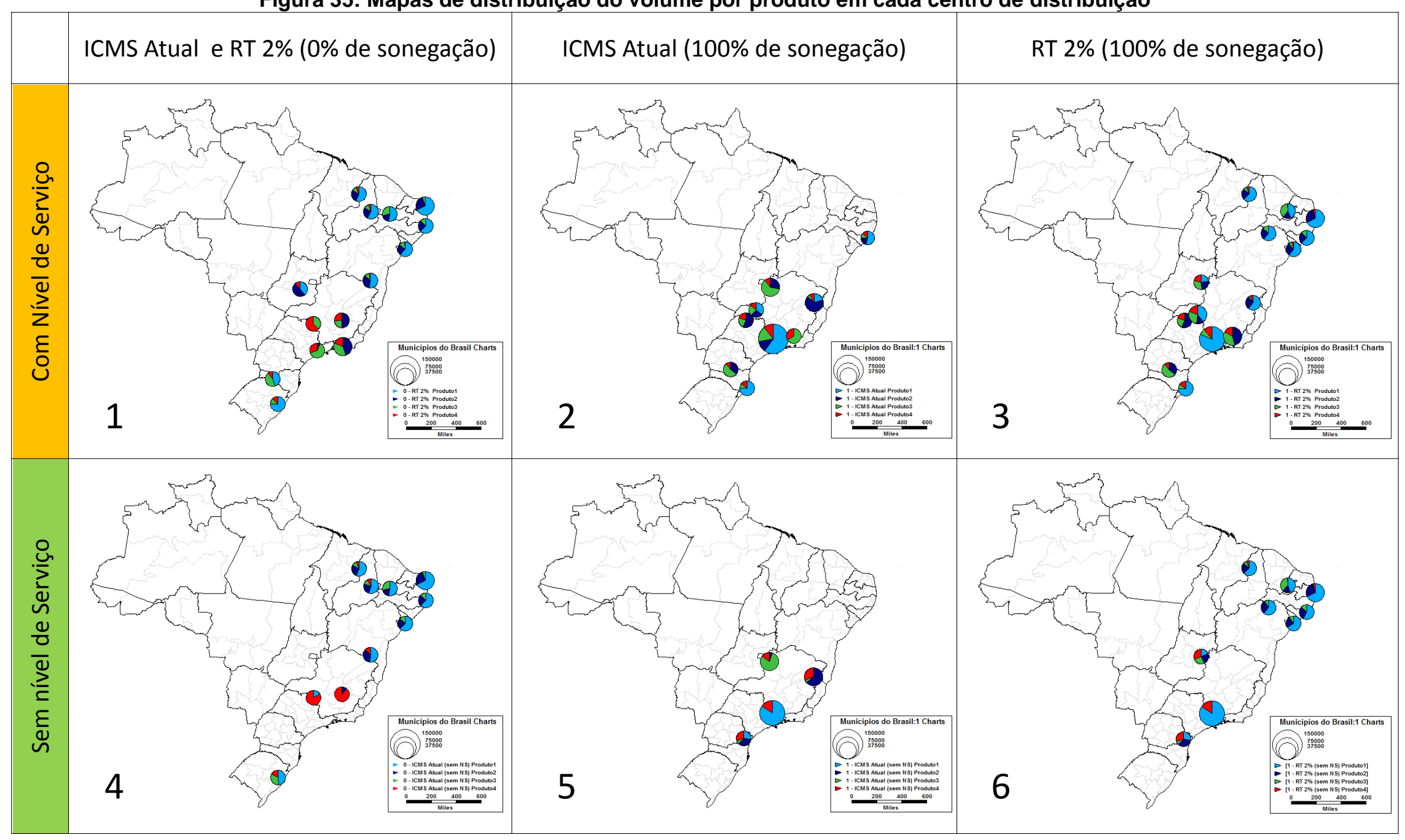




\subsubsection{Modificação do nível de serviço}

Para entender o comportamento da rede logística de acordo com o aumento do nível de serviço foram desenvolvidos mais alguns cenários, permitindo assim visualizar a modificação dos custos logísticos e do número de centros de distribuição à medida que o nível de serviço é aumentado.

O nível de serviço utilizado nesse estudo é exatamente igual para todas as mesorregiões, diferenciando-se da restrição de nível de serviço utilizado no estudo anterior que possuía uma restrição de nível de serviço para cada faixa de população na mesorregião.

Esse estudo permite avaliar a evolução dos custos logísticos de acordo com o aumento da restrição de nível de serviço. A Figura 36 mostra a evolução do custo logístico e do numero de instalações de acordo com o aumento do nível de serviço.

Os níveis de serviço em quilômetros utilizados para esse estudo foram: 500, 750, $1000,1250,1500,1750,2000,2250,2500,2750$ e 3000.

O comportamento da rede logística com a estrutura atual de ICMS mostra que existe um espaço maior entre os cenários no gráfico do custo logístico, evidenciando uma influência maior da sonegação. Essa diferença modifica de 75 ( $0 \%$ de sonegação) para 83 milhões (100\% de sonegação) no cenário com o nível de serviço de $3000 \mathrm{~km}$. O cenário com a reforma tributária não sofre variação do custo logístico tanto quanto o cenário com a estrutura atual sofre à medida que o nível de serviço aumenta.

Um ponto de destaque está relacionado ao cenário com a estrutura atual de ICMS. Quando o nível de serviço fica acima de $1250 \mathrm{~km}$, ocorre uma melhora do custo logístico. Todas as mesorregiões do Nordeste são atendidas por CD's localizados em Minas Gerais para um nível de serviço de 3000 a 1250 km e a partir do momento que o nível de serviço é aumentado, muitas das mesorregiões do Nordeste não conseguem ser atendidas diretamente do Estado de Minas Gerais. Essa modificação proporciona 
uma melhora no custo logístico, visto que o cenário ótimo possui muitas instalações localizadas no Nordeste.

A partir de 1250 quilômetros, as redes logísticas da estrutura atual de ICMS e da reforma tributária são muito parecidas devido ao limite de atendimento imposto pelo nível de serviço.

Figura 36: Evolução do custo logístico e do número de instalações de acordo com o aumento do nível de serviço.

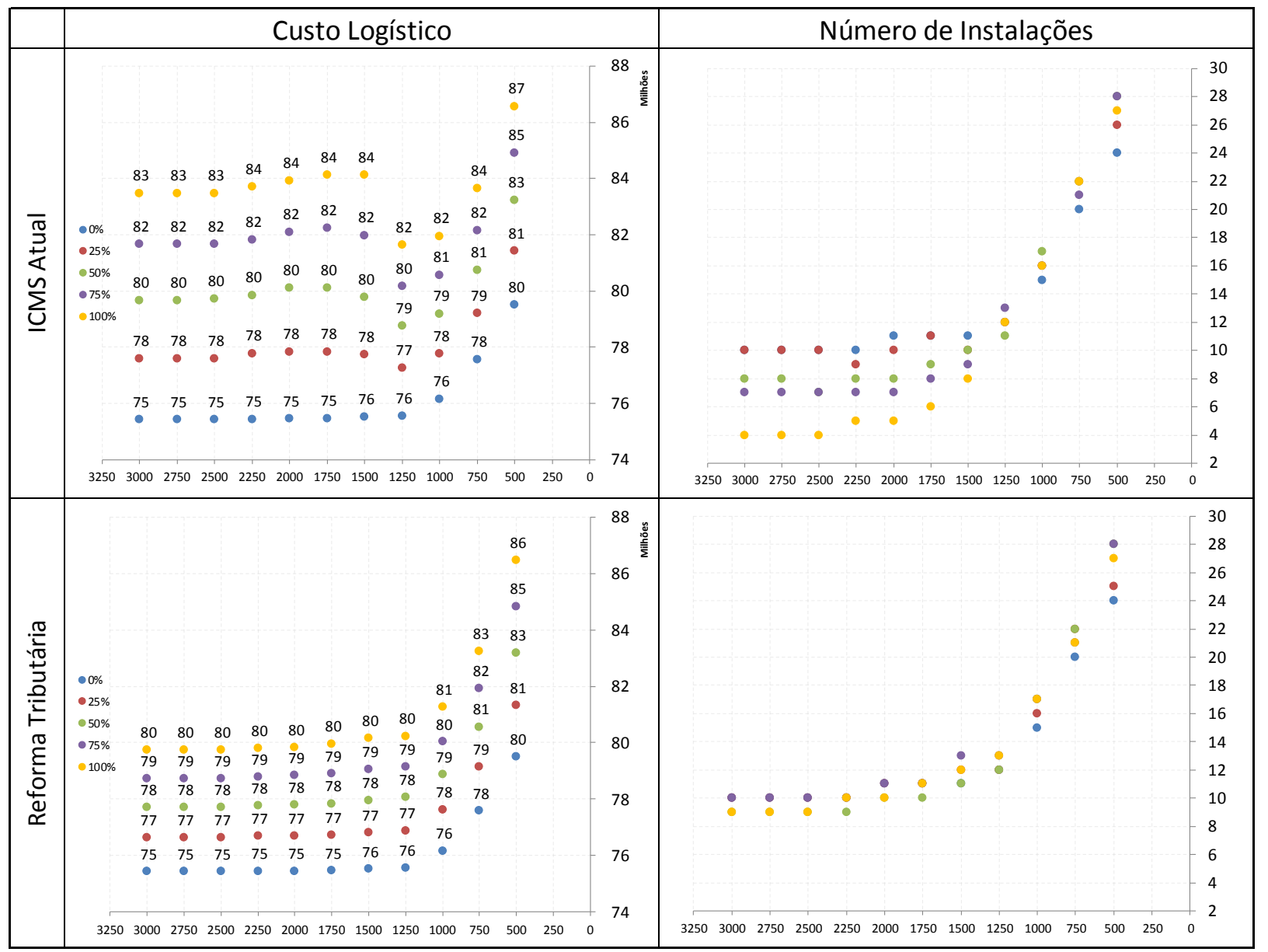

O número de instalações também é modificado a partir do aumento do nível de serviço. No cenário com a estrutura atual de ICMS é possível perceber que ocorre um desvio maior entre o número de instalações nos cenários de $0 \%$ a $100 \%$ de sonegação. Á medida que o nível de serviço vai aumentando, esse desvio é reduzido. No cenário com a reforma tributária, não ocorre desvios significativos entre os cenários de $0 \%$ a 
100\% de sonegação. A Figura 37 mostra o mapa de fluxo, localização e nível de serviço para os cenários com 500, 1250 e $3000 \mathrm{~km}$.

Figura 37: Mapa de localização, fluxo e nível de serviço.

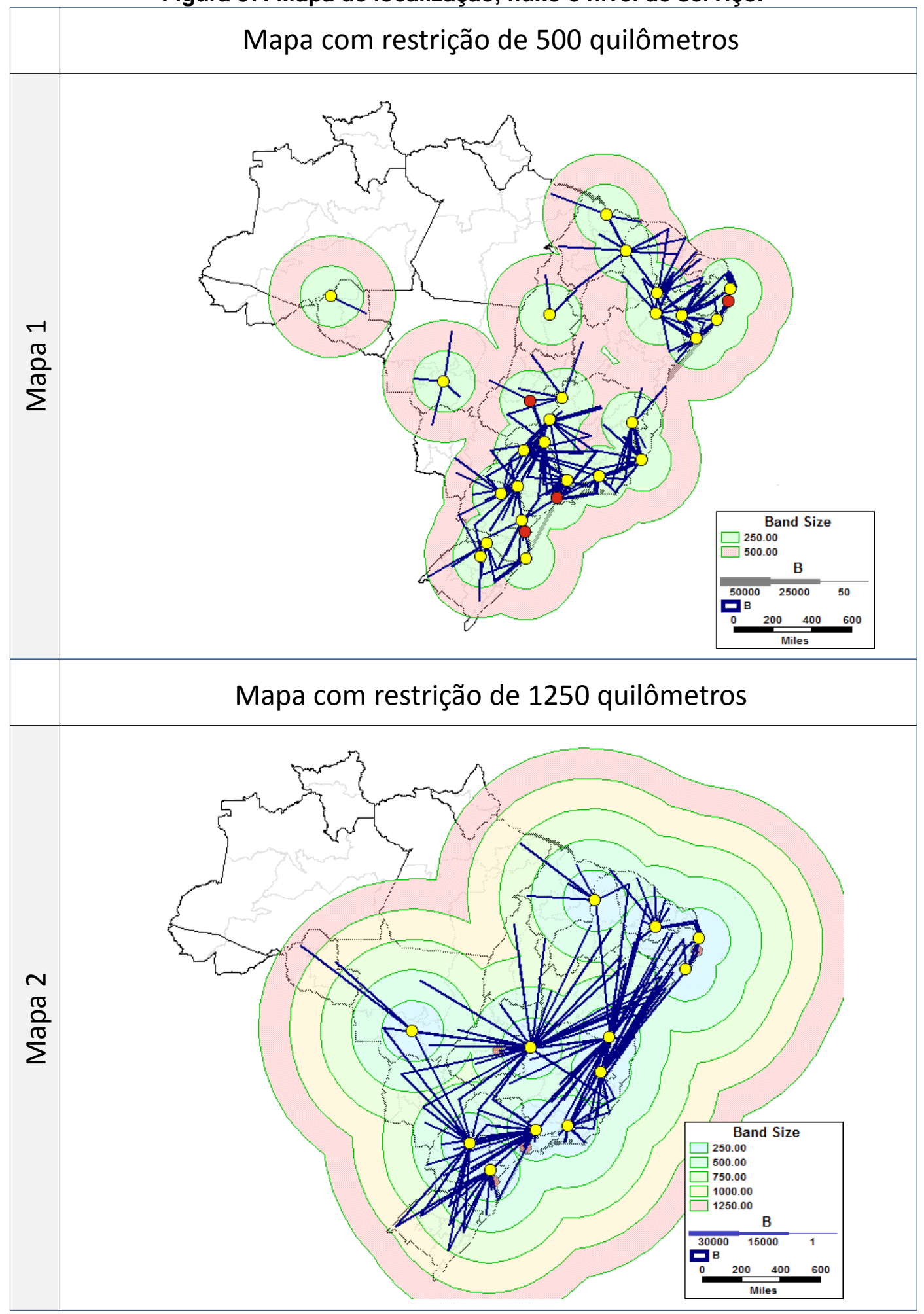


Figura 37: Continuação dos mapas de localização, fluxo e nível de serviço.

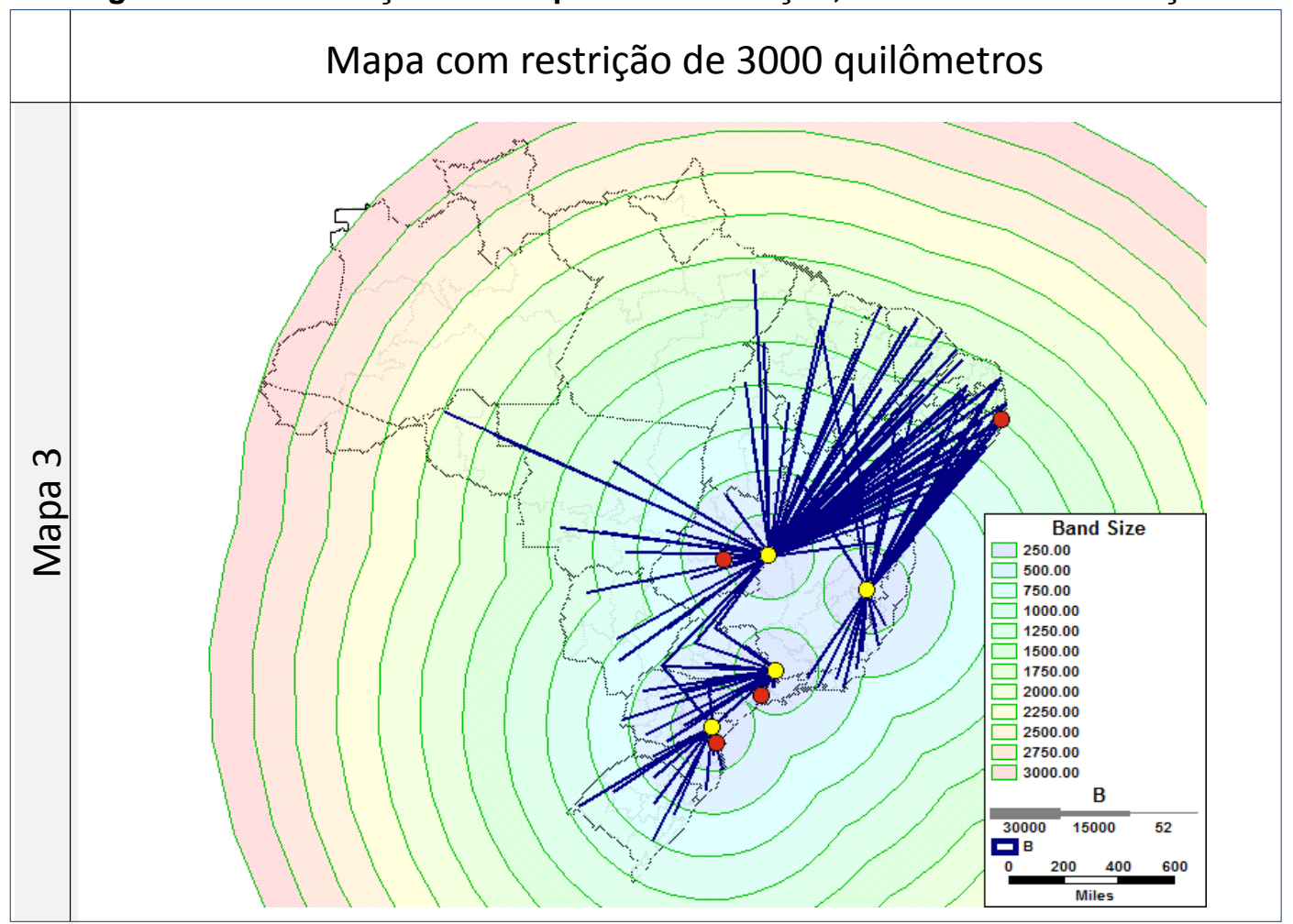

\subsubsection{Modificação na alíquota interestadual da Reforma Tributária}

A proposta apresentada pelo Senado (2008) institui uma alíquota de $2 \%$ no transporte interestadual. Todo o estudo até aqui desenvolvido foi utilizado à alíquota interestadual de $2 \%$, contudo, como seria a modificação da rede logística para uma alíquota interestadual de $4 \%$ ?

Devido à constante dificuldade de definição da melhor alíquota por parte do governo e dos Estados, sentiu-se a necessidade de analisar o comportamento da rede para diferentes alíquotas. Essa alternativa proporciona uma expansão do conhecimento das relações causa e efeito no planejamento de redes logísticas com ICMS.

Para isso, desenvolveram-se novos cenários com diferentes alíquotas interestaduais, partindo de uma alíquota interestadual de $2 \%$ até a alíquota interestadual de $17 \%$, mantendo as alíquotas internas conforme a estrutura atual de ICMS (mínimo de 17\% e máximo de 19\%). 
Os resultados encontrados mostram que somente a partir da alíquota interestadual de $16 \%$ é que a rede logística sofre alguma alteração. Isso acontece devido à diferença entre as alíquotas internas e interestaduais. Esse resultado encontrado no estudo mostra que para uma alíquota interestadual abaixo de $16 \%$ a rede logística é exatamente igual à rede logística encontrada para a alíquota interestadual de $2 \%$. A única diferença é no montante de imposto arrecadado pelos Estados. A Figura 38 mostra o aumento do custo logístico de acordo com a modificação da alíquota interestadual.

Figura 38: Aumento relativo do custo logístico

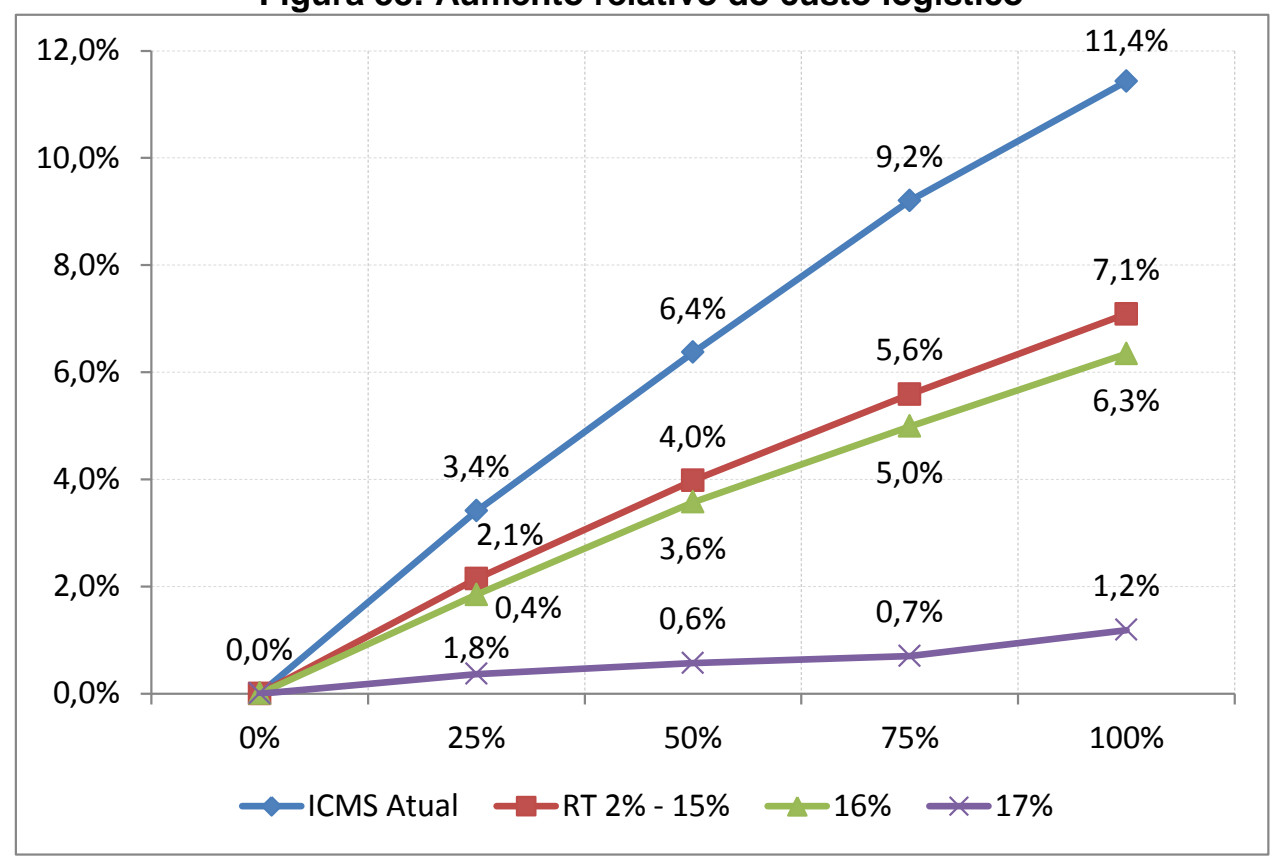

A Figura acima mostra que o aumento relativo do custo logístico no cenário com alíquota interestadual $16 \%$ é de $6,3 \%$ (100\% de sonegação). Para o cenário com a alíquota interestadual de 17\%, o aumento do custo logístico é de 1,2\% (100\% de sonegação).

A distorção encontrada na rede logística com a estrutura atual de ICMS é devido à diferença entre Estados exportadores e importadores, ou seja, os fluxos dos Estados do Rio de Janeiro, São Paulo, Rio Grande do Sul, Minas Gerais, Santa Catarina e Paraná para os Estado do Nordeste possuem a alíquota de 7\%, o restante dos fluxos 
interestaduais possuem alíquota interestadual de 12\%. Essa diferença ocasiona a maioria dos problemas encontrados no planejamento de redes logísticas no Brasil.

Contudo, a simples unificação da alíquota já seria suficiente para reduzir o impacto tributário no planejamento de redes logísticas. Um dos principais problemas encontrados na aprovação da reforma tributária é a definição da alíquota, visto que, a representatividade do ICMS na receita dos Estados é muito grande e a modificação da mesma poderia acarretar profundos déficits orçamentários. Porém a simples unificação da alíquota já poderia melhorar muito a competitividade das empresas e reduzir a distorção da rede logística ocasionando uma redução do custo logístico conforme demonstrado pelo estudo.

Muitos dos benefícios e vantagens encontrados nesse estudo são devido ao processo de unificação da alíquota interestadual e não por causa propriamente da alíquota interestadual. A demora na aprovação da reforma tributária gira em torno da definição da alíquota interestadual mais adequada, porém esse estudo mostra que no que tange ao aspecto de planejamento logístico, o mais importante não é a alíquota, mas sim o processo de unificação. Com isso, o simples fato da unificação das alíquotas já poderia melhorar o planejamento de redes logísticas impactando diretamente na redução a médio prazo do chamado "Custo Brasil". 


\section{5 -CONCLUSÃo}

A estrutura atual do ICMS sobrecarrega a rede logística com movimentações desnecessárias (turismo fiscal) e aumenta o custo logístico total, aspecto também analisado por Ribeiro (1999), Yoshizaki (2002), Silva (2007), Yoshizaki et al (2008), Carraro (2009) e Wanke (2009). O presente modelo do ICMS foi estabelecido pela constituição de 1988 (antigo ICM), sendo um dos seus objetivos promover a descentralização do desenvolvimento industrial pelo estabelecimento de alíquotas diferenciadas entre Estados importadores e exportadores (cf.CARAZZA, 2009).

Nos cenários analisados, dois fatores geram o turismo fiscal: a estrutura de alíquotas diferenciadas do ICMS e a existência de sonegação deste imposto. Apesar de não haver estatísticas precisas sobre a sonegação do ICMS, ela é considerada significativa (YOSHIZAKI, 2002). Uma estimativa de $25 \%$ de sonegação levaria a um incremento no custo logístico de $3 \%$ na cadeia de distribuição modelada (vide Figura 18). Como somente a economia informal no país em 2010 chegou a 18,3\% do PIB (IBRE, 2011), o acréscimo da sonegação fiscal por canais não-informais faz a estimativa de $25 \%$ parecer conservadora. Assim, a estrutura do ICMS atual, que ajudou - Brasil a descentralizar o desenvolvimento, está prejudicando a competitividade das empresas ao retirar capacidade da sobrecarregada infraestrutura logística brasileira e ao aumentar o custo Brasil.

Uma importante conclusão do estudo é que a nova estrutura do ICMS mantém o incentivo ao turismo fiscal, por parte da cadeia de distribuição que atua informalmente e, continua distorcendo a estrutura logística resultante, pela artificialidade da demanda resultante. $O$ incremento no custo logístico associado diminui de $3 \%$ para $2 \%$ no caso de uma sonegação de 25\%, (vide Figura 18), mas ainda é significativo.

As principais diferenças na rede logística com a reforma tributária estão na localização e na capacidade das instalações. No presente sistema do ICMS ocorre centralização das instalações em regiões com alíquotas relativas mais baixas, como Minas Gerais. A reforma tributária proporciona descentralização das instalações que 
passam a atender Estados vizinhos, reduzindo a distância de atendimento aos mercados. Pode-se assim prever que haverá uma alteração na presente geografia da rede de atacadistas e centros de distribuição, caso a sonegação continue nos níveis atuais. A sonegação pode ser reduzida com o uso compulsório de novas tecnologias de automação comercial e faturamento, como a nota fiscal eletrônica.

As regiões Nordeste e Centro-Oeste têm sua topologia alterada com a reforma tributária, mas diferem quando comparadas à solução sem a influência do ICMS (ótimo logístico). À medida que a sonegação de imposto aumenta, a rede logística com a estrutura atual de ICMS sofre mudanças significativas, porém com o Novo ICMS tal modificação é menos marcante, sendo os cenários muito parecidos independentemente do grau da sonegação.

O modelo mostra que a rede logística é pouco sensível à modificação das alíquotas internas: mudanças acontecem apenas quando elas chegam a 3\% (a partir dos atuais 19 a 17\%), criando uma rede logística intermediária entre a estrutura atual de ICMS e o cenário base (sem influência do ICMS). Assim, mesmo uma redução moderada das alíquotas pouco influenciaria neste cenário de turismo fiscal.

Foram avaliadas as alterações na rede logística de acordo com a modificação do nível de serviço. Os principais resultados mostram que o custo logístico aumenta conforme a melhora do nível de serviço e o aumento da sonegação. No cenário com a estrutura atual de ICMS, o fluxo da fábrica para o mercado é incentivado. Na rede com a reforma tributária, o fluxo da fábrica para o mercado não é tão incentivado quando comparado ao aumento do fluxo no cenário com a estrutura atual de ICMS. Os custos de distribuição sofrem aumento, contudo, os custos de transferência sofrem redução à medida que aumenta a sonegação (Figura 29 e Figura 30).

Ao reduzir o nível de serviço no cenário com a reforma tributária, a concentração de instalações no Estado de Minas Gerais não é incentivada. Essa concentração é encontrada no cenário da reforma tributária com nível de serviço, porém esse efeito é reduzido. No cenário com a estrutura atual de ICMS ocorre a concentração de instalações independentemente do nível de serviço (Figura 31). 
Para os produtos com origem em São Paulo, a reforma tributária estimula o fluxo de transferência, porém a redução do nível de serviço não modifica significativamente os fluxos da fábrica para o mercado e do CD para o mercado. Para os produtos com origem em Joinville, Goiânia e Recife, esse processo se mostrou inverso, ou seja, a alteração do nível de serviço influencia muito mais os fluxos de transferência e os fluxos diretos do que a alteração da estrutura atual do ICMS para a reforma tributária

A alteração da alíquota interestadual proporcionou o entendimento de qual alíquota a rede logística começaria a ser modificada. Para qualquer alíquota interestadual abaixo de $16 \%$, mantendo as alíquotas internas atuais (mínimo de $17 \%$ e máximo de $19 \%$ ), a rede logística permaneceria a mesma do cenário com a alíquota interestadual de $2 \%$. Esse resultado mostra que simplesmente a unificação da alíquota já proporcionaria a modificação e as vantagens encontradas no estudo, ou seja, os resultados encontrados podem são encontrados desde o cenário com alíquota interna de $2 \%$ até a alíquota interestadual de $16 \%$.

Muito tem se discutido sobre qual seria a melhor alíquota interestadual, sendo este um dos motivos para a dificuldade na aprovação da proposta da reforma tributária. Porém, esse estudo mostra que independentemente da alíquota abaixo de $16 \%$, o cenário seria o mesmo. No que tange ao aspecto de planejamento de redes logísticas, a adoção de uma alíquota unificada já traria muitos benefícios conforme constatado no estudo. Todos os resultados encontrados nesse estudo podem ser utilizados para qualquer alíquota interestadual abaixo de $16 \%$.

Mesmo a adoção de uma alíquota interestadual unificada de 12\% (teoricamente considerada uma tarifa alta), as empresas iriam reduzir seus custos logísticos a médio prazo, contribuindo assim para a redução do turismo fiscal e melhoria do chamado "Custo Brasil". A redução dos custos logísticos pode ser visualizada na Figura 26.

A definição da alíquota mais adequada seria a segunda parte da reforma tributária, sendo que a primeira seria a unificação da alíquota. Com isso, as empresas já poderiam usufruir de benefícios em suas redes e nos seus custos, deixando a definição da alíquota mais adequada para um segundo plano. Primeiramente seria necessária 
definir uma alíquota que pudesse manter as arrecadações nos níveis atuais e em um segundo momento, seria necessário criar um plano de redução das alíquotas. Porém, com a alíquota já unificada seria mais fácil criar um plano mais adequado aos interesses do governo e dos Estados.

A não inclusão do crédito de ICMS oriundo do fornecedor na modelagem matemática constitui uma das principais limitações do estudo. Contudo, por se tratar de um parâmetro fixo, a inclusão do crédito na modelagem matemática não modificaria as conclusões encontradas nesse estudo. Caso a empresa estudada tivesse a opção de comprar de fornecedores diferentes em Estados diferentes, a inclusão do crédito de ICMS deveria ser incluído na modelagem matemática.

A reforma tributária foi elaborada para reduzir o impacto na competividade das empresas frente a uma estrutura que está ultrapassada para os níveis atuais de desenvolvimento. Conforme constatado pelo estudo vigente, no que tange ao aspecto logístico, a reforma tributária irá trazer melhorias significativas no aspecto de fluxo de origem e destino bem como na localização das instalações.

Estudos futuros poderiam detalhar a representatividade do ICMS nos orçamentos estaduais bem como a definição de uma alíquota interestadual adequada para o processo de unificação do ICMS. Outros estudos poderiam abordar a influência do crédito de ICMS oriundo do fornecedor quando existe a possibilidade de comprar de diferentes fornecedores em diferentes Estados com diferentes preços. 


\section{BIBLIOGRAFIA}

ACKOFF, R. L. Beyond prediction and preparation. Journal of Management Studies. p. 59-69, 1983.

AIKENS, C. H. Facility location models for distribuition plannig. European Journal of Operation Research. v. 22, n. 4, p. 263-279, 1985.

ANSOFF, H. I. The state of practice in planing system. Sloan Management Review. p. 1-24, 1977.

BALLOU, R. H. Gerenciamento da Cadeia de Suprimentos. Porto Alegre: Bookman, 2006.

BRANDEAU, M. L.; CHIU S. S. An overview of representative problems in location research. Management Science, v. 35, n. 7, p. 645-674, 1989.

BERTAGLIA, P. R. Logistica e gerenciamento da cadeia de suprimento. São Paulo: Saraiva, 2005.

BOWERSOX, D. J.; CLOSS, D. J. Logistica Empresarial: o processo de integração da cadeia de suprimento. São Paulo: Atlas, 2001.

BOWERSOX, D. J.; CLOSS, D. J.; COOPER, D. J. Supply Chain Management. New York: McGraw-Hill, 2002.

CARAZZA. ICMS. São Paulo: Malheiros, 2009.

CARRARO, P. R. Avaliação da influência dos aspectos logisticos, fiscais e ambientais no projeto de redes de distribuição física. Dissertação (Mestrado). Programa de Mestrado em Engenharia de Sistemas Logísticos, Escola Politécnica da USP. São Paulo, 2009.

CASTRO, N. R. Logistic Cost and Brasilian Regional Development. The World Bank. 2004.

CEL/COPPEAD. Panorama de Custos Logisticos no Brasil. 2008.

CHANDLER, A. D. J. Strategy and Structure: chapters in the history of the industrial enterprise. MIT Press. Cambrigde, 1962.

CHOPRA, S.; MEINDL, P. Gerenciamento da Cadeia de Suprimentos, Estretégia, Planejamento e Operação. São Paulo: Prentice Hall, 2003. 
COPACINO, W.; DONALD, B. R. Analytic tools for strategic planning. International Journal of Physical Distribution and Materials Management. v. 15, n. 13, 1985.

CROXTON, K. L.; ZINN, W. Inventory consideration in network design. Journal of Businnes Logistic. v. 26, 2005.

CUNHA, C. B.; MUTARELLI, F. Modelagem de redes de distribuição aplicada ao caso de uma editora de revistas. XVIII congresso da ANPET., 2004.

CURRENT, J.; DASKIN, M.; SHILLING, D. Discrete network location models. In: DREZNER, Z.; HAMACHER, H. Facility location theory: applications and methods. Berlin: Springer-Verlag, p. 81-118,

DASKIN, M. S. Network and discrete location: models, algorithms and applications. New York: John Wiley \& Sons, 1995.

DAY, S. G. A dinâmica da estretégia competitiva. Rio de Janeiro : Campus, 1999.

FAZENDA, M. Cartilha da Reforma Tributária. Ministério da Fazenda, 2008. Disponível em: <http://www.fazenda.gov.br>. Acesso em: 22 de abr. 2011

FLEURY, P. F.; WANKE, R.; FIQUEIREDO, K. Logistica Empresarial: A Perspectiva Brasileira. São Paulo: Atlas, 2000.

GEOFFRION, A. M.; BRAVES, G. W. Multicommodity distribuition system design by benders decomposition. Management Science. v. 20, n. 5, p. 822-844, 1974.

GEOFFRION, A. M.; POWERS, R. F. Twenty years of strategic distribuition system design. Interfaces. v. 25, n. 5, 1995.

GUALDA, N. F. Terminais de transportes: contribuição ao planejamento e ao dimensionamento operacional. Tese de Livre Docência, Escola Politecnica - Universidade de são Paulo, São Paulo, 1995.

IBGE. Censo, 2010. Disponível em: <www.ibge.com.br>. Acesso em: 15 de abr. 2011.

IBRE. Índice da Economia Subterrânea Disponível em: <http://www.etco.org.br/publicacoes/estudos-pesquisas/estudos-e-pesquisas/.>. Acesso em: 22 de fev. 2012. 
JUNQUEIRA, R.; MORABITO, R. Um modelo de otimizaçaõ linear para o planejamento agregado da produção e logistica de sementes de milho. Revista Produção. v. 16, n. 3, p. 510524, 2006.

JUNQUEIRA, R.; MORABITO, R. Planejamento otimizado da produção e logística de empresas produtoras de sementes de milho: um estudo de caso. Gestão \& Produção. v. 15, n. 2, p. 367380, 2008.

KLOSE, A.; DREXL, A. Facility models for distribuition planning. European Journal of Operation Research. v. 22, n. 3, p. 4-29, 2005.

LACERDA, L. Consideração sobre o estudo de localização de instalações. In: FLEURY, P. F.; WANKE, P.; FIQUEIREDO, K. F. Logistica empresarial: a perspectiva brasileira. São Paulo: Atlas, 2000.

LEE, H. L.; PANDMANABHAN, V.; WHANG, S. Information distortion in a supply chan: the bullwhip effect. Management Science. 4, 1997. 546-558. Acesso em 1 mar 2012. Disponivel em http://mansci.journal.informs.org/cgi/content/abstract/50/12_supplement/1875.

LOPES, M. L. R. Direito tributário brasileiro. Niteroi: Impetus, 2009.

LOVE, R. F.; MORRIS, J. G.; WESOLOWSKY, G. O. Facilities location: models \& methods. New York: North-Holland, 1988.

MACIEL, P. H. L.; DALVI, W. E. S. Consideraçãos sobre tributos e estoques na modelagens de redes logisticas. Trabalho e Conclusão de Curso, Departamento de Engenharia Industrial, Rio de Janeiro, 2006.

MELO, M. T.; NICKEL, F.; SALDANHA, F. Facility location and supply chain management. European Journal of Operation Research. v. 196, p. 401-412, 2009.

MINZBERG, H.; AHLSTRAND, B.; LAMPEL, J. Safári de estretégia: um roteiro pela selva do planejamento estretégico. Porto Alegre: Bookman, 2000.

MOREIRA, V.; CANOTILHO, G. Fundamentos da constituição. Coimbra: Coimbra, 1991.

NAZÁRIO, P. R. Impactos fiscais na decisão de localização de instalações: estudo de caso. Dissertação (Mestrado), Programa de Engenharia de Produção da Universidade Federal do Rio de Janeiro, Rio de Janeiro, 2000. 
NIELSEN. Retail Index, 2012. Disponível em: < http://www.abrasnet.com.br/economia-epesquisa/indice-de-volume/indice/>. Acesso em: 9 de jan. 2012.

NOVAES, A. G. Logistica e Gerenciamento da Cadeia de Suprimentos. 3ª edição. Rio de Janeiro: Elsevier, 2004.

PORTER, M. E. Competitive strategy: techniques for analyzing industries and competitors. Free Press. New York, 1980.

PORTER, M. E. Competição: estretágias competitivas essenciais. Rio de Janeiro: Campus, 1999.

QUEIROZ, T. S. O Efeito do ICMS no planejamento de redes logisticas. Dissertação (Mestrado), Universidade Federal do Rio de Janeiro, Rio de Janeiro, 2011.

RIBEIRO, N. V. Contribuição ao aperfeiçoamento de sistemas logísticos de distribuição no contexto tributário brasileiro: estudo de caso em indústria de bens de consumo. Dissertação (Mestrado), Faculdade de Economia, Administração e Contabilidade da USP. São Paulo, 1999.

ROBESON, J.F.; COPACINO, W.C. The logistics handbook. New York: The Free Press, 1994.

SENADO. Relatório preliminar da subcomissão temporaria da reforma tributária. Congresso Nacional, 2010. Disponível em: < http://www.senado.gov.br>. Acesso em: 20 de abr. 2011

SILVA, M. B. Otimização de redes de distribuição física considerando incentivo fiscal baseado no crédito presumido de ICMS. Dissertação (Mestrado). Programa de Mestrado em Engenharia de Sistemas Logísticos, Escola Politécnica da USP. São Paulo, 2007.

SLACK, N. CHAMBERS, S.; JOHNSTON, R. Administração da Produção. São Paulo: Atlas, 1996.

SOUZA, M. V. S. Direito tributário e seus conceitos gerais, 2005. Disponível em: <http://www.advogados.adv.br/artigos/2005/marcusviniciusguimaraesdesouza/direitotributarioco nceitosgerias.htm. >. Acesso em: 08 de mar. 2012.

WANKE, P. Gestão de estoques na cadeia de suprimentos: decisçoes e modelos. São Paulo: Atlas, 2003. 
WANKE, P.; MONTEBELLER, E. J. J.; VOUGA, R. T. Introdução ao planejamento de redes logisticas. São Paulo: Atlas, 2009.

WINSTON, W. Introduction to mathematical programming. New York: Duxbury Press, 1995.

WRIGHT, P.; KROLL, M.; PARNELL, J. Administração estratégica: conceitos. São Paulo: Atlas, 2000.

YOSHIZAKI, H. T. Y. Projeto de redes de distribuição física considerando a influência do Imposto de Circulação de Mercadorias e Serviços. Tese de Livre Docência, Escola Politecnica da USP, 2002. Disponivel em http://cislog.poli.usp.br/dlm/27/Livre-Docencia/.

YOSHIZAKI, H. T. Y. Carta de Brasília e Logistica. Jornal: Valor Econômico. São Paulo, 2003. Disponível em: <http://www.bv.fapesp.br/namidia/noticia/17559/carta-brasilia-logistica/>. Acesso em: 23 de jan. 2011.

YOSHIZAKI, H. T. Y.; HINO, C. M.; ROSIN, R. A. Reforma Tributária: Avaliando a influência do novo imposto de circulação de mercadorias e serviços (ICMS) na futura configuração da logística brasileira. Simposio Brasileiro de Pesquisa Operacional. João Pessoa, 2008. 


\section{ANEXO A - Tabela de ICMS}

\begin{tabular}{|c|c|c|c|c|c|c|c|c|c|c|c|c|c|c|c|c|c|c|c|c|c|c|c|c|c|c|c|}
\hline \multicolumn{28}{|c|}{ Estrutura Atual de aliquotas de ICMS } \\
\hline & $A C$ & $\mathrm{AL}$ & M & AP & $\mathrm{BA}$ & $\mathrm{CE}$ & DF & ES & GO & MA & $M G$ & MS & MT & PA & PB & $\mathrm{PE}$ & $\mathrm{PI}$ & PR & RJ & $\mathrm{RN}$ & RO & $\mathrm{RR}$ & RS & SC & $\mathrm{SE}$ & SP & TO \\
\hline $\mathrm{C}$ & & & & $2 \%$ & $\%$ & & $\%$ & $\%$ & $12 \%$ & & & & $\%$ & & $2 \%$ & $12 \%$ & $\%$ & $\%$ & $12 \%$ & $12 \%$ & $12 \%$ & $2 \%$ & $2 \%$ & $2 \%$ & $12 \%$ & $2 \%$ & \\
\hline IL & & & & & $\%$ & & & & $\%$ & & & & $\%$ & & $\%$ & $\%$ & $\%$ & $\%$ & $2 \%$ & $12 \%$ & $12 \%$ & $\%$ & $\%$ & $2 \%$ & $12 \%$ & $2 \%$ & \\
\hline $\bar{M}$ & & & & & & & & & & & & & & & & & & & $\%$ & $\%$ & $\%$ & & & $\%$ & $12 \%$ & $\%$ & \\
\hline $\mathrm{P}$ & $2 \%$ & & $\%$ & $\%$ & $12 \%$ & $12 \%$ & $\%$ & $\%$ & $12 \%$ & & & & $\%$ & & $2 \%$ & $\%$ & $\%$ & $\%$ & $2 \%$ & 12 & 12 & $2 \%$ & $\%$ & $\%$ & $12 \%$ & $\%$ & \\
\hline BA & $12 \%$ & & $12 \%$ & $2 \%$ & $\%$ & $2 \%$ & $2 \%$ & $2 \%$ & $2 \%$ & $12 \%$ & $2 \%$ & $\%$ & $12 \%$ & $\%$ & $12 \%$ & $12 \%$ & $12 \%$ & $2 \%$ & $12 \%$ & $12 \%$ & $12 \%$ & $12 \%$ & $2 \%$ & $2 \%$ & $12 \%$ & $12 \%$ & 28 \\
\hline $\mathrm{CE}$ & $12 \%$ & $12 \%$ & $\%$ & $2 \%$ & $12 \%$ & $7 \%$ & $2 \%$ & $2 \%$ & $\%$ & $\%$ & $2 \%$ & $\%$ & $12 \%$ & $\%$ & $12 \%$ & $12 \%$ & $12 \%$ & $12 \%$ & $12 \%$ & $12 \%$ & $12 \%$ & $12 \%$ & $2 \%$ & $12 \%$ & $12 \%$ & $12 \%$ & $12 \%$ \\
\hline $\bar{F}$ & $2 \%$ & $\%$ & $\%$ & $\%$ & $12 \%$ & $12 \%$ & $7 \%$ & $\%$ & $\%$ & $\%$ & $\%$ & $\%$ & $\%$ & $\%$ & $2 \%$ & $12 \%$ & $12 \%$ & $2 \%$ & $2 \%$ & $12 \%$ & 12 & $12 \%$ & $2 \%$ & $2 \%$ & $12 \%$ & $12 \%$ & $12 \%$ \\
\hline ES & $12 \%$ & $\%$ & $12 \%$ & $12 \%$ & $12 \%$ & $12 \%$ & $12 \%$ & $17 \%$ & $12 \%$ & $2 \%$ & $2 \%$ & $12 \%$ & $12 \%$ & $2 \%$ & $12 \%$ & $12 \%$ & $12 \%$ & $\%$ & $12 \%$ & $12 \%$ & 12 & $12 \%$ & $2 \%$ & 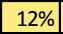 & 12 & $12 \%$ & $12 \%$ \\
\hline GO & $12 \%$ & $\%$ & $12 \%$ & $12 \%$ & $12 \%$ & $12 \%$ & $12 \%$ & $12 \%$ & $17 \%$ & $12 \%$ & $12 \%$ & $12 \%$ & $12 \%$ & $2 \%$ & $12 \%$ & $12 \%$ & $12 \%$ & $2 \%$ & $12 \%$ & $12 \%$ & $12 \%$ & $12 \%$ & $2 \%$ & $2 \%$ & $12 \%$ & $12 \%$ & $12 \%$ \\
\hline MA & $12 \%$ & $\%$ & $12 \%$ & $12 \%$ & $12 \%$ & $12 \%$ & $12 \%$ & $12 \%$ & $12 \%$ & $17 \%$ & $12 \%$ & $12 \%$ & $12 \%$ & $12 \%$ & $12 \%$ & $12 \%$ & $12 \%$ & $2 \%$ & $12 \%$ & $12 \%$ & $12 \%$ & $12 \%$ & $2 \%$ & $12 \%$ & $12 \%$ & $12 \%$ & $12 \%$ \\
\hline MG & $7 \%$ & $7 \%$ & 79 & $7 \%$ & $7 \%$ & $7 \%$ & $7 \%$ & $7 \%$ & $7 \%$ & $7 \%$ & $18 \%$ & & $7 \%$ & $7 \%$ & $7 \%$ & $7 \%$ & $7 \%$ & $12 \%$ & $12 \%$ & $7 \%$ & $7 \%$ & $7 \%$ & $12 \%$ & $12 \%$ & $7 \%$ & $12 \%$ & \\
\hline $\mathrm{MS}$ & $\%$ & $\%$ & $12 \%$ & $\%$ & $\%$ & $2 \%$ & $12 \%$ & $12 \%$ & $12 \%$ & $\%$ & $2 \%$ & 17 & $\%$ & $\%$ & $12 \%$ & $12 \%$ & $\%$ & $2 \%$ & $2 \%$ & $12 \%$ & $12 \%$ & $2 \%$ & $\%$ & 6 & $12 \%$ & $12 \%$ & $12 \%$ \\
\hline MT & $2 \%$ & $\%$ & $12 \%$ & $\%$ & $2 \%$ & $12 \%$ & $12 \%$ & $12 \%$ & $12 \%$ & $2 \%$ & $12 \%$ & $\%$ & $\%$ & $\%$ & $12 \%$ & $12 \%$ & $2 \%$ & $\%$ & $2 \%$ & 12 & 12 & $12 \%$ & $\%$ & 6 & 12 & $12 \%$ & 129 \\
\hline PA & $12 \%$ & $12 \%$ & $12 \%$ & $12 \%$ & $12 \%$ & $2 \%$ & $12 \%$ & $12 \%$ & $12 \%$ & $12 \%$ & $2 \%$ & $\%$ & $\%$ & $\%$ & $12 \%$ & $12 \%$ & $\%$ & $2 \%$ & $2 \%$ & $12 \%$ & $12 \%$ & $\%$ & $2 \%$ & $.2 \%$ & $12 \%$ & $\%$ & 29 \\
\hline PB & $12 \%$ & $\%$ & $12 \%$ & $12 \%$ & $\%$ & $2 \%$ & $12 \%$ & $12 \%$ & $12 \%$ & $12 \%$ & $12 \%$ & $\%$ & $\%$ & $\%$ & $17 \%$ & $12 \%$ & $\%$ & $\%$ & $12 \%$ & $12 \%$ & $12 \%$ & $\%$ & $\%$ & $2 \%$ & $12 \%$ & $12 \%$ & $2 \%$ \\
\hline $\mathrm{PE}$ & 14 & $\%$ & $12 \%$ & rol & $\%$ & $12 \%$ & $12 \%$ & $12 \%$ & $12 \%$ & $12 \%$ & $12 \%$ & 12 & $12 \%$ & $\%$ & $12 \%$ & $17 \%$ & $12 \%$ & $2 \%$ & \begin{tabular}{|l|}
$12 \%$ \\
\end{tabular} & $12 \%$ & $12 \%$ & $12 \%$ & $2 \%$ & $12 \%$ & 12 & $2 \%$ & $2 \%$ \\
\hline $\mathrm{PI}$ & $12 \%$ & $12 \%$ & $12 \%$ & $12 \%$ & $12 \%$ & $12 \%$ & $12 \%$ & $12 \%$ & \begin{tabular}{ll|}
$12 \%$ \\
\end{tabular} & $12 \%$ & $12 \%$ & $12 \%$ & $12 \%$ & $12 \%$ & $12 \%$ & $12 \%$ & $17 \%$ & $12 \%$ & $12 \%$ & $12 \%$ & $12 \%$ & $12 \%$ & $2 \%$ & o & $12 \%$ & $12 \%$ & 12 \\
\hline $\mathrm{PR}$ & 79 & $7 \%$ & 79 & 79 & $7 \%$ & $7 \%$ & 79 & 79 & & $7 \%$ & $12 \%$ & & $7 \%$ & & $7 \%$ & 79 & $7 \%$ & $8 \%$ & $2 \%$ & & $7 \%$ & $7 \%$ & $2 \%$ & $12 \%$ & $7 \%$ & $12 \%$ & \\
\hline RJ & $7 \%$ & $7 \%$ & $7 \%$ & $7 \%$ & $7 \%$ & $7 \%$ & $7 \%$ & $\%$ & 7\% & $7 \%$ & $12 \%$ & $7 \%$ & $7 \%$ & $\%$ & $7 \%$ & $7 \%$ & $7 \%$ & $\%$ & \begin{tabular}{|l|}
$19 \%$ \\
\end{tabular} & $7 \%$ & $7 \%$ | & $7 \%$ & $2 \%$ & $12 \%$ & $7 \%$ & $12 \%$ & \\
\hline $\mathrm{RN}$ & $12 \%$ & $12 \%$ & $12 \%$ & $12 \%$ & $12 \%$ & $12 \%$ & $12 \%$ & $12 \%$ & $12 \%$ & $12 \%$ & $12 \%$ & $12 \%$ & $12 \%$ & $2 \%$ & $12 \%$ & $12 \%$ & $12 \%$ & $2 \%$ & $2 \%$ & $17 \%$ & $12 \%$ & $2 \%$ & $2 \%$ & $12 \%$ & $12 \%$ & $\%$ & \begin{tabular}{|l}
$12 \%$ \\
\end{tabular} \\
\hline $\mathrm{RO}$ & $12 \%$ & $12 \%$ & $12 \%$ & $12 \%$ & $12 \%$ & $12 \%$ & $12 \%$ & $12 \%$ & $12 \%$ & $12 \%$ & $12 \%$ & $12 \%$ & $12 \%$ & $12 \%$ & $12 \%$ & $12 \%$ & $12 \%$ & $12 \%$ & \begin{tabular}{|l|}
$12 \%$ \\
\end{tabular} & $12 \%$ & $17 \%$ & $12 \%$ & $2 \%$ & $2 \%$ & $12 \%$ & $12 \%$ & $12 \%$ \\
\hline 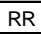 & $12 \%$ & $12 \%$ & $12 \%$ & $12 \%$ & $12 \%$ & $12 \%$ & $12 \%$ & $12 \%$ & $12 \%$ & $12 \%$ & $12 \%$ & $12 \%$ & $12 \%$ & $12 \%$ & $12 \%$ & $12 \%$ & $12 \%$ & $12 \%$ & $12 \%$ & $12 \%$ & $12 \%$ & $1 / \%$ & $2 \%$ & $\%$ & $12 \%$ & \pm & $12 \%$ \\
\hline $\mathrm{RS}$ & 79 & 79 & $7 \%$ & & $7 \%$ & & & & & & $122^{\circ}$ & & & & & & 701 & 80 & $12 \%$ & & & & 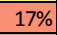 & & & & \\
\hline SC & - & $7 \%$ & $7 \%$ & $7 \%$ & $7 \%$ & $7 \%$ & & $7 \%$ & & 7 & $12 \%$ & 79 & $7 \%$ & & 이 & $7 \%$ & $7 \%$ & $\%$ & $2 \%$ & $7 \%$ & $7 \%$ & $7 \%$ & $\%$ & $7 \%$ & $7 \%$ & $\%$ & \\
\hline SE & $12 \%$ & $12 \%$ & $12 \%$ & $12 \%$ & $12 \%$ & $12 \%$ & $12 \%$ & $12 \%$ & $12 \%$ & $12 \%$ & $12 \%$ & $12 \%$ & $12 \%$ & $12 \%$ & $12 \%$ & $12 \%$ & $12 \%$ & $\%$ & $12 \%$ & $12 \%$ & $12 \%$ & $12 \%$ & $2 \%$ & $2 \%$ & $17 \%$ & $\%$ & $12 \%$ \\
\hline SP & $7 \%$ & $7 \%$ & $7 \%$ & $7 \%$ & $7 \%$ & $7 \%$ & $7 \%$ & $7 \%$ & $7 \%$ & $7 \%$ & $12 \%$ & $7 \%$ & $7 \%$ & $7 \%$ & $7 \%$ & $7 \%$ & $7 \%$ & $12 \%$ & $12 \%$ & $7 \%$ & $7 \%$ & $7 \%$ & $12 \%$ & $12 \%$ & $7 \%$ & $18 \%$ & $7 \%$ \\
\hline TO & $12 \%$ & $12 \%$ & $12 \%$ & $12 \%$ & $12 \%$ & $12 \%$ & $12 \%$ & $12 \%$ & $12 \%$ & $12 \%$ & $12 \%$ & $12 \%$ & $12 \%$ & $12 \%$ & $12 \%$ & $12 \%$ & $12 \%$ & $12 \%$ & $12 \%$ & $12 \%$ & $12 \%$ & $12 \%$ & $12 \%$ & $12 \%$ & $12 \%$ & $12 \%$ & $7 \%$ \\
\hline
\end{tabular}

Estrutura de aliquotas da Reforma Tributária segundo Senado (2010)

\begin{tabular}{|c|c|c|c|c|c|c|c|c|c|c|c|c|c|c|c|c|c|c|c|c|c|c|c|c|c|c|c|}
\hline \multicolumn{28}{|c|}{ Estrutura de aliquotas da Reforma Tributária segundo Senado (2010) } \\
\hline & C & AL & $\mathrm{Al}$ & AP & $\mathrm{BA}$ & $\mathrm{CE}$ & $\mathrm{DF}$ & ES & $\mathrm{GO}$ & \begin{tabular}{|l|} 
MA \\
\end{tabular} & MG & $\mathrm{MS}$ & \begin{tabular}{|l|} 
MT \\
\end{tabular} & PA & PB & $P E$ & $\mathrm{PI}$ & $P R$ & RJ & RN & RO & $\mathrm{RR}$ & $\mathrm{RS}$ & $\mathrm{SC}$ & SE & $P$ & 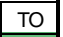 \\
\hline$A C$ & $17 \%$ & $2 \%$ & & $2 \%$ & 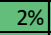 & $2 \%$ & 1 & & 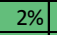 & $a t$ & $2 \%$ & & $2 \%$ & $2 \%$ & 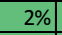 & $2 \%$ & & 2 & $2 \%$ & & & 70 & $2 \%$ & $2 \%$ & $2 \%$ & 7 & \\
\hline $\bar{A}$ & $2 \%$ & 17 & & 20 & $2 \%$ & t & & & 6 & 6 & $\%$ & & & $\%$ & & $\%$ & & & & & & & & + & & & \\
\hline & $2 \%$ & 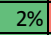 & $\%$ & $\%$ & $2 \%$ & $2 \%$ & & & $2 \%$ & $2 \%$ & $2 \%$ & & & $\%$ & $2 \%$ & $2 \%$ & & & & & & & & $\%$ & & & \\
\hline A & $2 \%$ & & $\%$ & $7 \%$ & $2 \%$ & $2 \%$ & $\%$ & & $2 \%$ & $2 \%$ & $2 \%$ & & & $2 \%$ & $\%$ & $2 \%$ & & & & $2 \%$ & $\%$ & & & $\%$ & $\%$ & & \\
\hline$B A$ & $2 \%$ & $\%$ & & $2 \%$ & $17 \%$ & $2 \%$ & $2 \%$ & $\%$ & $2 \%$ & $2 \%$ & $2 \%$ & $\%$ & & $\%$ & $2 \%$ & $2 \%$ & 7 & & & $2 \%$ & $2 \%$ & $\%$ & & $\%$ & $\%$ & & \\
\hline$\overline{C E}$ & $2 \%$ & $2 \%$ & & $2 \%$ & $2 \%$ & $17 \%$ & $2 \%$ & & $\%$ & $2 \%$ & $2 \%$ & & & $\%$ & $2 \%$ & & & & & & & & & & & & \\
\hline DF & $2 \%$ & $2 \%$ & $2 \%$ & $2 \%$ & 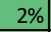 & $2 \%$ & $17 \%$ & $2 \%$ & 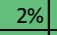 & $2 \%$ & $2 \%$ & & & $2 \%$ & $2 \%$ & $2 \%$ & & & & & & & & $2 \%$ & $2 \%$ & & \\
\hline$\overline{E S}$ & & & & $2 \%$ & & t & $\%$ & $7 \%$ & $\%$ & $2 \%$ & $2 \%$ & & & $\%$ & $2 \%$ & $2 \%$ & & & & & & & & t & & & \\
\hline $\mathrm{GC}$ & $2 \%$ & & & $2 \%$ & & $2 \%$ & & $\%$ & $7 \%$ & $2 \%$ & $2 \%$ & & & $2 \%$ & $2 \%$ & $2 \%$ & & & & $2 \%$ & & & & & & & \\
\hline M & 2 & & & 6 & & & & & 6 & $17 \%$ & $2 \%$ & & & & & & & & & & & & & & & & \\
\hline & $2 \%$ & $\%$ & & & 2 & $\%$ & 6 & & 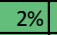 & $\%$ & $18 \%$ & & & $\%$ & $2 \%$ & & & & & & & & & & & & \\
\hline $\bar{M}$ & 29 & $2 \%$ & & & & $2 \%$ & 1 & & & $2 \%$ & $2 \%$ & $\%$ & & $\%$ & $2 \%$ & 2 & & & & & & & & $2 \%$ & 1 & & \\
\hline $\bar{M}$ & & $2 \%$ & & $2 \%$ & & 29 & & & & $2 \%$ & 29 & $2 \%$ & $17 \%$ & $2 \%$ & & & & & & & & & & $2 \%$ & $2 \% \mid$ & & \\
\hline$P /$ & $2 \%$ & & & $2 \%$ & & 29 & & & & $2 \%$ & & & & $17 \%$ & $2 \%$ & & & & & & & & & & & & \\
\hline $\mathrm{PE}$ & $2 \%$ & & & & & & & & & & & & & $\%$ & $17 \%$ & & & & & & & & & & & & \\
\hline$P \mathrm{E}$ & $2 \%$ & $\%$ & & $2 \%$ & 28 & $2 \%$ & $\%$ & 2 & $2 \%$ & $2 \%$ & $\%$ & & & $2 \%$ & $2 \%$ & $17 \%$ & $\%$ & & & & & & & $\%$ & $\%$ & & \\
\hline $\mathrm{PI}$ & & 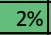 & & & & & $2 \%$ & & & & 28 & & & & & $2 \%$ & $17 \%$ & & & & & & & 70 & $\%$ & & \\
\hline $\mathrm{PR}$ & & & & & & & & & & & & & & & & $2 \%$ & | & $18 \%$ & & & & & & $\%$ & 70| & & \\
\hline$R_{u}$ & 29 & $2 \%$ & & $2 \%$ & & & & & & & & & & $\%$ & $2 \%$ & $2 \%$ & & $\%$ & 19 & $2 \%$ & & & & $\%$ & $\%$ & & \\
\hline $\mathrm{RN}$ & 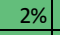 & $2 \%$ & $2 \%$ & $2 \%$ & & 29 & $2 \%$ & & & $2 \%$ & & & & $\%$ & $\%$ & $2 \%$ & & & $\%$ & $17 \%$ & 7 & & & $\%$ & $\%$ & & \\
\hline $\mathrm{RO}$ & $2 \%$ & 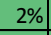 & $2 \%$ & 27 & & $2 \%$ & 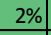 & & & & & & & & $2 \%$ & 29 & & & & $2 \%$ & $17 \%$ & & & $\%$ & $\%$ & & \\
\hline $\mathrm{RR}$ & $2 \%$ & $2 \%$ & $2 \%$ & 29 & & $2 \%$ & $2 \%$ & & $2 \%$ & & $2 \%$ & & & $2 \%$ & & 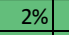 & & & & & $2 \%$ & $17 \%$ & & $2 \%$ & $2 \%$ & if & \\
\hline $\mathrm{RS}$ & $2 \%$ & & & 24 & & 29 & & & & & & & & & & & & & & & & & $\%$ & $\%$ & $2 \%$ & & \\
\hline SC & & & & & & & & & & & & & & & & & & & & & & & & $17 \%$ & $2 \%$ & & \\
\hline S & 2 & & & $2 \%$ & & & & & & & & & & & & & & & & & & & & $\%$ & $17 \%$ & $2 \%$ & \\
\hline or & $2 \%$ & $2 \%$ & $2 \%$ & $2 \%$ & $2 \%$ & $2 \%$ & $2 \%$ & 200 & $2 \%$ & $2 \%$ & 27 & $2 \%$ & & $2 \%$ & $2 \%$ & 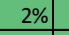 & $2 \%$ & & & $2 \%$ & $2 \%$ & $\%$ & & 70 & $2 \%$ & $18 \%$ & \\
\hline 10 & $2 \%$ & $2 \%$ & $2 \%$ & $2 \%$ & $2 \%$ & $2 \%$ & $2 \%$ & 210 & $2 \%$ & $2 \% \mid$ & $2 \%$ & $2 / 01$ & $2 \%$ & $2 \%$ & $2 \%$ & $2 \%$ & $2 / 01$ & $2 / 0$ & 2,0 & & 210 & 210 & 10 & iv & 10 & $\%$ & \\
\hline
\end{tabular}


ANEXO B - Mapa com os fluxos de origem e destino e nível de serviço

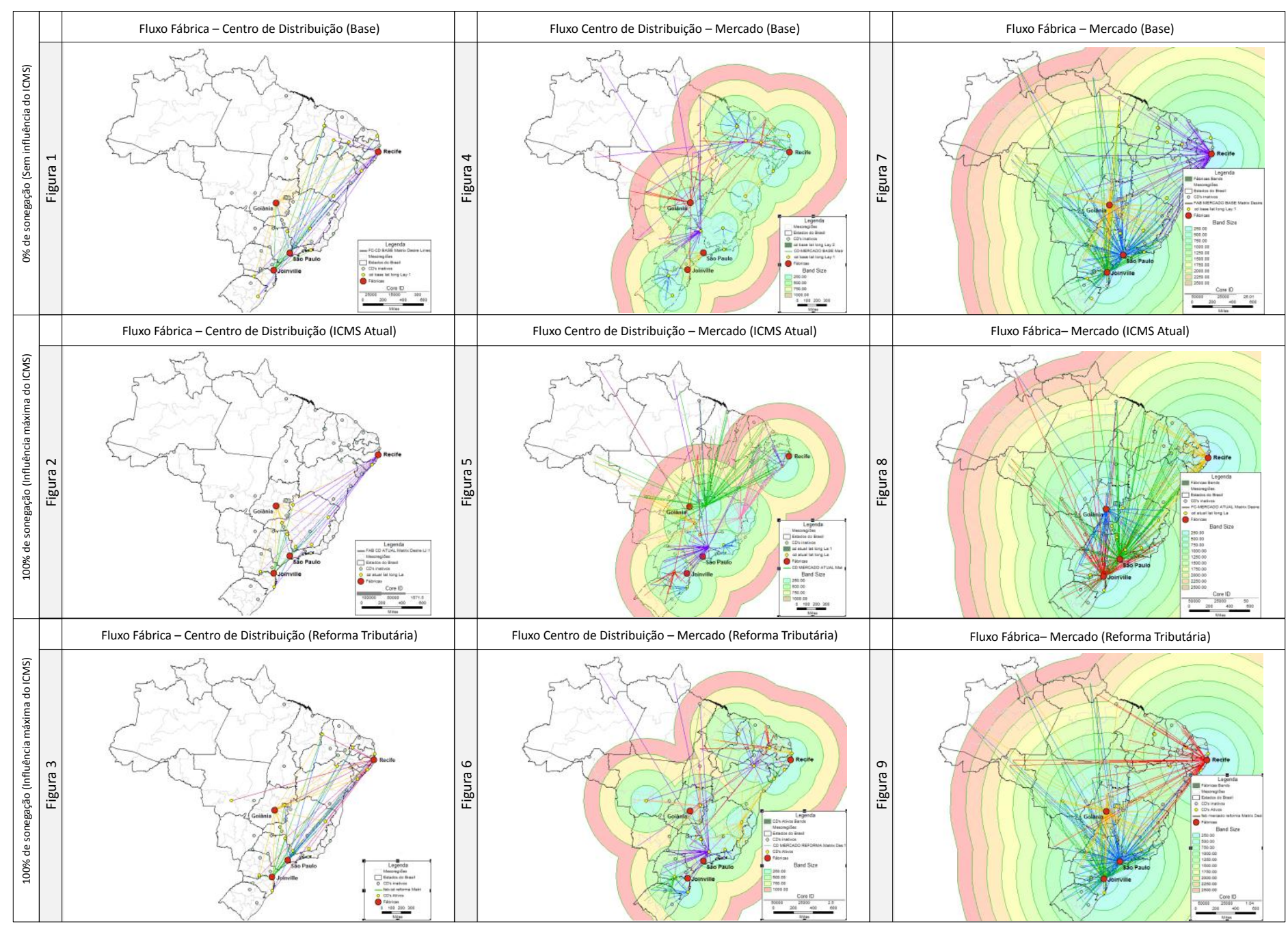


ANEXO C - Tabela de custos logísticos absolutos e relativos.

\begin{tabular}{|c|c|c|c|c|c|c|c|c|c|c|c|}
\hline \multirow[b]{2}{*}{ Modelo } & \multirow[b]{2}{*}{ Custo } & \multicolumn{5}{|c|}{ Custo Absoluto } & \multicolumn{5}{|c|}{ Custo Relativo } \\
\hline & & $0 \%$ & $25 \%$ & $50 \%$ & $75 \%$ & $100 \%$ & $0 \%$ & $25 \%$ & $50 \%$ & $75 \%$ & $100 \%$ \\
\hline \multirow{6}{*}{ ICMS Atual } & Distribuição & 41.861 .400 & 46.717 .000 & 53.267 .400 & 58.130 .600 & 62.228 .000 & $0,0 \%$ & $11,6 \%$ & $27,2 \%$ & $38,9 \%$ & $48,7 \%$ \\
\hline & Transferencia & 29.093 .500 & 26.504 .400 & 22.437 .100 & 19.896 .000 & 17.550 .200 & $0,0 \%$ & $-8,9 \%$ & $-22,9 \%$ & $-31,6 \%$ & $-39,7 \%$ \\
\hline & Transbordo & 320.000 & 340.000 & 325.883 & 340.000 & 346.041 & $0,0 \%$ & $6,3 \%$ & $1,8 \%$ & $6,3 \%$ & $8,1 \%$ \\
\hline & Fixo & 4.782 .950 & 5.089 .680 & 4.871 .950 & 4.689 .400 & 4.627 .150 & $0,0 \%$ & $6,4 \%$ & $1,9 \%$ & $-2,0 \%$ & $-3,3 \%$ \\
\hline & Logistico & 76.057 .800 & 78.651 .100 & 80.902 .300 & 83.056 .100 & 84.751 .500 & $0,0 \%$ & $3,4 \%$ & $6,4 \%$ & $9,2 \%$ & $11,4 \%$ \\
\hline & Débito de ICMS & 291.416 .000 & 269.200 .000 & 247.687 .000 & 229.511 .000 & 220.289 .000 & $0,0 \%$ & $-7,6 \%$ & $-15,0 \%$ & $-21,2 \%$ & $-24,4 \%$ \\
\hline \multirow{6}{*}{$\begin{array}{c}\text { Sem NS } \\
\text { ICMS Atual }\end{array}$} & Distribuição & 48.370 .200 & 54.018 .300 & 60.409 .300 & 64.541 .200 & 71.651 .900 & $0,0 \%$ & $11,7 \%$ & $24,9 \%$ & $33,4 \%$ & $48,1 \%$ \\
\hline & Transferencia & 23.524 .900 & 20.043 .600 & 16.018 .700 & 13.678 .700 & 9.011 .120 & $0,0 \%$ & $-14,8 \%$ & $-31,9 \%$ & $-41,9 \%$ & $-61,7 \%$ \\
\hline & Transbordo & 220.000 & 220.000 & 210.000 & 224.869 & 200.000 & $0,0 \%$ & $0,0 \%$ & $-4,5 \%$ & $2,2 \%$ & $-9,1 \%$ \\
\hline & Fixo & 3.311 .670 & 3.311 .670 & 3.031 .580 & 3.213 .590 & 2.604 .650 & $0,0 \%$ & $0,0 \%$ & $-8,5 \%$ & $-3,0 \%$ & $-21,3 \%$ \\
\hline & Logistico & 75.426 .900 & 77.593 .600 & 79.669.700 & 81.658 .400 & 83.467 .700 & $0,0 \%$ & $2,9 \%$ & $5,6 \%$ & $8,3 \%$ & $10,7 \%$ \\
\hline & Débito de ICMS & 274.291 .000 & 255.574 .000 & 242.148 .000 & 228.265 .000 & 218.284 .000 & $0,0 \%$ & $-6,8 \%$ & $-11,7 \%$ & $-16,8 \%$ & $-20,4 \%$ \\
\hline \multirow{6}{*}{ RT 2\% } & Distribuição & 41.861 .400 & 43.700 .000 & 44.367 .900 & 44.976 .300 & 45.788 .700 & $0,0 \%$ & $4,4 \%$ & $6,0 \%$ & $7,4 \%$ & $9,4 \%$ \\
\hline & Transferencia & 29.093 .500 & 28.623 .000 & 28.925 .300 & 29.260 .500 & 29.324 .200 & $0,0 \%$ & $-1,6 \%$ & $-0,6 \%$ & $0,6 \%$ & $0,8 \%$ \\
\hline & Transbordo & 320.000 & 340.000 & 370.000 & 400.000 & 420.000 & $0,0 \%$ & $6,3 \%$ & $15,6 \%$ & $25,0 \%$ & $31,3 \%$ \\
\hline & Fixo & 4.782 .950 & 5.027 .330 & 5.423 .050 & 5.671 .950 & 5.916 .320 & $0,0 \%$ & $5,1 \%$ & $13,4 \%$ & $18,6 \%$ & $23,7 \%$ \\
\hline & Logistico & 76.057 .800 & 77.690 .300 & 79.086 .200 & 80.308 .800 & 81.449 .300 & $0,0 \%$ & $2,1 \%$ & $4,0 \%$ & $5,6 \%$ & $7,1 \%$ \\
\hline & Débito de ICMS & 175.665 .000 & 119.560 .000 & 92.026 .200 & 58.465 .300 & 41.614 .800 & $0,0 \%$ & $-31,9 \%$ & $-47,6 \%$ & $-66,7 \%$ & $-76,3 \%$ \\
\hline \multirow{6}{*}{$\begin{array}{c}\text { Sem NS RT } \\
2 \%\end{array}$} & Distribuição & 48.370 .200 & 49.752 .700 & 51.487 .300 & 52.298 .700 & 53.763 .300 & $0,0 \%$ & $2,9 \%$ & $6,4 \%$ & $8,1 \%$ & $11,1 \%$ \\
\hline & Transferencia & 23.524 .900 & 23.087.100 & 22.380 .200 & 22.278 .700 & 21.806 .600 & $0,0 \%$ & $-1,9 \%$ & $-4,9 \%$ & $-5,3 \%$ & $-7,3 \%$ \\
\hline & Transbordo & 220.000 & 240.000 & 250.000 & 270.000 & 279.754 & $0,0 \%$ & $9,1 \%$ & $13,6 \%$ & $22,7 \%$ & $27,2 \%$ \\
\hline & Fixo & 3.311 .670 & 3.556 .040 & 3.582 .680 & 3.889 .410 & 3.893 .930 & $0,0 \%$ & $7,4 \%$ & $8,2 \%$ & $17,4 \%$ & $17,6 \%$ \\
\hline & Logistico & 75.426 .900 & 76.635 .900 & 77.700 .100 & 78.736 .800 & 79.743 .600 & $0,0 \%$ & $1,6 \%$ & $3,0 \%$ & $4,4 \%$ & $5,7 \%$ \\
\hline & Débito de ICMS & 136.998 .000 & 87.796 .800 & 68.754 .000 & 56.044 .200 & 41.614 .800 & $0,0 \%$ & $-35,9 \%$ & $-49,8 \%$ & $-59,1 \%$ & $-69,6 \%$ \\
\hline
\end{tabular}




\section{ANEXO D - Modelo Matemático - IBM ILOG CPLEX}

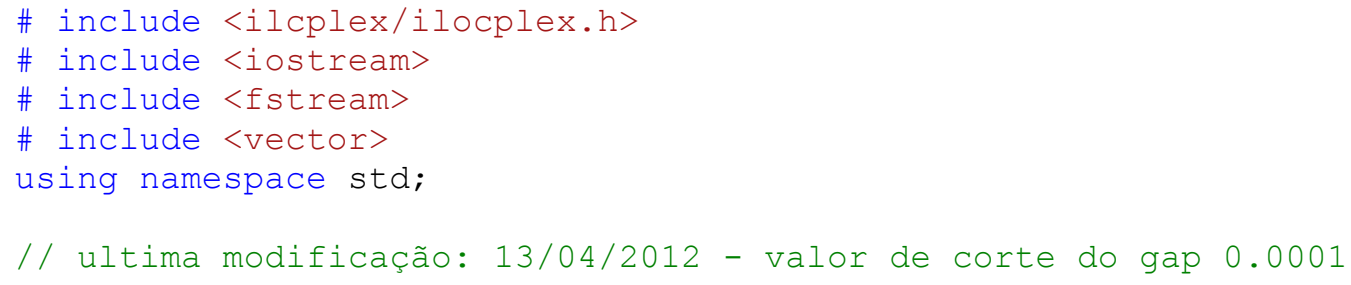




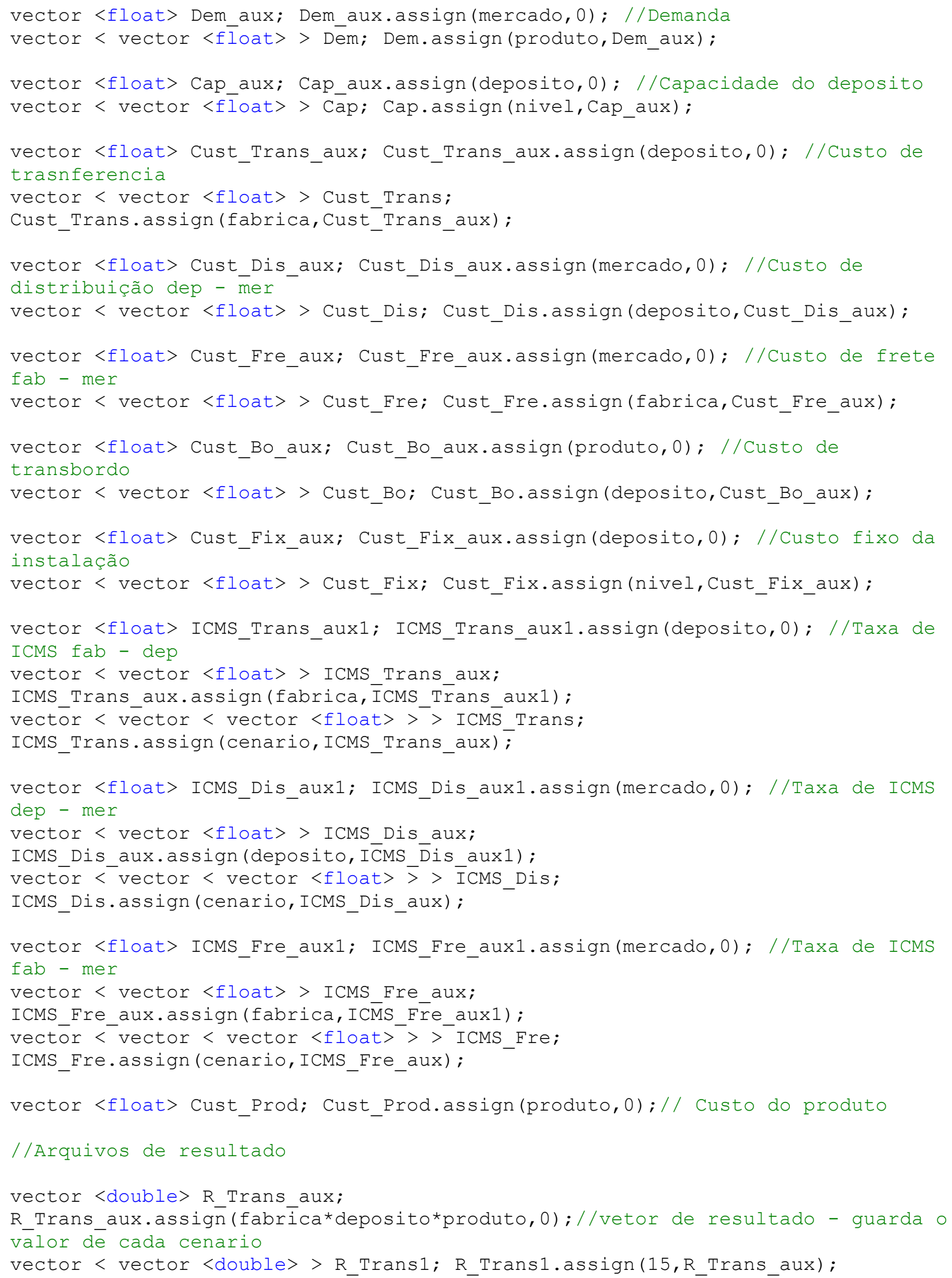




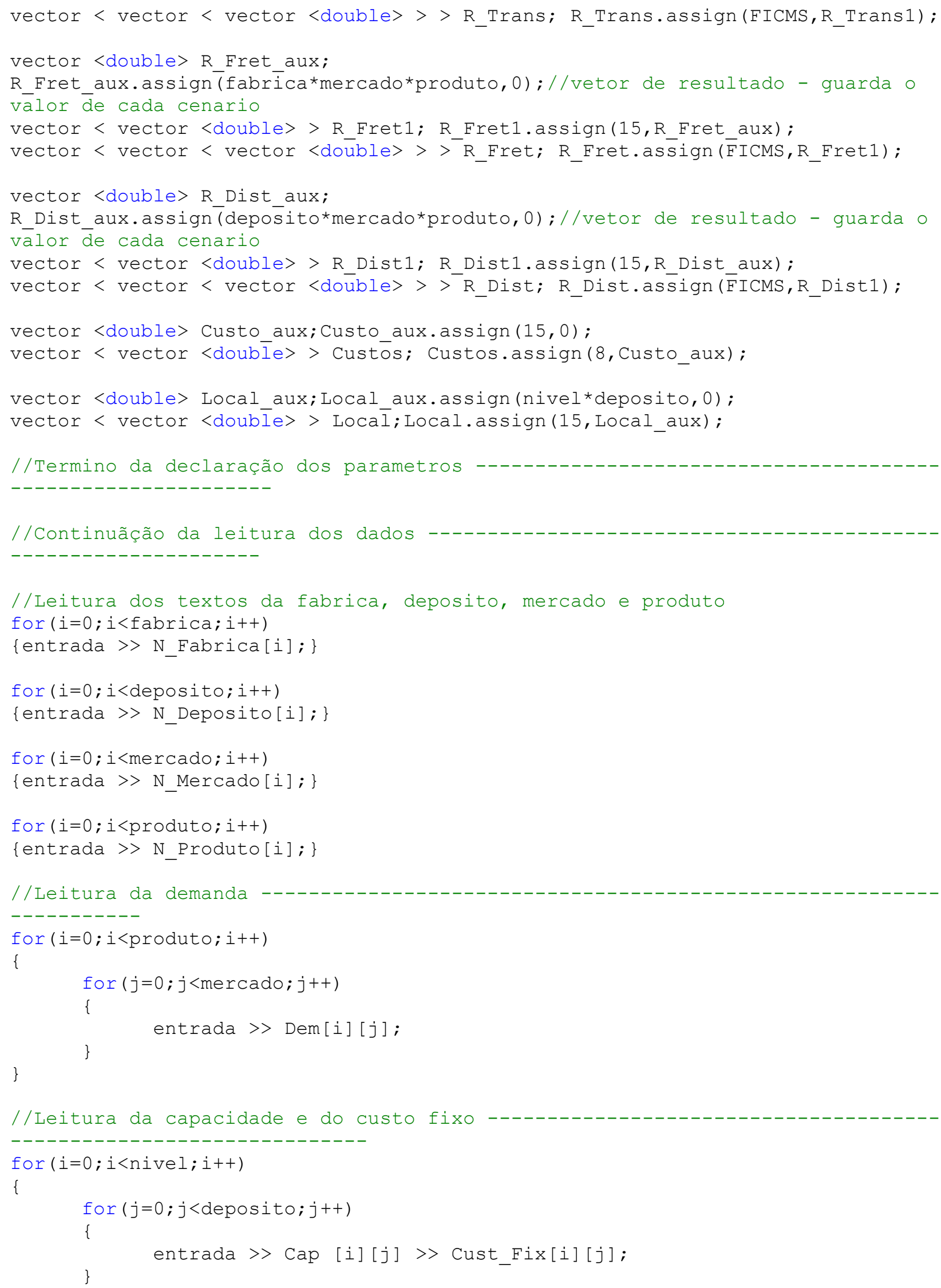


//Leitura do custo de transferencia fab - deposito -----------------------

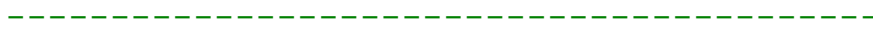




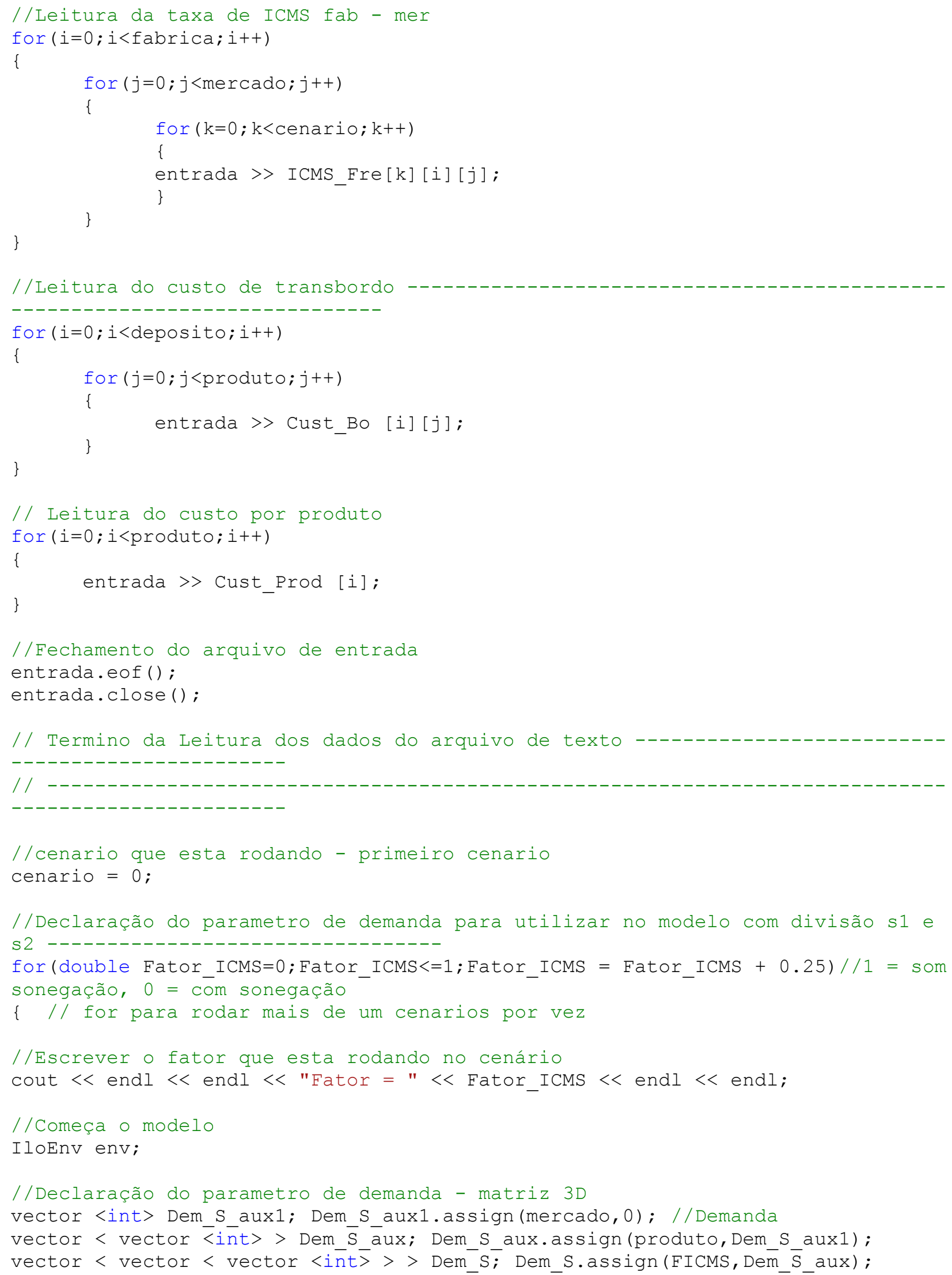




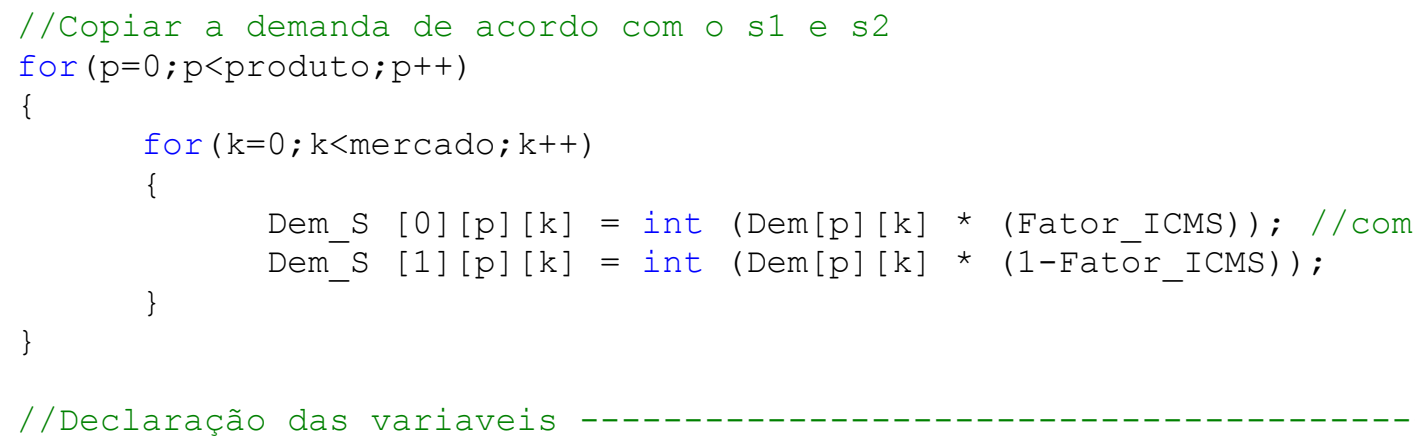




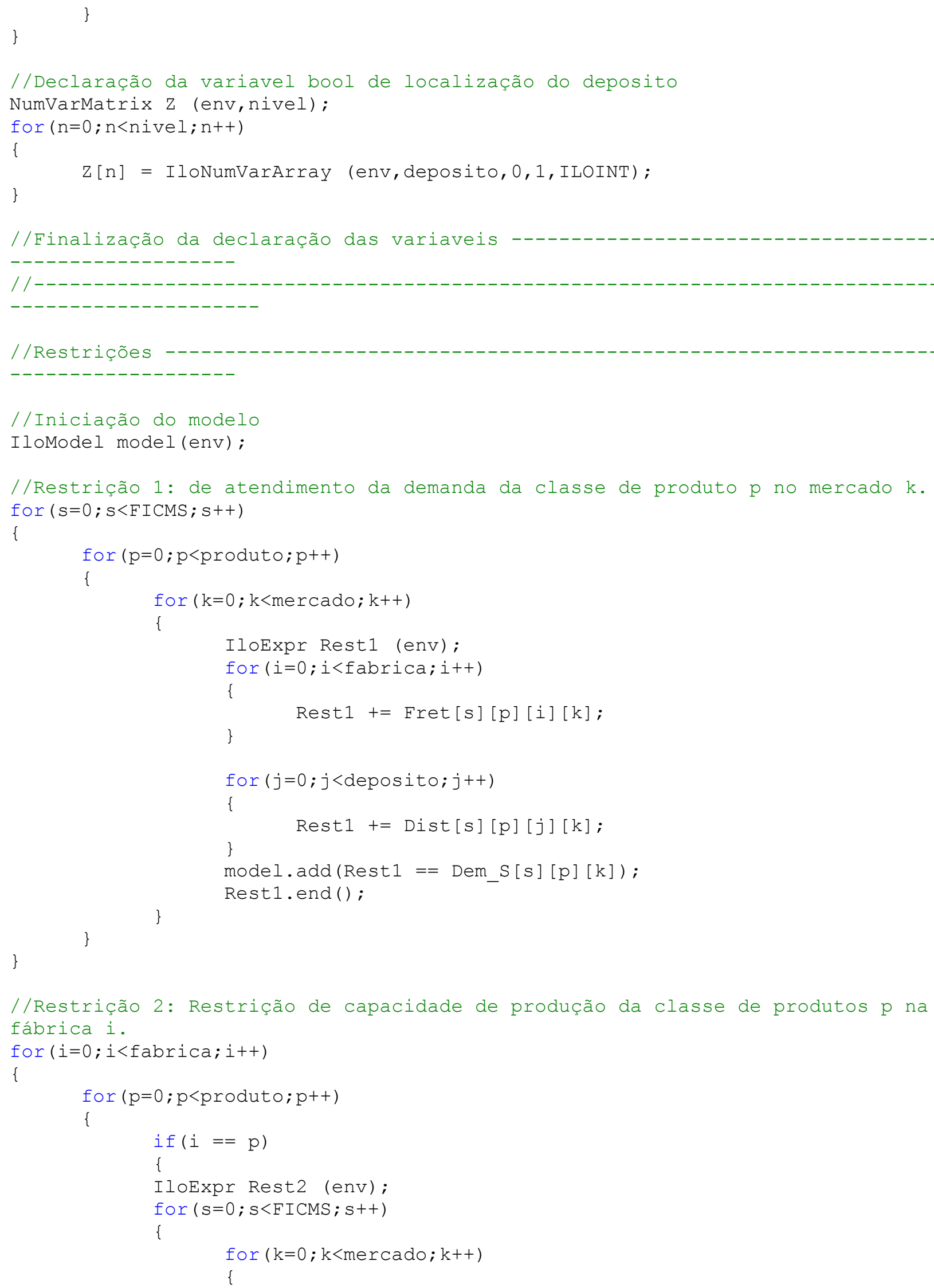




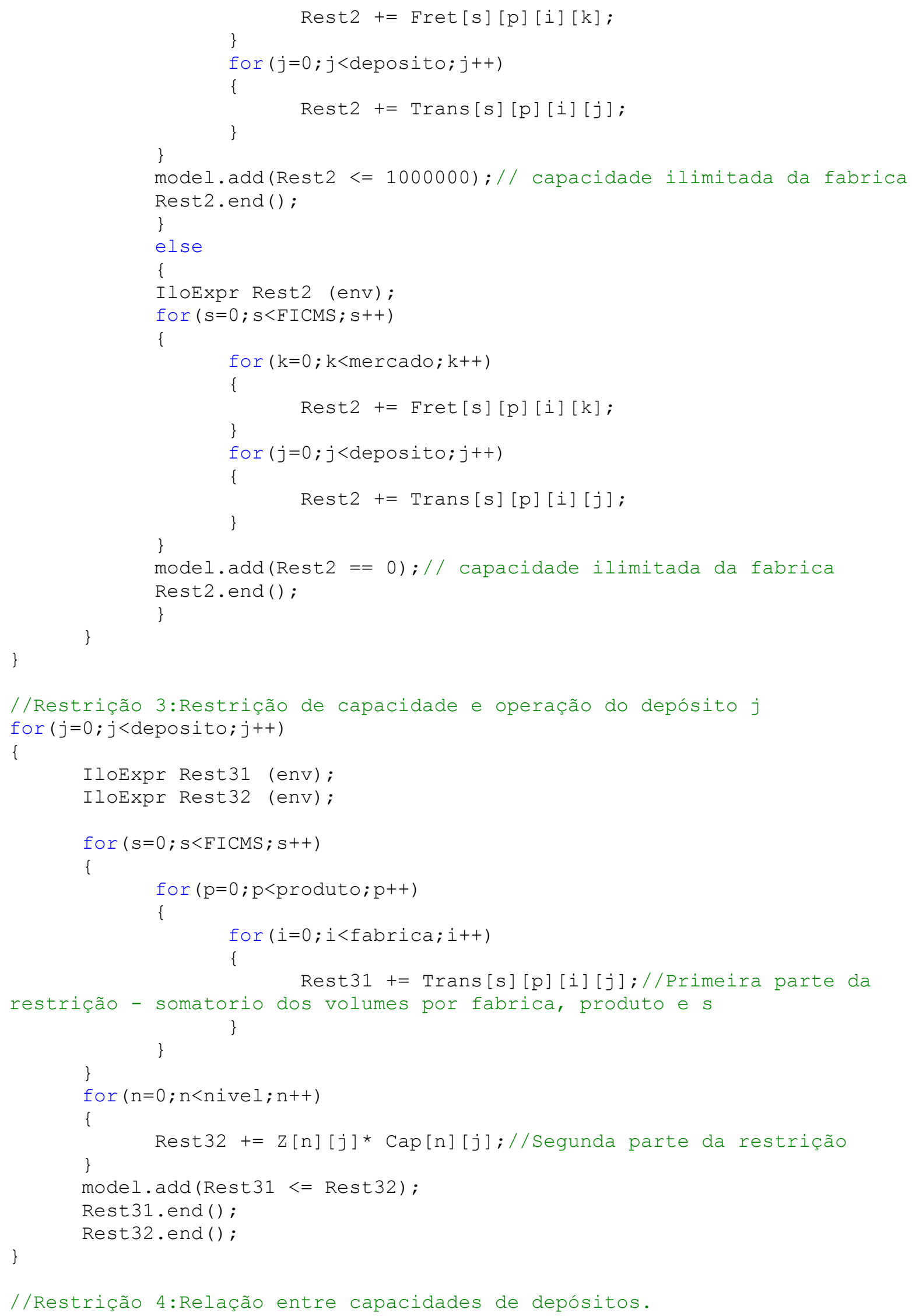




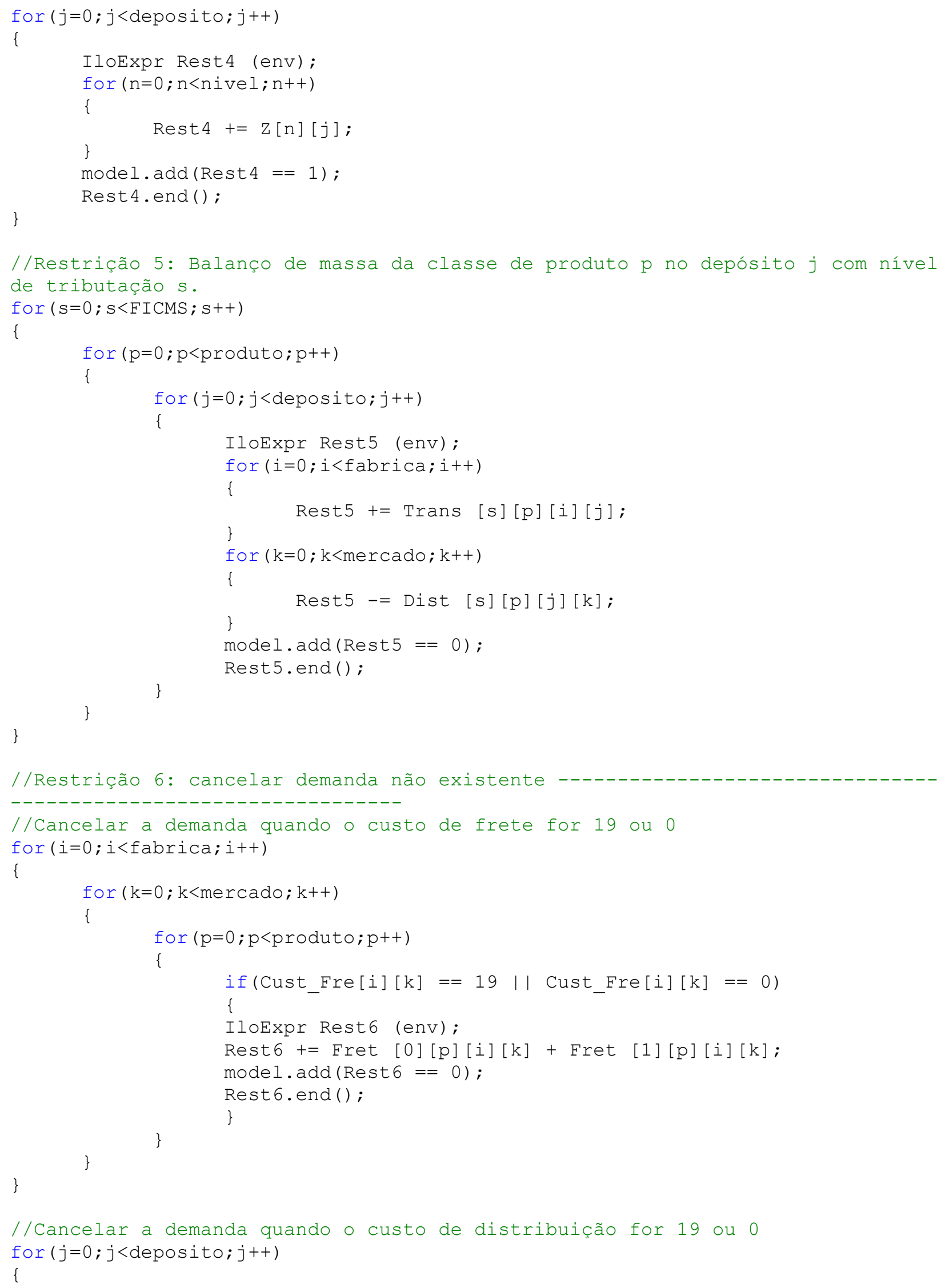




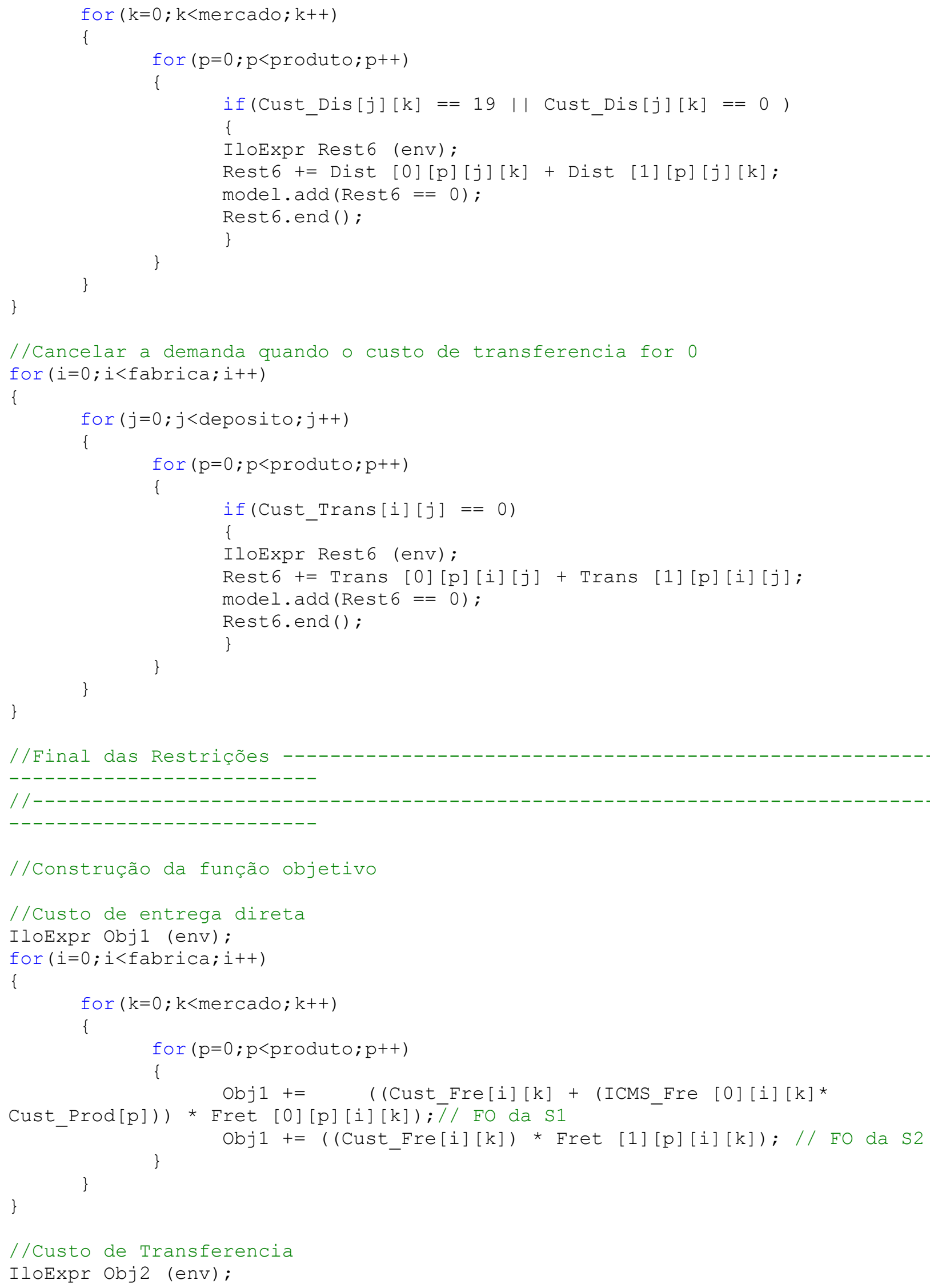




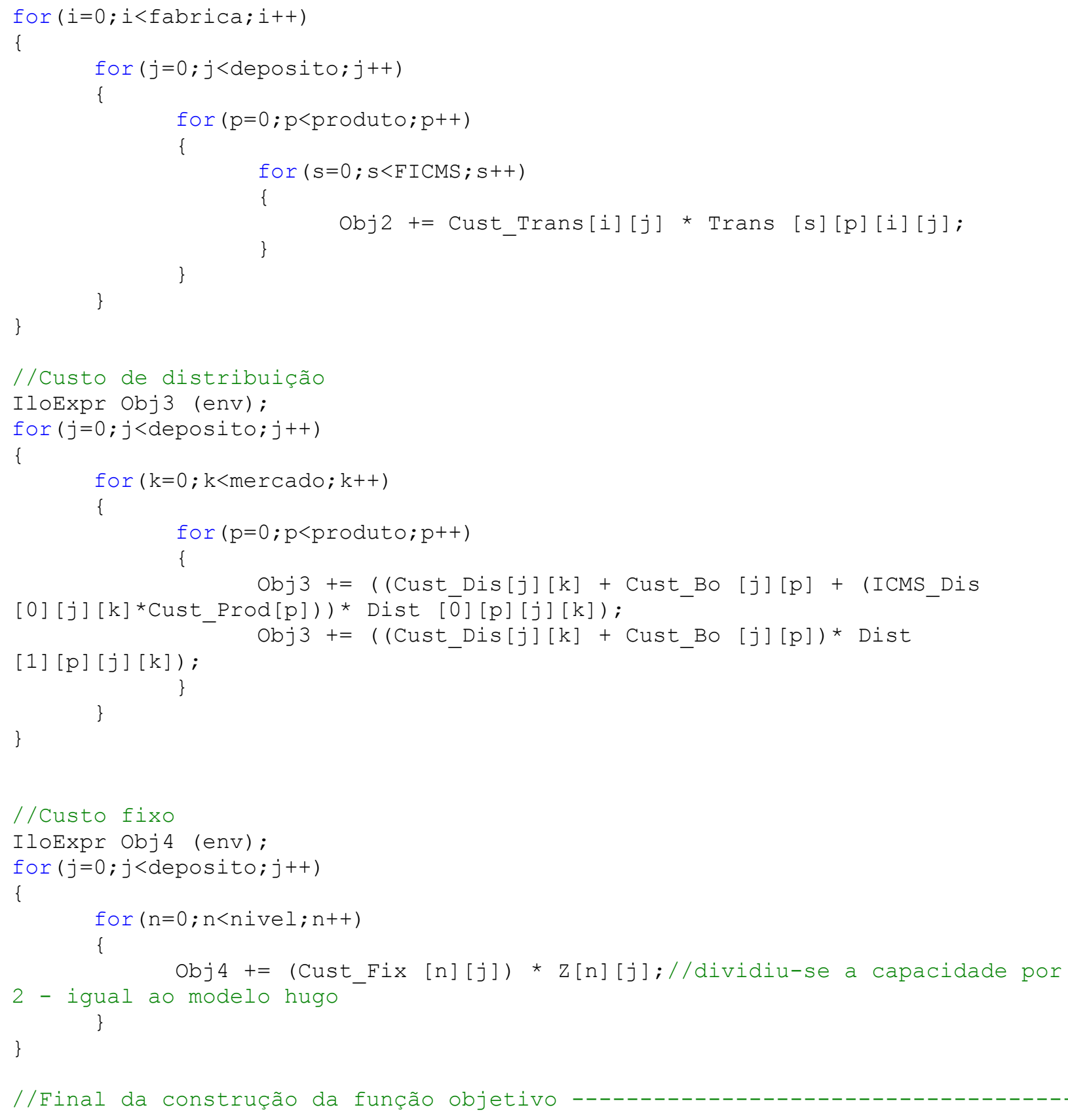




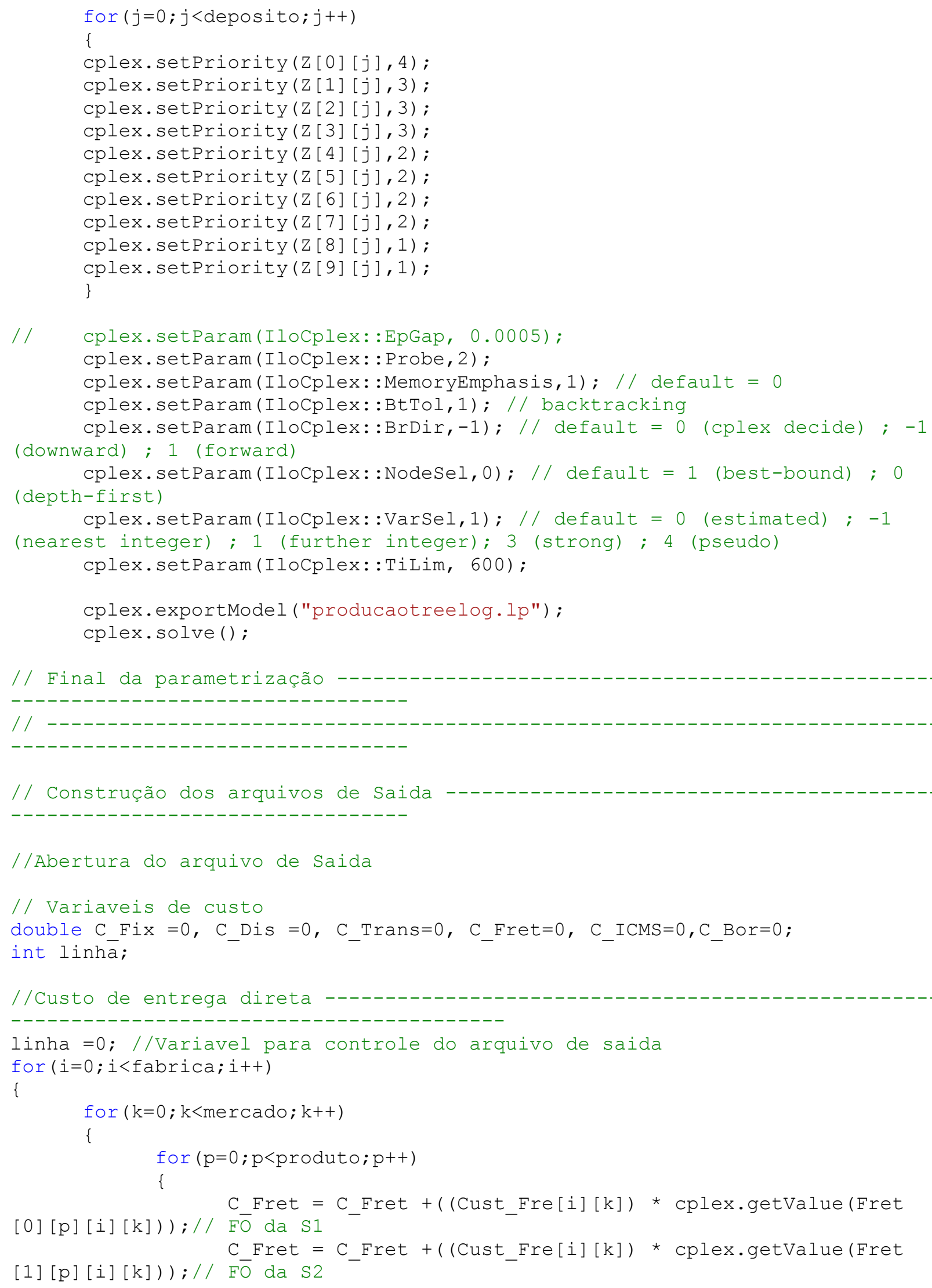




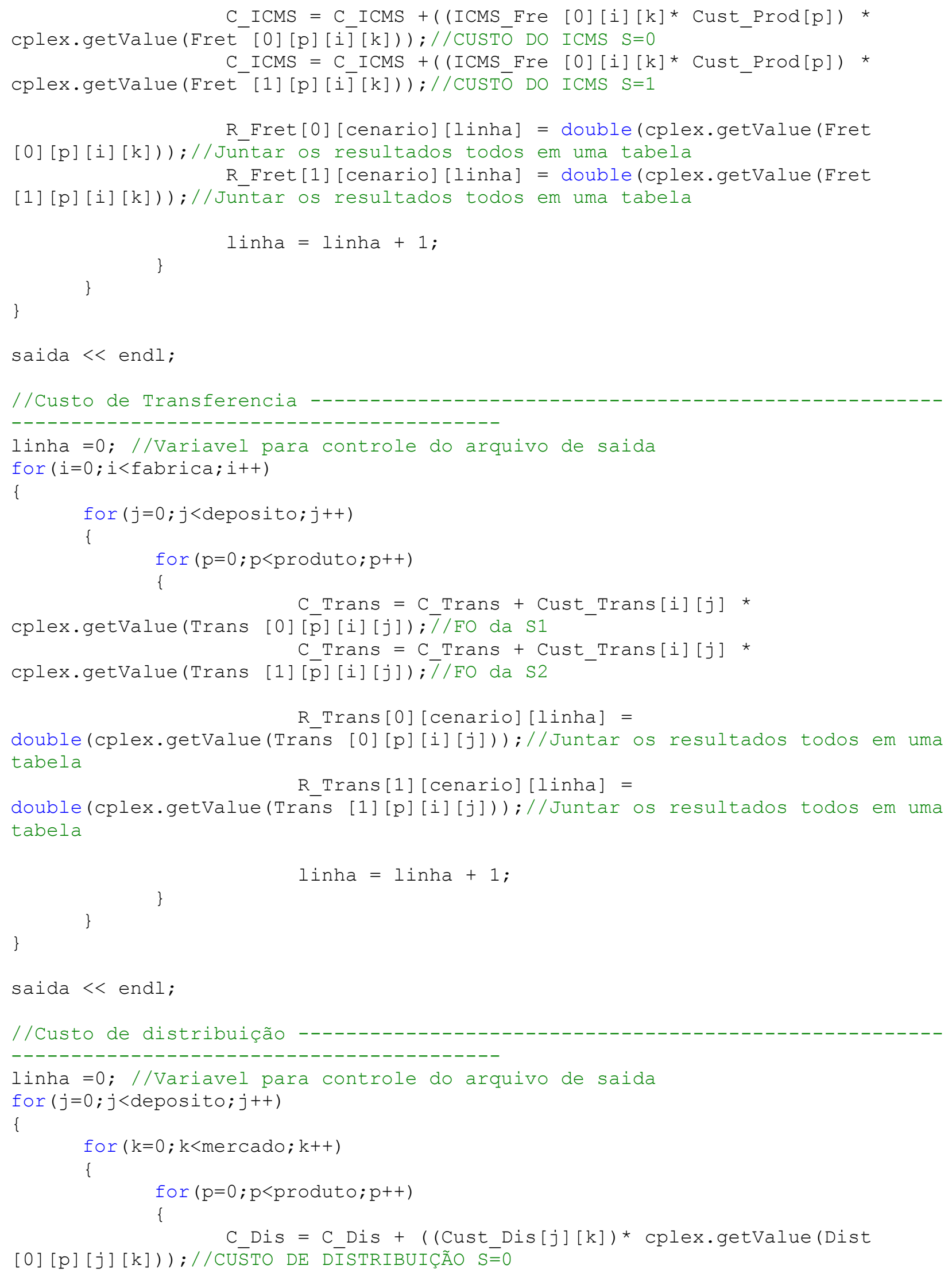


C_Dis $=$ C_Dis + ((Cust_Dis $[j][k]) *$ cplex.getValue (Dist [1] [p] [j] [k]));//CUSTO DE DİSTRIBUIÇÃO $S=1$

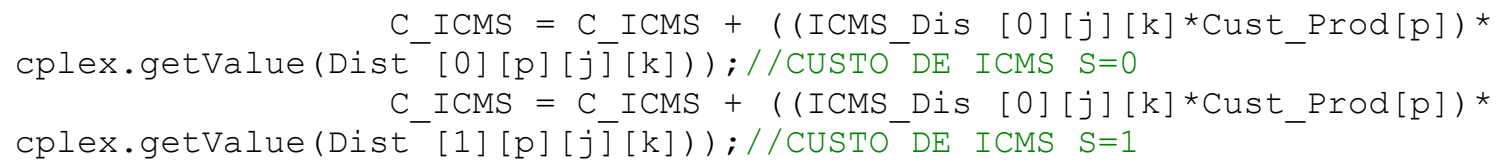

R_Dist [0][cenario][linha] = double(cplex.getValue(Dist [0][p][j][k])); //Juntar os resultados todos em uma tabela R_Dist [1][cenario][linha] = double(cplex.getValue(Dist [1][p][j][k]));//Juntar todos os resultados

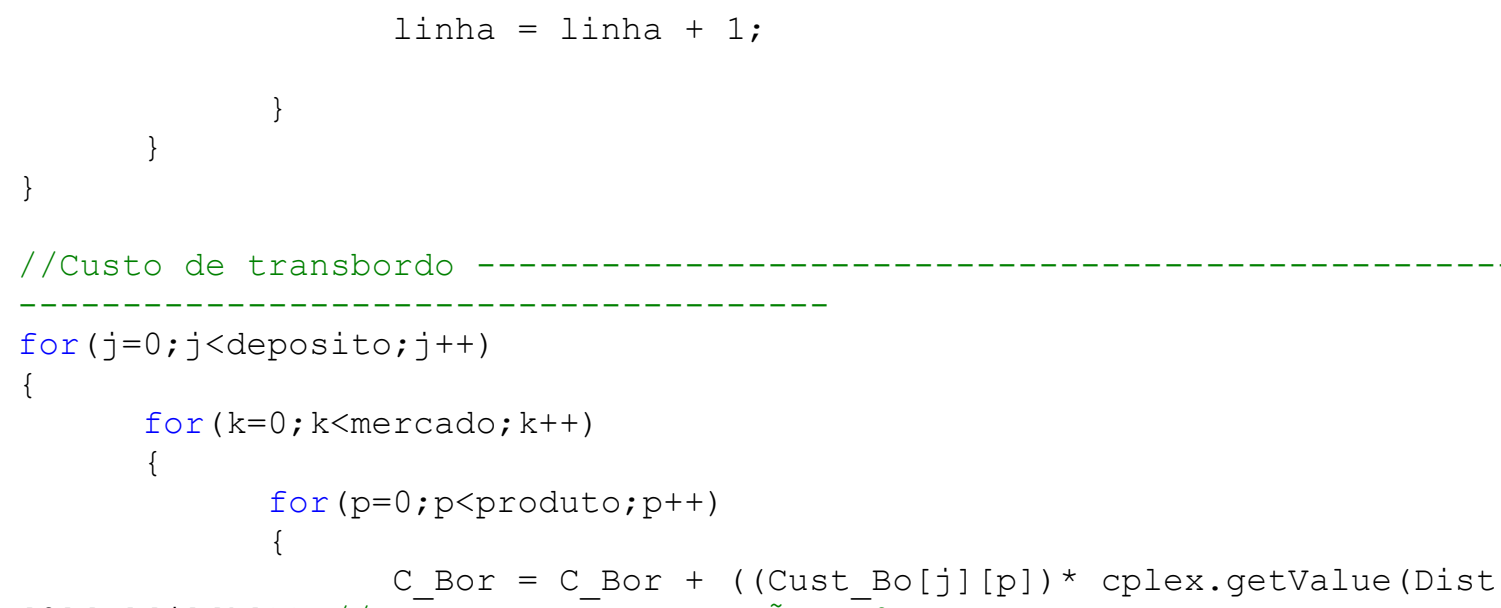




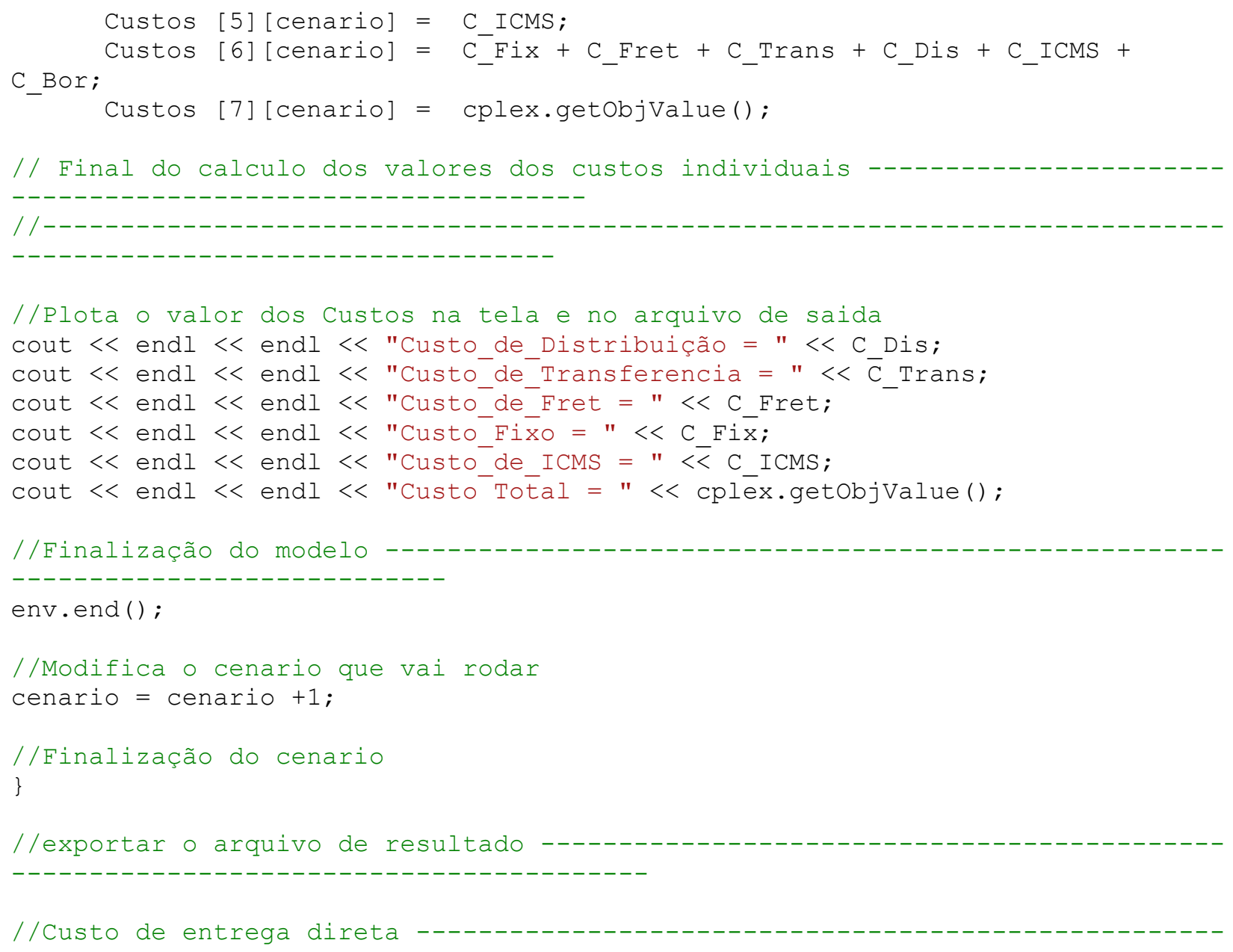

for $(\mathrm{s}=0 ; \mathrm{s}<\mathrm{FICMS} ; \mathrm{s}++)$

\{int linha $=0 ; / /$ Variavel para controle do arquivo de saida for $(i=0 ; i<$ fabrica; $i++)$

\{

for $(k=0 ; k<$ mercado; $k++)$

\{ for $(\mathrm{p}=0 ; \mathrm{p}<$ produto $; \mathrm{p}++)$

\{

Fret $<<$ N_Produto [p] $<<" \quad "<<$

N_Fabrica $[\mathrm{i}] \quad<" \quad$ " $<$ N_Mercado[k] $<<"$ " $<<\mathrm{s}<<$ " ";

os dados por cenario

" ;

for (int cen=0; cen<cenario; cen++) // extrair

Fret $\quad<" \quad "<<$ R_Fret[s][cen][linha] $<<"$

\}

Fret $<<$ endl;

linha $=$ linha +1 ;

\} 


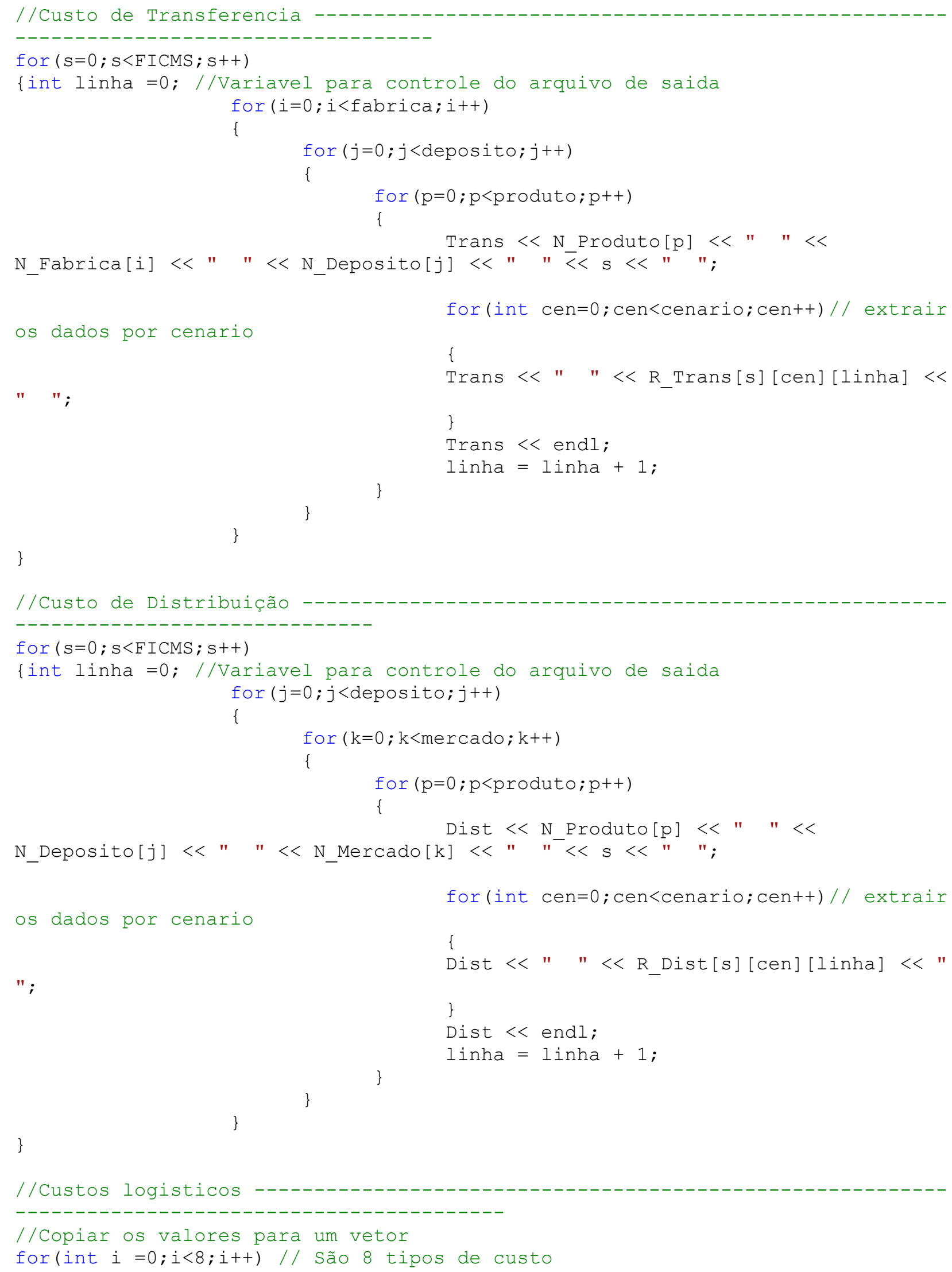


\{

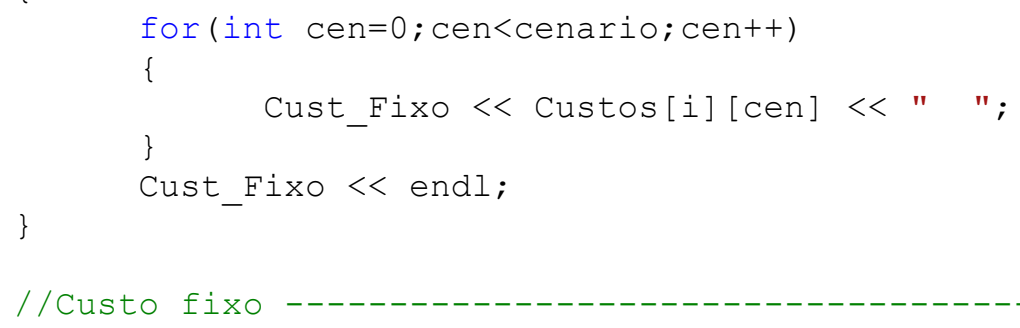


